\title{
SILENCING AND INSTITUTIONAL RACISM IN SETTLER-COLONIAL EDUCATION
}

\author{
BY \\ LIANA MACDONALD
}

\begin{abstract}
A thesis
submitted to the Victoria University of Wellington in fulfilment of the requirements for the degree of Doctor of Philosophy
\end{abstract}

Victoria University of Wellington 2018 
My silences had not protected me. Your silence will not protect you.

Audre Lorde, Sister Outsider, 1984

Our bodies can remember these histories, even when we don't.

Sara Ahmed, On Being Included, 2012

They falsely own our land so they really don't We've been ripped off man so shut up I won't You gotta learn the history to know where ya truly are Learn it somehow this ignorance has gone too far. Upper Hutt Posse, E Tū, 1988 


\begin{abstract}
Twenty years ago, Charles Mills argued that a Racial Contract underwrites and guides the social contract and assigns political, economic, and social privileges based on race. This thesis argues that a settler manifestation of the Racial Contract operates through processes and structures of silencing in the New Zealand education system. Silencing is a racial discourse aligned with state ideologies about biculturalism that supports ignorance and denial of the structuring force of colonisation. Within schools, a state narrative of biculturalism advances the notion of harmonious settler-colonial race relations by marginalising or denying violent colonial histories and their consequences in the present.
\end{abstract}

Silencing in the education system is examined through the lived experiences of Māori teachers of English language as they teach New Zealand literature in secondary school classrooms. Interviews with nineteen teachers and observations of four teachers' classroom practices (with follow up interviews from the teachers and some of their students) reveal that everyday classroom interactions perpetuate silencing through a hidden curriculum. This hidden curriculum appeals to settler sensibilities by: drawing on teaching pedagogies that soften or mute historical harm, validating "lovely" knowledge about Māori society and assessment approaches that privilege settler-colonial imperatives. This thesis identifies that harmonious notions of biculturalism circulate through the spatial and temporal dimensions of secondary schools because epistemological structures (policy, curriculum, and pedagogy) silence the meanings and effects of colonisation. In this way, a Settler Contract operates to sustain institutional racism in the New Zealand education system and white supremacy in settler-colonial societies. 


\section{Acknowledgements}

Early in the study one of my supervisors rightly predicted I would be a "different Māori" by the end of this thesis. There are many people to thank for this consciousness-raising experience.

The participants in this study let me into their teaching worlds with professional candour and I cannot thank them enough. They may be surprised at the direction this study has taken and the significance of their everyday schooling lives. To the four who participated in phase two; I only wish I had been half as good at teaching as you.

My supervisors, Joanna Kidman and Gillian Hubbard, were vital to the direction and completion of this thesis. Thank you for your unwaivering support, excellent critique, feedback and literature guidance throughout the thesis process. I am very grateful for your supervision - especially through my clumsy handling of existential crises.

I was extremely lucky to receive the Whāia Ngā Pae o te Māramatanga Doctoral Excellence Scholarship as this award allowed me to study full time during the second half of the thesis. Thanks also to Te Runanga o Ngāti Kuia Trust for financial assistance. I am also indebted to the Ministry of Education for the teaching release time given through several study grants and awards while I was working during the first few years of the thesis. At that time, I was employed at Onslow College and the staff were very supportive of my study as well.

Thanks also to fellow Victoria University PhD students, lecturers and friends. Also, extended whānau and friends outside the doctorate world.

Finally, my mother Mary, my sister Gemma and my daughter Anaïs, are the three who have really seen the good, the bad and the ugly of this $\mathrm{PhD}$ journey over the last five years. Thanks for keeping it real. 


\section{Table of contents}

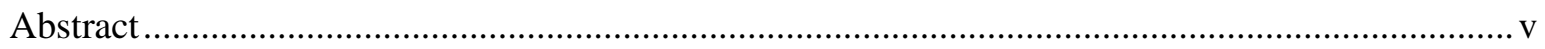

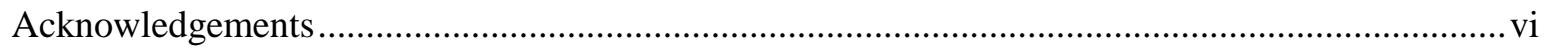

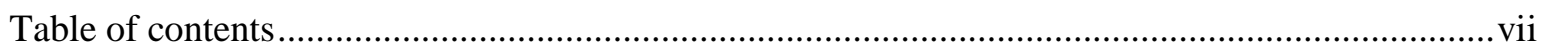

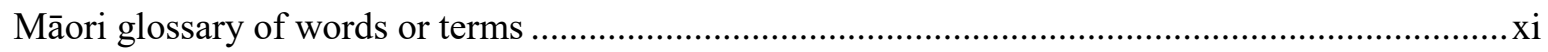

\section{Chapter One}

Introduction to the study .........................................................................................................................1

Tracing the disappearance of race: use of terminology in the thesis .............................................. 3

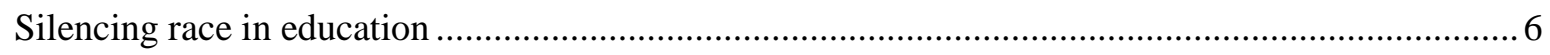

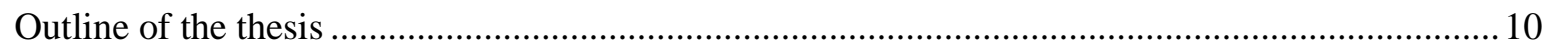

\section{Chapter Two}

Conceptualising settler silencing as institutional racism..........................................................14

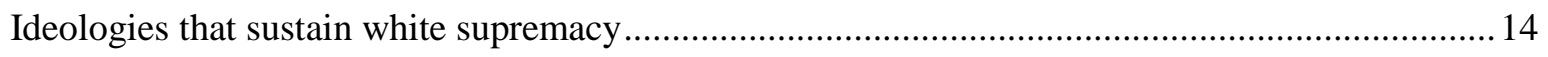

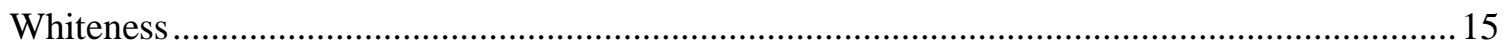

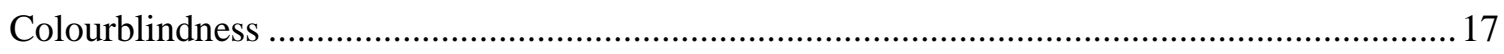

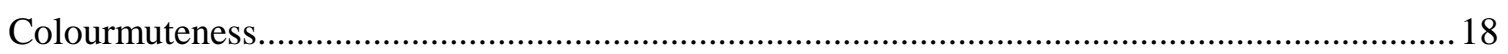

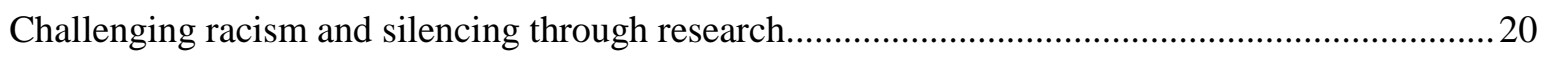

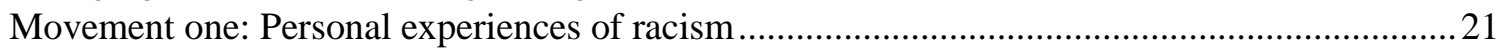

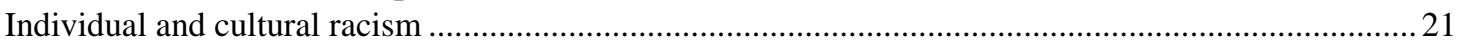

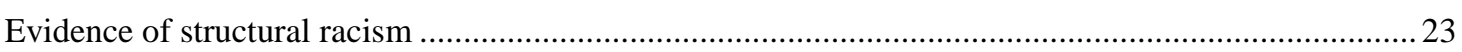

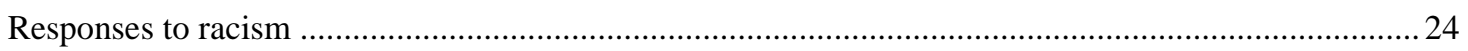

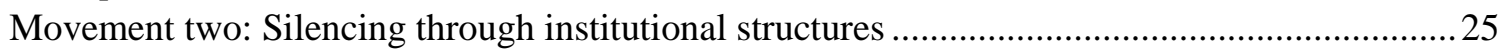

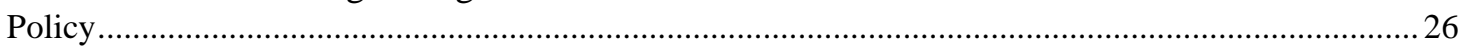

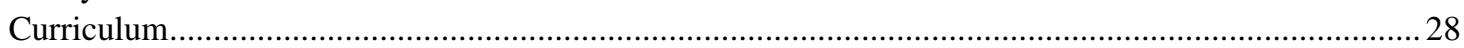

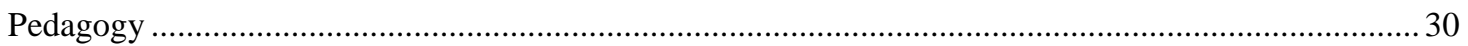

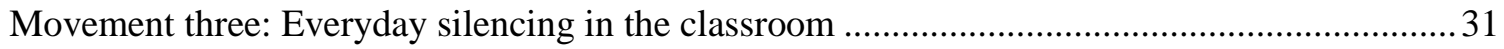

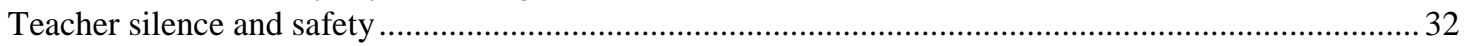

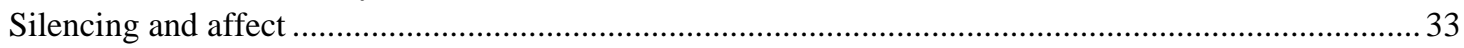

Movement four: The hidden curriculum of settler silencing......................................................... 35

\section{Chapter Three}

Ignorance and amnesia .....................................................................................................................40

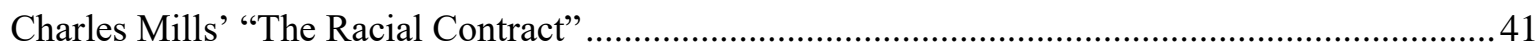

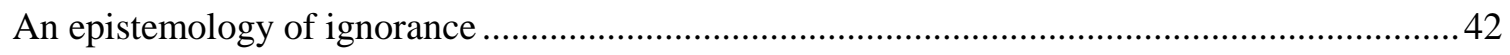

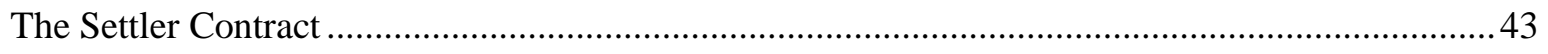

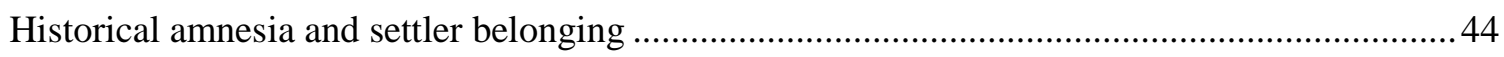

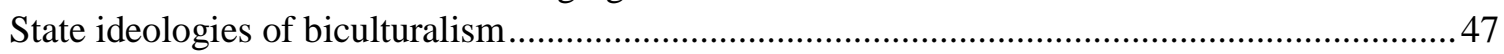

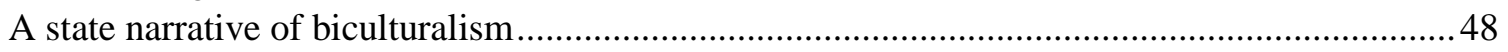




\section{Chapter Four}

Rewriting the Settler Contract in state secondary schools..............................................51

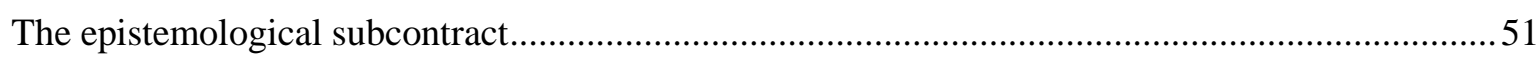

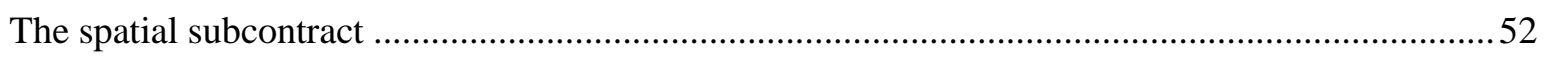

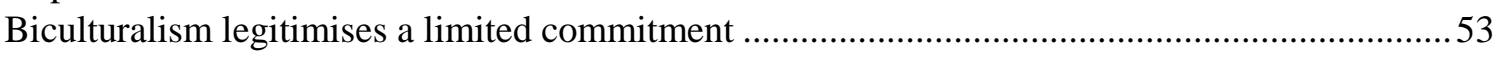

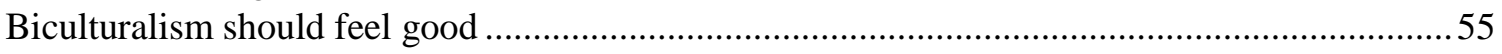

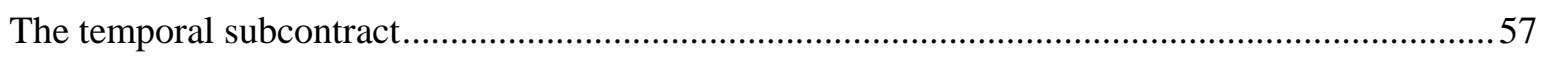

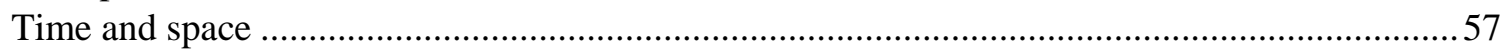

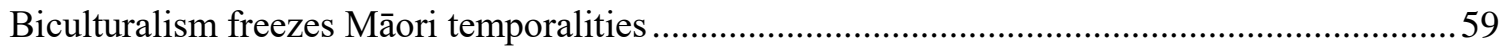

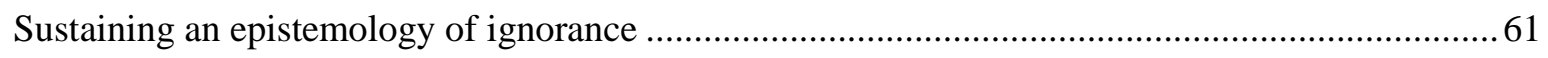

\section{Chapter Five}

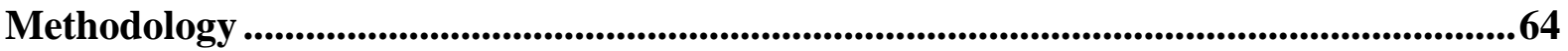

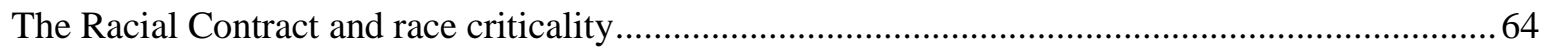

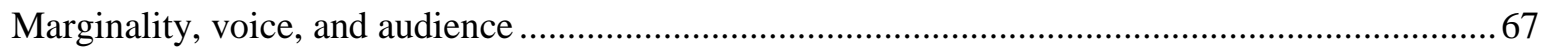

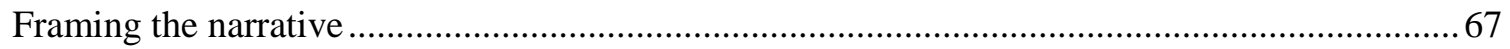

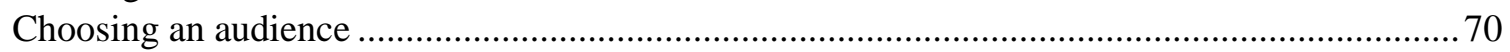

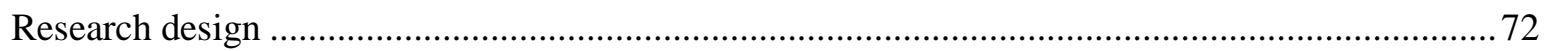

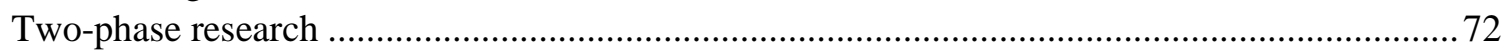

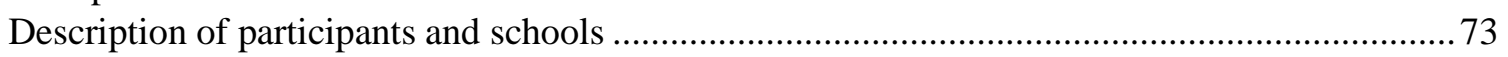

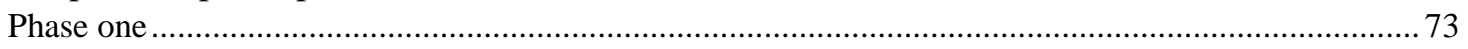

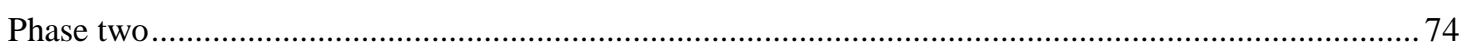

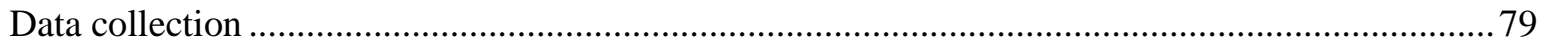

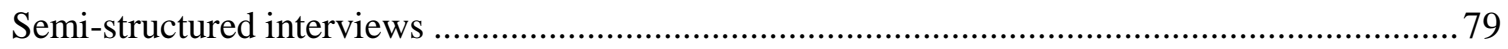

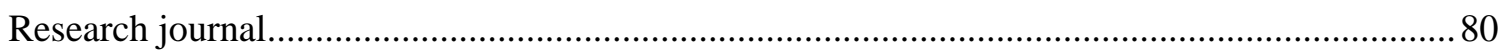

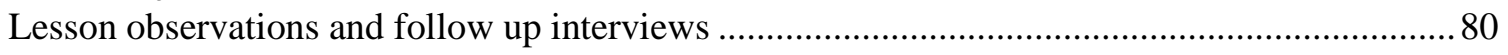

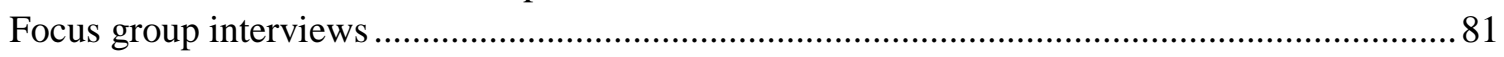

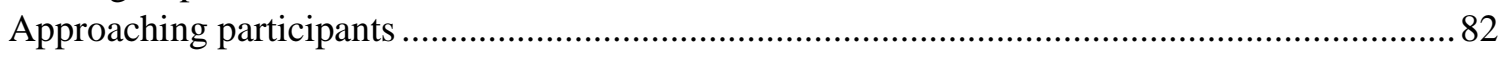

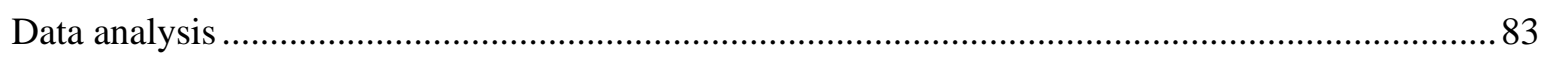

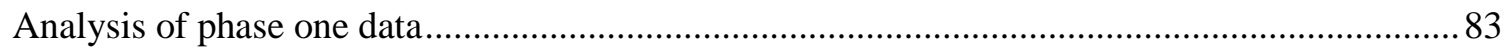

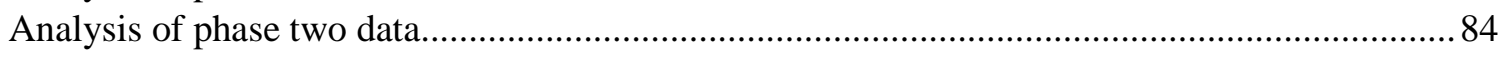

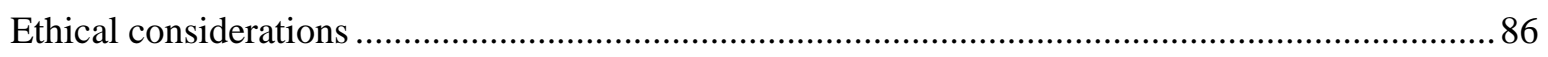

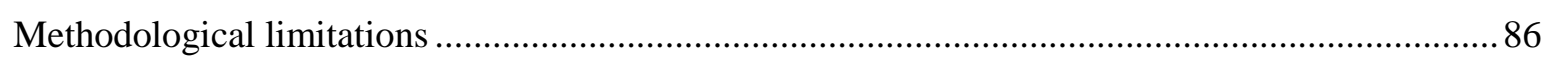

\section{Chapter Six}

Hitting "The 'porous' wall": Māori English teachers' perceptions of race and racism .89

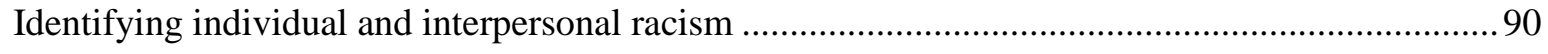

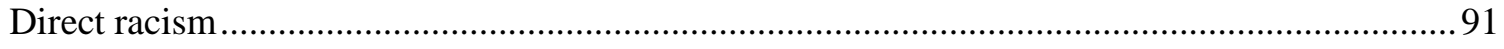

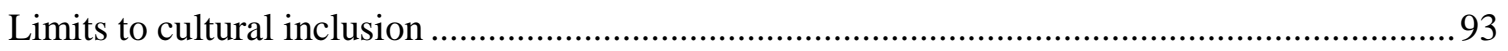

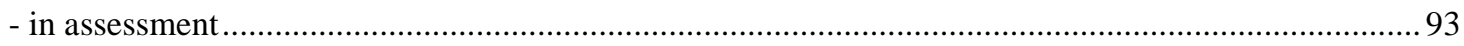

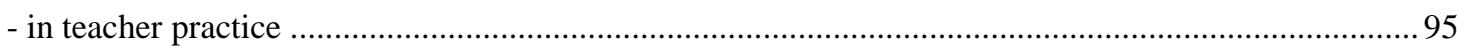

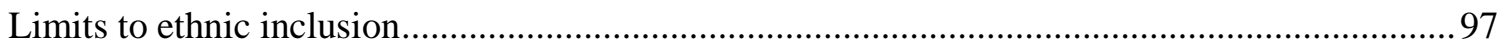

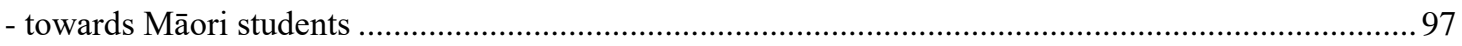

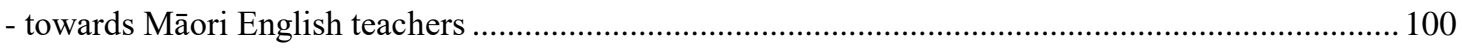

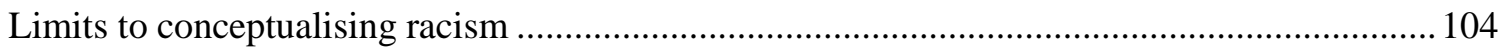




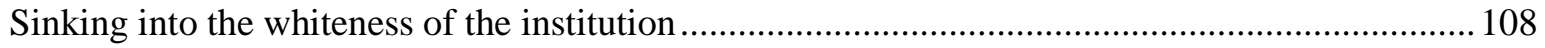

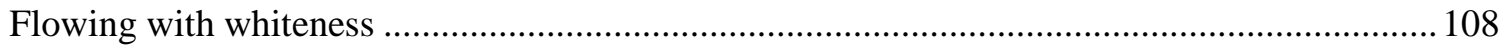

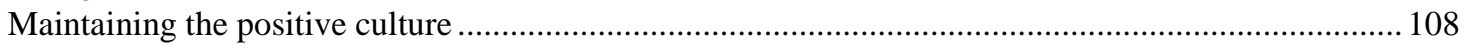

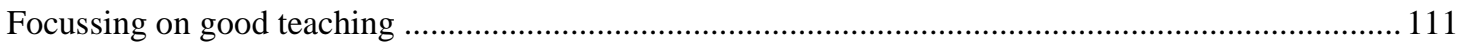

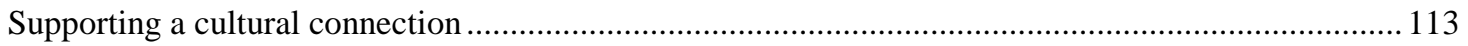

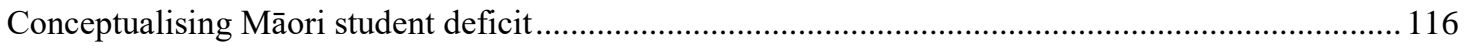

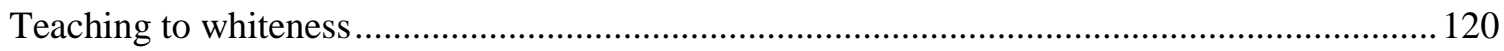

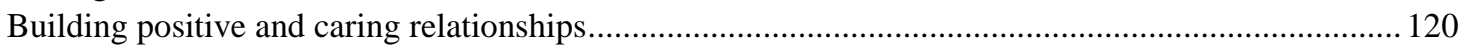

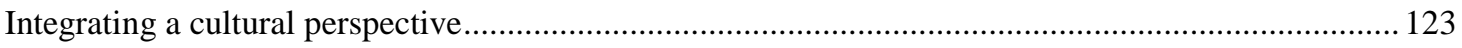

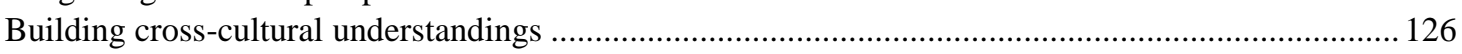

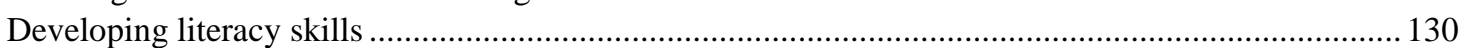

\section{Chapter Seven}

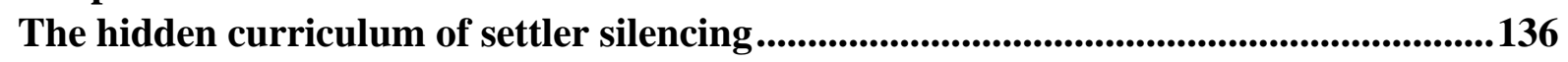

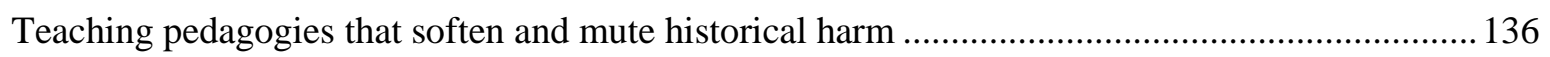

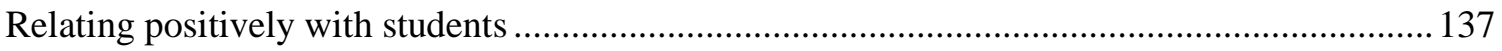

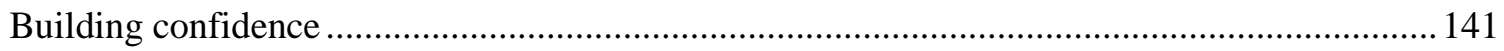

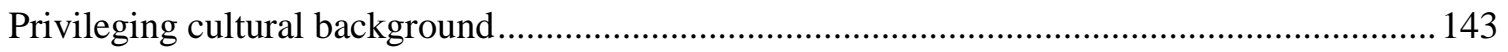

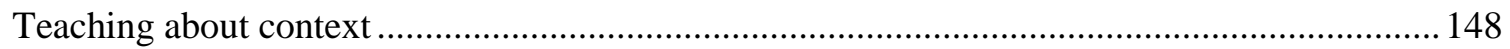

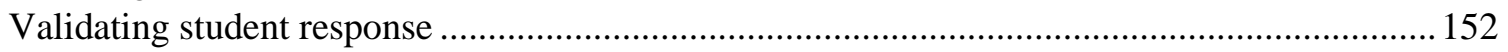

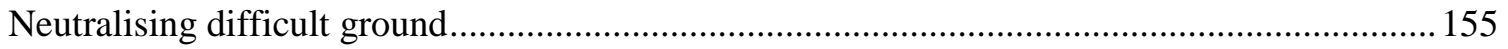

Assessment approaches that privilege settler-colonial imperatives .............................................. 159

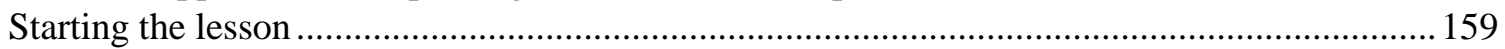

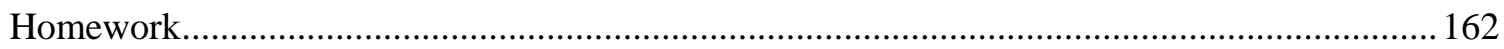

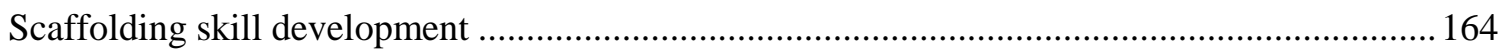

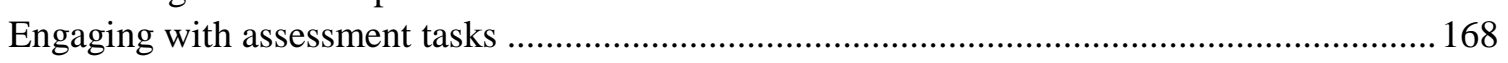

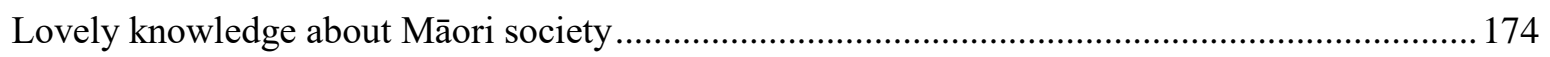

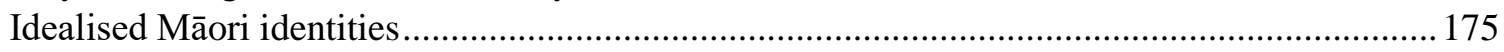

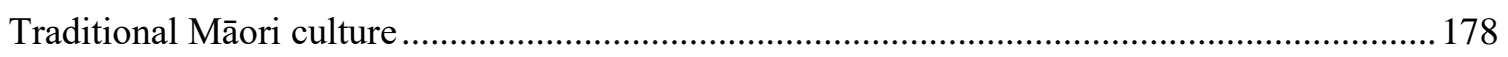

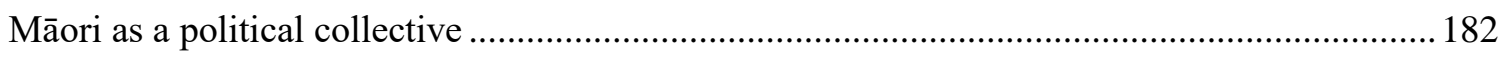

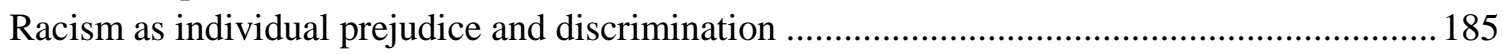

\section{Chapter Eight}

Oppression and resistance...........................................................................................................190

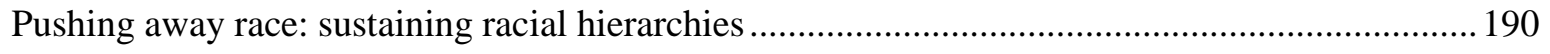

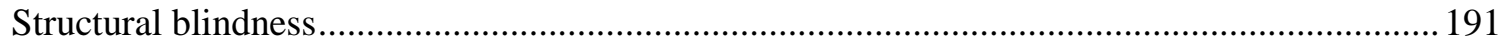

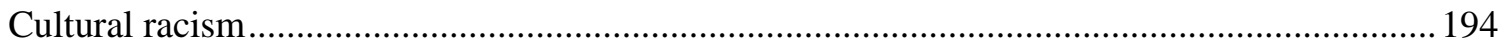

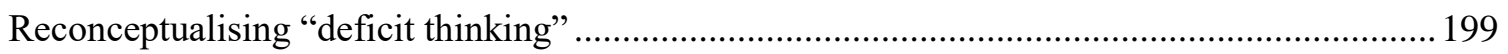

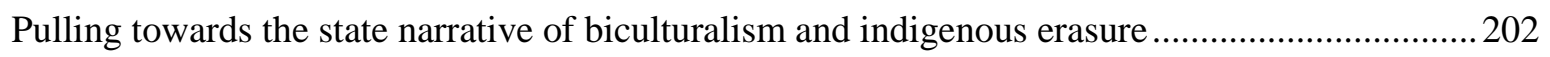

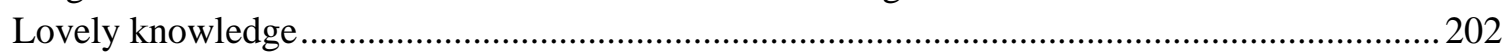

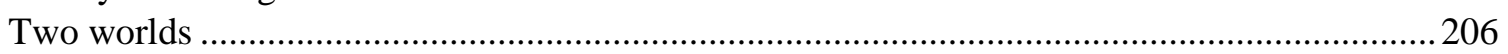

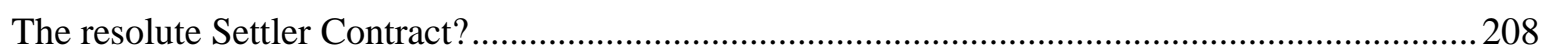

\section{Chapter Nine}

Conclusion ..................................................................................................................................................214

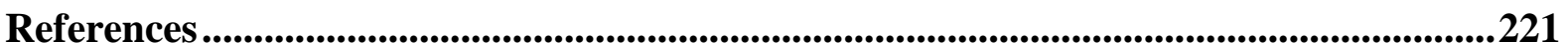




\section{Appendices}

Appendix A: Phase one research participant information and consent form ............................. 241

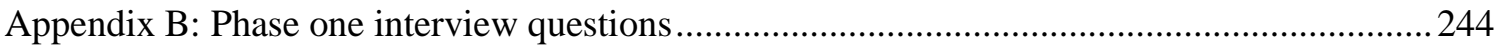

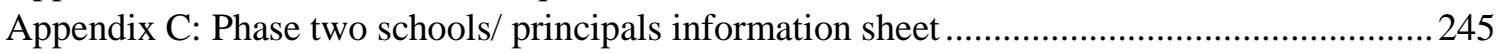

Appendix D: Phase two research participant information and consent form............................248

Appendix E: Phase two student research participant information and consent form..................252

Appendix F: Sample of the third iteration of phase one data analysis - process coding (Text

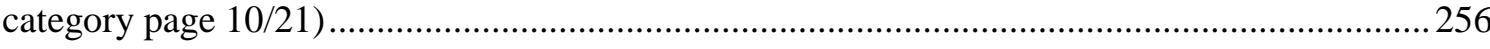

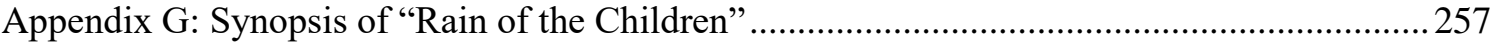

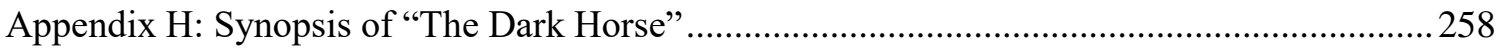

Appendix I: "Māori Battalion Veteran” by Alastair Te Ariki Campbell (2001)..........................259

Appendix J: “Our Tīpuna Remain” by Jacqueline Carter (2010) ................................................261 
Māori glossary of words or terms ${ }^{1}$

\begin{tabular}{|c|c|}
\hline Word/Term & Definition \\
\hline anei & (particle) here \\
\hline Aotearoa & Māori name for New Zealand \\
\hline aroha & love, affection \\
\hline awa & river, stream \\
\hline āwhina & (verb) to assist, help, support \\
\hline bilingual education & $\begin{array}{l}\text { when school subjects are taught in two languages. Ideally } \\
\text { students become fluent speakers of both language by the end } \\
\text { of schooling. However, second language use is variable } \\
\text { between schools. }\end{array}$ \\
\hline haka & $\begin{array}{l}\text { (verb) to dance, } \\
\text { (noun) performance of a type of dance (the haka) }\end{array}$ \\
\hline hapū & kinship group, subtribe \\
\hline hāngī & food cooked in an earth oven \\
\hline Hangarau & (noun) technology \\
\hline hōhā & $\begin{array}{l}\text { (stative) be boring, tiresome } \\
\text { (noun) nuisance }\end{array}$ \\
\hline hui & (noun) gathering, meeting \\
\hline iwi & extended kinship group, tribe \\
\hline Ka Hikitia & $\begin{array}{l}\text { a policy strategy released by the Ministry of Education that } \\
\text { aspires to change the education system to support Māori } \\
\text { students' educational needs }\end{array}$ \\
\hline ka pai & good \\
\hline kai & $\begin{array}{l}\text { (verb) to eat } \\
\text { (noun) food }\end{array}$ \\
\hline kaiako & teacher \\
\hline kaikaranga & $\begin{array}{l}\text { caller - woman(-en) who calls visitors onto the marae and the } \\
\text { corresponding caller from the visiting group during a powwiri }\end{array}$ \\
\hline kaitiaki(tanga) & (noun) trustee, guardian \\
\hline kanohi ki te kanohi & face to face \\
\hline karakia & $\begin{array}{l}\text { (verb) to pray, recite a prayer } \\
\text { (noun) ritual, chant }\end{array}$ \\
\hline kapa haka & Māori cultural group, haka group \\
\hline kaupapa & $\begin{array}{l}\text { 1. (noun) topic, matter for discussion } \\
\text { 2. (noun) level surface, ground (see also Chapter Five) }\end{array}$ \\
\hline kaupapa Māori & $\begin{array}{l}\text { 1. Māori approach, Māori topic, Māori institution } \\
\text { 2. see also Chapter Five }\end{array}$ \\
\hline kaumātua & (noun) adult, elder \\
\hline kia kaha & be strong, get stuck in \\
\hline Kia ora & hello, good luck \\
\hline kōhanga reo & Māori language preschool \\
\hline kōrero(rero) & (verb) to tell, speak, talk \\
\hline koretake & be useless, no good \\
\hline
\end{tabular}

\footnotetext{
${ }^{1}$ The English translation for these words and terms have been retrieved from http://Māoridictionary.co.nz/. There may be multiple meaning for the words or terms listed, however, I have only included definitions that I perceive are pertinent to this thesis. Māori words used within the definition of terms are also listed in the glossary.
} 


\begin{tabular}{|c|c|}
\hline Word/Term & Definition \\
\hline koutou & (pronoun) addressing three or more people \\
\hline kuia & elderly woman \\
\hline kupu & word, vocabulary \\
\hline kura & school \\
\hline kura kaupapa (Māori) & $\begin{array}{l}\text { primary school operating under Māori custom and using } \\
\text { Māori as the medium of instruction }\end{array}$ \\
\hline mahi & work \\
\hline mana & (noun) prestige, power \\
\hline mana whenua & $\begin{array}{l}\text { jurisdiction over land or territory, including history and } \\
\text { legends based on the land the tribe has occupied over } \\
\text { generations }\end{array}$ \\
\hline manaakitanga & hospitality, kindness \\
\hline Māori & (noun) indigenous person of Aotearoa/New Zealand \\
\hline Māoridom & te world of Māori people \\
\hline Māoritanga & Māori culture, worldviews, and practices \\
\hline Māori-medium education & $\begin{array}{l}\text { immersion education where Māori is used for teaching most } \\
\text { of the time. Many students speak Māori as their second } \\
\text { language }\end{array}$ \\
\hline mārama & to be clear, easy to understand \\
\hline mātauranga Māori & Māori knowledge \\
\hline marae & (noun) courtyard - the open air in front of the wharenui \\
\hline marae-ā-kura & school based marae \\
\hline matā & (noun) bullet, lead, cartridge \\
\hline maunga & mountain \\
\hline Maungapōhatu & $\begin{array}{l}\text { sacred mountain of Tūhoe where the prophet Rua Kēnana } \\
\text { established a home for his followers }\end{array}$ \\
\hline mōrena & good morning \\
\hline ngahere & bush, forest \\
\hline Pākehā & New Zealander of European descent \\
\hline Pākehātanga & Pākehā worldviews and practices \\
\hline pepeha & (noun) tribal saying, proverb \\
\hline pōtiki & youngest child \\
\hline pōwhiri & welcome ceremony on a marae \\
\hline rangatahi & (noun) younger generation, youth \\
\hline rangatira & (noun) chief (male or female) \\
\hline Rātana & $\begin{array}{l}\text { a religious movement that also became a major political } \\
\text { movement in the late } 1920 \mathrm{~s} \text {. }\end{array}$ \\
\hline Ringatū/ Te hāhi Ringatū & $\begin{array}{l}\text { a faith that was founded by Te Kooti on the East Coast, NZ in } \\
\text { the mid-1860s. It is practised today. }\end{array}$ \\
\hline rohe & boundary, region \\
\hline Rua Kenana & $\begin{array}{l}\text { Tūhoe; prophet who established a thriving community at } \\
\text { Maungapōhatu around } 1905 .\end{array}$ \\
\hline rūnanga & (noun) council, legislative assembly \\
\hline taiohi & (noun) youth \\
\hline tamariki & (noun) children \\
\hline Tama Iti & a Tūhoe Māori activist in New Zealand \\
\hline taiaha & long wooden weapon \\
\hline taiohi & (noun) youth, adolescent \\
\hline
\end{tabular}




\begin{tabular}{|c|c|}
\hline Word/Term & Definition \\
\hline tangata whenua & (noun) local people, indigenous people \\
\hline tau & (verb) to settle down, abate \\
\hline tauira & (noun) student, pupil \\
\hline te ao Māori & $\begin{array}{l}\text { the Māori world; encompasses te reo, tikanga, marae, waahi } \\
\text { tapu (sites of importance), and access to whānau, hapū and } \\
\text { iwi }\end{array}$ \\
\hline Te Aho Matua & $\begin{array}{l}\text { the philosophical base for kura kaupapa Māori education for } \\
\text { the teaching and learning of children }\end{array}$ \\
\hline Te Kooti & prophet and founder of the Ringatu faith \\
\hline $\begin{array}{l}\text { te reo Māori } \\
\text { Te Reo Māori }\end{array}$ & $\begin{array}{l}\text { the Māori language } \\
\text { a Māori language secondary school subject }\end{array}$ \\
\hline te reo Pākehā & the English/Pākehā language \\
\hline Te Reo rangatira & $\begin{array}{l}\text { a Māori language secondary school subject catered for } \\
\text { students who grew up learning the language }\end{array}$ \\
\hline teina & younger brother or sister of the same gender \\
\hline tikanga & correct procedure, custom \\
\hline tīpuna/ tupuna & ancestors, grandparents \\
\hline titiro & look \\
\hline tohunga & (noun) skilled person, chosen expert \\
\hline tuakana & elder brother or sister of the same gender \\
\hline tumuaki & head of an institution, leader, principal \\
\hline tūrangawaewae & $\begin{array}{l}\text { place where one has rights of residence and belonging } \\
\text { through kinship and whakapapa }\end{array}$ \\
\hline tūturu & (verb) to be fixed, permanent, real \\
\hline Tūhoe & tribal group of the Bay of Plenty, New Zealand \\
\hline waiata & (noun) song, chant \\
\hline wairua(tanga) & spirit, soul \\
\hline waka & canoe \\
\hline wānanga & tertiary institution that caters for Māori learning needs \\
\hline whaea & $\begin{array}{l}\text { (noun) mother. Used also as a marker of respect for a female } \\
\text { teacher (usually of Māori heritage) in schools }\end{array}$ \\
\hline whakamā & (noun) shame, embarrassment \\
\hline whakahīhī & (verb) arrogant, proud \\
\hline whakapapa & (noun) genealogy, lineage \\
\hline whakapono & (noun) faith, belief \\
\hline whakarongo mai & listen to me \\
\hline whakaruruhau & (verb) to protect, shield \\
\hline whānau & (noun) extended family, family group \\
\hline whanaungatanga & relationship, kinship, sense of family connection \\
\hline wharekura & (noun) secondary school run on kaupapa Māori principles \\
\hline wharenui & meeting house, main building of a marae \\
\hline whenua & land, country \\
\hline
\end{tabular}




\section{Chapter One}

\section{Introduction to the study}

The first lesson of my Te Reo Māori class at secondary school is about türangawaewae; a place we felt connected to. My classmates and I are given a black and white picture of a landscape that includes a river, hills, a cottage, and animals, with blank spaces for text. Just before Mr. Kingi begins to instruct the class I'm told to come up the front and join Huia, the other Māori girl. I walk past my Pākehā classmates to join Huia and she gives me a smirk. We sit together and colour in our pictures while Mr. Kingi instructs the rest of the class to learn the Māori words associated with türangawaewae. Previous comments from Māori girls about the nature of the class were ringing in my ears, "Māori with Mr. Kingi is awesome" they'd said. "You don't have to do anything”. But I felt uncomfortable at being singled out and a bit annoyed because I wanted to learn Māori vocabulary too. More than that, I wanted to be good, so sat there and quietly coloured in for the rest of the lesson and those that followed.

(Class memory, age 13)

The New Zealand education system was established with the view that it would "civilise" or "Europeanise" the indigenous Māori population (Simon, Smith, \& Cram, 2001). This approach to schooling was consistent with the larger colonial project that sought to relieve Māori from land, language, and culture (Belich, 2007; King, 2012; Walker, 2004). A country colonised towards the end of the imperial project, New Zealand was subject to less coercive and more hegemonic methods of colonial assertions of power than previous settler-colonial territories (Mamdani, 1999). In 1867, Native Schools were established as a parallel system to mainstream ${ }^{2}$ schooling in the hope that these would better accommodate Māori student needs, but it has since been noted that they operated as a less aggressive but no less damaging form of colonial rule (Barrington, 2008; Kidman, 2009). British-centric values and structures formed the basis of schooling operations, disadvantaging Māori from the outset (Simon et al.,

\footnotetext{
${ }^{2}$ References to the "mainstream" in New Zealand society include many ethnic groups; however, Pākehā (New Zealanders of European descent) constitute the largest group, followed by Māori, then Pacific. Māori are also included in the mainstream but do not share the same level or degree of power because Pākehā ways of being and existing in New Zealand society dominate mainstream interests.
} 
2001). That many of these structures still exist today is the basis for statements that the New Zealand education exists as a system of "biased failure" (Penetito, 2010).

Despite these overtly racist beginnings, very few New Zealand educators today would conceive that subtle mechanisms of racial domination continue to play out in state schooling institutions. Not only is the significance of race diminishing in education policy documents purported to support Māori learners (Ministry of Education, 2007, 2011, 2013), but many New Zealanders perceive that state institutions are racially neutral and that Māori perspectives and interests have been equitably included (Johansson, 2004; O'Sullivan, 2007; Smits, 2014). The prevalence of colourblind ideology - the wide-ranging public view that society is "beyond race" and harmful historical grievances no longer impact on the lives of people today (Bonilla-Silva, 2014; Leonardo, 2005a) - is captured by studies that show while New Zealanders recognise different races, religions, and cultures, support for principles of distributive justice which would address structural inequalities between Māori and Pākehā is low (Sibley et al., 2011; Sibley \& Ward, 2013; Ward \& Masgoret, 2008). Ignorance and denial of the structuring force of colonisation, a phenomenon described in this thesis as silencing, persist despite significant disparities between Māori and Pākehā in educational achievement data ${ }^{3}$, health outcomes ${ }^{4}$, youth suicide ${ }^{5}$ and incarceration rates ${ }^{6}$.

However, few studies have been conducted about whether issues of race, racism, and silencing impact on the teaching and learning that occurs in New Zealand classrooms (Sheehan, 2011). The Ministry of Education (the government branch of education) and many in teacher training institutions seemingly operate under the premise that race is of no consequence. In "The Racial Contract", Charles Mills (1997) argues that whites no longer see the implications of historical racial oppression or the ways that racial bias moderates modern society. Whites implement and maintain a system of "forgetting" that permeates social structures and institutions through an epistemology of ignorance. Following Mills, I argue that the disappearance of race is not accidental or insignificant. New Zealand

\footnotetext{
${ }^{3}$ For example, see: https://www.educationcounts.govt.nz/statistics/indicators/main/education-and-learningoutcomes/school leavers_with_ncea level_2_or_above

${ }^{4}$ For example, see: http://www.health.govt.nz/nz-health-statistics/health-statistics-and-data-sets/Māori-healthdata-and-stats

${ }^{5}$ For example, see: http://socialreport.msd.govt.nz/health/suicide.html

${ }^{6}$ For example, see: http://www.stats.govt.nz/browse_for_stats/snapshots-of-nz/yearbook/society/crime/ corrections.aspx
} 
secondary school institutions ${ }^{7}$ operate in elusive, complex, and wilful ways to silence racial critique. Silencing is reproduced through a carefully crafted racial discourse that supports New Zealand society to remain culturally and historically ignorant of our colonial past; particularly the violence inflicted on Māori communities through the dispossession of land, language, and culture and the ongoing consequences of those actions in the present day.

In this thesis, interviews and observation data centred on the lived experiences of Māori secondary school English teachers demonstrate that a silencing discourse is so entrenched in everyday teaching practice that it occurs without conscious thought. Moreover, the ease in which ignorance and denial of the structuring force of colonisation occurs in schools is consistent with the way that mainstream New Zealand society frames settler-colonial race relations. In view of these insights, the main research question of this thesis is: What do lived experiences of Māori English teachers reveal about silencing and institutional racism in New Zealand secondary schools? The following sections of this chapter provide background to this problem by first considering how the disappearance of race is a social norm that infuses institutional existence. This is followed by a discussion about silencing in the education system, before presenting the outline of the thesis in the final section.

\title{
Tracing the disappearance of race: use of terminology in the thesis
}

\begin{abstract}
Heading to the canteen I purposefully avoid looking at the row of bench seats adjacent to the line of students. I know all the girls who sit there, and I don't want to make eye contact. I think they are tough Màori girls who get into trouble in class, have boyfriends and do adult stuff in the weekend. I don't belong; I'm not like them; I'm not a real Māori; I feel like a sell-out.
\end{abstract}

(School memory, age 14-15)

The notion of "race" is contested and linked to power in society. Race was traditionally used to emphasise biological and physical differences as a basis for determining a social hierarchy (Clair \& Denis, 2015). Sociologists now recognise that race is a historical and social construct that operates as a means for the dominant culture to moderate access to power and privilege in society (Apple, 2014; Omi \& Winant, 1986). However, perceived biological

\footnotetext{
${ }^{7}$ New Zealand secondary schools traditionally operate from year 9 (age 13-14) to year 13 (age 17-18)
} 
differences do continue to moderate social existence and how the dominant culture assigns meaning to reflect inferiority and superiority (DiAngelo, 2012; Lee, 2014). Moreover, notions of race are not fixed; they change and evolve as the dominant culture manoeuvres to maintain power (Doane, 2017).

The racial inferiority of indigenous Māori was commonly accepted during the early imperial project. Māori were believed to be "savages" who were in need of "saving" (Mills, 1997). Colonial systems of control shifted from a primarily economic and military base to the arrival of settler immigrants who are "here to stay" (Wolfe, 2006). Settler-colonialism is distinguished from other forms of imperialism and state control by a logic that seeks to establish settler permanence by physically replacing and eliminating "the natives" from their land (Tuck \& Yang, 2012; Veracini, 2010, 2011; Wolfe, 1999, 2006). Indigenous people may be transformed or displaced several ways; "by assimilating them, by killing them off, or more often by preventing them from accessing traditional resources and reproduce" (Veracini, 2015, p. 25). To accommodate Māori subsequently, the New Zealand settler population developed a new approach to race relations by undergoing historical amnesia about the history and nature of settlement (Bell, 2006).

Historical amnesia descended as overt racism became seen as less morally acceptable. In the 1980s, ideologies of biculturalism were constructed to preserve Pākehā privilege and maintain a legitimate sense of national belonging (Doane, 2006). State ideologies of biculturalism constitute a framework of beliefs about the relationship between Māori and Pākehā (Hall, 1986; van Dijk, 1998). One historical event, the signing of the Treaty of Waitangi in 1840, is central to how mainstream New Zealand society remembers colonial history in ways that protect group interests. The Treaty of Waitangi was signed by Māori rangatira and government officials to recognise collective Māori ownership of lands, forests, and other properties, and gives the Māori the rights of British subjects. But whether Māori ceded sovereignty of New Zealand to the Crown or sought to retain their chiefly status is one of many issues exacerbated by different versions of the Treaty of Waitangi (Orange, 2014).

Despite inconsistencies about the signing process, the Treaty of Waitangi sits at the heart of mainstream beliefs about settler-indigenous race relations. The event is used in much state discourse to advance the view that the signing heralded two peoples (Māori and Pākehā) coming together as one nation (Brash, 2004). However, this "one people" ideology has been 
criticised for overlooking historical grievance and the need for state reparation (Johansson, 2004; O'Sullivan, 2008). Another aspect of the Treaty of Waitangi signing that captured public imagination was the notion of "partnership". A partnership trope became salient in the mid-1970s in response to growing Māori activism regarding historical, political, and economic oppression (Poata-Smith, 2008). In the 1980s, bicultural policy was adopted in state institutions to reinforce the perception that Māori and Pākehā cultures equally exist side by side in New Zealand society.

Although biculturalism implies an equal partnership, Dominic O'Sullivan (2007) argues that Māori are "junior partners" because power is unequally shared and the framework overlooks or ignores structural change. State ideologies of biculturalism only include unproblematic and superficial aspects of Māoritanga to give the appearance of cultural harmony and sense of national belonging that has links to our past and is moving forward into the future (Smits, 2014). The movement to link biculturalism to nationalist rhetoric has been associated with a neoliberal political agenda that serves to keep the dominant-subordinate relationship between Māori and Pākehā intact (Duhn, 2008; Ritchie, Skerrett, \& Rau, 2014; Smits, 2014). Implicit in these criticisms is the way that the affective concerns of Pākehā contribute to the racially biased structures of state institutions. In an analysis of an exhibition at "Te Papa", the New Zealand national museum, Kidman (2018a) argues that the notion of a harmonious bicultural partnership is materially constructed as a narrative that is convenient and comforting for Pākeha, whose claims for national belonging rest on a history of violence and racial oppression

In view of this positioning, terminology becomes important in this thesis. My use of terminology will run counter to a mainstream belief that bicultural race relations are now resolved or at least, progressing positively. It is perhaps unsurprising that "race" is not commonly used in either official or informal discourses as a concept to analyse how different groups of people access power in New Zealand society. The term "ethnicity" may be used as a place-holder for race in New Zealand (see, for example, Ministry of Education statistics ${ }^{8}$ ); however, ethnicity harbours softer connotations because it is variable and changing, involving the "participation of groups themselves in the construction, reproduction and transformation of their own identities" (Cornell \& Hartmann, 1998, p. 37). Sometimes when

\footnotetext{
${ }^{8}$ Retrieved from https://www.educationcounts.govt.nz/statistics
} 
the concept of race is silenced, groups of people can be both a race and an ethnicity. This occurs when collectives are positioned in a racial hierarchy but have self identified as an ethnic group as well, subscribing to their own culture and shared history (Cornell and Hartmann, 2007). The two largest ethnic groups in New Zealand are "Pākehā" (New Zealanders of European/settler descent) and then indigenous "Māori". Pākehā constitute the dominant race because Pākehātanga is the normative cultural paradigm in mainstream New Zealand culture; an observation that is invisibilised through silencing (Bell, 2006).

Conversely, Māori are the minoritised race, whose ethnic identities are culturally and structurally positioned in ways that align with the mainstream culture and the sensibilities of the dominant race (Spivak, 1988).

In this thesis, the term "white" is a generic term used in race scholarship to describe the racially dominant group. "Minoritised" is a term used to identify peoples from a range of settings who are ethnically and racially oppressed. I have chosen this over other place-holder terms, such as "marginalised", because minoritised has been previously used in literature associated with students from minority groups who are subject to institutional and structural processes that limit access to schooling (Benitez Jnr, 2010). The term "indigenous" captures the same racialised power dynamic as minoritised but the nature of racialisation is specific to the context of settler-colonialism. The term "black" is similarly used in this thesis to indicate a specific racial group within the minoritised collective who come from the United States or Britain. Other terms associated with individual studies are identified accordingly to differentiate between different ethnic groups. The following section locates ideas about biculturalism and silencing within the New Zealand education system.

\title{
Silencing race in education
}

\author{
...Then I spoke \\ My name is Tu the freezing worker \\ Ngati D.B. is my tribe \\ The pub is my marae \\ My fist is my taiaha \\ Jail is my home... \\ (Excerpt from "Sad Joke on a Marae" by Apirana Taylor)
}


The English lesson with my largely Pākehā year 11 class revolved around Taylor's poem and it did not go well. One Mãori girl storms out as soon as the class is finished, with a handful of students at her heels, but not before throwing me a venomous look. I speak to a colleague and she helps me think about how I positioned those students in a school community that is largely ignorant about anything Māori. I recently transitioned from a school with all Māori students and this kind of ethnically diverse classroom dynamic is new to me. Yet here I am, a supposed "expert" on Māori students and Māori text, failing to do justice to either.

(Teaching memory, 2009)

Following the New Zealand Wars", a Native school system was established to educate Māori youth as part of a "civilising mission" (Simon et al., 2001). The terms of the education system were set out by the Native Education Act, which stated,

If we attempt to hunt them into education, as we have hunted them into selling their lands, a spirit even of resistance will naturally be engendered. Make education a part of the Runanga: give the direction of it to themselves; let them feel that it is their own work. Once conscious of being free agents, they will take European advice and assistance. (Reports of Inspectors, 1862, p. 17)

The cessation of Native schools in 1969 may have heralded the end of an explicit settlercolonial stance of assimilation and colonial control, but to what extent have subsequent educational policies deviated from this original approach?

The current educational climate in New Zealand is largely silent on the issue of race and racism; an approach that aligns neatly with a wider societal aversion to the topic (Penetito, 2010). The New Zealand Ministry of Education perceives that a focus on "ethnicity" and "culture" is enough to bridge an achievement gap between Māori and Pākehā youth (Ministry of Education, 2011, 2013). In this thesis, I explore how an institutionalised climate of racial

\footnotetext{
${ }^{9}$ Kidman, Ormond, and MacDonald (2018) write that the New Zealand Wars "is a term coined by the historians in the 1980s to describe this series of conflicts between the government and Māori between 1845 and 1872" (p. 239).
} 
silencing is conducive to sustaining hegemony. Hegemony is an important social mechanism whereby those in power try to normalise dominant ways of seeing the world. People who do not benefit or are oppressed by dominant cultural ideologies are manipulated into believing that this is reality (Gramsci, 1992). State-sanctioned policies of cultural and ethnic inclusion, perceived to adequately meet the educational needs of Māori students, in fact result in institutional performances that sanitise or obscure the ongoing effects of historical harm and contemporary racial bias. In this way, affectively-moderated institutional structures align with Pākehā sensibilities and worldviews, thereby orientating what teachers can and cannot do by putting certain things within reach (Ahmed, 2007).

In this study, the lived experiences of Māori English teachers are considered through an ontology that acknowledges the materiality of race (Mills, 1997, 2002, 2007, 2014a). Seen through this lens, the participants in this study were positioned by state secondary school institutions to perpetuate ideologies that legitimise silencing and indigenous oppression, while also navigating the inconsistencies of a lived racialised existence. Docker (1978), Pratt (2014) and Veracini (2010) argue that colonial values, systems and structures persist in settler-colonial societies despite a formal decolonisation process of independence or liberation from the colonial power, or a process of recognition, reconciliation and partnership-building between settler and indigenous communities. In this way, the ongoing implementation of historically-entrenched, colonial processes and structures continue to covertly oppress indigenous peoples. Indeed, Gordon (2008) argues that the ability for the past to make its presence felt in the present may be described as a "haunting" whereby "organized forces and systemic structures that appear removed from us make their impact felt in everyday life" (p. 19).

A critical examination of a settler-colonial education system in relation to an ontology that acknowledges the significance of race, takes into account the way that discursive representation is subject to the materiality of institutional structures (Zembylas, 2017). For instance, a discourse of culturally responsive pedagogy is central to policies of ethnic and cultural inclusion. Culturally responsive pedagogies promote the view that teachers who build caring learning relationships by incorporating Māori culture into the classroom make a positive difference to Māori students' motivation and achievement (Bishop, Berryman, Cavanagh, \& Teddy, 2007; Macfarlane, 2004; Meyer et al., 2010). This approach assumes that secondary school teachers who harbour low academic expectations or deficit thinking 
make it difficult for Māori students to succeed academically (Ministry of Education, 2007). Consequently, the Ministry of Education assumes that Māori interests are progressed through policies and pedagogies designed to rectify some form of individual need or deficiency in indigenous students and their teachers. In doing so, the prospect that the structures of settlercolonial education are racially biased is rarely subject to critique.

However, Kidman et al. (2018) argue that the New Zealand education system is wedded to a Settler Contract that aims to legitimise a system of settler domination. They propose that cultural and historical amnesia is purposefully built into the epistemological structures of schooling (policy, curriculum, and pedagogy) to maintain ignorance about the structuring effects of colonisation. This thesis breaks new ground by showing how these seminal education structures facilitate a silencing discourse in New Zealand secondary school English classrooms. Doane (2006) describes a racial discourse as "the collective text and talk of society with respect to issues of race ... through racial discourse, individuals and groups 'frame' racial issues as they strive for ideological and political advantage" (p. 256). Through a silencing discourse, the racist implications of settler-colonial administration systems are hidden or pushed away, while institutional existence pulls towards the performance of a state narrative of biculturalism to legitimise settler belonging by erasing the real conditions of a lived indigenous existence.

In the real world of teaching, a silencing discourse arising from a correlation between macrolevel ideologies, meso-level institutional structures and micro-level classroom interactions, protects state imperatives through what is described by Giroux (1983) and Apple (2004) as a "hidden curriculum". In settler-colonial societies, several scholars argue that the hidden curriculum is tied to the maintenance of state control through processes that reinforce a colonial national identity (Kidman, Abrams, \& McRae, 2011; Luykx, 1993; Milne, 2017; Regalsky \& Laurie, 2007). This thesis makes an original contribution to research by demonstrating ways in which the hidden curriculum, mediated by a silencing discourse, advances white supremacy and the aims of settler-colonialism in New Zealand society. That this process has material and debilitating consequences for Māori youth, adults and the wider collective are reasons to conclude that the New Zealand education system is institutionally racist. 


\section{Outline of the thesis}

One of my PhD supervisors gives me a reading from a text edited by Zeus Leonardo (2005b) called "Critical Pedagogy and Race". I read it and think what the hell is this? Whiteness is the dominant ideology of society? A colourblind discourse perpetuates white supremacy? (I grew up believing that being colourblind is a good thing). I later discuss my doubts about the ideas from the readings with my supervisor: "Surely the claims these authors are making are not worth taking seriously because they don't relate to today's society. Isn't racial inequality a thing of the past?"

(Personal research journal, March 2013)

The argument that a silencing discourse supports the operations of a Settler Contract in the state education system is advanced in Chapter Two, the literature review. The review forefronts three ideologies related to silencing (whiteness, colourblindness and colourmuteness). This is followed by four movements that show how fieldwork has progressed to track a deepening understanding of the theoretical, philosophical, affective, and material dimensions of racism and silencing in the education and indigenous studies fields. The first three movements expose different layers to a hidden curriculum that sustains white supremacy at the micro-, meso- and/or macro-levels of schooling. This thesis makes an original contribution to race, education, and indigenous studies scholarship through a fourth movement, to propose that a hidden curriculum of settler silencing fulfils the aims of the Settler Contract.

The theoretical framework underpinning the fourth movement in the literature review is outlined in Chapter Three. The backbone of the chapter is Charles Mills' (1997) seminal work on the Racial Contract, which explores how a system of white supremacy is built on the wilful oppression of indigenous and minoritised peoples. In the contract, white personhood, and minoritised subpersonhood is naturalised through an epistemology of ignorance; an agreement to misinterpret the real racialised conditions of lived existence through "a certain schedule of structured blindnesses and opacities" (p. 19). The implications of Mills' work are then considered within a settler-colonial context. In the Settler Contract, historical ignorance towards colonial infractions is aided by popularist ideologies about biculturalism. State 
institutions adopt policies of biculturalism to equally include Māori and Pākehā interests, but the nature of inclusion is questionable. However, criticisms are quelled by a narrative of biculturalism that advances the notion of harmonious settler-colonial race relations, in line with fostering a sense of settler attachment and belonging to the land.

Chapter Four explores how a state narrative of harmonious bicultural race relations is performed in New Zealand secondary schools as part of a silencing discourse. A silencing discourse and the truth claims of state ideologies of biculturalism are examined in relation to the epistemological, spatial and temporal subcontracts of the Settler Contract. I also show how an epistemology of ignorance is sustained in state school institutions. The main research posed in the opening of this chapter was: What do the lived experiences of Māori English teachers reveal about silencing and institutional racism in New Zealand secondary schools? Three sub-questions are:

1. What do Māori English teachers' responses to New Zealand curriculum requirements (Ministry of Education, 2007) for critical approaches to text, identity, and biculturalism reveal about the operations of a silencing discourse?

2. What is the shape of a hidden curriculum of settler silencing? What does the hidden curriculum reveal about the operations of a silencing discourse?

3. How does the hidden curriculum of settler silencing fulfil the aims of the Settler Contract (and consequently the claim that New Zealand schools are institutionally racist)?

The methodological approach is outlined in Chapter Five. The Racial Contract and race criticality are presented as complementary paradigms that connect lived experiences of race to macro systems of racial oppression. The research design was structured around two phases of data collection. Phase one involved interviews from nineteen Māori English teachers about their school and classroom experiences. Phase two examined the classroom interactions and teaching practices of four phase one participants as they taught New Zealand literature to a senior English class. I wanted to examine the lived experiences of Māori English teachers because of my own background as a secondary school English educator, and because discussions about our colonial history may be more easily facilitated in the subject of English through the study of literature. I also discuss how my growing understanding of racial oppression affected the data collection and analysis process. 
The research findings are presented in the following two chapters. Chapter Six consists of two main sections of data from phase one of the research design. The first section presents participants experiences of hitting "the wall", which I describe as the sedimentation of structural oppression. Conversely, the second section reveals that participants sink into the whiteness of the institution, thereby aligning with the dominant culture of the institution. Chapter Seven displays the findings from phase two of the research, under the rubric of the hidden curriculum of settler silencing. There are three aspects to the hidden curriculum: teaching pedagogies that soften and mute historical harm, assessment approaches that privilege settler-colonial imperatives, and lovely knowledge about Māori society.

The discussion in Chapter Eight examines the data in relation to the aims of the Settler Contract. That is, how the hidden curriculum, mediated by a silencing discourse, pushes away a sense of structural racial bias to maintain subordination of the colonialised, and pulls those in the institution towards the performance of a state narrative of biculturalism to protect settler interests. The final section of the chapter considers how the state and mainstream New Zealand may implement an equitable indigenous-colonial education system that transcends the Settler Contract. In Chapter Nine, I conclude the thesis by summarising what has been done, the original contribution to knowledge, strengths and limitations of the research and ways in which we can speak back to the Settler Contract, now.

The argument that silencing is at the crux of institutional racism in the New Zealand education system arises also from my own personal and professional experiences which have played a significant role in shaping this story. After my father (who was Māori) passed away when I was seven, my community, school, and family life mostly reflected the Pākehā values of my mother. Because I did well at school and sought to please others, I did not really face significant hardships that made it difficult to get through adolescence. My career as a secondary school English teacher spanned ten years. During that time, I was never taught or thought to consider race in relation to my experiences as a Māori teacher and as a teacher of Māori students. Learning to see and understand racial oppression through this study has presented meaningful answers to my own unspoken racial tensions. The thoughts of others (whether on paper or in person) have given me words to understand the insecurities I harboured in relation to my own racialised identities; that mainstream society today exists in part because many young Māori are made to feel inadequate. I have captured some of these 
tensions in vignettes to acknowledge what my own experiences bring to this study, but also to question what has really changed for Māori youth today? As we move into the thesis in earnest, I close by asserting that it is the mundane and the everyday that really counts. 


\title{
Chapter Two
}

\section{Conceptualising settler silencing as institutional racism}

\author{
Lunchtime. Shanelle sits next to me but I can't remember what we talk about. \\ Perhaps something about what we did in class, or what we're going to do in the \\ weekend. She pipes up “You're so lucky you've got a culture because you're \\ Māori. I've got no culture - what have I got?" "Yeah." I reply. I don't really \\ think I'm THAT different. "But you're not like real Māori” she says. "You're \\ like a bounty bar. Brown on the outside and white in the middle”. She cracks up. \\ Maybe I snigger too? I don't remember but I don't say anything.
}

(School memory, age 16)

The purpose of this chapter is to examine how literature from the fields of education and indigenous studies in the United States, Australia, Britain and New Zealand, has progressed towards a deepening understanding of the philosophical, theoretical, affective, and material dimensions of racism and silencing in schooling. Scholarly progression is demonstrated through the way that empirical and conceptual research peels back different layers of a hidden curriculum that sustains white supremacy in education.

The review forefronts three ideologies that emerged from the empirical studies reviewed in this chapter (whiteness, colourblindness and colourmuteness). The fieldwork is then presented under three movements that challenge racism and silencing operating at the micro-, meso-, and/or macro-levels of schooling. The fourth movement advances a hidden curriculum of settler silencing to examine how white supremacy is enacted in settler-colonial education. A hidden curriculum of settler silencing framework is the means to examine how institutional racism in seminal to the New Zealand education system.

\section{Ideologies that sustain white supremacy}

Three racial ideologies emerged from fieldwork that challenges racism and silencing and education. Whiteness, colourblindness and/or colourmuteness are macro-level ideologies that are reinforced through a hidden curriculum designed to sustain white supremacy in school 
institutions and society. Although these ideologies have arisen mainly from research in nonindigenous settings, they are relevant to the theoretical design and enactment of a hidden curriculum of settler silencing.

The idea that state education harbours a hidden goal of ideological conditioning and transmission is not new. The concept of the hidden curriculum refers to the idea that schooling is a highly political process of perpetuating social inequalities and the ideological interests of those who hold power in society (Apple, 2004; Giroux, 1983). This notion was first developed by Western scholars who were critical of the hegemonic implications of liberal education and the way that schools are coercive forces in perpetuating state interests (Bowles \& Gintis, 1976; Illich, 1973). Ideas underpinning the hidden curriculum evolved to include explicit connections between macro- and micro-level processes, including the role of teachers and the way routines and daily practices reproduce ideology (Apple, 2004; Giroux, 1983).

Empirical studies reviewed in section two of this chapter show how the social organisation of the school, and power relationships between teachers and students, reproduce a hidden curriculum that legitimises racial oppression. This section relays scholarship that examines whiteness, colourblindness, colourmuteness and the relationship between each, to provide a macro-level backdrop to the reviewed fieldwork and the findings in this study.

\section{Whiteness}

Whiteness is an ideology, racial discourse, and worldview that is implicated in the historical invasion and enslavement of non-white parts of the world for racial domination (Leonardo, 2009). Leading United States scholars of whiteness and race, Doane and Bonilla-Silva (2003), argue that whiteness and those (usually whites) who align with white views and perspectives are positioned at the top of a racialised social system, supported by institutions and material practices that shape intergroup relations. They state that minoritised people are also beneficiaries of white privilege if they comply with the processes and structures that benefit white ways of being, behaving and knowing. Pākehātanga is a term used by Penetito (2010) to describe the New Zealand equivalent to whiteness and I use the two terms interchangeably in this thesis because they are speaking from a racially dominant position. 
Peggy McIntosh (1989) argues the benefits accrued through whiteness often goes undetected. In a landmark article about white privilege, she delivers a consciousness-raising appeal about the unacknowledged benefits of being white in the United States:

\begin{abstract}
As a white person, I realise that I had been taught about racism as something which puts others at a disadvantage, but had been taught not to see one of its corollary aspects, white privilege, which puts me at an advantage. . . I have come to see white privilege as an invisible package of unearned assets which I can count on cashing in each day, but about which I was 'meant' to remain oblivious (para. 2).
\end{abstract}

White privilege assures that white people "can arrange to be in the company of people of my race most of the time" (para. 8) and are "never asked to speak for all the people of my racial group" (para. 22). These everyday examples of privilege are powerful reminders of the routine and hidden ways that whiteness often goes undetected, making it "the most dangerous form of white supremacy" (Gillborn, 2005, p. 485).

Since McIntosh's article was published, scholars have noted that discussions about whiteness have done little to alleviate racial injustice. One criticism is that whiteness is conceptualised in wide-reaching and vague terms because there is little or no analytical, empirical or material analysis (Andersen, 2003). Doane and Bonilla-Silva (2003) note that the true nature of whiteness (how it is socially and politically complicit in reproducing white supremacy) may be hidden through explaining it as an ideology or category, instead of a system of oppression that contributes to racism. This thesis draws on empirical evidence to show how the systems and structures of state secondary schools reproduce and circulate whiteness or Pākehātanga. Lipsitz (1998) argues that those who have a possessive investment in whiteness may frame perceptions of white supremacy as negative and contemptuous actions, rather than a system for protecting the privileges of whites (Lipsitz, 1998). In this study, I show that the extent of this possessive investment is built into the very fabric of state school institutions, guiding those within towards a view of individual and interpersonal racism to protect the status quo.

The tendency for whites to perceive of whiteness in self-affirming ways has been linked to emotional and ego-centric concerns. For example, whiteness may lead to a positive white identity, where white subjects feel good about "their" antiracism (Ahmed, 2012, p. 170). 
Whites may also believe that they are victims in a world where racism affects members of society equally (Doane, 2006). White intellectual alibis may profess solidarity with the nonwhite Other, yet protect their privilege by striving for racially "safe" spaces that continue to marginalise the interests of minoritised people (Leonardo \& Zembylas, 2013). Cautionary insights about the way that whiteness can be utilised to protect and reify white interests reinforce the slippery and difficult nature of "whiteness as the invisible norm" (Andersen, 2003, p. 24). However, as this study reveals, minoritised peoples are also implicated in reproducing whiteness, even when aspects of its oppressive nature becomes visible. Individuals are therefore so immersed in whiteness that it is easier to gravitate towards a belief system that absolves one of white complicity, as outlined in the following section.

\section{Colourblindness}

One of the most significant ideologies to perpetuate whiteness is the notion of racial "colourblindness". Racial colourblindness has been described as "feigning" an oblivion to race, suggesting that it is convenient for those who benefit from whiteness to remain ignorant of structural racism (Leonardo \& Porter, 2010). One reason that ignorance towards structural racism is upheld is because of the view that racial injustice is a personal or individual act. As a result, institutional spaces and structures are perceived to be racially neutral, thus preserving whiteness and racism in society (Doane \& Bonilla-Silva, 2003; Giroux, 2003).

Another reason colourblind ideology thrives is because individualistic explanations of social and economic achievement advance meritocracy; the idea that everyone has equal opportunities to better their circumstances in life if they work hard enough, regardless of cultural or ethnic orientation (Doane \& Bonilla-Silva, 2003). Mainstream New Zealand society prides itself on being fair and kind ${ }^{10}$, however, such rhetoric may be used to drive perceptions of individual freedom that are associated with a "one nation" or "one law for all" discourse ${ }^{11}$. Accordingly, individuals are perceived to be equal and no-one should be "given" special rights. Colourblindness underpins a "one nation" discourse that is used to deny Māori the right to self-determination and redistributive justice for historical grievance (O'Sullivan,

\footnotetext{
${ }^{10}$ See, for example, the New Zealand Prime Minister's speech to the United Nations General Assemby. Retrieved from https://www.newshub.co.nz/home/politics/2018/09/jacinda-ardern-s-full-speech-to-the-ungeneral-assembly.html

${ }^{11}$ Don Brash, the leader of the main opposition political party, delivered a Nationhood speech in 2004 that derided the Waitangi Tribunal claims process by arguing that Māori were receiving "special rights" and that all New Zealanders should be subject to "one law for all” (Brash, 2004; Johansson, 2004; O'Sullivan, 2008).
} 
2007). Through this line of thinking, individual hardship and deprivation is attributed to poor decision-making. Meritocracy also impedes the ability to view the consequences of structural racism, ensuring that explanations of educational inequity are attributed to individual deficit (Castagno, 2008; Gillborn, 2005).

Entrenched whiteness and the hegemony of colourblindness are racial ideologies that contribute to silencing. In Chapter One, I proposed that silencing is a normalised condition of mainstream New Zealand that shields its citizens from colonial violence and the nature of racial domination. To do so, silencing initiates both Pākehā and Māori into a hegemonic way of thinking. A landmark study by Eduardo Bonilla-Silva (2014) provides important insights about how a colourblind racial perspective is articulated and rationalised by mainly white Americans as a hegemonic discourse. He finds that a colourblind discourse consisting of four racial frames (abstract liberalism, naturalization of personal preferences, cultural racism, and minimisation of racism), and styles and scripts were utilised by participants when talking about race. Participants used semantic moves and verbal pirouettes to demonstrate that race is not relevant in contemporary society. Bonilla-Silva's study demonstrates that everyday language may be a measure of how individuals understand race, shows that consistent and patterned responses are associated with reproducing a racist ideology through verbal exchanges, and that a relationship may be drawn between ideology, discourse, and everyday conversations. His study was important to the development of this thesis because it informed the way I thought about how silencing and dominant cultural ideologies are reproduced by individuals operating in state school institutions.

\section{Colourmuteness}

Unlike colourblindness, which is a framework that supports whites to assert the individualised nature of race and racism, colourmuteness denotes the absence of race or racial discussions altogether. One consequence of this ideology is that omitting race language presents a façade of racial neutrality that covertly perpetuates racism, and reinforces deficit thinking and meritocracy (Castagno, 2008). An inability to think critically about the implications of a raced existence can result in dysconscious racism; a form of racism that quietly accepts white privilege and norms (King, 1991).

An ethnographic study by Pollock (2004) in one United States high school shows how colourmute school policies and practices advance whiteness in ways that have deleterious 
consequences for minoritised students. She finds that colourmute ideology may be systematically imbedded in formal and informal school structures and processes, leading to the view that race is not an aspect of inequality (Pollock, 2004). Although colourmute conditions may have been created as a well-meaning attempt to bring about a colourblind society and avoid uncomfortable racial discussions, Pollock (2004) argues that racial inequality is exacerbated by deleting race words or using them carelessly. For example, race labels for "low-income", "minority" groups and individuals who are "at risk" and "disadvantaged", simplify the complex realities of a raced existence (Fine, 1987). Deleting race words or using de-raced words in policy language can have the adverse effect of creating more racialised conditions.

Colourmuteness resonates with the current approach by the New Zealand Ministry of Education to respond to issues of culture and ethnicity rather than race, as identified in Chapter One. Following the logic of colourmuteness, policies that refer to culture and ethnicity are highly racialised and implicated in reproducing inequality. For example, a policy document released by the Ministry of Education (2013) to address Māori underachievement, "Ka Hikitia" (Ministry of Education, 2013), advances the vision "Māori achieving success as Māori”. The policy states,

This vision means ensuring that all Māori students, their parents and their whānau participate in and contribute to an engaging and enjoyable educational journey that recognises and celebrates their unique identity, language and culture. This journey will support Māori students to achieve the skills, knowledge and qualifications they need to achieve success in te ao Māori, New Zealand and in the wider world. (p. 13)

As will be shown through interview methods in Chapter Six, Māori English teachers struggled with these aspirational phrases, particularly when observing how Pākehā teachers apply their own understandings to such policy.

According to the literature, whiteness, colourblindness and colourmuteness operate in covert and overlapping ways to further the individual and collective interests of whites. These macro-level ideologies sit at the heart of the empirical studies presented in this review. 


\section{Challenging racism and silencing through research}

The literature in the following four movements symbolise empirical and conceptual shifts towards a deepening understanding of how silencing and racism is enacted in secondary school education. "Movement" is a descriptive term that shows how fieldwork has progressed to challenge silencing and racism operating at the micro-, meso-, and/or macrolevels of schooling. In exposing different facets of a hidden curriculum, the empirical studies provide a concrete reality to the way that whiteness, colourblindness and colourmuteness ideologies circulate through school institutions. In league with the fieldwork is conceptual or theoretical research. This more abstract discussion highlights methodological limitations to the fieldwork within each movement and some directions to plug these gaps.

In movement one, the white cultural bias of school institutions is exposed through counternarrative fieldwork to identify how interpersonal and individual acts of racism are enacted in schools. The studies in movement two challenge colourblind ideology by revealing how institutional structures that propose to support minoritised students are implicated in hegemony. The third movement examines everyday classroom interactions to uncover how emotion, silences and silencing, pedagogical approaches and nationalist concerns may be subject to colourmute conditions. This thesis advances a fourth movement, in which a hidden curriculum of settler silencing facilitates institutional racism through the covert operations of a silencing discourse.

Most of the studies in this review are grounded in critical race theory. Critical race theory emerged in the United States following the civil rights movement as a counter-discourse to racism within legal structures and practices (Bell, 1992b; Crenshaw, 1988). In education, critical race theory was adopted in response to a dearth of discussion about race in critical theory and pedagogy (Freire, 1970; Kincheloe, 2004; Ladson-Billings \& Tate, 1995; Leonardo, 2005a; Lynn, 2005). Several scholars recognised that a focus on class and economic inequality trivialised the impact of oppression that results from historic and institutionalised racial grievances (Allen, 2005; Ellsworth, 1989; Ladson-Billings, 1997; Leonardo, 2002). 
Critical race theory positions race and racism at the centre of social analysis. The approach prioritises the use of counter-narratives (the perspectives of minoritised peoples) to challenge an accepted and therefore "normal" narrative that reflects the worldviews of the dominant culture (Delpit, 1988; Lynn, 2005). Other tenets of critical race theory include: a challenge to dominant ideologies and deficit perspectives, interdisciplinary analyses, and an explicit commitment to social justice (Solórzano, 1998). The first movement of the review is defined by a belief in the emancipatory power of counter-narratives to challenge racism and silencing.

\section{Movement one: Personal experiences of racism}

In line with critical race theory, studies that privilege counter-narrative research are powerful because they expose the lived realities of racism (Stanley, 2006). These studies challenge the silencing of minoritised peoples and how they are positioned by the whiteness of school institutions. However, one main drawback to relying solely on this method of data collection is that minoritised people are not immune to dominant racial ideologies that tend to view racism as an individual problem (Castagno, 2008). The studies in this movement are presented under the sub-themes: individual and cultural racism, evidence of structural racism, and responses to racism.

\section{Individual and cultural racism}

One issue that emerged from the narratives of marginalised students was the prevalence of individual and cultural racism. Individual racism refers to prejudiced attitudes and discriminatory behaviours based on race, described by Clair and Denis (2015) as the "first phase" of the sociological study of racism (circa 1920s to 1950s). Cultural racism assigns groups of people with specific cultural attributes which makes individuals more predisposed to deficit discourses and stereotypes (Mukhopadhyay \& Chua, 2008).

Minoritised students report that they were regularly subjected to racial stereotypes, negative behaviours and verbal and physical abuse by white teachers and students because of their ethnic heritage (Dovemark, 2013; Graham \& Robinson, 2004; Hällgren, 2005; Kohli, 2009). Kohli (2009) interviewed twelve Asian-American, black and Latina female teachers in the United States. The women reported that white educators attribute low levels of classroom engagement to minoritised students who "don't want to learn . . . weren't motivated" (p. 246) or were "difficult to work with" (p. 248). The teachers' responses about the importance of learning the English language were subtly denigrating of the students' backgrounds. Kohli 
observed that limited structural analysis meant the teachers "often allowed deficit beliefs to shape their understanding of their students" (p. 247).

Minoritised teachers similarly experienced individual and cultural racism. This was manifest through covert assumptions about their professionalism by white colleagues. For example, six Aboriginal Canadian school teachers were subjected to inequitable hiring practices and were told that their teacher training institutions provided lower quality training. These participants felt like they were not perceived by white school communities to be "real teachers" and some felt lonely, isolated and discriminated against by both Aboriginal and white peoples as a result of not belonging in "either world" (Young et al., 2010, p. 297). Indigenous educators also experienced greater work demands from the school and wider communities than their white counterparts (Santoro \& Reid, 2006). Interviews with twentyfive indigenous Australian educators revealed they were frustrated by the expectation that they were meant to act as:

A 'bridge' between Indigenous and non-Indigenous communities, to be role models for Indigenous students, to be cultural experts, to fill the gaps in the knowledge of white teachers about Indigenous education and to take responsibility for the implementation of Indigenous educational policies and initiatives at school level. (p. 293)

Although the teachers wanted to support indigenous students they received little acknowledgement for the extra work. Instead of being teachers, they were positioned as "indigenous teachers" and subsequently viewed as having a different role and responsibilities within the school. In New Zealand, accounts of racism and marginalisation at universities were often ignored; indeed, white scholars were observed to silence Māori scholars who challenged the status quo through a "racialising of dissent" that may lead to labels such as "angry native" (Kidman, Chu, Fernandez, \& Abella, 2015, pp. 65-66). These studies show that if personal experiences of racism are not ignored by the dominant culture, they are considered biased, hysterical, self-serving, over-sensitive, or a manifestation of reverseracism (Essed, 1991; Mills, 2007).

These findings show that racist attitudes, discrimination, stereotypes and deficit thinking are a part of school culture and continue to negatively impact minoritised people today, even 
though colourblindness assumes that society is "beyond race" (Bonilla-Silva, 2014; Leonardo, 2005b). The accounts of individual and cultural racism demonstrated by these studies resonate strongly with the interview data from the Māori English teachers of this study; however, as will be seen in Chapters Six and Seven, institutional manifestations of cultural racism may be attributed to reasons other than individual bias as demonstrated by the studies in this section.

\section{Evidence of structural racism}

Although participants from studies in movement one generally draw attention to individual prejudice, discrimination, and cultural racism, some counter-narrative research identifies white racial bias in institutional structures. Colourblind policy and curriculum design was observed by nine women of color in a majority white Canadian university. They articulated that racism was prevalent in most areas of the academy, including curriculum design, evaluations, administrative support, and in their relations with mainstream students. For example, all the women reported that the curriculum was Eurocentric and excluded the "contributions of scientists from developing countries" (Samuel \& Wane, 2005, p. 80). Asian-American, black and Latina female teacher trainees similarly noted a colourblind curriculum in the schools they were assigned (Kohli, 2009).

Twenty-seven minoritised scholars (African American, American Indian, Asian, Asian American, Latina/o, Native Pacific Islander, and South African) named multiple ways that colourmute practices were enacted in everyday academic life, such as teaching, mentoring, collegiality, identity, service and racism. For example, one scholar spoke about how black faculty members "tend to perform more service ... we are picked often for committees that need diverse representation, and become the "safe" person [to whom] underrepresented minority students turn to discuss their climate issues" (Stanley, 2006, p. 719). In New Zealand, university diversity initiatives that were supposed to support Māori scholars and students were described as "tokenistic" and observed to exacerbate problems without changing "the power structures of the university" (Kidman et al., 2015, pp. 46-47), drawing attention to ineffective institutional approaches to culturally include minoritised groups.

The Māori English teachers who were interviewed in this study also identify ways in which some institutional structures are racially biased as a result of brushing up against them in their daily lives. Unlike the studies in this section of the review, however, participants' 
articulations of structural racism are reframed according to a colourmute policy framework endorsed by the Ministry of Education. This process raises new insights about counternarrative accounts of racial injustice.

\section{Responses to racism}

Another issue that emerged from counter-narrative research is that minoritised peoples respond to interpersonal and cultural racism in creative and self-protective ways.

Minoritised educators and students may retreat to silence. Minoritised scholars indicate that this is a tactical manoeuvre to distance oneself from harm but recognise that silence may be read as agreement or complicity (Delpit, 1988; Frideres, 2015; kumar, 2010; McNeil, 2011; Rodriguez, 2011). Rodriguez (2011) uses the phrase "silent rage" to describe the powerlessness and invisibility she feels when she is ignored by white colleagues and rationalises her feelings by recognising that they sit within a racial context of white supremacy. Alternatively, Rollock, Gillborn, Vincent, and Ball (2014) examine how members of the black British middle class silence aspects of their working class and cultural backgrounds to be accepted by the white middle class. Blacks negotiate white education spaces by appealing to white sensibilities through language, code switching, or donning a "mask of performance" (p. 151). Black people may also follow "rules of racial engagement" to manage racialised incidents with whites (Rollock, 2012). Silencing aspects of one's identity, then, may be interpreted as reactive strategies to whiteness because of conscious attempts by participants to minimise racist harm.

Minoritised students similarly adopt strategies to counter the emotional toll of racism. Black university graduates from predominantly white institutions perceived little encouragement from white professors and students, so gravitated towards positive support from black professors and peers (Johnson-Bailey, Valentine, Cervero, \& Bowles, 2008). Furthermore, Swedish-born minority interviewees between 15-34 years of age (for example, Sami, Swedish Finns, Tornedalers, Roma and Jews) and Asian-American, black and Latina female teacher trainees students in majority white settings report that they have to "work harder" to prove themselves and counter negative and disparaging attitudes, low expectations and questions about their intellect from white educators (Hällgren, 2005; Kohli, 2009). Again, the studies reviewed in this section are purposefully included because they resonate with the 
approaches articulated by Māori English teachers interviewed in phase one of the research design to combat individual and cultural racism in their schooling lives.

The literature reviewed in this section reveals a significant drawback to relying only on counter-narrative research without considering a wider contextual understanding of structural inequality. Minoritised peoples are rarely cognisant of the the effects of colourblind and colourmute ideologies and how they direct people to view racism as more than just an individual act. As such, the participants in the studies reviewed here are affected by a white racialised view of the world that is only partial (Alcoff, 2014), and underpinned by Western ways of thinking that are limited by Western philosophies and epistemologies (Leonardo, 2014).

Conversely, researcher cognisance of the limitations of counter-narrative research can be used to highlight to what extent dominant racial ideologies and discourses moderate state schooling (that is, the character of hegemony is exposed). A seminal study about "everyday racism" by Essed (1991), which focussed on the narratives of black women from California and Surinamese women from the Netherlands, found that innocuous racialised comments and actions were grounded in dominant cultural (white) beliefs about racial superiority and the "natural" order of things. The ingrained nature of white supremacy led Essed to argue that non-whites can practice everyday racism too. As such, minoritised educators' perspectives, behaviours, and teaching practices may be subject to ideological critique.

The drawbacks posed by counter-narrative research may be minimised by considering teacher perception against classroom observations to show how the learning environment and institutional structures (the social setting) are implicated in silencing and racism. Taken together, these two forms of data collection demystify existing structural barriers that make it difficult for minoritised people and whites to see the nature of racism and white supremacy in their everyday lives. In line with thinking about the social, I now turn to a critique of three seminal school structures to think about how the structural design of institutions are implicated in racism and silencing.

\section{Movement two: Silencing through institutional structures}

This movement responds to the lack of structural critique posed by counter-narrative methodology. Research here challenges the way that the policy, curriculum, and pedagogy 
structures of education are covertly implicated in hegemony and reproducing racial ideologies in schooling.

\section{Policy}

Educational policy plays a significant role in silencing minoritised people. In the United States and Britain, racial colourblindness, or "whiteness-as policy", informs policy design that may appear to be fair and equitable, but attributes racial disparities to cultural and ethnic deficit, developmental delays and competition between groups (Leonardo, 2009). For example, standardisation is a policy approach that includes streaming and testing practices that are meant to support diverse learners, but which in reality, disadvantage black people (Gillborn, 2006). Inequitable outcomes are produced because these practices do not recognise the historically entrenched nature of the achievement gap or account for the racial and economic backgrounds of students or school communities, thus exacerbating a racist ordering that benefits whiteness (Gillborn, 2006, 2008; Tuck \& Gorlewski, 2016). For example, Gillborn (2006) argues that citizen education in England is a placebo that promotes "a vision of society as based on liberal universalistic principles" (p. 97) but fails to respond to the "institutionalization of failure" (p. 90), or calls (triggered by the Lawrence Inquiry ${ }^{12}$ ) to investigate racism in public institutions. Colourblind policies may therefore be more detrimental than the official curriculum because the educational requirements of people of colour appear to be included (Frideres, 2015).

In a similar vein, colourmute policy practices that omit any form of support to address the complexities of race inadvertently also communicate to teachers and students that race is not an important part of the schooling experience (Pollock, 2004). Racial ommission has implications for the continued reproduction of colourblind perceptions of racial injustice, deficit theorising and cultural racism. For example, Pollock (2004) found that the state education board collected data from all schools in the district about achievement disparities according to race. However, teachers in her school of study are not exposed to this information because of a colourmute culture, so attribute achievement "problems" to "the district", "economics", “culture" and "parents" (p. 166). Behind closed doors, teachers sometimes told Pollock that a student's cultural or ethnic background was reason for

\footnotetext{
${ }^{12}$ The Stephen Lawence Inquiry Report was generated in response to the death of Stephen Lawrence, an 18year-old Black college student, who was stabbed to death by white youths who were never convicted of the crime. The judge-led public inquiry advanced deeper understandings of racial injustice by suggesting that the police's failure to act constitutes institutional racism (Gillborn, 2006).
} 
academic failure. Conversely, "the district" (education board) would shift blame about student underachievement from culture, to teachers who were perceived to have "low expectations" (p. 168) and school administrators. Pollock (2004) notes that a culture of blame was central to everyday school life. A similar pattern of locating achievement "problems" with individuals was evident through data collected in phase one and two of the research design in this study; however, rather than a haphazard process of blame, policies that appear to adequately include Māori interests direct participants towards specific reasons that are problematic or pathologising for Māori student academic failure.

Two studies find that white teachers interpret policy designed to include and support indigenous students in ways that avoid engaging with issues of race (Siteine, 2016; Vass, 2015). Siteine (2016) interviewed eleven primary school ${ }^{13}$ teachers about the New Zealand curriculum identity policy directive and found that simplistic and essentialising views about how best to support Māori students were guided by the policy framework. The teachers demonstrated defacto understandings about how culture, ethnicity or affirming students' identity leads to academic success. The research found that teachers who do not draw from curriculum support or theory will focus on social knowledge at the expense of academic knowledge, thus limiting opportunities for Māori students to transcend their economic and social situation. Conversely, Australian teachers avoided and deflected racial conversations when asked to consider educational policy designed to "close the gap" and minimise the literacy and numeracy disparities between indigenous and non-indigenous students (Vass, 2015). Both studies find that policies that do not direct teachers to consider issues of race, reify whiteness through the articulation of colourblind and cultural deficit discourses.

Similar to Siteine (2016), a study by Gebhard (2017) examines the contractions and limitations of policies that advance cultural approaches to indigenous education in the Canadian Prairies. She cites work by St. Denis (2007) who "underlines the irony in suggesting indigenous students fail in school because they have too little culture - in the past, 'failure was attributed to Aboriginal students who arrived at school with too much culture"" (p. 759). Gebhard interviewed thirteen indigenous and non-indigenous educators and finds that cultural approaches as part of policy appeared to support non-indigenous teachers to feel like they are adequately meeting the needs of indigenous students. However, the study finds

\footnotetext{
${ }^{13}$ New Zealand primary schools traditionally operate from year 1 (age 5-6) to year 6 (age 10-11).
} 
that integrating cultural elements actually supported some participants to hold low expectations or fixed views about indigenous students. For example, one participants perceived that the "right kind" of indigenous students was one who is "knowledgeable about her background" (pp. 762-763). In addition, some participants silenced discussions about race and this appeared to be a normalised aspect of school culture. However, Gebhard interviews one indigenous teacher who identified that cultural approaches to learning (for example, making dream catchers and little tuna drums) were superficial, and throught that the environment constrained underachieving indigenous students, who "don't feel comfortable or that there's a place for them" (p. 768). This was the only participant who challenged cultural approaches and wanted anti-racist education. In a similar vein, this thesis considers how policy approaches that claim to support indigenous students contributes to a racial discourse that shapes the perspectives of New Zealand educators and their understanding of racial injustice.

Studies that examine the contradictions and tensions underpinning education policy and practices that apply fixed ethnic labels, find that these approaches silence the complexity of minoritised students' lived existence. For example, a black/white racial identity binary in schools from the United States was found to exclude and silence indigenous Alaskan Native or American Indian students. Indigenous youth were determined by white students to be racialized "Others", or black or white, and were subject to diverse forms of stereotypes and race-based assumptions (Castagno, 2005). In two other studies, minoritised students who do not fit into a typical black/white racial binary reported that they were often asked the question "What are you?" as peers attempted to categorize them (Castagno, 2005; Milner, 2015).

The studies in this section highlight that the intention of policy designed to support minoritised and indigenous students looks very different in theory to how it is understood by the educators who are vested with implementation. This thesis builds on these insights by examining the implications of how such policies are performed in the classroom, thereby identifying what the policy actually does in the teaching and learning process rather than what it hopes to do.

\section{Curriculum}

Education policy can also create inclusion and exclusionary mechanisms that determine what is taught in the school curriculum and the knowledge or perspectives that are privileged. 
Ethnic labelling policy and practices, for example, are perceived to encourage identity politics by ascribing students to set racial categories that become "bricks in a wall of power relations" (Lipsitz, 1998, p. 49). Pollock (2004) finds that the curriculum in her school revolved around six "official" ethnic groups. These groups influenced what was taught in the classroom and silenced the potential to learn about knowledge from other ethnic groupings in the student body.

Classroom curriculum itself, it seemed, played a key role in simplifying Columbus' infinite diversity into manageable units . . . while students often conformed to the student world by proclaiming racial mixture, then the classroom world typically prompted students to select single, lump sum identifications within a finite system of options. (pp. 41-42)

Another way that curriculum is implicated in silencing is that the resources or texts that teachers use may flatten the depth and breadth of indigenous experience. Studies find that school texts may support a curriculum that romanticises indigenous peoples and reinforce hegemonic messages of imperialism and colourblindness. This includes overlooking the way structures and institutions are implicated in historical racial violence and slavery (Brown \& Brown, 2011; Van de Kleut, 2011). Van de Kleut (2011) notes that some texts promote safe, sanitised versions of colonial history, devoid of political and ideological concerns, and encourage Eurocentric readers to consume the text without applying an emotional response. Alternatively, Brown and Brown (2011) critique the version of history that is offered through historically sanitised texts, explaining the students learn to view "racial violence as historic, isolated incidents that were done by a few 'bad men' and that only affected the individuals directly involved in the violent act" (p. 50).

While the white racial bias of the curriculum is connected to policy design and text resources, the studies in this section do not consider how the racial setting of the classroom (that is, the culture of the learners and their relationship with the teacher) affects the transmission of curriculum knowledge. Furthermore, other influences may affect the teaching and learning process, as outlined in the following section. 


\section{Pedagogy}

Teaching approaches designed to cater to the learning needs of students are implicated in hegemonic relations. Multicultural education was one of the earliest pedagogical approaches to acknowledge the importance of race and ethnicity in the classroom. It was envisaged that this approach would support students' backgrounds and encourage the development of positive perceptions of racial identity, to result in successful schooling experiences (Banks, 1993; Gay, 2002). However, scholars note that some aspects of multicultural education are practiced selectively, such as curriculum reform, whereas knowledge construction and prejudice reduction are ignored (Ladson-Billings, 1998). Another education support for minoritised students is culturally responsive pedagogy. This approach was first articulated by Ladson-Billings (1995) who argues that teachers should: hold high academic expectations and offer appropriate support such as scaffolding; act on cultural competence by reshaping curriculum, building on students' funds of knowledge, and establishing relationships with students and their homes; and cultivate students' critical consciousness regarding power relations.

The New Zealand Ministry of Education similarly privileges a discourse of culturally responsive pedagogy, in line with work by Ladson-Billings (1995). Well-resourced and funded teacher professional development initiatives, such as Te Kotahitanga, finds that secondary school teachers who incorporate Māori culture into the teaching and learning of the classroom make a positive difference to Māori students' motivation and achievement (Bishop et al., 2007; Bishop, Berryman, \& Wearmouth, 2014; Macfarlane, 2004). Such research advances the notion that curriculum and pedagogical approaches adequately support the schooling needs of Māori students. Building relationships, for example, is understood to be an important pedagogical approach for increasing Māori student engagement in class (Bishop et al., 2007). However, criticisms of culturally responsive pedagogy in relation to the education of indigenous youth argue that educators ignore how racialised power relations affect the teaching and learning process (Castagno \& Brayboy, 2008; Gutschlag, 2007; MacDonald \& Reynolds, 2017).

Scholars in the United States also note that implementation of multicultural education and culturally responsive pedagogies are problematic. One issue is that teachers enact the pedagogies in limited and simplistic ways (Ladson-Billings \& Tate, 1995; Sleeter, 2012). For example, Sleeter (2012) argues that there are four methods of practitioner simplification: 
cultural celebration (marginalising student, school and classroom culture), trivialisation (steps to get to know students), essentialising (fixed and homogenous view of culture or ethnic group) and substituting cultural for political analysis (silencing racism and oppression). Morrison, Rose, and Robbins (2008) and Sleeter (2012) contend that another problem associated with culturally responsive pedagogy is that teachers are increasingly pressured to meet neoliberal reforms, such as standardisation processes in relation to teaching units of work or assessment measures. A review of culturally responsive literature suggests that standarisation affects how teachers may implement contructionist pedagogy (Morrison et al., 2008), while Sleeter (2012) notes that working with students to raise test scores means teachers have less time to develop curriculum that meet the needs of their students. While these critiques of neoliberalism identify ways in which education policies are subject to cultural and political bias, the analysis does not consider how historical and ongoing structural manifestations of racism influence the implementation of policy and subsequent teaching approaches. This research responds to this gap by considering the implications of culturally responsive pedagogy within systems of white supremacy and settler-colonialism.

The policy, curriculum and pedagogy structures in this section highlight contradictions between policy and teaching practices that that claim to cater to the interests of indigenous students, yet legitimise a centring of white interests to result in schooling processes that further marginalise racially oppressed groups of learners (Gillborn, 2006, 2008; Leonardo, 2009). However, one drawback to the studies in this section is that the effects of these structures on everyday teaching and learning processes are not examined. The third movement highlights the racism and silencing that occurs at the micro-level of schooling.

\section{Movement three: Everyday silencing in the classroom}

The third movement considers literature that examines how emotion and affect moderate racialisation processes as they occur in everyday classroom practice. The first group of studies show that racism may be perpetuated through a desire not to talk about race or an inability to see classrooms as highly racialised spaces. The second group explores ways in which the affective concerns of the dominant race moderates schooling and how this is linked to issues of national identity and belonging. 


\section{Teacher silence and safety}

Classrooms that seek to create a "safe" space when discussing issues of race have been problematised by critical race scholars (Castagno, 2008; Fine, 1991; Leonardo \& Porter, 2010). The concept of safety may arise out of good intentions to keep everyone happy, but perceptions around when and where to have safe conversations are informed by fear or not knowing how to talk about race.

White educators may silence issues of race in the classroom because they are fearful of the consequences of drawing attention to social injustice or the problems that students experience. For example, some teachers chose to ignore problematic behaviours by black students, such as truanting, because they did not want to be accused of discrimination (Pollock, 2004). Similarly, ethnographic research conducted by Fine (1987) about the schooling experiences of low-income black and Latino "dropouts" from a New York City high school found that educators,

Seemed to survive by not naming or analyzing social problems. They taught the curricula and pedagogical techniques they hoped would soothe students and smooth social contradictions. Many would probably have not considered conversation about social class, gender, or race politics relevant to their courses, or easily integrated into their curricula. One could have assumed, therefore, that they had benignly neglected these topics. (p. 161)

Alternatively, teachers may not wish to name a raced existence because they do not know how to address it (Castagno, 2008). In a study examining racial discourse within Australian high school classrooms, Vass (2013) observes that one white educator was silent during two racial exchanges. During the second exchange, an indigenous male student challenges a white female student for making light of a racist remark that in her view was "funny racism" (p. 22), however, the teacher responds by correcting the grammar in his challenge and ignoring the accusation of racism. Another study examining how whiteness is legitimised through silence, found that teachers in two United States schools were similarly observed down-playing derogatory comments that students made towards indigenous peoples and their practices (Castagno, 2008). While avoiding difficult or uncomfortable emotions may be perceived to be in the best interests of students, the practice perpetuates the denial of a racialised lived existence. 
Research also shows that minoritised educators struggle with colourmute school settings and may unwittingly perpetuate racism because they are inexperienced at dealing with issues of race. Two black student art teachers from a predominately white art education programme were isolated in their attempts to grapple with race. One of the student teachers created a lesson that was designed to get her students to think about their racial positioning. However, instead of empowering the one black student in the class, this embarrassed him (Kraehe, 2015). A black English teacher (Anthony) in a school in the United States was also complicit in perpetuating silence and evasion during particularly tense discussions about race (Thomas, 2015). Anthony was observed using direct questions, commands, personal pronouns and student feedback as a tactical manoeuvre to get students to buy into reading a book with strong race themes, but did not work critically with students to examine the socially constructed nature of complex racial/ethnic descriptors. He also navigated aggressive student responses when discussing issues of class from the book but did not engage with critical questions of power. The researcher suggests that "greater metalinguistic awareness among English teachers" (p. 172) is needed to resolve racial conflict in and outside the classroom.

Empirical research that focusses on teacher silence or racial avoidance draws attention to the way that emotional concerns, such as safety and fear, moderate silencing in the classroom. However, analysis is limited by attributing silencing and racism to the implicit or unconscious bias of teachers, rather than the structures of the institution. Unconscious bias is described as "an automatic tendency for humans to perceive people, situations and events in stereotypical ways" (Blank, Houkamau, \& King, 2016, p. 13). Consequently, racism is framed as negative attitudes or feelings of inferiority towards a student(s) based on ethnicity (Clair \& Denis, 2015). This thesis moves beyond research that associates everyday racism and silencing with psychology, by considering the relationship between classroom interactions and structural factors.

\section{Silencing and affect}

Another form of silencing in the classroom is linked to a political or nationalist agenda. The studies here show how the affective concerns of the dominant race directs those in school institutions towards a certain way of thinking and feeling about society (Leonardo \& Zembylas, 2013). Affect is more subliminal and less discursive than emotion because it creates formations of exclusion and inclusion, or relations of entitlement and belonging 
(Ahmed, 2004). Such boundaries are designed to advance the national interests of the dominant culture and sustain power relationships that suppress minoritised people.

The idea of maintaining "safe" space in discussions about race is also perceived to protect whites from being exposed as racist by sustaining imaginary nationhood narratives. A Canadian study by St. Denis (2011) investigated the impact of multicultural policy towards indigenous education and how indigenous knowledge, histories and teacher experiences are received in schools. Multiculturalism argues St. Denis, silences indigenous sovereignty and their distinctive relationship to land creates space for non-indigenous educators to ignore the brutal realities of colonisation. These insights were captured by comments by indigenous teachers who perceived that non-indigenous teachers only want to "talk about fluff" (p. 314) instead of real or difficult knowledge. St. Denis writes,
Ahmed (2007-2008, 127) has argued that multiculturalism encourages a politics of happiness, whereby those who encounter multiculturalism as racism in disguise or another form of colonialism are socially pressured into silence in order to "maintain signs of getting along": otherwise, they risk being positioned as the "killjoy". Silencing and further oppression is achieved by suggesting that the "exposure of violence becomes the origins of violence". Resistance to making Aboriginal content and perspectives in schools "real"' is similarly positioned when there is pressure being applied to avoid teaching "difficult knowledge" so that the image of Canada as a fair and just country can be preserved. (p. 315)

The emotional impact of racial conflict is explored in studies that consider the politics of memory and how difficult histories are remembered or forgotten in classrooms. In a study by Zembylas, Charalambous, and Charalambous (2014), the teaching style of a Greek-Cypriot teacher was examined to show how emotions and memories are implicated in pedagogical interactions that bolster the interests of the dominant race. During a class discussion, the teacher was observed to include or omit student feedback that aligned with the Hellenocentric character of the Greek-Cypriot educational system. Students were also directed towards divisive feelings associated with Turkish-Cypriots and encouraged to articulate feelings of fear, abandonment, anger, and nostalgia for a lost homeland. The discussions sympathised with Greek interests and positioned the Turkish-Cypriots as Other and so influenced how 
interactions between Turkish-Cypriots and Greek-Cypriots should be remembered (Zembylas et al., 2014).

Classroom and school processes that strengthen racialised dichotomies, such as "victims" and "perpetrators", in relation to historical events were also observed in an elementary school in Cyprus (Zembylas, 2010). Teachers from the majority Greek-Cypriot population were observed implementing subtle segregation processes between Greek-Cypriot and Turkishspeaking children, had lower expectations, and were less willing to engage with Turkishspeaking children. The principal and staff also interpreted school policies in ways that favoured the majority student population. Zembylas (2010) labels this "a politics of resentment", designed to exacerbate existing racial tensions towards a foreign or different Other to bolster the identity of the dominant culture. He suggests that teachers are caught in a bind, when "schools are caught between reproducing the hegemonic discourses of resentment and approaching them critically. . . [particularly when] analyzing how racialization (and ethnicization) is manifest in everyday school practices that perpetuate the uncritical use of race and ethnic categorizations" (p. 256). Consequently, school practices, policies, and informal institutional frameworks can be conceptualised as "structures of resentment" (p. 266); historical and politically-motivated technologies that create inclusion or exclusionary mechanisms. In this way, the affective concerns of the dominant culture underpin the design of institutional structures, moderating the behaviours and thought processes of teachers in schools set against a backdrop of difficult histories.

The literature associated with classroom processes of silencing show how misguided notions about safety and racial illiteracy protects the emotional sensibilities of whites. Moreover, some literature in movement three suggests that teachers are positioned by affectivelymoderated school structures to operate in ways that support the national interests of the dominant race. In line with these points, the final movement of this review considers how the affective needs of settler populations are reproduced in everyday classroom settings through a hidden curriculum framework.

\section{Movement four: The hidden curriculum of settler silencing}

Existing indigenous scholarship works through movements one and two to consider how a hidden curriculum framework is tied to the maintenance of state control. The enduring effects of colonialism in settler-colonial Latin America are discussed by Pratt (2014), who 
argues that the succession of the Creole settler class did not sever the colonial relationship. In this instance,

\begin{abstract}
Social and economic relations do not decolonize, nor does the cultural relation with the metropolis ... Independence struggles, though conducted within ideologies of liberation, served to relegitimize and refunctionalize colonial hierarchies and the practices and institutions that sustained them. (p. 462-463)
\end{abstract}

The white/colonial cultural bias of school institutions - the subject of studies in movement one-emerges from research that examines the schooling of indigenous youth (Kidman et al., 2011; Kim, 2015; Milne, 2017; Wallerstein, 1997). A study by Milne (2017) finds that students learn to adapt to the white cultural norms that permeate classroom practices, school structures, and government policies as they get older, demonstrating increased socialisation and competence at operating in a schooling environment that primarily values Eurocentric ways of being and learning. These results reveal that Eurocentric epistemologies so central to the overtly racist design of colonial education administrations, are covertly reproduced and perpetuated in today's settler-colonial educational environments.

Tacit and coercive processes that seek to constrain indigenous populations and assert a colonial national identity are central to studies that resonate with movement two. Indigenous peoples' ethnic and cultural identities are constructed by the state in ways that support the covert transmission of state hegemony (Gramsci, 1992; Kidman et al., 2011; Luykx, 1993; Milne, 2017; Regalsky \& Laurie, 2007). Research identifies that pedagogical or curriculum approaches may advance settler interests by including some aspects of indigenous culture, while excluding others. For example, Kidman et al. (2011) interviewed $10-12$ year old Māori students in one school and found that cultural supports, such as teaching through the medium of te reo Māori, is not enough for Māori students to bridge the hidden implications of the Eurocentric curriculum and attain advanced levels of achievement in the Science curriculum. The study indicates a relationship between hegemony and silencing, although the affective motivations that underpin everyday teaching and learning practices have yet to be fully theorised.

Movement four draws together insights from movement two and three to consider how "structures of resentment" are implemented at the everyday level of schooling (Zembylas, 
2010). School structures create mechanisms of inclusion and exclusion to ensure that school interactions are sensitive to the affective and emotional concerns of the dominant Pākehā population. In Chapters Three and Four, I theorise how a facade of equitable race relations is central to a "logic of elimination" that supports settler-colonial administrations to covertly thrive and sustain racial hierarchies (Wolfe, 2006), while distancing New Zealand citizens further from the real conditions of a lived indigenous existence. A hidden curriculum of settler silencing is therefore designed to bolster Pākehā claims of national belonging and suppress awareness of historical colonial violence to maintain the subordination of indigenous populations.

This thesis makes an original contribution to research by showing how a hidden curriculum of settler silencing advances white supremacy and the aims of settler-colonialism. In drawing a relationship between the two, I demonstrate that the state secondary school system is institutionally racist. In the United States, Carmichael and Hamilton (1967) argued that antiblack attitudes and practices that "permeates the society, on both the individual and institutional level, covertly and overtly" (p. 5), arise from "the predication of decisions and policies on considerations of race for the purpose of subordinating a racial group and maintaining control over that group" (p. 3).

However, since Carmichael and Hamilton (1967) institutional racism has faced criticisms that it is vague, hard to identify with certainty, and difficult to analyse through research. In Britain, a definition of institutional racism offered by The Stephen Lawrence Inquiry Report (Macpherson, 1999) has been widely accepted on one hand, but criticised for being too wideranging on the other (Pilkington, 2011). The report defined institutional racism as:

The collective failure of an organization to provide an appropriate and professional service to people because of their colour, culture, or ethnic origin. It can be seen or detected in processes, attitudes and behaviour which amount to discrimination through unwitting prejudice, ignorance, thoughtlessness and racist stereotyping which disadvantage minority ethnic people. (Macpherson, 1999, p. 49)

In response to the report, Ahmed (2012) argues that "a politics of recognition" limits how institutional racism is perceived. For example, she observes that the Macpherson Report 
locates racism as a "collective failure" rather than "an ongoing series of actions that shape institutions, in the sense of the norms that get reproduced or posited over time" (p. 45).

A politics of recognition could similarly be applied to a study investigating institutional racism in one British university. Pilkington (2011) identifies institutional racism through a "racist discourse" that includes "four features: identifying groups, which reproduce themselves over time, based on physical markers; seeing essential differences between them; associating Others with negative characteristics; and visualising the dissolution of boundaries as undesirable" (p. 7). In this way, institutional racism is conceptualised as individual prejudice or discriminatory behaviours directed at oppressed individuals or groups; by distinguishing racism as "hostile" institutional processes or those that involve "unfair treatment" (Pilkington, 2011, p. 11). The outcome of determining whether the academy was institutionally racist leads Pilkington to "appreciate the sheer weight of whiteness" (p. 138) and to generalise that this is indicative of all British institutions.

Pilkington (2011) does not think it is fair to identify the academy as institutionally racist because he could not determine the presence of a racist discourse. However, the outcome of the study may have been different if a "racial discourse" was examined. Doane (2006) defines a racial discourse as "the collective text and talk of society with respect to issues of race ... through racial discourse, individuals and groups 'frame' racial issues as they strive for ideological and political advantage" (p. 256). The theoretical framework in Chapters Three and Four show how silencing is established as a racial discourse that mediates the operations of a hidden curriculum of settler silencing in state secondary education. In this way, a silencing discourse frames the cultural norms and habits of school institutions (Ahmed, 2012), ensuring that micro-level classroom interactions produce an epistemology that is conducive to settler sensibilities and Pākehā worldviews.

In conclusion, this chapter has introduced whiteness, colourblindness and colourmuteness as three racial ideologies that underpin studies associated with racism and silencing. Research that demonstrates a deepening understanding of the relationship between silencing and racism has been presented through three movements. Each movement progressed scholarly understanding about how institutional structures and processes ensure that dominant racial ideologies saturate state schools, but also pose significant methodological and conceptual limitations that this study seeks to overcome. The fourth movement builds a case for 
silencing as institutional racism by investigating how a hidden curriculum of settler silencing straddles the micro-, meso- and maco-levels of settler-colonial education. Central to this process is a silencing discourse, designed to uphold the aims of the Settler Contract. 


\section{Chapter Three}

\section{Ignorance and amnesia}

Here we go again. I sigh inwardly at a wall of grim statistics: " $80 \%$ of Pākehā students gain NCEA Level $2^{14}$, followed by $60 \%$ of Māori..." I'm attending an English planning workshop with my head of department and we settle in to an afternoon planning session of altering department programmes and units of work to cater for culturally marginalised students. She looks at me, rolls her eyes and holds her hands up in exasperation, "Well, what can we do? We hardly have any Màori students at our school, it's not relevant for us". I'm a little shocked at how quickly she'd reached for the "too hard" basket but don't respond. Instead, we potter around and look busy for the rest of the afternoon.

(Teaching memory, 2013)

Chapters Three and Four explore how the Settler Contract and silencing is reproduced in New Zealand society, then in state school institutions through a hidden curriculum. This chapter begins by considering the key tenets of Mills' (1997) “The Racial Contract” before applying them to New Zealand. In the Settler Contract, historical amnesia towards colonial violence supports the settler population to feel a sense of belonging and attachment to indigenous territories. Historical amnesia is further reinforced by state ideologies of biculturalism that legitimise historically sanitised views about contemporary settler-colonial race relations. These commonly accepted beliefs align with a social narrative of biculturalism, which produces both discursive and material evidence of silencing. This aim of this chapter is to introduce the macro-level framework for investigating what the lived experiences of Māori English teachers reveal about silencing and institutional racism in the New Zealand secondary school system.

\footnotetext{
${ }^{14}$ NCEA stands for National Certificate in Educational Achievement and it is the official secondary school qualification in New Zealand. NCEA is administered by a branch of the Ministry of Education called the New Zealand Qualifications Authority (NZQA). It is made up of three certificates at Levels 1, 2 and 3 and usually studied at secondary school in years 11,12 and 13 .
} 


\section{Charles Mills" "The Racial Contract"}

Mills (1997) wrote "The Racial Contract" as a way of explaining the persistance of racial inequality and the continuing subjugation of minoritised people world-wide. Through this extended essay, he asserts the existence of a sociopolitical system of white supremacy by showing how whiteness operates as a set of power relations (Leonardo, 2013). I am applying and extending Mills" argument in this thesis by developing the concept of "subcontracts". The Racial Contract underpins the social contract. The social contract generates judgements about social norms, behaviour, and justice and is a widely-accepted, informal arrangement that legitimises the authority of the state over the individual. Mills begins to assert the existence of wilful white ignorance by exposing the entrenched racist beliefs of seminal social contract theorists and its terms.

The ability for whites to ignore and overlook the impact of historical and structural racial oppression and how these have created present-day racial inequities and injustice is not a new “cognitive dysfunction" (Mills, 1997, p. 18). The writings of Western philosophers and social contractarians, Thomas Hobbes, John Locke and Immanuel Kant are central to a modern-day liberal democratic society; however, Mills argues that the theorists' own racial stance and beliefs means that the apparently open and liberal tenets upon which modern society rests actually only pertain to whites. The ethical philosophies of Kant, which emphasise individual moral decision making, have elsewhere been criticised for excluding structural or historical responsibility for past actions (Lee, 2014). The white normative position and colourblind foundations on which an objective social contract rest are exposed to give credence to the view that structured, wilful white ignorance is the ongoing cause of racism through the "'spread of misinformation', the 'distribution of error' . . and the 'social practices' that encourage it" (Mills, 2007, p. 16).

In analysing the history of white ignorance and its socio-structural causal mechanisms, Mills demonstrates how white normative assumptions about the superiority of the white race guided and legitimised colonisation and the subjugation of minoritised people. The demarcation of uninhabited territories to civil/light and wild/dark spaces is one way that the colonisers justified methods to "expropriate lands and resources for the material advantages and cultural pleasures of European Whites" (Leonardo, 2015, p. 89). The terms of existence 
for indigenous and minoritised people are also rewritten in ways that accomodate white worldviews. For example, during the signing of the Declaration of Independence, Thomas Jefferson commented on the "merciless Indian Savages", however, Mills (2007) claims that this expression did not cause any "cognitive dissonance with the earlier claims about the equality of all "men," since savages are not "men" in the full sense" (p. 26).

By examining colonial historical references to land and minoritised people, and the racist underpinnings of Eurocentric philosophical thought, Mills (1997) argues that modern society is founded on the notion of personhood/subpersonhood. The designation of minoritised people as less-than-people (subpersons) provides the moral logic required for conceiving that indigenous peoples are inferior savages, whose empty lands need rescuing by white colonisers. For example, Hokowhitu (2003) recites how an early European traveller called Arthur Thomson, rationalised the biological inferiority of Māori,

It was ascertained by weighing the quantity of millet seed skulls contained ... that New Zealanders heads are smaller than the heads of Englishmen, consequently the New Zealanders are inferior to the English in mental capacity ... The memory they possess is the memory of boyhood; and their minds may be compared to mirrors ... incapable of retaining any trace of the past ... The faculty of imagination is not strongly developed among them, although they permitted it to run wild in believing absurd superstitions ... This analysis shows the New Zealanders have the minds of children. (p. 195)

The colonisers believe that the colonised are incapable of self-rule and autonomy, which has implications for the ability of indigenous people to challenge white beliefs or thinking. Whites are therefore classed as people who count, and minoritised people are classed as subpersons who are epistemologically, ontologically, and existentially written into the contract in ways that benefit those who count.

\section{An epistemology of ignorance}

One aspect of the Racial Contract is that it is constantly being rewritten. The Racial Contract adapts to localised contexts through "a certain schedule of structured blindnesses and opacities" (Mills, 1997, p. 19), so it appears that colonised people are equal without any fundamental change to systems that support racial privilege. In doing so, one views the 
world as objective, rather than politically, morally, and epistemologically shaped by racism and race. Mills calls this process an epistemology of ignorance; in this sense, ignorance is used "to cover both false belief and the absence of true belief" (Mills, 2007, p. 16). In this delusional world, notions of minoritised subpersonhood involve:

Colourblindness, the refusal to perceive systemic discrimination, the convenient amnesia about the past and its legacy in the present, and the hostility to black testimony on continuing white privilege and the need to eliminate it to achieve racial justice. . . These analytically distinguishable cognitive components are in reality all interlocked ... jointly contributing to the blindness of the white eye. (Mills, 2007, p. 35)

White blindness, or an epistemology of ignorance, provides the perfect cover for whites to construct and maintain white privilege. A framing of ignorance keeps racism and its harm at the edge of consciousness so that whites may avoid responsibility for racial exploitation (Jungkunz \& White, 2013). A convergence between white group interests and white ignorance additionally leads to meritocratic reasoning whereby whites conveniently forget "that they inherited much of what they own" (Mills, 2007, p. 37). In a settler-colonial context, ignorance is fostered by mechanisms of silencing. Silencing generates a race-less view of society by overlooking the realities of imperial invasion and the ways that historically-located, socially-constructed structures and processes of racial domination moderate society today. Ignorance and silencing are the cornerstones of a Settler Contract that modifies the tenets of the Racial Contract to an indigenous context.

\section{The Settler Contract}

The terms of the Racial Contract have been previously considered within the context of settler-colonialism and indigenous peoples' unique relationship with the land as a Settler Contract (see, for example, Pateman, 2007). The aims of the Settler Contract are to maintain ignorance and denial of the structuring force of colonisation, with the view of sustaining white supremacy and advancing the aims of settler-colonialism in New Zealand society. When overt racial discrimination and prejudice was deemed immoral, historical amnesia descended on mainstream New Zealand to support a sense of settler belonging. State 
ideologies of biculturalism and a state narrative of biculturalism can be seen as the latest in a long line of official phrases constructed to maintain silencing and support wide-spread ignorance of a lived racialised existence.

\section{Historical amnesia and settler belonging}

British colonisers rejected the view that indigenous peoples lived in legitimate societies prior to their arrival because they (the colonisers) had firm ideas about what constituted a civilised society. The invaders were driven by the belief that indigenous peoples needed to be lifted out of a state of nature, so a perceived lack of indigenous sovereignty and government systems was the basis for establishing the Settler Contract (Pateman, 2007).

The imposition of new colonial systems and structures included Western constructions of time because the colonisers believed they occupied a superior form of temporal existence. As Nanni (2013) argues in the Australian context, Aboriginal peoples measured time according to natural occurrences, such as phases of the moon, sun, stars or changing plant life. Settlers, missionaries, and colonial officials framed Aborigines as being closer to nature and "more like flora and fauna than owners and inhabitants of the land" (Nanni, 2013, p. 73). These observations vindicated the Western imperial project and the law of "terra nullius", in which the settlers applied the rights of husbandry to the empty lands (Pateman, 2007).

In the 1860 s, Māori were written in to an education system that sought to make indigenous peoples more British (Kidman et al., 2018; Simon et al., 2001). The colonial administrators sought to "instil British values in the young and connect successive generations of children to the imperial project" (Kidman et al., 2018, p. 230). Western temporal structures (for example, timetables and timekeeping) moderated Native schools and supplanted the temporal practices of Māori communities. Proficiency in the English language was deemed to be the most important strategy for bringing Māori children closer to civilised humanity. Indeed, many Māori families supported this policy in response to volatile social developments, such as the New Zealand Wars and changes to democratic processes designed to further marginalise Māori political influence (Barrington, 2008).

At a time when indigenous minds were perceived to be a territory in need of taming, Māori land was being forcibly removed and sold to accommodate an increasing settler population (Kidman et al., 2018). As was stated in Chapter One, imperial expansion shifted from an 
economic or military colonialism that culminates in the departure of the coloniser, to settlercolonialism and immigrants who are here to stay (Wolfe, 2006). Indigenous peoples may be displaced in a number of ways, including assimilation, murder, limiting resources or the ability to reproduce (Veracini, 2015). To establish settler legitimacy and belonging on foreign soil, a collective amnesia descended on mainstream New Zealand regarding the painful and violent events of colonisation (Bell, 2006; Kidman, 2018a).

Socially-constructed historical amnesia is a phenomenon designed to protect settler-colonial societies from a sense of historical wrong-doing, while at the same time reconstructing of a sense of national belonging. Bell (2006) explains that historical amnesia arises from Pākehā anxieties about the tenuous nature of colonial settlement on indigenous territories. Drawing on the notion of sedentarianism, she argues that earlier notions of racism were declining and new forms brought claims of a rooted attachment between colonising migrants and the land into question. Pākehā must somehow maintain narratives that legitimise political control and support the development of a unique identity (Bell, 2009).

A study by Gray, Jaber, and Anglem (2013) reveals that some white New Zealanders adopt a "Pākehā" identity as a means of expressing a positive relationship with Māori that disavows white privilege and present-day implications of historical colonial violence. In this way, colonial violence may acknowledged through a process that distances Pākehā from the actions of their settler forebears. For example, a significant act of violence occurred in 1843 between Māori (Ngāti Toa) and British settlers over the purchase of land in the Wairau Valley. For many years, the settlers labelled the exchange the "Wairau Massacre" because of the high number of European deaths. In recent times, the name has twice changed to the "Wairau Affray", and then the "Wairau Incident" in acknowledgement that it was the settlers who disobeyed the law and caused the violence. .

Pākehā who perceive historical colonial harm, or the unearned benefits of white privilege, may enter a state of white fragility. White fragility is described as a condition "in which even a minimum amount of racial stress becomes intolerable, triggering a rage of defensive moves" (DiAngelo, 2011, p. 57). One example of white fragility occurred when the Waitangi 
Tribunal, set up to investigate historical grievances, ${ }^{15}$ awarded financial restitution to several iwi (Kidman, 2018a). In the 1980s, white backlash to the establishment of the tribunal was so severe that the chair, Eddie Durie, made his telephone number confidential after receiving many abusive telephone calls ${ }^{16}$. Some members of the public felt that the ruling conflicted with liberal democratic notions of egalitarianism, meritocracy and the creed of "one nation" (O'Sullivan, 2007). Others claimed that historical compensation amounts to a form of Māori privilege (Johansson, 2004; O'Sullivan, 2008). The increasing visibility of indigenous peoples' relationship with the land unsettled notions of settler belonging (Hokowhitu, 2017).

Another example of white fragility occurred in 2014, when a petition was presented to parliament asking that a national day be set aside to commemorate the New Zealand Wars. The possibility of a public Remembrance Day based on historical colonial infractions triggered feelings of distress, defensiveness, shame, and guilt in some Pākehā. Calls against a public commemoration denigrated revisionist history, cited Māori greed and Pākehā victimhood, and argued against pluralism and separatism among ethnic groups. One submission against the petition stated,

When Europeans arrived and settled in this country they brought with them two thousand years of knowledge and culture. They found one of the worst, most savage and primitive tribal mob of cannibals ever seen anywhere. Indeed, these tribal misfits were still beating each other over the head well into the twentieth century. (O’Malley \& Kidman, 2017, pp. 303-304)

In these instances, O’Malley and Kidman (2017) argue that Pākehā backlash was perceived to be,

An indication of deeper anxieties in New Zealand settler society that are triggered when public silences surrounding the violence at the heart of the colonial nationbuilding enterprise are broken ... the politics of white backlash often become highly ethnicised as attempts are made to curtail the visibility of those who challenge cultural belief or public silences about the colonial past. (p. 301)

\footnotetext{
${ }^{15}$ The Waitangi Tribunal is a commission of inquiry set up in 1975 by the government to investigate Treaty of Waitangi violations.

${ }^{16}$ Retrieved from https://teara.govt.nz/en/waitangi-tribunal-te-ropu-whakamana/page-3
} 
Latent anxiety may surface when Pākehā are directly confronted by evidence of a racialised existence and the benefits accrued through the oppression of indigenous peoples. But white fragility may be avoided altogether if a "partnership" trope, typical of settler societies that strive to subsume or extinguish indigeneity saturates mainstream thought, as outlined below (Veracini, 2010).

\section{State ideologies of biculturalism}

An upsurge in Māori activism in the mid-1970s led to circumstances that made it difficult for Pākehā to avoid white fragility and the implications of colonial violence (Poata-Smith, 2008). Doane (2006) and van Dijk (1998) argue that dominant cultural ideologies may adapt when members of dominated groups assert counter-ideologies. In this way, settler-colonial denial adapted to pro-actively include indigenous Māori into the nation-building enterprise in ways that upheld the façade of harmonious race relations and racial silencing. This was achieved by implementing state ideologies of biculturalism in public institutions and "state sponsored" sites of historical remembering (Bell, 2006; O'Sullivan, 2007).

As discussed in Chapter One, state ideologies of biculturalism are based on a belief that both Māori and Pākehā cultures are equally valued and contribute to New Zealand society. This view grew out of "a particular interpretation of the Treaty of Waitangi that is limiting rather than liberating" (O'Sullivan, 2007, p. 24). That is, in 1840 Māori and the British Crown "founded" contemporary New Zealand society when they came together in partnership to sign the Treaty of Waitangi (Bell, 2009). In this sense, Bell (2009) argues that the Treaty of Waitangi signing symbolises a "birth of a nation" story; a "master narrative" that affectively draws the New Zealand public towards a version of colonial history that supports Pākehā to cling to gentler forms of national identity, place attachment, and belonging (Fivush, 2010; Gilroy, 2004; Kidman, 2018a).

However, this official discourse of biculturalism was challenged by O'Sullivan (2007) who argued that the notion of partnership and the inclusion of Māori culture in state institutions is token and symbolic. In addition, scholars observe that "equal inclusion" does not require that the majority make concessions to their own cultural practices and values (O'Sullivan, 2007; Smits, 2014), or implement lasting policies of distributive justice (Lashley, 2000). Moreover, economic and social disparities between Māori and Pākehā have not lessened since bicultural 
policy was implemented in the 1980s (Bell, 2006; Kidman, 2018a). O'Sullivan (2007) notes that over time, vague references to a Treaty of Waitangi partnership may be used to as a moral and legal force to quell Māori discontent and suppress autonomy and resistance. In this way, Māori come to internalise and accept their place as "junior partners" (O'Sullivan, 2007).

A third way that the notion of a partnership is problematic is because it assumes a culturally homogeneous Māori and non-Māori population. The notion of a homogeneous cultural identity is particularly damaging to Māori, whose marginalised position as "junior partners" in institutional arrangements leaves little room to consider the interests of iwi, hapu and the different cultural, political, and social realities of Māori. Consequently, biculturalism is not equipped to "consider the complexities and relationships of Māori society and the cultural foundations of different Māori political identities" (O'Sullivan, 2007, p. 24). In Chapter Four, I expand on the racialised character of the way that three hidden state ideologies of biculturalism (that biculturalism should feel-good, advances a one-sided partnership, and Māori cultural homogeneity) operate in state schooling institutions.

\section{A state narrative of biculturalism}

While state ideologies of biculturalism guide how mainstream New Zealanders think about the relationship between Pākehā and Māori, a state narrative of biculturalism is the expression of these beliefs. As noted by Mills (2007), historical practices that underpin collective memory and amnesia are central to the way that settler-colonial societies frame race relations. Kidman (2018a) argues that the Treaty of Waitangi centrepiece at the New Zealand national museum, Te Papa, is an example of a bicultural artefact, whereby "the representation of the Treaty of Waitangi in 'Signs of a Nation' locates the origins of the nation as a negotiated and mutually agreed upon covenant between two peoples rather than as the result of the invasion and expropriation of Māori land and culture" (p. 104). There are clear parallels between state ideologies of biculturalism identified in the previous section, and the analysis of a "Signs of a Nation" exhibition by Kidman (2018a), that give expression to a state narrative of biculturalism.

In line with a settler need to secure a sedentarist attachment to indigenous territory (Bell, 2006), a state narrative of biculturalism overemphasises idealistic aspects of state histories, while deleting or obscuring more painful events. Kidman (2018a) observes that "Signs of a 
Nation" reinforces a "two worlds" approach that positions Māori and Pākehā interests as separate and fixed to particular landscapes, cultural conditions, and spiritual and economic outlooks (Kidman, 2018a; O'Sullivan, 2007). This is a bifurcated view of race relations that silences colonial entanglements, including the diversity of Māori peoples' lived existence and the realisation of a Pākehā identity that is connected to a colonial past (Bell, 2006). "Signs of a Nation" also symbolises how the past, present, and future may be imagined through a pedagogy of forgetting, where "difficult knowledge" is avoided in favour of "lovely knowledge" and beatific notions of bicultural citizenship (Kidman, 2018a, p. 5).

Lovely knowledge is heavily implicated in the way that New Zealand society chooses to remember the past and historical grievance. In line with state ideologies of biculturalism, Kidman (2018a) argues that the Treaty of Waitangi exhibition is presented as a birth-of-anation story that,
Allows Pākehā citizens to imagine themselves as partners with Māori in the nation-making quest. In this sense, it exists within nationalist discourse as a form of 'lovely knowledge' that permits people to visualize their role within the nation's story as benign, altruistic and at times, even heroic. (p. 105)

Conversely, difficult knowledge is described as "the recognition that understandings of our collective selves of national identities are partial and incomplete and often rely on factual misrepresentation as well as a degree of structural forgetting about the colonial past" (Kidman, 2018, p. 98). "Screen memory" is also a term associated with the inaccurate reconstruction of past events that are infused with trauma. Schwab (2010) argues that screen memories "can produce both cultural memory and forgetting" (p. 22) through "psychic splitting" (p. 23) that simplifies the victim/perpetrator binary or locates violent histories elsewhere, foreclosing the ability to properly mourn. Veracini (2010) similarly emphasises the "consciously concealing, or inherently untruthful" (p. 91) character of screen memories in relation to reconstructing national histories. A state narrative of biculturalism is therefore designed to silence the effects of historical racial injustices by consolidating an idealised settler-colonial present.

In this way, a sanitised and discursive narrative of colonial history aligns with state ideologies of biculturalism to shelter mainstream New Zealanders from white fragility. Hook 
(2005) argues that subtle mechanisms of whiteness are buried within nationalist discourse and affect positions that generate (white) entitlement and (non-white) exclusion. He observes that government regimes generate a potent set of affective investments that exclude or disqualify marginalised groups who view the past differently. These affective investments indoctrinate society through a "downward saturation" of power (para. 26), and mediate individual practice through technologies of affect. Affect positions are relayed through multiple technologies (such as practices, skills, knowledge, and techniques) and various mediums (imposed on individuals by others or themselves, either from a social locus of control to self-governing forms) to support white supremacy (Leonardo \& Zembylas, 2013).

Like museums, New Zealand secondary schools are conduits for transmitting affective investments that reinforce state ideologies of biculturalism and circulate a bicultural master narrative (or screen memory) that justifies setter belonging. In a similar manner, historical amnesia and the notion of harmonious Māori and Pākehā race relations are logically and purposefully constructed in school institutions. A silencing discourse produces an epistemology of ignorance that erases "difficult knowledge" about colonisation through various technologies and mediums that produce moments of affect "rooted through a third position" (Hook, 2005, para. 30). This third position stems from the affective and ideological concerns of Pākehā settlers to maintain the Settler Contract and uphold social and political power in society. The process may be described as a form of structural genocide designed to expedite the oppression of indigenous peoples in settler-colonial societies (Wolfe, 2006).

To summarise, this chapter introduced the Racial Contract as an ontological position from which to explore the macro-level dynamics of silencing in New Zealand society. In the Settler Contract, historical amnesia about colonial violence protects Pākehā from white fragility. Ideologies of biculturalism reinforce a discourse of partnership through the Treaty of Waitangi signing to legitimise settler belonging, but in ways that suppress Māori interests. The affective sensibilities of the Pākehā are furthermore appeased through the production of a narrative of biculturalism. Chapter Four applies the principles of the Settler Contract discussed in this chapter to the epistemological, spatial, and temporal dimensions of state education. 


\title{
Chapter Four
}

\section{Rewriting the Settler Contract in state secondary schools}

\author{
Another English teachers' workshop. A Pākehā woman begins to moan at the gathered \\ group. She is frustrated because she has been working very hard with colleagues to \\ create an English programme that should meet the needs of struggling (brown) students. \\ Except it doesn't. "We have done everything for the students . . these students just \\ don't get it . . nothing else can be done for them!' And because she is sincere and \\ contrite, and has done the best she can, her hands and conscience are clean.
}

(Personal research journal, August 2013)

Chapter Four shows how the principles of the Settler Contract are rewritten and negotiated in settler-colonial secondary school institutions through three interlocking subcontracts. The first section, the epistemological subcontract, introduces a silencing discourse as the means for mediating historical amnesia and ignorance about the structuring force of colonisation in New Zealand education. The enactment of this discourse is discussed under the spatial and temporal subcontracts. The final section, sustaining an epistemology of ignorance, brings the Settler Contract in line with the aims of settler-colonialism.

\section{The epistemological subcontract}

According to the Racial Contract, an epistemology of ignorance entails "a particular pattern of localized and global cognitive dysfunctions (which are psychologically and socially functional)" (Mills, 1997, p. 18). In New Zealand state secondary school institutions, ignorance and denial of the structuring forces of colonisation is similary constructed in a systematic and purposeful way through the epistemological subcontract. As argued by Kidman et al. (2018),

This sub-contract facilitates and maintains cultural and historical amnesia with regard to the curriculum (what is taught in schools), pedagogy (how things are taught) and educational policy (the framework for deciding what is taught and how it is delivered). (p. 234) 
Epistemological ignorance and historical amnesia about the ongoing implications of colonial violence is delivered through a silencing discourse. The three key structures of schooling (that is, curriculum, pedagogy and policy) undergo a push-pull process of cultural and ethnic inclusion and racial exclusion. Doane (2006) writes, "On one hand discourses shape the mental models, or 'common sense' beliefs, through which individuals interpret social reality; on the other hand, they collectively reinforce or transform ideologies" (p. 256). In this way, a silencing discourse ensures that aspects of indigeneity that do not support Pākehā ways of being and existing are erased or marginalised, while national history is rewritten and framed in accordance with a state narrative of biculturalism. The logical and predictable pattern of a silencing discourse gives credence to the assertion by Wolfe (2006) that settler-colonialism is "a structure rather than an event" (p. 390).

The following sections relay how the push-pull process of a silencing discourse operates in the temporal and spatial dimensions of school institutions. In doing so, I show how the policy, pedagogy and curriculum structures are aligned with state ideologies of biculturalism, as described in the previous chapter. Although I separate space and time through different subcontracts, the discussion in these sections demonstrate that the two are intimately related. However, the Settler Contract is a settler-colonial construct. The separation of the spatial and temporal subcontracts is consistent with a Western/settler epistemology that denies any suggestion that an indigenous relationship with the land supersedes that of settlers.

\section{The spatial subcontract}

Leonardo (2015) considers Mills’ Racial Contract within the context of United States education. He examines how physical, corporeal and cognitive school spaces cultivate "the rejection of everything black, such as ways of knowledge and feeling, unless they serve the commodification of blackness within white capitalism" (p. 90, italics in original). In the Settler Contract, the spatial subcontract shows that the affective demands of settlers require a selective inclusion of indigenous interests, so that particular ideas pertaining to biculturalism circulate through the cultural spaces of school institutions. Two state ideologies about biculturalism dominate educational institutional space and are discussed below. The first is 
that biculturalism legitimises a limited commitment to Māori interests, while the second advances the belief that biculturalism should feel good.

\section{Biculturalism legitimises a limited commitment}

The New Zealand Native school system was differentiated from earlier imperial attempts to assimilate indigenous peoples. The colonisers perceived that "threading aspects of indigenous ways of life and culture into state systems of native education would be more productive than attempting to eliminate cultural differences altogether" (Kidman et al., 2018, p. 235). Instead of attempts to eradicate or assimilate indigenous groups, the colonial government sought more hegemonic means to establish permanent control over the indigenous Māori population (Veracini, 2011).

When overt racism became viewed as morally reprehensible and historical amnesia descended following the signing of the Treaty of Waitangi, the systems and structures that supported racial privilege were officially silenced (Kidman et al., 2018). In this way, the colonial bias underpinning a "cultural differences" approach towards including Māori interests in state education became subsumed into institutional culture as an unremarkable and normalised habit. Habits are how certain behaviours and actions become institutionalised; a case of “"how we do things here,' where the very claim of a 'how' does not need to be claimed" (Ahmed, 2012, p. 25). In this way,

[Silences that] frequently omit or sanitize acts of imperial violence or military force against indigenous peoples . . . harden into denial over what took place in the past and this has a significant impact on settler-indigenous relations in the present. (Kidman et al., 2018, p. 234)

Today, Pākehā value systems and norms are able to dominate because silencing and colourblindness enforce oppressive conditions of existence for Māori. The Ministry of Education continues to "thread" Māori concerns through a separate branch of schooling in same manner as the colonial administration of Native schooling (Ministry of Education, 2011, 2013). These policies acknowledge "culture" and "ethnicity" to ensure that Māori interests are somewhat included, thereby maintaining the settler-colonial facade of equitable race relations. 
New Zealand education policies are therefore colourmute (Pollock, 2004), foreclosing how bodies are racially and contextually located (Lee, 2014). More recently, policies of cultural and ethnic inclusion advance the view that curriculum and pedagogical approaches may adequately support Māori students (Bishop et al., 2007; Bishop et al., 2014; Macfarlane, 2004). This policy approach locates schooling success and failure with the performance of individuals at different levels of the institution (that is, students, teachers, management) by listening to the feedback of Māori stakeholders. For example, a recent Ministry of Education initiative called "Kia Eke Panuku", draws on the voices of year 9 and 10 Māori students to support teachers to develop a culturally responsive and relational pedagogical approaches. While Māori students can identify individual and interpersonal barriers to a positive schooling experience, the literature review in Chapter Two shows that the structural limitations of the school system are invisibilised ${ }^{17}$. Moreover, Kia Eke Panuku claims to be informed by kaupapa Māori and critical theories, in which "conscientisation, resistance and transformative action" are central concepts ${ }^{18}$. A government initiative that claims to be liberatory and emancipatory, yet silences the effects of structural racial bias, is implicated in hegemony by endorsing a system that is aligned with the interests of the status quo.

Doane (2006) observes that the notion of racism is contested because of what groups of people stand to lose or gain by conceding to the existence of structural injustice. Attributing racial injustice to the actions and attitudes of individuals not only absolves the institution of change but enhances the belief that schools are progressive and helpful places. Moreover, attributing racism to "bad" individuals produces culturally-located explanations for ethnic disparities in schooling. In this way, differences in academic achievement are understood as resulting from the deficits of ethnically minoritised groups and individuals. Clair and Denis (2015) deduce that colourblind theories explaining racial inequality "often acknowledge the history of racism in shaping inner city black culture but argue that subordinates' cultural behaviours are at least one immediate cause of continuing racial inequality" (p. 859). Omitting the impact of structural racism protects Pākehā from white fragility and an ability to see how they continue to benefit from the current state of institutional arrangements.

\footnotetext{
${ }^{17}$ Retrieved from https://kep.org.nz/dimensions/culturally-responsive-and-relational-pedagogy

${ }^{18}$ Retrieved from https://kep.org.nz/dimensions/closing-the-gaps
} 
A silencing discourse is therefore enacted through policies of cultural and ethnic inclusion that pull towards colourblind and colourmute readings of institutional existence. A limited commitment to Māori interests is legitimised through biculturalism, in which the perception of an equitable partnership becomes a form of "image management" that covertly perpetuates white privilege (Ahmed, 2012). Those who operate in school institutions are supported to "sink" into a culture of whiteness (Ahmed, 2007, 2012), while the effects of structural racism recede from conscious view through a process of locating barriers to academic achievement with individuals. In this way, the colonial relationship of state domination and indigenous subordination, central to Native schooling, is inherited and reproduced through settlercolonial administrations. The following section considers the implications of contemporary policies underpinned by settler-colonial imperatives towards pedagogical and curriculum practices.

\section{Biculturalism should feel good}

The deliberate erasure of race from institutional existence should be a feel-good affair for Pākehā. Māori interests appear to be included, yet educators and students are distanced from a violent colonial past and present-day structural inequalities to legitimise a sense of settler belonging. Matias and Zembylas (2014) argue that teachers who ignore structural barriers (such as oppression, violence or poverty) that impact on the schooling of minoritised students are practicing "disgust". Disgust is performed when social inequality, racism and the suffering of minoritised peoples is alleviated by "caring" (for example, pity, love, and empathy) in the name of social justice. However, teacher performances of caring and disgust are compounded in settler-colonial contexts that "include" limited forms of indigeneity.

Culturally responsive pedagogies are advanced by the New Zealand Ministry of Education to accommodate Māori students' cultural, ethnic and academic needs (Bishop, 1999; Ministry of Education, 2007, 2011). However, in this thesis I argue that this teaching approach cultivates "affect positions" that act as a form of permission for educators to practice indifference towards histories of colonial oppression and ways in which they moderate Māori peoples' lived existence (Ahmed, 2012; Hook, 2005; Leonardo \& Zembylas, 2013). As a result, interpersonal caring or perfunctory forms of inclusion may be perceived as legitimately catering to Māori interests; for example, relational pedagogies that involve pronouncing names correctly or talking nicely to Māori students about their day. Indeed, the perception that disgust and caring constitutes the fulfilment of a bicultural partnership can instil a sense 
of pride, as the effects of colonial violence are alleviated by the act of giving kindness (Ahmed, 2004).

Pedagogical and curriculum interactions that soften historical colonial harm are also attributed to a focus on the consequences of a colonial "legacy". Pratt (2014) argues that the notion of legacy fails to explain how contemporary processes and structures are "ongoingly renewed and reintegrated into a changing world through continuing permutations of its signifying powers, administrative practices, and forms of violence" (p. 461). In this way, the teaching and learning process generates "lovely knowledge" about biculturalism, because the notion of legacy may be enacted as a form of silencing that obscures the racial bias in contemporary social structures. The effects of a legacy discourse are captured by Lehrer and Milton (2011) in relation to lovely knowledge that "allows us to think of ourselves-due to our identifications with particular groups-as, for example, timelessly noble, or long-suffering victims, and to reject any kind of information about ourselves that might contradict or complicate the story" (p. 8). Culturally responsive pedagogies tend to the notion of indigenous peoples as "long-suffering victims" without challenging structural racism.

Teaching approaches that soften historical harm are colonial in nature because they were also seminal to the Native school system. In 1885, a Native school inspector called James Pope, wrote texts based on activities that Māori were perceived to be doing during that time, such as digging for gum and pig-hunting, and these were dispersed across New Zealand (Barrington, 2008, p. 61). Learning that emphasised "active experience and breaking down barriers between school and community" (Barrington, 2008, p. 176) was implemented by another inspector called Douglas Ball in 1920. Māori arts and crafts were also included in the curriculum, such as poi, mat-weaving, tukutuku, taniko, carving and flax-plaiting. Teachers in Native schools were expected to design child-centred lessons that suited the needs of their region, rather than storing knowledge and facts. While these activities hold great cultural value, they do not by themselves challenge power relations. As a result, aspects of Māori culture may be used in schooling in ways that fulfills the affective requirements of the dominant race. These historical approaches to teaching practice will seem very familiar when findings are presented in Chapters Six and Seven.

Feel-good biculturalism may also be maintained through curriculum and pedagogies that mute historical harm. Ahmed (2012) argues that the presence of a white somatic norm 
"generates an idea of appropriate conduct without making this idea explicit" (p. 38). In such environments, an avoidance of white fragility is paramount as minoritised people who go against whiteness evoke fear and anxiety in the dominant race. Minoritised peoples who name racism then become the problem and the threat, rather than the actual racism of the institution (Ahmed, 2007). The fear of being seen as "angry person of colour" is a powerful mechanism for self-censorship that may deter Māori from speaking about racism, generate self-doubts about whether racism has been read correctly and even lead to its concealment (Ahmed, 2012). Silencing becomes "a form of public comfort" by attending to affective responses that are in line with Pākehā needs (Ahmed, 2007, p. 158). The affective pressures to reproduce feel-good biculturalism are therefore both covertly corrective and punitive.

In conclusion, a silencing discourse, facilitated through the policy, pedagogy and curriculum structures of state schooling, pushes away evidence of a racialised existence by pulling towards the cultural and ethnic "needs" of minoritised youth. This arrangement trends towards the performance of lovely knowledge and perceiving harmonious contemporary race relations, in turn, hiding the true nature of state ideologies of biculturalism (that they legitimise a limited commitment to Māori interests and should feel good). The following section shows how the temporal dimension of state education operates alongside the spatial, to strengthen the character of individual and collective Pākehā in school institutions.

\section{The temporal subcontract}

Although not officially identified in literature as a subcontract of Mills' Racial Contract, racialised institutional time is increasingly becoming a subject of academic attention in indigenous education studies (Kidman \& Chu, 2017; Tuck \& Gorlewski, 2016). This section begins by theorising the relationship between time and space, including the impact of white/colonial time. This is followed by the way that a state ideology of biculturalism freezes Māori temporalities.

\section{Time and space}

The imposition of Western notions of time and its impact on indigenous temporalities is a relatively unexplored aspect of the Settler Contract, however, indigenous peoples' temporal existence and relationship with the land was misunderstood and used to justify imperial expansion. The colonisers perceived that indigenous peoples had a less sophisticated, 
backward measure of time because it was based on the rhythms of nature, the seasons, the reproduction of vegetation, and migrations patterns (Donaldson, 1996; Nanni, 2013; Perkins, 1998). Standardised, Western time and "civilised" notions of temporal uniformity divested of any natural biological or geographical associations, were deemed superior and consequently forced on indigenous peoples (Nanni, 2011).

Time is an idea that can be embodied through rituals, calendars, routines, devices, and discourses to provide a sense of rhythm and regularity (Nanni, 2013). Conversely, temporality relates to variable socio-cultural understandings of time and how the values, understandings, and particularised experiences of groups can inform temporal meaning (Iparraguirre, 2016). Temporal routines and rituals, such as the immediacy of responding to the toll of a bell, were introduced by the colonisers to implant notions of temporal austerity and bring about order (Nanni, 2013). Those who did not follow standardised constructions of time were deemed to be idle, lazy, sinful, and subject to a primitive constitution. The notion of temporal Otherness was then used by colonial authorities and settlers to imply a sense of homelessness that bolstered their own claims to the land (Perkins, 1998).

Colonial time supplanted indigenous conceptions of time and continues today to shape Māori existence. Colonial time is akin to the concept of "white time", which Mills (2014b) describes as the standard upon which all human existence is based because only whites are permitted full personhood. As was discussed in earlier sections, state school institutions have inherited colonial structures and historical amnesia has subsequently silenced the ability to comprehend the effects of colonial bias. As a result, colonial time moderates the institution through,

The suppression of the alternative histories, the non-White times, of other humans ... [which] manifests itself as a nominally timeless ideal theory, white excludes the non-white times that would make the remedying of non-ideal injustices the normative priority. (Mills, 2014b, p. 33)

Indeed, if Māori interests appear to be included through a bicultural partnership that is limited in scope and regulated by the dominant culture, institutional structures governed by a "white temporal imaginary" (Mills, 2014b, p. 29) may legitimately oppress the diverse temporal realities of indigenous peoples. As will be discussed in later chapters, this omission has 
grave consequences for the schooling experiences of indigenous youth and pathways towards academic success.

Burgeoning sociological interest in the relationship between time and space is, however, starting to consider how social existence is affected by multiple, dynamic temporalities (Lingard \& Thompson, 2017). This approach paves the way for thinking about how and in what ways indigenous temporalities are disrupted by colonial constructions of time. Earlier attempts by scholars to understand social time through "clock-time", for example, are inadequate for this purpose because of the way that time is treated as a sequential, linear process (Thompson, 1967). A linear view has since been challenged because it does not account for the various ways that people are differently socially positioned to time (Sharma, 2014), or that time "flows in multiple directions, such that the past and future are always available in the present" (Lingard \& Thompson, 2017, p. 6).

The following section theorises how state institutions attempt to freeze an indigenous temporal existence in line with the aims of the Settler Contract. The impact of colonial constructions of time underpin why Rifkin (2017) argues that indigeneity should embrace "temporal multiplicity" (p. 17), and refuse recognition "that indigenous peoples have an existence not a priori tethered to settler norms and frames" (p. 14). A process that demystifies state mechanisms of temporal oppression supports indigenous peoples to recognise and challenge limitations imposed by settler-colonialism.

\section{Biculturalism freezes Māori temporalities}

A temporally frozen, anachronistic view of Māori personhood is in line with settlercolonialism's need to subsume indigeneity in ways that validate settler belonging (Veracini, 2010, 2011). As Rifkin (2017) explains,

The pursuit of recognition by the settler state often results in a translation of Indigenous histories, modes of collectivity, and relations to place into forms that better fit extant legal and administrative frames. Official non-native discourses themselves employ temporal narratives that produce limited visions of Native collective selfhood. (p. 6) 
The requirement that indigenous people fit extant legal and administrative frames to assert individual and collective rights pulls the curriculum and pedagogy structures of state education towards a frozen or fixed view of Māoridom (Kowal, 2015). This paradoxical relationship requires that indigenous peoples prove their indigeneity by necessitating a politics of recognition (Ahmed, 2012).

One way that indigenous peoples may exercise a level of self-determination within state education is through asserting an authentic version of "pastness that disavows the 'complexities' of Native life, including 'the historical realities of accident, succession, alienation, passion, personal conflict, dissension, and disparity"' (Barker, 2005, as cited in Rifkin, 2017, p. 6). Limited temporal recognition fits neatly with an imagined partnership narrative that supports the dominant race to feel good. Acknowledging and celebrating ways of being Māori that speak to an uncomplicated, pan-tribal, and traditional cultural existence directs those operating in schools away from the consequences of assimilation or structural racial bias (Ahmed, 2012). Pākehā are consequently protected from white fragility and feeling implicated or responsible for the social ills faced by indigenous peoples (Alcoff, 2007; Kowal, 2015). In this way, the presence of a frozen indigeneous temporal existence explains the seemingly contradictory relationship between rational knowledge and ignorance, where whites "clearly 'see' race at the same time that they use colorblind discourse to justify black racial standing" (Leonardo, 2015, p. 93).

Peters and Mika (2017) argue that while consolidating ethnically distinct groups through terms like "indigenous" may be beneficial, ignorance of a term's origin and usage in relation to colonial/Western power can create complications for indigenous peoples. For example, uncritically accepting institutional boundaries pertaining to a frozen, yet perceived "authentic", state of indigeneity justifies the retention of white frames of reference. The maintainance of white frames of reference mean that the full range of Māori worldviews are marginalised and oversimplified (O'Sullivan, 2007). Thus Māori are "locked in a different temporality, incapable of self-regulation by morality and law, they are humanoid but not human" (Mills, 2007, p. 27).

Freezing indigeneity to align with precepts of traditional Māori culture additionally discredits and alienates Māori people whose do not fit this construct. Indeed, the standard of temporal existence may be so exacting that doubt is cast on whether those who do not align with a 
frozen temporality can truely be considered indigenous (Kowal, 2015; Rifkin, 2017). Whether utilised as an act of indigenous resistance, or offering protection from white fragility, curriculum and pedagogical structures that reproduce a frozen Māori temporal existence do so under the guise of an equitable bicultural partnership.

\section{Sustaining an epistemology of ignorance}

State ideologies of biculturalism dominate the spatial and temporal dimensions of institutional existence because they are locked into a circular relationship with the silencing discourse. That is, the discourse (the policy, curriculum and pedagogy structures) push away evidence of a racialised existence, while pulling those in the institution toward performing a narrative of biculturalism. Material manifestations of the narrative, condition Pākehā and Māori to emphatically believe the truth claims of state ideologies of biculturalism (Candlin, 1997; van Dijk, 1998). Ideologies that align with Pākehā sensibilities are deemed to be the "normal" way of thinking about race, so justify the upkeep of the silencing discourse and so on and so forth. This circular arrangement maintains a racial equilibrium that fulfils the aims of settler-colonialism and accounts for the way those operating in state schools learn to overlook and accept racism as an everyday occurrence.

The normalisation of this agreement is an effective form of non-coercive ideological control that covertly pulls those operating in secondary institutions towards white ways of thinking, feeling, and acting. Thus, we see that the true educative function of state secondary schooling transcends institutional arrangements to maintain racial inequality in New Zealand society. However, there is one important caveat to the nature of this hegemonic, circular relationship, as van Dijk (1998) explains:

If an ideology is taken as an abstract system of the group as a whole, it is concretely (mentally) 'distributed' over its members. That such members will make (sometimes vastly) different uses of this ideological system in different social contexts, is obvious, and defines the large variation in ideological discourses and other social practices. (p. 141) 
Individuals hear, see, and interpret social situations in ways that are relevant for them. In this way, state ideologies of biculturalism are considered according to the personal histories, intentions, and purposes of individuals operating in institutions (van Dijk, 1998). For example, a teacher's motivations are shaped by their perception of the audience (and vice versa), while other aspects of context influence what and how learning is to occur. This subjective aspect of context is important. Chapter Six presents Māori English teachers' diverse articulations of coming up against institutional articulations of silencing. The teaching interactions of four participants (see Chapter Seven) also show how culturally and ethnically diverse classrooms and subjective interpretations of context create a wide-ranging hidden curriculum.

"The wall" is a term used by Ahmed (2012) to describe what it feels like to come up against the cultural norms and habits of an institution. The wall is visible to those in the institution who do not neatly inhabit the categories they have been given and is invisible to those who get so used to silencing that they learn not to see it. In a similar vein, the wall is used in this study to denote moments when participants perceive a refusal to engage with the reality of racializing behaviour at the same time as erasing from the conversation difficult questions about culture and ethnicity,

When you don't quite inhabit the norms, or you aim to transform them, you notice them as you come up against them. The wall is what we come up against: the sedimentation of history into a barrier that is solid and tangible in the present, a barrier to change as well as to the mobility of some, a barrier that remains invisible to those who can flow into the spaces created by institutions. (Ahmed, 2012, p. 175).

In this study, the wall is the sedimentation of structural oppression; it is the ongoing manifestation of a "civilising mission" repackaged through a silencing discourse to legitimise state ideologies of biculturalism (Simon et al., 2001). Māori teachers of English are well positioned to hit walls of silencing because they are often demographically marginalised within both the institution and their subject area. In addition, they are working with literature that requires direct engagement with issues of race. It can be anticipated that they will hit the wall in variable ways and are differently aligned to bicultural ideologies but not immune to ideological control. 
To conclude, I have shown how the Settler Contract is rewritten in state secondary schools through the interplay of epistemological, spatial and temporal subcontracts. A silencing discourse is the cornerstone of a push-pull process that seeks to distance mainstream New Zealand youth and their teachers from the realities of a racialised lived existence, including state ideologies of biculturalism that legitimise a limited commitment to Māori, maintain feel-good race relations and freeze Māori temporalities. The Ministry of Education focusses on cultural and ethnic inclusion, which facilitates the performance of a historically-sanitised narrative of biculturalism. The self-perpetuating relationship between discourse and ideology locks the Settler Contract in place. The theory in this chapter goes against the grain of how mainstream society is taught to think about race relations. However, in this thesis I propose that this alternative account reflects the real racialised conditions of settler-colonial education. 


\section{Chapter Five}

\section{Methodology}

How do you draw a line between theory and life? It can't be healthy to always question day-to-day social interactions through race. I went to visit my sister in her new house yesterday. When I pulled outside her house I was met by the neighbour across the road. She asked if I'd just moved in, then followed up by saying that it's a quiet neighbourhood. Immediately, I thought "Why did you tell me that? Is this a veiled warning to keep it that way? Are you assuming that because I'm Māori I'm going to bring trouble?"

(Personal research journal, June 2015)

Methodology is described as the nexus where theory and research methods meet (Solórzano \& Yosso, 2002). A significant aspect of the research process was how my own shifting racial consciousness affected methodological decisions and the shape of this thesis. This chapter begins by exploring the ontological and epistemological assumptions of the Racial Contract and race criticality. This is followed by discussion of issues of voice and audience which became notable features of the methodology as I began to understand the implications of a racialised existence. The practicalities of the research are discussed next, including the features of a two-phase research design, the process for approaching participants and a description of participant demographics, including teaching contexts. This is followed by the data collection and analysis procedures. Finally, ethical considerations and research limitations of the thesis are presented.

\section{The Racial Contract and race criticality}

The previous two chapters theorise how a silencing discourse maintains white supremacy in a settler-colonial context. In this thesis, the Racial Contract is the underpinning philosophy and methodology that reveals how socially-constructed practices and institutional arrangements contribute to the persistent and ongoing silencing of a racialised reality (Bell, 1992a; Mills, 2002). Mills (2002) argues that the Racial Contract is more than just a hypothesis and points 
to the historical, intentional, and cumulative effects of political decisions that govern society. This point is in line with general contract theory, as Jeremy Walden writes:

\begin{abstract}
A set of institutional arrangements may evolve by gradual steps over a period of time; but if each step involves elements of choice, deliberation and purpose, then the whole process takes on an intentional flavour, becomes susceptible to intentionalist categories, and may be evaluated in terms of human purposes in the way that contract theory requires. (1994:69, cited in Mills, 2002, pp. 78-79)
\end{abstract}

This means that the Racial Contract has material outcomes for those working in institutions, therefore, the claim that it is a hypothesis is false. Another criticism directed at the Racial Contract as a methodology is that it does not address the idea of tacit consent (Garcia, 2001). However, Mills (2002) responds that the purpose of the Racial Contract is not to focus on the micro-realm of interpersonal racism and individual responsibility but to theorise a system of white supremacy and the mechanisms of collective white agency. I argue that race criticality may be applied as methodological approach that complements the "broad strokes" of the Racial Contract. Race criticality does so by working from individual and group experiences of racialisation (abstract particularity) towards common or universal themes across different groups (concrete universalism) to emphasise how everyday, recursive interactions comprise a "systemic distortion of social relations ... [that] assumes that racial stratification is not random but predictable and unevenly distributed" (Leonardo, 2014, p. 250).

Race criticality therefore starts from the position of race as lived before applying a critical lens that considers individual experiences within a theory of race and systems of racial oppression (Leonardo, 2014). This means that localised and contextually-driven issues of race are at the forefront of ideological consideration, rather than an "idealist pursuit of race reality" (p. 250) that places theory and claims to end racism before the intricacies and complexities of a real racialised existence. In this study, interview and observation data based on Māori English teachers' experiences of working within state schooling institutions was the starting point from which I reconstituted established scholarship about racism for the purpose of thinking about the mechanisms of silencing and institutional racism in a settlercolonial context. 
One important principle of race criticality is to question how we think about "critical" in relation to race and racism. This insight may be used to counter potential shortcomings of critical race theory, in which past applications of the theory have led to the view that "the word 'critical' has become a sliding signifier" (Apple, 2014, p. 263). According to Solórzano and Yosso (2002), some "critical" social science literature is observed to revolve around a majoritarian story to reinforce racism. Another practical challenge of utilising critical race theory is the tendancy for scholarship to cherry pick research methods, for example, relying solely on narratives of people of color, without linking these stories to systems of racial domination (Ladson-Billings, 2014). Race criticality minimises a reading of racism that perpetuates whiteness by demanding linkages between the personal and ideological (Leonardo, 2014).

An indigenous methodological approach that aspires to the aims of race criticality, yet is vulnerable to trivialisation and misuse like critical race theory, is kaupapa Māori theory. Like race criticality, a kaupapa Māori theoretical position responds to issues of race that are grounded in the local; that is, the political, social, and historical idiosyncrasies of New Zealand (Smith, 2012). Although doctorate studies have implemented kaupapa Māori theory in ways that are emancipatory, methodologically vigorous and creative (see, for example, Pihama, 2001; Stewart, 2007), the theory is open to exploitation. This misappropriation arises from the researcher's inability to comprehend or acknowledge that they are immersed in the (kau)papa (the ground) on which they stand (Mika, 2017). Mika (2017) argues that the researcher and their work cannot be conceptualised as final, causal or linear; New Zealand education research is conducted within a field of colonial ontological assumptions that we cannot escape. Therefore, kaupapa is non-foundational and it is the Māori researcher's role to "trouble the certainty of the text" (p. 129).

Proclaiming oneself as a kaupapa Māori researcher without examining how Western ontologies frame the research comes with an air of certainty that defies the non-foundational essence of kaupapa (Mika, 2017). To illustrate how kaupapa Māori research is open to misuse I draw on two personal anecdotes. First, I have heard non-Māori doctoral students say they need to put kaupapa Māori methodology "somewhere" in their thesis. It felt like they were asking for my permission or thoughts about how they could easily do this. Second, I was presenting data from my Masters thesis at an education conference through a framework of ideological state apparatus by Althusser (2008) and critical race theory. Māori 
employees from the Ministry of Education criticised the conclusions I had drawn in a study because I had not used kaupapa Māori theory. I found it troubling that government employees were advancing the use of a research paradigm designed to emancipate indigenous peoples from colonialism. It seemed to me that kaupapa Māori theory was being used (and abused) to silence state accountability towards schooling inequities (Alcoff, 1991).

Nevertheless, many ideas that underpin kaupapa Māori theory are imbedded in this research design. Critical theory and critical race theory are approaches that have contributed to the genesis of kaupapa Māori methodology (Denzin, Lincoln, \& Smith, 2008). Consequently, questions that are central to kaupapa Māori methodology are central to this thesis, such as who initiates and who benefits from indigenous research (Bishop, 2005).

\section{Marginality, voice, and audience}

A methodology underpinned by the Racial Contract and race criticality was not the approach that I set out to take at the beginning of this study. As the research process unfolded, so did my ability to see the structural implications of racism and how best to tell a story of what it means to exist at the margins of state schooling (indeed, to see a story of race needed to be told at all). My shifting understanding of race consequently informed important decisions about how to frame the data, the narrative of the thesis and how silencing is implicated through the research design. This is followed by a discussion about why this thesis prioritises an audience who are indigenous or minoritised.

\section{Framing the narrative}

This section discusses the implications of the way the narrative has been framed, otherwise known as the voice of the thesis. Alcoff (1991) describes how the issue of speaking for others is a matter of representation that involves "participating in the construction of their [and my own] subject positions" (p. 9). The narrative voice of the thesis changed as the research process progressed and I travelled from a state of colourblindness to one that to some extent perceives how the structuring effect of race impacts social existence. This ontological shift made me re-evaluate the epistemological framework of the research and how I was perpetuating silencing in my own work. 
At the beginning stages of the research and in line with a tenet of critical race theory (Solórzano, 1998), I reasoned that Māori English teachers' perceptions of schooling would provide an important counter-narrative to mainstream understandings of Māori education. I naively thought that critical aspects of the research were supported by the ethnic locatedness of myself and my participants; that we embodied the residual effects of colonialism in the way that Denzin and Lincoln (2005) describe as combining past histories and present personal experience. Although it is perceived that indigenous narrators and their participants can "disturb discourse by exposing the complexities and contradictions that exist under official history" (Mutua and Swadener, as quoted in Denzin \& Lincoln, 2005, p. 946), the notion of disturbance is questionable without a critique of racial ideologies that researcher and the participants bring to the research process (Spivak, 1988).

A critical approach to research that does not consider how a narrative voice is influenced by ideology may support a false representation of truth or subjective authenticity. Ideological bias may be perpetuated through aspects of the research design, which affects the quality or shape of what participant voices say (Jackson \& Mazzei, 2008). For example, the researcher and their participants may percieve that racial injustice is best challenged through the humanisation of whites. This narrative assumes that whites need to do more to help alleviate racial injustice, rather than give up advantages which result in meaningful structural change (Leonardo \& Porter, 2010). Naturalised racial (mis)understandings and dominant cultural and ideological biases mean that nonwhites may not always conceptualise race relations in ways that are emancipatory or challenge racial injustice (Leonardo, 2014).

Bearing in mind ideological bias, I drew on Kincheloe and McLarin (2008) to reflexively question how silencing discourses had shaped the research process and design. One resulting change was to forego collaborating with my participants around data analysis. In line with Heron and Reason (1997), I initially thought that a constructivist approach would support a more vigorous research design. As the research progressed, however, I perceived that collaborating might mean making concessions to the racial discourse I was attempting to critique. A second pitfall I discovered in hindsight was my focus on the teaching of "Māori text". The thesis now refers to New Zealand literature after I realised - through discussions with several participants and my supervisors - the study was aligned with the temporal subcontract by perpetuating a fixed view about how Māori are presented in New Zealand's 
literary tradition. This is a limitation of the methodology as most of the data collection processes referred to Māori text.

Although I identify some moments when a silencing discourse was perpetuated through the research design, I acknowledge that I cannot account for all potential silencing practices. This metholodogical insight resonates with a tenet of race criticality in which the study of racial oppression sits on a knife edge between understanding and reification (Leonardo, 2014). Research about race should not be considered above reproach; however, I have tried to minimise researcher objectivity and claims of subjective narrative truth in three main ways. First, by inviting criticism by being transparent about the theoretical and methodological assumptions that frame the thesis and inform the data analysis; and second, by making it clear that my own racial stance is compromised and developing (Kincheloe \& McLarin, 2008). To do this, I have framed the data collected in phase one and two of the research design according to the theoretical frameworks in Chapters Three and Four and have referenced other literature where appropriate. This is an attempt to locate myself and this conceptualisation of a Settler Contract within a colonising gaze; to bear my theoretical and ontological anticipations so that my own colonial bias may be subject to critique (Mika \& Stewart, 2016).

A third way I challenge the assumption of the scholar as an invisible or neutrual observer in the research process is through personal vignettes at the start of each chapter (four in the introduction) (Jackson \& Mazzei, 2008). These vignettes draw on racial tensions that I have experienced to show how individuals are affected by different racial ideologies and may move between them (Leonardo, 2014). The use of personal vignettes also emphasises that I am part of the narrative of this thesis; that "scholarly knowledge" is both attributed to the perspectives of the research participants and researcher bias (Aldiabat \& Le Navenec, 2011). Indeed, the researcher shapes the narrative of the thesis in ways that participants cannot. Moreover, I do believe that the research process has been a form of therapy and a means for me to make sense of the world; of asserting my "truth". Drawing on aspects of an autoethnographic approach therefore presents an opportunity to challenge the construction of master narratives and Western forms of knowledge (Spry, 2001). In doing so, indigenous peoples may "confront dominant forms of representation and power in an attempt to reclaim marginalized representation spaces" (Holt, 2003, p. 16). 
I am aware that the vignettes in this thesis may unsettle or anger individuals who may recognise themselves in these exchanges. Although I have done my best to ensure their anonymity, it may be possible that individuals will get upset at the thought that they are implicated in racism and positioned as abusers of power or privilege. However, the role of a scholar activist is to "speak back" to power and racial inequalities (Kidman, 2015; Rollock, 2012). That the use of vignettes is a potent means for minoritised peoples to speak their truth and disturb, unsettle, call into question and challenge the status quo, outweighs (in my view) the potential for individuals to feel discomfort. The vignettes are not an attack on individuals, but a critique of the way that whiteness saturates everyday lived existence as an often-overlooked tool of indigenous oppression.

\section{Choosing an audience}

To whom and how one speaks about issues of race has been debated by minoritised scholars for centuries (Du Bois, 1935; Fanon, 1970; Lorde, 1984). A main issue that arises is the futility of talking to white audiences about race; whether helping whites to change or become racially conscious is a productive use of racially marginalised peoples' time and energy. The first reason why concentrating on white audiences is disheartening is because scholarship by minoritised people is not held in the same esteem. For example, literature by Du Bois (1935) regarding racial injustice made a significant contribution to critical theory, but this has been overlooked in favour of scholarship from Germany's Frankfurt School (Ladson-Billings, 2014; Tuck \& Gaztambide-Fernández, 2013). Work by Althusser (2008) on ideological state apparatus and interpellation is celebrated, whereas an analysis of subjecthood by Fanon (1970, 2004) is less well-known (Tuck \& Gaztambide-Fernández, 2013).

Second, overlooking academic work by minoritised people is symptomatic of the broader issue of silencing discussions concerning race and power. Nearly three decades ago, Alcoff (1991) observed:

How what is said gets heard depends on who says it, and who says it will affect the style and language in which it is stated, which will in turn affect its perceived significance (for specific hearers). The discursive style in which some European post-structuralists have made the claim that all writing is political marks it as important and likely to be true for a certain (powerful) milieu; whereas the style 
in which African-American writers made the same claim marked their speech as dismissable in the eyes of the same milieu. (p. 13)

More recently, Gloria Ladson-Billings (2014) argued that when minoritised scholars engage in critical discussions about race they are perceived to be:

Self-interested, the scholar has an axe to grind, the scholar has a chip on his shoulder, the work is too narrow, the work is too political, or this is not scholarship it is activism. However, White scholars can engage in "race work" and be considered "objective," "dispassionate," and "disinterested," thus providing a "scholarly" analysis untained by emotion or hysteria. (p. 32)

The emotional and hysterical stigma applied to non-whites who talk about race is applied more readily to minoritised women (Ahmed, 2012; Kidman \& Chu, 2017; Lorde, 1984). In general terms, I am an indigenous female who is writing critically about race so will be perceived to be forthright, loud and emotional whether I am or not. Although this is a sobering thought, it is also one that comes with some freedom. Ahmed (2012) explains that anger is creative and challenges perceptions that it is pointless and should not be evoked. She writes, "After all, even if we use softer language, we are already sore points. We might as well do things with these points. To speak about racism is to labor over sore points" (p. 171).

Finally, the choice to direct this thesis at a Māori/indigenous/minoritised audience is consistent with Racial Contract methodology. The premise underpinning an epistemology of ignorance is that whites are socialised not to see the mechanisms of racial domination. Mainstream society is socially-constructed to ensure that whites are tone-deaf to issues of race because social location matters in terms of how one able to see and process racial matters (Alcoff, 1991; Fleras, 2016). Whites are moreover content to exist in alliance with the structures that support white supremacy (Mueller, 2017). Drawing on the notion of "the wall” (Ahmed, 2012), it is almost certain that all Māori have experienced structural racial tensions; therefore, the ideas in this thesis are much more likely to resonate with Māori than a Pākehā audience.

The Racial Contract and race criticality provide a philosophical and methodological framework that supports Māori experiences of marginality within state schooling to speak 
from a non-dominant position. Voice and audience are also central considerations when supporting a resistance narrative that challenges the moral imperative of what is regarded by the dominant culture to be truth (Fivush, 2010).

\section{Research design}

This section begins by briefly outlining the two-phase research design. The process for approaching participants for the study is next. This is followed by a summary of participants from phase one of the study, then a detailed description of the phase two participants and their school contexts.

\section{Two-phase research}

Two complementary phases of data collection were undertaken to study silencing and institutional racism. Phase one involved 19 individual semi-structured interviews with Māori secondary school English teachers (focussed on participants' perceptions of three parts of the following English curriculum statement, highlighted in bold). Then the second phase of the study was a multiple case study involving four teachers from phase one.

By understanding how language works, students are equipped to make appropriate language choices and apply them in a range of contexts. Students learn to deconstruct and critically interrogate texts in order to understand the power of language to enrich and shape their own and others' lives.

Students appreciate and enjoy texts in all their forms. The study of New Zealand and world literature contributes to students' developing sense of identity, their awareness of New Zealand's bicultural heritage, and their understanding of the world. (Ministry of Education, 2007, p. 18)

The participants' everyday classroom interactions, presented in Chapter Seven, draw attention to manifestations of covert structural silencing that sit underneath the consciousness of those working in institutions. The four phase two teacher participants' personal and professional conduct, school and classroom contexts, teaching approaches, and philosophies, are juxtaposed against each other. This data sits alongside the corpus of data collected from phase one, to develop a deep understanding of the way silencing and institutional racism is 
enacted in state secondary school institution. In the next section, I describe the processes undertaken to invite participants to be involved in this study.

\section{Description of participants and schools}

Two phases of data collection that involved Māori English teachers who worked in demographically diverse school settings are outlined below.

\section{Phase one}

Twenty-one teachers were interviewed for phase one, with nineteen interviews being analysed. A small number of the participants were not teaching secondary school English at the time of their interview and were currently working in a different part of the education sector. Although participants fitted the criteria of being Māori teachers of secondary school English, there were significant differences in other areas of their professional lives, as outlined below:

- Four early career English teachers (1-2 years teaching experience)

- Three mid-career English teachers (3-8 years teaching experience)

- Six held head of English or assistant head of English positions

- Five held senior management positions (principal/tumuaki/deputy principal)

- Two were specialist literacy or specialist classroom teachers

- One advisor from the Ministry of Education, one education consultancy advisor and one resource teacher for learning and behaviour (employed by the Ministry of Education to support for individual teachers and their students)

- Four teachers had taught or were currently teaching in kura kaupapa Māori or bilingual unit contexts

- Most participants had experiences of working in classrooms of all Māori learners

- Half of the participants were proficient speakers of te reo Māori

The findings from phase one are presented in Chapter Six. When direct quotes from the participants are used, I identify the speaker according to gender and whether that are earlycareer, mid-career, or experienced teachers (nine years upwards). 


\section{Phase two}

Phase two teacher participants comprised three women and one man who taught in coeducation settings. The names of these participants have been changed to protect confidentiality (the pseudonyms were chosen from a website of ten most popular Māori names in 2015). These participants' professional lives were also diverse. For example, one woman was a relatively new teacher while the other three teachers were experienced educators. Of those who were experienced, one was new to teaching the English curriculum within a mainstream context (she had previously taught for many years at a kura kaupapa Māori school). There were also some similarities among the group, for example, three of the four teachers were proficient te reo Māori speakers and regularly spoke reo in the classroom.

\section{Aroha}

Aroha is between 40-49 years old. She was a teacher in the mid-career teacher but explained that working in a mainstream school setting and as a secondary school English teacher was a relatively new experience. Aroha was trained to work in primary and kura kaupapa Māori school settings. She had taught a wide range of subjects previously including Te Reo Māori, History, Art, and Social Studies. Aroha began studying te reo Māori in a university before moving to a wānanga tertiary institution to access a higher level of te reo. She has a Masters in Education and is actively seeking ways to put her study to practical use.

Aroha has "always been a prolific reader" since a very young age, opting to read books instead of watching television. Her father is a white New Zealand immigrant and her mother's iwi hail from a different part of the country. Aroha's mother and her mother's siblings are native te reo Māori speakers but only a small fraction of their children (including Aroha) have carried on the tradition. She thought that her background gave her a "slightly different take on teaching English".

Aroha was observed teaching a mixed-gender, Year 13 English class of approximately 12 students. She engendered a friendly and relaxed classroom environment in the three observed lessons. The lessons included close reading activities based on a novel and revision for a written internal assessment. There was a lot of joking and humour in Aroha's lessons and this appeared to elicit a genuine sense of student engagement towards the studied text. 


\section{Nikau}

Nikau is also between 40-49 years of age. He grew up in the same area that the school where he teaches is located but is also tribally connected to an outside area. Nikau has over 20 years experience teaching English and Te Reo Māori at his current workplace. He is a passionate English teacher who has taught all year levels and particularly enjoys teaching Shakespeare and New Zealand literature.

Nikau was observed teaching a mixed-gender, year 13 English class. Six to eight students attended class over the six observed lessons. During the first and second lessons the students delivered a speech assessment on Shakespeare's "Othello". The following two lessons involved pre-teaching of the historical, political and racial contexts for a film study, "Rain of the Children" directed by Vincent Ward (2008). The final two lessons covered writing and conference tasks about the film.

Of the four teachers, Nikau conveyed the deepest understanding of race and power, made conscious decisions to teach New Zealand history and challenged political and education structures. Nikau operated a quiet learning environment. This may have been due to a smaller number of students, but it also appeared to be part of his teaching style. These factors contributed to long stretches of silence and sustained periods of whole class discussion where each student had an opportunity to contribute and develop the own understandings around text.

Nikau and Aroha teach in a bilingual unit which caters to over 200 Māori students within a large mainstream secondary school in a major urban setting. This bilingual unit used te reo Māori as the medium of instruction in many classes, but the English language was predominantly used during the observed lessons. Nikau is the head of the bilingual unit and Aroha is one of ten teachers. The ethnic and socio-economic demographic of the school had changed over the previous 20 years from a decile 3 predominantly Māori and Pacific community to one that is now more affluent, liberal, predominantly Pākehā, and regraded a 
decile $8 .{ }^{19}$ Approximately $25 \%$ of the school is comprised of Māori who come from middle and working-class backgrounds.

The bilingual unit experienced distinct challenges in relation to the mainstream school. One challenge was that there were two "types" of student; one who was fluent in te reo Māori and the other who is learning to speak te reo. Another tension that affected resourcing and programme planning was that the unit had grown from 60 to 70 students to 220 in the space of a few years. The biggest teaching challenge, however, was the low literacy levels presented by students who entered the bilingual unit. Aroha explained that these were significantly lower than students entering the mainstream because students have moved between multiple schools and experienced a lower quality of education. She pointed out that students with lower literacy levels made good gains throughout their time in the bilingual unit, but personal growth was often overlooked by official reporting measures.

The bilingual unit site was visibly positioned in front of the school. The classrooms and administration blocks displayed study guides and lesson content. Māori culture and iconography were displayed throughout the schooling environment. The staff and students exuded warmth and there appeared to be professional yet relaxed relationships between the staff members and staff and students. The community gathered in front of the wharenui for karakia, waiata, school notices and roll-call at the start of each day. Staff and students appeared to hold Nikau and Aroha in high esteem. When they were not in front of the class or attending to large groups of students, they were observed doing paperwork or talking with individual students.

\section{Anahera}

Anahera is similarly between 40-49 years old. Like Nikau, she has over twenty years of teaching experience and holds a senior management position (assistant principal) alongside teaching a senior English class. At university, Anahera majored in English and Te Reo Māori and has held head of English and head of Te Reo Māori roles in previous schools and at the same time. She is also teaching outside her tribal area. Like Nikau and Aroha, Anahera is

\footnotetext{
${ }^{19}$ A decile rating between 1-10 is "a measure of the socio-economic position of a school's student community relative to other schools throughout the country". Retrieved from https://www.education.govt.nz/school /running-a-school/resourcing/operational-funding/school-decile-ratings/. Lower decile schools are given more financial support from the government; however, this does necessarily result in equitable resourcing among diverse communities.
} 
very warm, well-liked, and respected by both her colleagues and students. She supports a range of extra-curricular activities, such as Manu Kōrero ${ }^{20}$ and sport.

Anahera teaches in a small to medium secondary school in a small, inland New Zealand city. Three quarters of the student population are Māori. Anahera models the importance of having an "affinity with Māori students" to her staff to ensure they also convey the same tone. She said literacy testing "reinforced what we already know, that our kids come in two curriculum levels below the norm ... it's a frustration but there's nothing we can do other than try and fix it". At the time of the interview, the school was trialling a cross-curriculum, collaborative approach with local iwi and kaumātua and seeking to build more local stories and tribal knowledge into the curriculum.

I observed Anahera teach English to a split-level class of predominantly male, year 11, 12 and 13 students. Attendance over three observed lessons ranged from eight to 14 students. One lesson was based on a feature film called "The Dark Horse" directed by James Napier Robertson (2014), and the other two lessons centred on a written internal assessment based on three New Zealand short films. Catering to students from three year levels meant that the start of class involved a little more administration time, but some of the older students were self-managing. Anahera was adept at maintaining positive and generally purposeful learning interactions with the students in an environment that would test many experienced teachers.

Anahera's class had a vocational pathway character and was comprised of "at risk" students who had struggled to fit into a mainstream school setting. The promise of employment at the end of the programme and clear learning and behaviour expectations appeared to support a positive class culture. Anahera spoke of the challenges that most of the students had already faced in their young lives, such as familial dysfunction, school suspensions and volatile interpersonal relationships. Despite these challenges, Anahera ensured that the classroom culture was relaxed, respectful and purposeful. The older students appeared to be very reliable and some kept the younger ones in line.

\footnotetext{
${ }^{20}$ Manu Kōrero is a national secondary school's speech competition where students speak about issues pertaining to te ao Māori in either te reo Māori or te reo Pākehā sections of the competition
} 


\section{Maia}

Maia is the youngest of the four teachers and was between 20-30 years old. She had taught for five years and in one other school prior to her current workplace. This was her first year teaching senior English but she professed that the History and Social Sciences curriculum were her biggest passions. In order to increase her employability, Maia majored in English (alongside History) at university because English jobs are more readily available.

Maia felt that her biggest teaching challenge was that she lacked real passion in English and "a huge knowledge of content, aside from what I'm interested in". She said her strengths lay in the craft of teaching; that is, utilising good teacher practices and pedagogies. This was evident in each of the three observed lessons as her lessons were organised, efficient, resourceful, and very purposeful. During this time, Maia focussed on teaching the skills required for an external assessment through the medium of two short texts. Maia said she enjoyed telling stories in class and bringing her voice and experiences into the study of text.

Maia's school is in a small coastal community, not far from a major urban environment. The large schooling institution is comprised of predominantly Pākehā students and just over 15\% of the roll is Māori.

Most of Maia's year 11 English class were Pākehā. Although Maia initially identified two Māori students, we discovered after an interview that two other students had also registered on the school file that they were of Māori ethnicity. The tone and working culture of Maia's class contrasted greatly to that of the other three participants; there was a lot more pedagogical activity, the transitions between learning activities were quick and the students appeared to generate more written work 
Table 1: Summary characteristics of three schools

\begin{tabular}{|l|l|c|l|l|l|l|l|}
\hline Participant & School demographics & \multicolumn{2}{|l|}{ Class demographics } & \multicolumn{3}{|l|}{ Focus group demographics } \\
\hline & Ethnicity & Decile & Character & Ethnicity & Year & Ethnicity & Gender \\
\hline Aroha & $\begin{array}{l}\text { Predominantly } \\
\text { Pākehā }\end{array}$ & 8 & $\begin{array}{l}\text { Bilingual } \\
\text { unit }\end{array}$ & Māori & 13 & N/A & N/A \\
\hline Nikau & $\begin{array}{l}\text { Predominantly } \\
\text { Pākehā }\end{array}$ & 8 & $\begin{array}{l}\text { Bilingual } \\
\text { unit }\end{array}$ & Māori & 13 & Māori & Mixed \\
\hline Anahera & $\begin{array}{l}\text { Predominantly } \\
\text { Māori }\end{array}$ & 2 & Vocational & $\begin{array}{l}\text { Predominantly } \\
\text { Māori }\end{array}$ & $11-13$ & N/A & N/A \\
\hline Maia & $\begin{array}{l}\text { Predominantly } \\
\text { Pākehā }\end{array}$ & 8 & Mainstream & $\begin{array}{l}\text { Predominantly } \\
\text { Pākehā }\end{array}$ & 11 & $\begin{array}{l}\text { Predominantly } \\
\text { Pākehā }\end{array}$ & Mixed \\
\hline
\end{tabular}

\section{Data collection}

Phase one data was collected between the months of September 2014 and April 2015. The first section describes how phase one data was collected through semi-structured interviews. The research journal process as a form of data collection is briefly presented next. This is followed by the data collection processes for phase two, in which four phase two teachers were each observed working with one senior English class over three to six lessons from June 2015 to September 2015. Data for this phase was collected through lesson observations, follow up interviews, and focus group interviews with two groups of students from Nikau and Maia's classes.

\section{Semi-structured interviews}

The interviews were organised as semi-structured, audio-recorded interviews (via dictaphone) that were conducted kanohi ki te kanohi, over the telephone or online through Skype. The interviews ranged from 40 minutes to one and a half hours and were guided by three phrases from curriculum statements: critically interrogate, developing sense of identity, and bicultural heritage (Ministry of Education, 2007). The semi-structured interview approach allows new ideas associated with the unique teaching experiences of the interviewees to surface (Edwards $\&$ Holland, 2013). Sometimes I did not need to ask the interview questions as they were addressed through the natural flow of conversation. 
The purpose of the interview and the interview script was read out at the beginning of each interview (Bishop et al., 2007). I shared some of my background and motivations for conducting the research and explained that these arose from the professional and personal tensions I experienced as a Māori English teacher working in secondary school institutions. The interview script directed conversation towards issues of culture, ethnicity, and pedagogy (see Appendix B). Issues of race and racism surfaced in response to perceived challenges associated with being Māori. I also pointedly addressed racism and issues of race as my own interest and understanding of this scholarly field grew.

\section{Research journal}

A research journal provided another important source of data in which I recorded my impressions of the research process; for example, my thoughts and feelings after an interview or observed lesson. The journal also included cross-case comparisons, reflective analysis linking the data to theory, research, or other literature and comparisons between the participants' and my own personal and professional experiences. For example, some of the vignettes that refer to my own schooling experiences are reclaimed memories that surfaced in response to aspects of the research process.

\section{Lesson observations and follow up interviews}

I conducted an informal meet and greet of four Māori English teachers (initially, identified as "primary participants") and their students (initially, identified as "secondary participants") during the school term prior to the official data collection. The teachers understood that I wanted to observe them teach a unit of work that was by a Māori author or director and/or delved into issues that concerned Māori. The primary participants chose the text and we negotiated the timing of the lesson observations to suit our schedules. Prior to the first observation we discussed general information about the class such as the curriculum and assessment that had already been covered, how the students were progressing in terms of achievement, self-management, the behaviour and learning culture, and individual and class goals.

I observed Aroha and Nikau teach during July and August and Anahera and Maia during August and September. The only participant who was observed teaching sequential lessons was Maia, whereas the other three sometimes had a two or three week gap between lesson observations. Three of the four participants lived outside of the Wellington region, so I could 
not observe more than three to six lessons because of the travel costs involved. The verbal component of classroom interactions was recorded on a dictaphone and I transcribed the audio within a week of the observation. I kept a running record of what transpired in the classroom and noted student attendance, seating arrangements, perceived relationship dynamics, and classroom imagery. I recorded in one column what I had observed during the lesson, then aligned this information with the time and all the dialogue from the dictaphone during the transcription process.

The primary participant and I usually met as soon as possible to debrief about the lesson. I asked open-ended questions about how they thought the lesson went. The participants spoke about a range of issues that they perceived were pertinent to the lesson and usually also responded with the next teaching and learning steps. During one interview the participants were asked to reflect on their lesson using the phrases from the English curriculum statements that guided the semi-structured interview process in phase one.

\section{Focus group interviews}

Two small groups of four to six students from Nikau and Maia's classes attended two focus group interviews. The focus group interviews were held during a lunch break and lasted approximately 30 to 40 minutes.

I facilitated the focus group interviews and asked questions designed to elicit more detail about what I had observed and heard during the observed lesson. Some of the questions were open-ended and asked students to communicate their thoughts about phrases from the English curriculum. Other questions were based on what students could remember from the lesson or previous lessons, the effectiveness of pedagogical approaches such as doing homework, and personal insights about schooling and education.

The primary participants did not view the student responses and, to encourage honest and truthful responses without fear of damaging their relationship with the teacher, the students were told that their teacher would not see their responses until the publication of the thesis. To further ensure anonymity, these students are only identified in this thesis according to ethnicity. 


\section{Approaching participants}

I began looking for potential participants through secondary school English organisations, the Ministry of Education, and the New Zealand Teachers Council. These investigations revealed that there is no national register for Māori teachers of secondary English in New Zealand. Participants were then sought through a snowball recruitment process. Snowballing is a method of recruitment that involves asking participants to norminate other prospective participants. This approach can more successfully access sensitive and difficult to reach populations (Browne, 2005). The snowballs were initially started through my personal contacts and those of my supervisors, as we are connected to community networks that include the target participant population. The process of finding Māori English teachers started slowly but gained momentum during January, February, and March 2015. Phase one participants primarily came from mainstream secondary school environments and I began to interview more teachers from Māori-medium environments towards the latter stages of the data collection process. One drawback to snowballing recruitment is that the process may be considered biased because participants are selected through social networks (Browne, 2005).

I began approaching teachers to take part in phase two while conducting the last of the phase one interviews. Despite a slow uptake, three teachers eventually agreed to take part in the multiple case study which required that they teach a text by a Māori writer/director in the second half of 2015. These participants coincidentally came from demographically diverse class and school contexts (decile ratings, ethnic and gender compositions). One participant invited a colleague to join the study, so I was fortunate to have four teacher participants for the multiple case study.

Phase two also included a student participant perspective. I spoke to all the students in the class of each teacher participant to inform them about the scope of the study and the focus group interview and to ask for their involvement provided parental permission was forthcoming. Research time constraints and limitations imposed by two schools' timetables meant that students from two teacher participants were involved. One group of students was predominately Pākehā and the other was Māori.

There were several coding and analysis review stages in the research process. All participants in phase one had an opportunity to review the interview transcripts and verify that they were a fair representation of the discussion or provide feedback outlining otherwise. 
The teacher participants from phase two were similarly asked to member-check observation and interview transcripts for accuracy and offer their perspectives of what transpired. I was never challenged about the legitimacy of the data.

\section{Data analysis}

Phase one and phase two generated a large corpus of data. I underwent several stages of analysis to deepen my understanding of the research problem by moving back and forth between the data and different theoretical approaches. A significant issue that surfaced during the analysis was my shifting racial perspective. As I became more critical and sensitive to issues of race, I began to see that earlier iterations of analysis which I thought were framed by a "neutral" lens were manifestations of silencing (Eisenhardt, 1989; Matsuda, 1993). This was an important realisation that contributed to a race-based analytical framework. The processes for analysing phase one and two data sets are presented in this section.

\section{Analysis of phase one data}

In line with race criticality, it was an important that I let the data speak. I read a wide range of research and theoretical literature throughout the research process and this led me to see that the Racial Contract was the paradigm that accounted for my data. Working from the data towards theory counters claims that a group-based cognitive distortion was uncritically applied as the reason for racial injustice (Garcia, 2001; Mills, 2002).

The data collected from interviews with nineteen Māori English teachers was processed through three iterations of analysis. First, I read each transcript as it was completed and applied initial codes along each line or section of data (Saldaña, 2013, pp. 100-105). The second cycle involved the use of an NVivo coding programme. The data from the first cycle were summarised and grouped according to a teaching or school practice (NVivo call this a child node). The data was then condensed further under the category of parent node, then summarised under seven general topics which represented broad themes (Saldaña, 2013, pp. 175-181). The themes were (from largest to smallest data set): pedagogy, text, teacher identities, teacher values, Māori students, school culture, and English department. NVivo also has a memo function where I attached hunches or perceived relationships between the data analysis and theory to the corresponding child/parent node. 
The third and most time-consuming iteration of data analysis involved a return to a manual, process coding approach to achieve a more conceptual analysis (Saldaña, 2013, pp. 96-100). The data remained in the thematic grouping from the second cycle, but each piece of summarised data was given a new sub-code label. Then each sub-code label was condensed to a code, then to a sub-category and finally category (see Appendix F). Gerunds were used to emphasise the active and processual nature of teaching (Charmaz, 2006). The filtering process for each theme occurred over three spreadsheets. For example, the first spreadsheet for the pedagogy theme was thirty-three pages long. The next spreadsheet was nineteen pages long because the "summary of data" category was removed and a category, called "column", was added to further conceptualise the data.

Once data from the seven themes had been processed this way, the analysis was reshaped so that participants' perceptions of unproblematic aspects of teaching English were at the top half of each spreadsheet and the racial tensions experienced by the participants were towards the bottom. When the third iteration of analysis was complete, themes emerged that from the top half of the spreadsheet that aligned with the operations of a Settler Contract. The bottom half of the spreadsheet demystified a pattern and logic to institutional responses to silencing. The findings for each section are presented in Chapters Six.

\section{Analysis of phase two data}

The second phase of data analysis demystified how policy, curriculum, and pedagogy structures contribute to silencing as an everyday, mundane occurrence. The findings from phase one showed the challenges and affordances experienced by Māori English teachers as they go about their daily business. However, the mediating role that the epistemological structures of settler-colonial education play towards generating silencing are not visible, so the data from phase two explains how participants are implicated in the whitecentric habits of the institution (Leonardo, 2014).

Classroom observations and teacher and student participant interviews were also processed through three iterations of analysis. Like phase one, the first coding cycle was a manual process of writing initial codes along lines or sections of interview transcripts. The codes supported the second coding cycle, which involved the transfer of raw data into the NVivo programme under a parent node that designated a specific pedagogical practice. Next, similar 
teaching practices were combined under a general topic that denoted English curriculum pedagogical actions. For example, Nikau's main pedagogical action was "enhancing individual learning experiences". Within this category were the following parent nodes: instructing students to write, asking questions to deepen understanding, setting up to learn, and conferencing and discussing text with individual students.

Once all four participants' data had been processed this way, the main pedagogical actions for each participant were printed, colour-coded, and cut out separately. This analysis was also informed by the way I was "sensitised" to particular patterns and concepts that arose from the phase one data analysis and the theoretical literature (Charmaz, 2006). I was also influenced by the theoretical framework provided by Kidman et al. (2018), and engaged in a tactile process of shifting, sorting, and grouping the observation and interview data from phase two until a pattern and logic to silencing began to emerge (Stake, 2005). These patterns were also identified through the triangulation of different data sources; for example, post-lesson interviews with the teachers, focus group interviews, and my own observations (Eisenhardt, 1989). Triangulation allowed me to make effective cross-case comparisons and think about why different aspects of silencing were implemented according to each participants' unique social and cultural conditions.

Schwab (2010) speaks of uncovering the effects of historical trama through learning to look at seemingly mundane and normalised social scripts in different ways. She writes,

Hiding in language exists even when stories are told; the traces of such hiding are to be found at the surface of language. To read language for these traces is, in a sense, to read against the grain of overt narratives. (p. 55)

Similarly, Ahmed (2012) insists that our perception of reality may be at odds with what is actually occurring at the everyday level of lived existence,

Institutions provide a frame in which things happen (or don't happen). To understand how "what happens" happens, we actually need to narrow (rather than widen) the frame: to think about words, texts, objects, and bodies, to follow them around, to explore what they do and do not do, when they are put into action. (pp. 49-50) 
These observations speak to the expression of the hidden curriculum of settler silencing in Chapter Seven. Through a constant comparison of theory and data, I learned how "to read against the grain" of the overt state narrative of biculturalism produced in everyday classroom settings. A process of understanding how race works in state school institutions helped me to challenge incongruities between policy and practice. Thus, I was able to reframe how I thought about the nature and purpose of state education.

\section{Ethical considerations}

Ethics approval through the Victoria University of Wellington Ethics Committee recognised the rights and interests of all my participants. The principal from each school that was involved in phase two was notified about the study (see Appendix C). The participants also volunteered to take part in the study and had the right to appeal transcripts or to withdraw from the research (see Appendices A, D, E).

The involvement of students required careful consideration of ethical research approaches. First, students of any cultural background were invited to participate in the study, provided parental consent was forthcoming. This ensured that there was no conflict of interest between teachers and students by engaging in a selection process. Second, I guaranteed confidentiality to those participating in the focus group interviews. This was important to ensure that the ongoing relationship between students and teachers remains intact and undamaged after the research has finished.

\section{Methodological limitations}

One major limitation that I have already discussed is the structural racial blindness of the myself, as researcher, and the tenuous line between challenging and contributing to racial hegemony through aspects of the research design (Leonardo, 2014). I have also raised the issue of tacit consent, which is a "slippery" issue for social contract theory in general (Garcia, 2001; Mills, 2002). Following Mills (2002), this study is focussed on "the macro issue of race as a political structure of domination" (p. 85) but questions may be raised about the interplay between the structures and processes that contribute to silencing and personal 
agency. For example, how much agency or choice do secondary school teachers have regarding teaching decisions (motivated, in part, by subjective and personal experiences) and how much of what they do is governed by the structures and processes of silencing?

A focus on structures does not mean that educators who work in institutions that ignore race, within a society that views race as irrelevant, are entirely blameless or without agency. Indeed, a criticism of structuralism is that a focus on the relationship between the coloniser and the colonised leaves little intellectual room to account for or imagine the multiplicity of indigenous peoples' lived experiences (Rifkin, 2017). Positioning minoritised peoples' lived existence within a Settler Contract may potentially reify traditional Western conceptions of the indigenous native as "Other" who is different to the norm (Smith, 2012). While it is important to acknowledge such criticisms, focussing on post-colonial multiplicity, hybridity, and agency - without an informed understanding of the way that structures moderate diverse forms of lived existence - is a means for hegemony to advance the colonial project. A dearth of research examining the socially-constructed nature of race and racism in the New Zealand education system is evidence that it is too early to assume that we can simply move beyond a structural analysis. As Ahmed (2012) writes: "To proceed as if the categories do not matter because they should not matter would be to fail to show how the categories continue to ground social existence (p. 182).

Another potential limitation is to what extent my shift towards an ontology of racial realism affected the research design (Bell, 1992b). I did not set out to critically investigate issues of race and this has undoubtedly affected the data collection process. My participants were told that the research centred on the English curriculum statements in what was originally an openended investigation of teacher practices and beliefs. I am unsure what difference it would have made to the data collection process had I articulated to participants that the research was focussing of issues of race, racism and mechanisms of white supremacy. One possible drawback to articulating a research focus on racism is that the fear of being perceived to be racist could lead participants to present their teaching practices in ways that are not consistent with their usual approach (DiAngelo, 2012). Conversely, one benefit could be that a stronger focus on race in the earlier stages of the study and the collection of data may have generated a more nuanced understanding of race in state schools and the operations of a silencing discourse through the hidden curriculum of settler silencing. 
This chapter presented the Racial Contract and race criticality as the underpinning methodological approach of this thesis. In doing so, I considered how my own shift towards a racialised reality affected aspects of the research design, including voice and audience.

This was followed by the key features of the research design, such as participant demographics, teaching contexts and data collection and analysis. Finally, research ethics and potential research limitations were considered. In line with acknowledging that a shifting racial perspective is part of the ontological kaupapa of this research (Mika, 2017), the following two findings chapters present the research data in a format that regularly revisits the theoretical framework and established scholarly literature about silencing and racism in settler-colonial education. 


\title{
Chapter Six
}

\section{Hitting "The 'porous' wall”: Māori English teachers' perceptions of race and racism}

\author{
The granddaughter took her book from her schoolbag and opened it. \\ "I killed all the butterflies," she read. "This is me and this is all the butterflies." \\ "And your teacher like your story, did she?" \\ "I don't know." \\ "What your teacher say?" \\ "She said butterflies are beautiful creatures. They hatch out and fly in the sun. The \\ butterflies visit all the pretty flowers, she said. They lay their eggs and then they die. You \\ don't kill butterflies, that's what she said." \\ The grandmother and the grandfather were quiet for a long time, and their \\ granddaughter, holding the book, stood quite still in the warm garden. \\ "Because you see," the grandfather said, "your teacher, she buy all her cabbages from \\ the supermarket and that's why."
}

(Excerpt from "Butterflies” by Patricia Grace (1990))

The findings in this chapter address the first research question, namely, "What do Māori English teachers' responses to New Zealand curriculum requirements (Ministry of Education, 2007) for critical approaches to text, identity and biculturalism reveal about the operations of a silencing discourse?" In Chapter Four, I argued that Māori English teachers come up against "the wall"; secondary school institutional processes that silence conversations about ethnicity or settler-indigenous relations that are accepted cultural norms or habits (Ahmed, 2012).

The first section of findings in this chapter present phase one participants' experiences of coming up against walls of silencing in New Zealand secondary schools. Participants' articulations of walls are attributed to individual and interpersonal racial prejudice and discrimination associated with the notion of cultural and ethnic inclusion. The first group of findings in this section portrays instances of direct racism experienced by fair-skinned participants. The second and third groups show that participants identify limits to the notion 
of cultural and ethnic inclusion. The final group of findings reveal that there are limits to Māori English teachers' ability to conceptualising structural racism.

The second section of findings reveal how participants' structural blindness ensure they sink into and flow with the whiteness of the institution, leading to the view that schools are positive, helpful and supportive place for youth. Māori English teachers are driven by a meritocratic belief that teacher practice is central to supporting academically struggling Māori students to overcome a perceived cultural or educational deficit. Discussions about the position of Māori in New Zealand society are silenced in classrooms where assumptions about the racial neutrality of New Zealand society hold sway (Doane \& Bonilla-Silva, 2003; Giroux, 2003). Consequently, Māori English teachers are pulled through the porous wall by enacting curriculum and pedagogical practices in line with the state-mandated focus on culture and ethnicity, to maintain the flow of whiteness and racism in their workplace.

\section{Identifying individual and interpersonal racism}

In Chapters One and Two, I suggest that the policy position adopted by the Ministry of Education to include culture and ethnicity may be described as colourmute. Pollock (2004) argues that colourmute ideology arises through deleting race words, which has the effect of obscuring the ongoing impact of colonisation and assimilation towards contemporary settlercolonial relations. Instead, the Ministry of Education systematically embeds non-racial expressions through formal and informal school structures and processes, such as the notion of "Māori achieving success as Māori” (Ministry of Education, 2013). Pollock (2004) claims that colourmute school policies have the effect of exacerbating racial inequalities. The findings in this chapter speak to the way framing issues of race in terms of culture and ethnicity legitimises individual and interpersonal prejudice and discrimination against Māori interests in state school institution.

In "movement one" of the literature review in Chapter Two, I examine the affordances and contraints of counter-narrative research. One benefit to gathering interview data based on minoritised peoples' institutional experiences is that they provide a starting point from which to expose the lived reality of racism. In this chapter, I present phase one participants' articulations of hitting walls of silencing as they relate to experiences of direct racism and 
narrow interpretations of culture and ethnicity. The final group of findings highlight the ways that that Māori English teachers' conceptualisation of racism is limited by structural blindness, as they rationalise the inconsistencies of structural racism in ways that align with a silencing discourse.

\section{Direct racism}

This section relays instances of direct racism experienced by the Māori English teachers in this study. In a climate of colourmuteness, the "fear of being labelled a racist" is an effective behavioural deterrent for articulating blatantly racist comments (Pollock, 2004, p. 2). Pollock's research might be explanatory of the fact that only fair-skinned Māori English teachers (who were perceived to be Pākehā in their respective education contexts) reported hearing racist slurs directed at Māori by adult Pākehā educators. Two participants shared the following stories,

When I was in Teachers Training College there was an election coming up, and [a teacher who was also training to teach English] said, "Oh, everyone thinks that as a trainee teacher that I would vote for Labour, but I vote for National because I am sick of all this Māori shit”, and I was just sitting in the car at the time and I didn't know what to do, I was just so deeply, deeply offended. . . Do you know what the Māori shit she was she was talking about? In one year of teachers' college, we had like three sessions where we did some Māori stuff. That was the big imposition on her which led to her to vote in a certain way. . . I think the most frightening thing is the number of things people will say on the assumption that you'll agree. It doesn't really occur to them that you would be offended by it, which makes you wonder how many other people that they talk to that aren't offended by it. (Mid-career female teacher)

In my first year teaching here, round senior exam time, a staff member from my department made some comments about Māori students. [They said] if they were able to answer their exams using bro language then perhaps they would have more of a chance of passing. Another staff member was there, and nothing was said; he was a junior member as well. It was a senior member making these comments and he was a strong personality. I really didn't know how to react, I was in shock, and I went home and just cried and cried . . It blows my mind a 
bit, but it hurt because I feel it and if you attack your kids I feel like you're attacking me. You're attacking those kids because they're Māori. I'm Māori too, don't you understand that that offends me? Like I'm not one of you, I'm one of them as far as I'm concerned. (Early-career female teacher)

Most Māori English teachers in the study however reported hearing overt racism from their students. In the classroom, participants were much more forgiving of such comments. For example, one Māori English teacher said, "a part of you gets angry" when listening to prejudice but thinks, "that's not necessarily them, that's their parents, that's their community". Although a few participants said they worked with many Pākehā who were open to studying New Zealand literature, many reported being told by students - even "nice" ones - that they had no interest in Māori topics. Negative responses included, "Oh, no, not more Māoris", "I don’t want to do this", "Why do we have to do this?", "Speak more English in class", "Do we ever do anything other than Māori stuff?"

The participants generally agreed that student resistance to learning about things Māori arose from cultural confusion. One participant said that Pākeha students "totally missed the point ... because of different values",

I suppose not a lot of them have had experiences of a Māori person or being marginalised or had to listen to someone pronounce your name wrong every year, every day. A lot of them are just like, "No it doesn't happen". Well actually it does, and then you tell them your experiences, or one of the other students will say this is what happened to me and they'll go "Oh" and it's a bit of an eye opener for them. I think there are some things that they relate to a lot easier, like the Marriage Equality Bill was one that they were all like "Oh that's so unfair". They could see the unfairness in that, but they couldn't translate that to seeing unfairness in a lot of other things - that the system is designed for a certain group in society. It's about I suppose making those connections. (Mid-career female teacher)

While direct racism of these kinds was reported, the participants' discussion often also teased away at more covert racism; situations where what was involved was less shock or assault but 
a sense of discomfort or not feeling at ease. The following two sections of findings move from blatant forms of racism to attitudes and actions that are more covertly racist.

\section{Limits to cultural inclusion}

As discussed in the introduction passage of this section, Māori English teachers identified contradictions and inconsistencies regarding the notion of cultural inclusion through assessment and teacher practice.

\section{- in assessment}

Several participants thought that the Ministry of Education and their school's assessment policies and processes were biased and disadvantaged Māori students. Some Māori English teachers commented that NCEA ${ }^{21}$ shapes teachers' motivations and perceptions of schooling success. One participant thought that Māori teachers had "a more holistic view" of schooling and that was needed to support Māori students,

I really struggle with ["Māori achieving success as Māori”], and especially in educational settings where success is alternately driven back to $85 \%$ of students passing Level 2. If you look at the curriculum there is a large body of information and things that students shouldn't and should be able to do as a part of being a citizen. If we were gonna say [what] a successful person [is], then those are the things that the curriculum demands, yet it all boils down to a grade in a class and a year at school. (Early-career male teacher)

Several participants shared a frustration that school administrators are more focussed on academic outcomes. Another Māori English teacher was critical of the covert values embedded in the liberal rhetoric of NCEA English assessment standards,

Where NCEA English standards are sitting now, it's got to where it's quite generic so that Māori text can come in ... I wish they would really acknowledge us in terms of Aotearoa that Māori literature, or Māori authors and writers and poets, do have a place in New Zealand English and I wish that they would have a

\footnotetext{
${ }^{21}$ As noted previously on p. 39, NCEA stands for National Certificate in Educational Achievement and it is the official secondary school qualification in New Zealand. NCEA is administered by a branch of the Ministry of Education called the New Zealand Qualifications Authority (NZQA). It is made up of three certificates at Levels 1,2 and 3 that are usually studied at secondary school in years 11,12 and 13.
} 
paper or exam that was around that. ... It's kind of like why don't you acknowledge these great writers and these great poets? Other curriculum areas do in art and and social sciences. How come in English it's not seen as a big deal? (Experienced female teacher)

Discriminatory assessment practices were identified by another participant in relation to the NCEA external examination. One participant recalled that in a previous year NCEA external markers criticised the use of "Butterflies" by Patricia Grace (1990) as a senior English text:

It got slammed by the examiners because they said, "it's too simple and too thin". There are so many layers of subtleties and nuances within, I think it's an absolutely brilliant piece of writing, but the examiners basically shat on it. . . I sat down and did my own little critique on it, and it just unpeeled so many layers of meaning and understanding for me, but because it's a Māori text it gets ripped to shreds and criticised like that and teachers get criticised when using it. Well it's not actually about the text itself it's actually about the lack of understanding within the teaching of it. . Now it's not taught because one wanky English examiner says no or criticises it, so instead of being a text that's celebrated, it's now a text that we avoid. (Experienced male teacher)

The ignorance of English heads of departments in relation to diagnostic and formative literacy testing through e-asTTle ${ }^{22}$ also positioned Māori students within a deficit framework,

If we look at Asttle testing, you know the attitudes are from the heads of department is that most of these year 9 and year 10 students haven't got above the national mean. They're all Māori and they all belong to the te reo bilingual class, so what are they not doing in their class? Oh, they are obviously speaking too much Māori and they are not really developing their English language skills. And so they're in a deficit attitude barrier. (Experienced female teacher)

\footnotetext{
${ }^{22}$ e-asTTle is an online assessment tool, endorsed by the Ministry of Education, developed to assess students' achievement and progress in reading, mathematics, and writing. It may be used in the junior school in secondary contexts. However, the e-asTTle test does not take account of students from other language backgrounds.
} 
In this section, participants identify that Pākehā educators interpret and implement assessment policy and processes in line with their own value systems and beliefs. Similar insights about cultural ignorance and prejudice were generated in relation to attempts to include Māori culture in teachers' professional practices, as is discussed below.

\section{- in teacher practice}

The term "tokenism" was used by many Māori English teachers to describe the inclusion of Māori culture within secondary schools. The participants were frustrated that their colleagues' ideas about inclusion were so vague that they amounted to very little. For example, one participant thought that if students were expected to learn more about te ao Māori then staff should too, "It's almost like we tell teachers to write the date on the board in Māori and it's almost - rolled eyes - is that all you can do?” (Experienced female teacher)

Several participants talked with a mixture of despair, resignation and cynicism that their colleagues resisted including even a minimal Māori perspective into their teaching practice. They were also aware of Pākehā colleagues who could not perform the school haka or waiata,

Despite being a languages teacher and despite the fact that culture was a massive part of what she taught, she didn't want a bar of the language or culture of this country. That is what it boiled down to, and she once again is a lovely lady and she doesn't see that attitude as racist. I was really having to pull her around to the fact that her attitude is the problem; no-one's expecting her to be fluent in Māori next week . . Just having to get it through to staff that this is not a hobby, this is a job and part of that job is inclusivity and whether they care about it or not, it is not anyone's problem, it's their job. (Mid-career female teacher)

Senior management teams also validated dismissive or apathetic attitudes. Some participants seemed bitter that management was reluctant to "make" staff do a professional development initiative to improve schooling for Māori students or would not enact consequences for teachers who did not meet appraisal or teacher registration requirements under the Treaty of Waitangi. School management decisions about the nature of cultural inclusion were also discussed, 
This is going to sound really bad, but we had one blind student, completely blind, and the whole school was fixed for her health and safety. Braille signs were put up everywhere, there's not a single permanent Māori language sign anywhere, so I find that a little bit strange... Obviously I think the government would've paid for [the braille signs], but it doesn't take much to put up Māori signs as well. (Mid-career female teacher)

The actions of people working in the Ministry of Education were also criticised in response to recently released education policy about cultural inclusion,

Sometimes I look at the state of our school and I think about English as such a core curriculum subject and sometimes I just feel like, why doesn't the Ministry of Education do more? Like it is all good well for them to say they would like "Māori to experience success as Māori". They have got these beautiful goals and Ka Hikitia is very valuable, but quite aspirational. I feel like there's a lot of smoke and mirrors going on, so they can tick a box. I just feel like, as someone on the front line, where are they? You know there was some talk about teachers having to know some Māori and I'm not seeing that. I'm not seeing any push to even to take an educated approach to these issues in schools. (Mid-career female teacher)

Some participants noticed that English department colleagues taught New Zealand texts in a perfunctory way to "meet policy requirements" (participant comment) or the needs of Māori students,

I sometimes cringe because I wonder whether or not people are doing texts because they believe that it's by a Māori person therefore it must be good for Māori people and Māori students. . . sometimes it's just that lip service, that it's playing to the idea of what everyone thinks we should be doing for Māori students; so in English the best thing we can possibly do is get them some Māori texts by Māori authors. (Early-career male teacher)

It would be great if my head of department had more knowledge of Māori text or if we consistently had more time as a department to explore texts that discover 
Māori themes ... It would be really cool if the school was maybe a little bit more active in seeking out those texts, rather than just resting on the trinity of Ihimaera, Grace and Tuwhare. ${ }^{23}$ (Early-career female teacher)

One reason that Pākehā English teachers were perceived to use New Zealand literature in a superficial way was because they lacked historical and cultural understanding of issues of race or the racial injustice that underpins the writing of seminal Māori authors,

What capacity do they have to teach the racism that existed within Aotearoa? ... I mean because you have to teach context and background etcetera in regards to any other text you know ... I'm able to do that for Shakespeare then why can't you do that Patricia Grace, or Witi Ihimaera? Because that would be the expectation of us as English teachers or English kaiako across the board.

(Experienced male teacher)

This participant wondered whether English teachers "question their deficits" regarding the ability to truly understand and teach New Zealand text. The token and indifferent attitudes of Pākehā colleagues towards Māori cultural inclusion was also observed by participants in relation to the treatment of Māori students and teachers and this is discussed further below.

\section{Limits to ethnic inclusion}

Māori English teachers also identified limits to the ethnic inclusion of Māori teachers and students by Pākehā educators, which included a range of negative and harmful assumptions about the schooling experiences of Māori.

\section{- towards Māori students}

In line with studies in the United States and Britain, the Māori English teachers involved with this study observed Pākehā colleagues problematising the cultural and ethnic backgrounds of Māori students, and rarely saw them as historically and culturally located beings (Dovemark, 2013; Graham \& Robinson, 2004; Kohli, 2009). Participants reported that deficit attitudes were covert and manifest as apathy towards Māori students, low expectations, careless pedagogical approaches and ethnic labelling practices.

\footnotetext{
${ }^{23}$ Witi Ihimaera (Te Aitanga-a-Mahaki), Patricia Grace (Ngāti Toa, Ngāti Raukawa, Te Āti Awa) and Hone Tuwhare (Ngāpuhi) are celebrated New Zealand authors of Māori descent.
} 
The Māori English teachers in this study observed that their Pākehā colleagues were often indifferent or unaware of the social barriers and hardships experienced by many Māori students and their families. One participant commented that Pākehā teachers "don't care if a boy's just got a hiding and come to school", and thought that Pākehā teachers hoped that Māori students would sort out their own "dysfunctional issues". Another criticised the apathy of English head of departments to lead by example,

[They] Can't believe that our people will ever, ever be achievers . . they don't want to be part of the decision making, they don't want to be part of creating the solution, they just want to, you know, stand on the periphery and judge . . . I was making it really clear to them saying no, you must take responsibility for every child ... there is no other destiny for them but greatness, however you people get in their way, you are the matā, you are the bullets that get in the way. (Experienced female teacher)

Other participants spoke about Māori students who were subjected to low academic expectations. Participants understood that it was harder for Māori students to achieve to their potential if teachers have a negative perception of them,

I had a wonderful year 13 student who did this speech on Māori achievement and her being Māori and it was clearly something that really upset her because she started crying. I suppose she felt that she was between these two worlds where she was either meant to be a teen mum or fail and actually people never push her any further than that. She's an excellent student but she said, 'I'm constantly told that you got a Merit that's good" but she's not a Merit student. (Mid-career female teacher)

The low academic and social expectations that this year 13 student objected to was similarly articulated by one experienced teacher participant. He observed that some of his Pākehā colleagues selected less challenging texts for Māori students to study so they might pass assessments, and believed that this approach to text choice reflected an inability to meaningfully engage students with "texts of substance", 
Rather than up-skilling themselves to be able to deliver those texts well to Māori, they default you know default to the most simple text that we can find, so that our Māori students pass NCEA. . . As the dumbing down continues to happen, I mean it's just repetitive or is compounded over the years. (Experienced male teacher)

A lack of deep understanding and cultural awareness were identified as reasons why teachers enacted culturally responsive pedagogies in superficial ways that are not helpful for Māori students,

Are we, as teachers and as departments, are we getting off lightly in terms of being able to just tick the boxes and say "yes, I know my students and yes, I've developed relationships" and like I say, that's really, really important, but is there a difference between knowing and understanding as well? Do you understand your students? Do you understand their history? Do you understand their background? Do you understand their stories? (Experienced male teacher)

Culture for me is made up of a lot more than just "I'm Māori" or "I'm Samoan" or "I'm Pākehā". I think cultural pedagogy needs to come from... you need to look at your class and see your kids as individuals. I know that's probably bad, but I'm not huge "Māori learn like this" or "Pākehā kids learn like this", I don't believe it's true. . . For professional development we're trying to raise Māori achievement and a lot of the research does say that. I cater to my kids in my class more so than I cater to "Māori" kids. But then it could be different if I had 30 Māori kids who identified as Māori and followed tradition and lived and breathed that part of their culture, it probably would be different, but I don't. This is what I've got. . . I don't think we should label our kids. (Early-career female teacher

The effects of a "tick the box" mentality and ethnic labelling practices were also associated with racial prejudice and discrimination. International studies find that school ethnic labelling processes homogenise or silence the cultural and ethnic diversity of minoritised students in school communities (Castagno, 2005; Milner, 2015; Pollock, 2004). Many of the Māori English teachers in this study similarly thought that Māori students are negatively judged because "they belong to this group of people who continue to be under the microscope" (participant comment). This sentiment was echoed by another participant who 
thought that identifying students based on ethnicity makes them "objects who need to be fixed in the eyes of whoever". He said,

[Māori students] Just want to be treated fairly . . . the same as everyone else . . what happens if we stop ticking boxes that said our students were Māori or not Māori or something else? How would that reflect how we treated them or how we approach them? (Early-career male teacher)

A participant who taught in a predominantly Māori, rural school also noticed that reporting on achievement through ethnicity oversimplified the overall academic performance of Māori students and cast the school in a favourable light,

When I went to the Board of Trustees with the Māori teacher to propose building a school marae - a marae $\overline{\mathrm{a}}$-kura - our argument was that we are losing Māori students, we have poor retention. We get a little bit sick of the statistics being given to us that show that Māori in year 13 of our school achieve quite well, because the reality is the ones who are left achieve quite well, but we lose a huge number of them along the way. And of the stand-downs and expulsions in our school, Māori are massively over-represented. (Mid-career female teacher)

Insights from Māori English teachers in this section shows how low expectations and perfunctory attitudes and discrimination towards the learning requirements Māori students arise from token notions of ethnic inclusion. The racialisation of Māori ethnicity is further explored through the working experiences of Māori English teachers in the following section.

\section{- towards Māori English teachers}

In "Colormute", Pollock (2004) argues that black students were both "hypervisible in the discourse of school problems" and "invisible" (p. 174) and ignored. Feedback from Māori English teachers in this study demonstrate a similar phenomenon, although arising from a settler-colonial education system built around token notions of inclusion, as opposed to segregation in the United States.

Many participants felt that they were positioned as cultural "experts" by the Pākehā school community and stated, “you're expected to know everything about Māori culture and 
language" and "anything Brown gets put in your basket". One Māori English teacher said she "didn't really have a choice" when told by school management that her successful English teaching job application also required that she also help out with Māori activities. Being perceived as an "expert" Māori also meant knowing everything about how New Zealand text is written and structured. However, one participant noted that "you're still a person looking at someone else's literary work".

Another problem was that a few participants witnessed Māori colleagues being thrust into positions where they were expected to be "experts" yet they had little Māori affiliation or knowledge,

But because they look Māori and they said that in their interview, they suddenly are the Treaty of Waitangi specialists and suddenly Māori student achievement rates should shoot up and literacy should be all done because we've got a brown face. (Mid-career female teacher)

Many participants identified that Māori teachers have greater workloads than non-Māori teachers in secondary schools, and a few said that the extra work that participants do to support Māori students and their colleagues is unacknowledged by staff. In line with research by Santoro and Reid (2006), some Māori English themselves described feeling burnt out, "knackered", or challenged by the demands of workplaces that "make you earn your money". The Te Reo Māori teacher was portrayed as "flat out", "over worked" and expected to look after all the Māori students. Greater workloads and cultural pressures were more often articulated by participants who were solitary or one of a few Māori staff in predominantly Pākehā schools,

The Te Reo Māori teacher was getting inundated with pastoral care of Māori students ... A lot of staff members can't distinguish between her and I. We don't look alike, but we're both the same age, teach at the marae and identify as Māori, so I get things in my pigeon hole for her all the time. I get people coming up saying "Oh, I need some help with such and such” and I go, “Oh, I don't actually teach them... you're probably thinking of [name of Te Reo Māori teacher]" and they go, "Oh, you're down there you can help me anyway. You're Māori, it's a Māori kid, it's your issue". (Early-career female teacher) 
Hypervisibility through expectations that Māori teachers attend to "Māori issues", is contrasted to that of participants whose cultural background was invisiblised and excluded from the institution. Fair-looking Māori English teacher participants said their Māori cultural perspective was often challenged because they look Pākehā. During an interview, one participant relayed numerous examples of white backlash and discrimination from other teachers because of her appearance,

I've always identified as Māori. I'm on the Māori electoral roll, I spoke a lot of Māori growing up, I spent a lot of time on the marae, my mother was chairperson of my marae for some years when I was younger. And so, my experience is probably a little bit unique in the respect that I am very fair. I mean I am naturally blonde and yet I am legitimately Māori. So yeah, that has made it really interesting because at times when I have tried to bring my Māori insights or my Māori perspective into different departments, I have sometimes been blocked by the sense of what would I know? And I have found that particularly interesting both at University and in High Schools, where I have seen people, who by their own admission speak no Māori whatsoever, have no affiliation, do not know what their tribe is and yet get promoted into Māori roles because they're brown. (Midcareer female teacher)

Despite feeling shunned by colleagues, the participant (who taught within her rohe) said that her ethnicity, cultural background, and status as Aunty ${ }^{24}$ was never questioned by Māori students because she was related to some of them. During an interview with another fairskinned participant, I asked whether divulging Māori heritage at school affected work relations,

You always get the, "Oh, but how much?" Does it matter how much?

[Researcher: Is that by teachers or kids?] I guess I get a bit of both, yeah kinda I'm used to it because for some reason quantity means something. I mean I'd probably say you know it's one of those things maybe I feel more Māori now

\footnotetext{
${ }^{24}$ It is common practice in most whānau, hapū and iwi, to refer to an older Māori relative as Aunty or Uncle. It is a term of respect and marker of shared whakapapa.
} 
than I did when I was younger but I'm technically still the same amount, if you try to put it down to that. (Early-career female teacher)

Many studies have highlighted that minoritised educators struggle to be accepted in majority white school spaces (Delpit, 1988; Frideres, 2015; Kidman et al., 2015; kumar, 2010; McNeil, 2011; Rodriguez, 2011). Colourism is the study of colour-based discrimination and how people of the same race experience advantages and disadvantages based on the shade of their skin tone and other visible features (Keith \& Monroe, 2016). While some literature notes that students with lighter skin are perceived to be more attractive or smarter (Hunter, 2004), the exclusion of fair-looking minoritised teachers from institutionally marginalised groups is not well documented.

In line with research by Young et al. (2010) who found that indigenous educators were not perceived to be "real" teachers, some brown-skinned Māori English teachers who came from Māori-medium teaching backgrounds or taught both Te Reo Māori and English at their workplace were challenged about their approach to the English curriculum. One participant thought she was subject to more criticisms about her practice from students and whānau because she is Māori, and two recounted how they had to prove their ability to teach English to the head of department. One said that she was moved from Te Reo Māori to the English department to teach "difficult" Māori and Pacific students and was treated "like a dumb Māori”,

The head of department came down on my case quite a lot at the beginning, "you haven't done this, you haven't done that". I'd say “well, I haven't but perhaps if you came to the class and showed me how I could get that done with my kids that would be cool". She couldn't show me how to do that, she said, "oh yes, I'm so busy with all of these things I won't get around to it" and I said "oh, okay". It never happened. One day she came down. . . We were having a huge debate about different ways of doing things and after that she said to me "that was a good lesson. Thank you for what you are doing for the kids". I never saw her again and I was under her for another three years or so. (Experienced female teacher) 
Another participant spoke about incorporating pedagogical approaches that were unfamiliar to her English department, which led to conflict with the head teacher,

It was more of an ESOL (English for Speakers of Other Languages) approach that [English department leadership] wanted me to take, where you're totally immersed in the English language, however, I would often not. I disagreed, especially to my kids who came from a kura kaupapa context. It was much easier to use te reo to explain the Pākehā context than to try to muddle my way through silent letters "Why Whaea? He aha ai? ${ }^{25}$ What the hell is a silent letter?" Basic dumb English rules that don't make any sense. I tried to use Māori context, often used te reo Māori to explain things and I'd get "no you need to just use English as well. No" ... When I explained to them what I was doing and how it was getting shifts [and] understanding with completing the work, just getting them to complete the work - or to read a book was cool. It eventually worked out. (Midcareer female teacher)

The professional capabilities of these two participants, who took the initiative to approach the English curriculum in a way that appeared to best engage Māori students, was questioned until the English heads observed their practice in action.

In this section of findings, Māori English teachers come up against walls of silencing based on an ethnic identification that simplifies the complex racial realities of a lived Māori existence. Māori students are subject to low expectations and assumptions about learning styles, while Māori teachers are branded as either experts, invisibilised or viewed as professionally incapable by colleagues. However, the following section reveals that Māori English teachers' racial critique is also limited because of an inability to conceptualise "a macro-level framework from which to analyse their experiences" (DiAngelo, 2012, p. 16).

\section{Limits to conceptualising racism}

In Chapter Two, I propose that minoritised people do not perceive the extent of structural racism because they are influenced by racial ideologies that tend to view racism as an individual problem (Castagno, 2008). This section of findings highlights contradictions in

\footnotetext{
${ }^{25}$ In schools, "Whaea" is a term of respect that is usually given by Māori students towards a Māori teacher. The literal translation of Whaea is Mother. The translation of "He aha ai" is "What is it?"
} 
participants' interviews, associated with how they sought to rationalise invisible structural racism in their everyday working lives.

Māori English teachers struggled to articulate the way that a homogenous ethnic "Māori" identity is problematic. For example, I asked two phase two participants, Maia and Anahera, what makes a text a "Māori text". I posed this question to the participants at a time when I was also struggling to understand what makes anything "Māori" in society,

For me a Māori text is something is something that Māori kids can relate to, I suppose. So, it doesn't even have to be... it doesn't have to be directed by Māori... I guess it's where the character... where they see themselves in the characters if they are Māori, I guess ... I guess anything New Zealand is still Māori but then you wouldn't say Katherine Mansfield is Māori. . . So, I think then, what is the Māori text then? I suppose it is because it's from a Māori perspective. (Anahera)

Um... so obviously I guess to me it would be written by a Māori author or had content was either relative to Māori people or... mmm, but I guess... like the one we looked at one Monday, I think Jacqueline Carter wrote it and she's only like... she's Irish, isn't she? I'm pretty sure she's from Waiheke Island but her ancestry is predominantly Irish and European. I think she whakapapas way back, which is interesting because a lot of that stuff that she's talking about is very Māori.

(Maia)

At the beginning of each excerpt, Aroha and Anahera advance the view that Māori ethnicity is subjective, but then they seem to naturalise a culturally homogenous Māori worldview at the end of their musings. In other interviews, some participants spoke about challenging the view that Māori are an ethnically or culturally homogenous population but attributed the idea of cultural homogeneity to individual perception, rather than a social construction. For example, one participant spoke about using New Zealand texts to challenge "some very stereotypical ideas that non-Māori students have about Māori students, and Māori students in the way they see themselves and Māori people". When another participant elaborated how she challenged stereotypes in class, she said, 
Sometimes, depending on the class, I will get them to come up, because there's a line in the poem that says, "someone said she doesn't look Māori” so I ask them, “Ok, put your hand up if you're Māori”. Lots of hands go up. [I say] "Right, come up here", and we've got a full spectrum from blonde blue eyes to really dark kids. I stand up there with them and say "Right, this is what Māori people look like" .. . The first time I taught that poem was for a Level 3 English paper. This kid got really emotional, "Yeah this poem is saying... you know it's like when you fellas say to me that I'm not Māori because I'm ginger, and it hurts my feelings, it pisses me off because I am". So that's been really interesting to hear how Māori kids connect with that particular poem. (Early-career female teacher)

To break from token and superficial notions of ethnic inclusion, participants focus on transforming individual prejudices in lieu of being unable to identify how the epistemological structures of schooling facilitate a silencing discourse. The effect of focussing on the individual is that this approach unwittingly consolidates the view that institutions are culturally and racially neutrality.

There were also fleeting moments in some interviews when Māori English teachers recognised that they could be personally implicated in promoting limited notions of cultural and ethnic inclusion, but struggled to find a meaningful alternative,

It's always surprised me at how ignorant New Zealand is about the Treaty. You know and it's... and the other thing that sort of... and I suppose it's because I haven't got a real handle on it, but you know how we had in all of our documents that we had to honour the Treaty of Waitangi doing whatever in our classrooms, well, what does that look like? I think people would be a lot more understanding and maybe forthcoming or less resentful if they knew how they could do that in the class because it's more than just giving Māori authors and Māori directors, it's more than that. It's more than that token myth and legends thing, you know. I just don't know how to take away or give better guidance to not being token. (Experienced female teacher)

In our top classes, our literature courses, there would be a smaller proportion of Māori in those classes because of whatever reason and I still haven't quite 
worked it out. . This is my first year in that job [head of department for English]. I was the assistant head last year and it's really been confronting for me. We are considering classes for next year and I'm saying, "Well, what about this kid? He can do work". "Yeah, but he hasn't done anything in year 10". Well, so I'm going to put him in the top class anyway. I think part of the problem is the streaming of our [Māori] students as well. The fact they get then put into those categories of being in the literacy class or in the lower ability class or whatever it is, and I believe they probably attach that to themselves as who they are. (Earlycareer male teacher)

In both excepts, participants articulate meritocratic solutions to barriers affecting Māori that absolve the institution of change. For example, at the end of the first discussion the solution to vague policy directives about the Treaty of Waitangi is to learn how to be a better teacher. In the second excerpt, the teacher thinks about working around streaming policies rather than adopting a different approach. Although the participants sense racial injustice, they cannot escape thinking and acting in ways that sustain the momentum of silencing because of an inability to articulate the underlying power structures that trouble their thinking. Leonardo (2015) refers to Mills when he claims that whites do not experience cognitive dissonance when overlooking the illogical underpinnings of a colourblind existence, because this mindset remains consistent with the Racial Contract. However, the findings throughout this first half of the chapter demonstrate that indigenous Māori English teachers do experience a form of cognitive dissonance. They move back and forth between pressures imposed by the dominant racial discourse and the reality of their own lived experiences, until they arrive at a position in line with silencing and the view that no conflict really exists (Britannica, 2018).

In conclusion, the experiences of Māori English teachers in this section of findings show that colourmuteness, or the refusal to engage with the reality of racialising behaviour at the same time as erasing from the conversation difficult questions about culture and ethnicity, legitimises interpersonal and individual racism. Although Māori English teachers identify ways in which racism is perpetuated through individual and interpersonal interactions, participants are trapped within an institutional existence that is determined by a partial, limited and white view of the world (Alcoff, 2014; Leonardo, 2014). In this way, structural blindness leads to a "sinking" into the institutional culture of whiteness (Ahmed, 2007), as discussed below. 


\section{Sinking into the whiteness of the institution}

The workshop is full of Pākehā secondary English teachers and the tension is palpable. My fellow-presenter explains that ten years ago she used "Butterflies" with a group of pre-service English teachers who did not think that the story was about racism. We talk a little bit about how the historical and cultural context of the story affects how the ideas are understood. The English teachers respond by saying,

"The preservice teachers' reactions could be quite different now"

"The teacher thought the butterflies were monarch butterflies, not cabbage-eating white butterflies. The teacher is not racist because they saw the situation differently to the girl"

"How do we know the neighbour is Pākehā? It doesn't say that in the story"

(Research journal, 2015)

In line with an ideology of colourblindness, the findings reveal that Māori English teachers generally perceive that the culture and structures of state school institutions are racially neutral, so are heavily influenced by meritocracy (Doane \& Bonilla-Silva, 2003; Giroux, 2003). The first group of findings in this section show how participants' behaviours and underlying attitudes and beliefs about education support whiteness to flow through the institution. The second group of findings reveal that participants' curriculum and pedagogical are also conducive to perpetuating whiteness

\section{Flowing with whiteness}

This findings in this section show that participants sought to maintain a positive workplace environment. In so doing, they focussed on being "good" teachers through implementing teaching approaches to help Māori students attain schooling success. As a result, Māori English teachers were aligned to a meritocratic discourse that attributed Māori students' success or failure in English to a form of individual deficit.

\section{Maintaining the positive culture}

Despite demographic and contextual variations between workplaces, most Māori English teachers in this study spoke optimistically about their school and the culture it sought to establish around learning and community relationships. Positive aspects of participants' workplaces included: good relationships with students, a positive teaching and learning environment, constructive connections between the school and the wider school community 
(including kaumātua, iwi, hapū and whānau), a focus on literacy, using good teaching practices, professional development initiatives, and small class sizes. One participant said a good thing about teaching in a school with low literacy levels is that teachers can see visible shifts in learning. Many participants articulated a perception that school institutions can be helpful and transformative places. For example,

English at a very young age for me was definitely a powerful subject because it determined whether you were going to be part of the society that was going to make it or the society that didn't make it and that determined whether you were going to be a blue collar or white collar worker ... That's the reason I came home ... and continue to work here and continue to teach English is because I've always wanted to ensure that our people access equitable outcomes. (Experienced female teacher)

In line with a benign view of school institutions, many participants spoke about an ethic of support and care between members of the school community. Colleagial support could come from a number of places including teacher aides, Māori colleagues, a "pedagogical friend" or a "go to" person to question or debate iwi history. Participants also willingly gave support to other staff members, particularly the Te Reo Māori teacher,

I'm going after this to get food for the Pōwhiri tomorrow. I mean I don't teach te reo Māori, I'm not involved with welcoming new staff, but it has to be done, and I don't want the Te Reo teachers to get landed with all the jobs so we all sort of pick up what we can and do what we can. (Early-career teacher, female)

The ability to support colleagues and contribute to the caring culture of the institution was also evidenced through participants who were given larger numbers of Māori and Pacific students in their classes or were moved from Te Reo Māori to the English department. On one hand, these decisions are based on the belief that Māori English teachers may act as a "bridge" between the school and indigenous concerns (Santoro \& Reid, 2006). On the other, Māori teachers may also be used to amend an institutional failing or to mask Pākehā indifference. One participant described herself as a "tool" to fix Māori literacy, while another felt she was better able to connect with disengaged Māori learners, 
I'm mainly qualified for years 7 to 11 for English. . . I was essentially employed as a Te Reo teacher but once they figured out I had other things in my pocket, and those things only came up because there were no decent Māori teachers in Science, in Sexual Health. Māori kids were getting kicked out Pākehā classes all the time, so I didn't want them to miss out, which is why they put me in English too, because they were getting kicked out all the time. Not all of them, but a fair bunch. (Experienced female teacher)

Nevertheless, findings show that Māori English teachers seemed genuinely willing to contribute and do their part for the team. This attitude, coupled with the view that the institution is helpful and positive, was also demonstrated when participants spoke about working alongside English teaching colleagues and within the bounds of department policy. Participants appreciated sharing resources, discussing the teaching of texts and literacy strategies, co-constructing reading lists for year levels and team teaching to raise literacy standards. Some participants supported colleagues to develop understandings about Māori perspectives, although there were limits to what Pākehā English teachers would digest, as discussed in previous findings sections,

I find that people, now in the department will come to me and ask, "Do you know any texts that fit this?" It's great to be involved in those conversations but it would be great if my head of department had more knowledge of Māori text, or if we consistently had more time as a department to explore texts that discover Māori themes. (Early-career female teacher)

Another reason that Māori English teachers generally looked favourably on the culture of their workplace and the education system was because personal or whānau experiences had been positive. For example,

There's an expectation to go to university especially on my mother's side; all of her siblings are graduates and doctors and stuff like that. So, it's not an expectation but a kind of eventually they [younger generation] go down that pathway. It's [my child's] first year of varsity. . . We don't force them, but they just find out that that's where they want to go. (Mid-career female teacher) 
I was quite conversant in both languages at quite a young age and when I went to school in an educational setting, I couldn't understand why my relatives and why my peers struggled with te reo Pākehā. That was the shaping of the pathway of education that I was going to take, which is I wanted to be a teacher to āwhina my own people in the subject area of English. (Experienced female teacher)

The findings in this section show that Māori English teachers contribute to a positive school culture in many ways. For many participants, the compulsion to be constructive and supportive arises from their own personal experiences of schooling success or the belief that schools can be liberal, open, and inclusive places. The perception that school institutions are culturally and racially neutral is advanced by policies that focus on culture and ethnicity which directs educators towards a view of schooling success or failure that is attributed to the decisions and actions of individuals. Some implications of meritocratic thinking are explored in the following sections.

\section{Focussing on good teaching}

Māori English teachers had diverse views about the implementation of the New Zealand English curriculum. Their feedback suggests they felt the curriculum was flexible and could accommodate a wide range of epistemological approaches. The Ministry of Education (2007) appears to advance the notion of an open and permissive English curriculum, evident through statements that teachers may use "professional judgement" when assessing levels of student understanding to inform how the curriculum may be implemented (p. 40). Examples of different approaches to the English curriculum are outlined below,

But then I think that's why we've got a much bigger push with literacy now, because literacy is now being recognised as a problem and I think there's a fairly recent John Hattie "Listener" article about children who are spoken to, and their vocabulary is about 10 times greater than those are not spoken to. (Experienced female teacher)

You see yourself as an English teacher but then you also see yourself as what you're bringing from your kind of experiences into a classroom. English gives you the scope to be able to do what you want to do, if that's where you want to go. That's what I love about English, you can reinvent stuff and do what you 
want. Quite often I think the best things in English is when there is no set learning. I don't think we do that enough. . . To be driven by what interests students and what they're passionate about and what we're passionate about. (Experienced female teacher)

I don't want our kids going out there into the world and feeling like because they've been in a Māori educational environment that they've missed out, or that they haven't had that experience. I suppose that's part of the reason why I've been so passionate about Shakespeare, because it is so universal that I want them to be able to have those understandings no matter what environment that they're in. To not go out there in the end feeling dumb because they don't know what their Pākehā counterparts are talking about. (Experienced male teacher)

Alongside variable reasons for approaching the English curriculum, were shared motivations for teaching English. Many Māori English teachers were enthusiastic about teaching literature and wanted to share their love of the subject with students. The teachers thought it was important to teach with passion, to be positive and feel like they were making a difference to student learning. Several participants said they enjoyed seeing students "take a book for what it is" or "grasp a book and want to read more".

Participants expressed a strong belief that good teaching practice significantly affects schooling outcomes. They were very committed to developing curriculum knowledge and pedagogical approaches, so they could "make a difference" (participant comment) in the classroom. To be a good teacher, participants felt it was important to be a reflective practitioner and adapt teaching practice accordingly,

My unit plans, yup they're always very brief because you have no idea where anything is going, and you'd rather go with it than go, oh no, need to come back here and then they don't engage with it. (Early-career female teacher)

In terms of my teaching platform some of that wasn't comfortable with some of those kids. . . So you know I can see the differences and within that I had to change my how I teach. (Mid-career female teacher) 
As a teacher, we should be the ones who try to make sure that we alter our practice to make sure people learn. (Experienced female teacher)

However, the tension between being student-centred and relaxed, or pushing the students towards academic success appeared to be a fine balancing act,

I'm about the formative assessment but in the end, you have no choice, you know $\mathrm{ERO}^{26}$ says we have to do this, NCEA says we have to do this, it's trying to manage the good teaching in between that actually is about education not about assessment. (Experienced teacher, female)

Many Māori English teachers in this study demonstrated a desire to provide "the kinds of teaching approaches that consistently have a positive impact on student learning" (Ministry of Education, 2007, p. 34), however, there were moments during some interviews - such as those presented in the section discussing limitations to conceptualising racism - when participants seemed to intuitively understand other educational forces made it difficult to balance "good teaching" with "education not assessment".

Reflective interludes such as these were short-lived. Flowing with whiteness and the perception that schools are helpful and culturally neutral meant that participants sought to improve their own professional practice to better students' schooling experiences. While participants genuinely sought to counter systemic racial bias through the teaching and learning process, the silencing discourse underpinning the Ministry of Education framework of cultural and ethnic inclusion meant that Māori English teachers unwittingly positioned indigenous students as cultural vessels, waiting to be filled.

\section{Supporting a cultural connection}

Meritocratic thinking, which emphasises the role that teachers play in the schooling success of students, also informed how Māori English teachers perceived Māori student success and failure in English. Gebhard (2017) finds that non-indigenous teachers thought the "right kind" of indigenous student, with a particular kind of cultural background, could engage positively with schooling. This same belief was evident among Māori English teachers who

\footnotetext{
${ }^{26}$ ERO stands for the Education Review Office. ERO is a division of the Ministry of Education tasked with evaluating and reporting on the education and care of students in state schools.
} 
indicated that successful Māori students are those who have a strong cultural background and/or some te reo Māori proficiency,

I find that the kids who have a really strong foundation in the Māori identity, they're the ones who take off and succeed really well in school ... Often when the kids have that sort of grounding, they probably got quite a strong family backing, that probably helps quite a lot. (Mid-career male teacher)

So even the Māori kids didn't respond to Māori writers . . . Some were ok with it, but those were the ones that were culturally located in themselves like they knew who they were, they were ok with that. (Mid-career female teacher)

The girls who come with te reo, they're through the system by year 11 . They have that real advantage and they're really successful. (Experienced teacher, female)

A lot of the Māori students are a lot more comfortable speaking in front of the class, but it could be also the type of students they are, that have come from kōhanga, where they're fluent Māori and that is their primary kind of way of communicating, is that art of language. So yes, I think what I have noticed though is Māori students tend to be able to produce better work when they can relate it to their own environment or their own lifestyle. (Mid-career female teacher)

Underpinning the notion of an "ideal” Māori learner who has a strong Māori cultural identity, is the naturalisation of a pan-Māori ethnic identity. A homogenous Māori identity was usually asserted at the beginning of participant interviews, after participants relayed their whakapapa. For example,

[I'm] Just plain old Māori and getting older every day and just enjoying being Māori. (Experienced female teacher)

It's not just about being Māori but about being strong in Māori and being able to interact with other people well. (Mid-career female teacher) 
One cultural aspect that participants associated with a Māori identity was a close relationship with whānau. Most participants spoke positively about their upbringings and some said that whānau support helped them to view te ao Māori as a source of strength. The second attribute associated with a strong cultural identity was the ability to speak te reo Māori. A few participants were brought up steeped in te reo Māori and English, while others learned the reo at a secondary school, university, or wānanga. Many participants spoke about the difficulties of learning te reo and moving past personal or social barriers that had earlier prevented them from wanting to engage with Māori language. For example,

I did kapa haka for a while and my dad tried to teach me te reo because even though Dad's Pākehā he's fluent in Māori, so my parents are fluent, but it wasn't what I wanted. . . It's coming back into teaching and having your own children that you actually start to think about what's important. (Experienced female teacher)

As you get older you kind of want to find out those parts of yourself and I mean it's definitely something I still want to find out a bit more. (Early-career female teacher)

The importance of moving towards a stronger sense of cultural identity was one reason Māori English teachers thought that cultural knowledge was an important aspect of being an ideal Māori learner. Another quality that supported Māori student achievement in English was the ability to function successfully in the "Māori" and "Pākehā" worlds,

The ability to walk in two worlds with students can be a strength and a challenge. (Experienced female teacher)

You know if you can speak te reo and you can speak English and get your literacy in both of them you can write your own ticket. (Experienced female teacher)

English has been quite important for us, for our tamariki. . That they be strong on both sides, English and Māori. To be successful in the world they need to be successful in both. (Mid-career female teacher) 
I guess we can walk in both worlds because we can teach Shakespeare and we can teach Witi Ihimaera and feel comfortable with both of them. . I think we're really lucky to be able to be Māori and teach English in this country, because we have the best of both worlds really. (Experienced female teacher)

Relating an ideal Māori learner identity with the ability to walk in "two worlds", speak te reo Māori or demonstrate other cultural characteristics like kapa haka and tikanga, alongside having strong connections with whānau, informed how Māori English teachers rationalised Māori student failure at school, as is discussed below.

\section{Conceptualising Māori student deficit}

In the literature, meritocracy is associated with the view that inequitable education outcomes may be attributed to individual deficit (Castagno, 2008; Gillborn, 2005). In the same vein, Māori school failure was attributed to educational or cultural deficits associated with literacy difficulties, parental backgrounds or ideal Māori learner identities.

In line with the view that Māori students who are culturally connected operate from a position of strength, some participants perceived that students who were not culturally connected were disadvantaged. Although several Māori English teachers spoke about their own struggles growing up as an "in-between", "different” or "urban” Māori, or "straddling that border of being Māori and Pākehā but not being Māori and Pākehā enough”, they also at times, associated lack of cultural connectedness with a sense of deficit. For example,

In the city they [Māori children] didn’t really have an understanding of their cultural roots. So, they were Māori but didn't know which iwi, haven't been on a marae ever because they've been brought up in the city because that's where mahi was. So, you had that type and then you had the type you knew where they were from, been back to the marae but still were in the city so they were kind of torn between the two. Then out in the country you had those who only knew of the farming life, so really you had to work where the kids were at, rather than where I hoped to show them where they were at, or what they could do. (Midcareer female teacher) 
The benefits of Māori students who are educated in a kura kaupapa environment were described by a few participants. One participant thought that the cultural support offered by kura kaupapa was integral to schooling success. When her own son had asked to move from kura kaupapa to a mainstream environment, she replied,

Oh yeah, ka pai. I'll send you to [name of mainstream school] but you'll be at the back of the classroom son, when they mispronounce your name. You'll get huffy every day, you know, that's what you've got to expect; when they don't ask you for your homework because they think you haven't done it, anyway; when they make you do the karakia because you're the Māori fella in the class. Then you wonder why you are starting to feel stink about yourself. Your confidence is super, super low and you're sick of being in the stink kapa haka team and you're at the back the class. Son let me know when you want to go back to [name of the kura kaupapa] to feel strong about yourself. (Mid-career female teacher)

In contrast, Māori students from low socio-economic backgrounds were reported as having more social issues or struggled to make it to year 13, while parents and students who had heavy work commitments found it difficult to engage positively with school. One participant said,

Not one [parent] doesn't care about their kid's future, they just don't know what it looks like. You know or they're working so hard. I mean my biggest thing over here is that parents are not with their kids because they work and if they're not working they're hunting for work and those that are not then sometimes they're whatever's happening there is not great but they're still trying to provide you know. . . Our value systems might be a little bit different, [some parents] might not know how to articulate or you know we have that glass ceiling, they might not have seen what's past that. . . and not that they didn't want to break through it they just didn't know how to get it to crack. (Experienced female teacher)

Another reason given by participants to explain academically struggling Māori students was dysfunctional households, 
You might never ever see their families, or if grandparents are really struggling with their naughty children and they send them off to us. . . Sometimes people send their children to [name of school] because they are worried about gang influences within their own schools. (Experienced female teacher)

It is just that whole building that self-efficacy. I know I work a lot on that. You know, it is almost like these kids have had this medicine, this drug where they've been told that they're no good at it or whether that's intrinsically or extrinsically, you know, from whānau and they have just believed that "nah, I am koretake at this" and so getting into the school, they think that. (Experienced female teacher)

The idea that Māori students needed to be culturally supported to overcome hardship was explicitly articulated by one participant,

Being able to analyse you know text and situations as well and try and see the positive and not see the negative of why and why is it always us? Why don't I have kai? Why can't I understand this? Why is my dad in jail? blah blah blah . . . Why are they always the ones on detention? Why are they always distracting? dah dah dah. So getting the whānau working right together so they work well with the other community. Its also giving responsibility to our whānau kids to interact with their school community as well. So making our kids teach the school haka to the rest of the school. Really empowering our kids. Make them grow some really staunch and great relationships with the Pākehā kids, especially school leaders and things, and actually seeing that they have a place in their kura, even if it is a Pākehā kura. (Mid-career female teacher)

Most participants discussed the consequences of educational debt or deficit in relation to Māori students who struggle in English. Some spoke of the English curriculum as confusing and challenging, while those working in rural and predominately Māori school settings said that Māori students lacked confidence, feared English or thought they were dumb. Declining literacy standards were a significant talking point. Statements that students don't read, at home or at school, were common, 
I'm always blaming somebody else, blaming the kids etcetera etcetera. But yeah, you know I'm certainly open to trying new things, but literacy strategies I completely totally believe in, well because I do teach in a school with no literacy . . . But this year I had an achievement standards course, and I discovered I had the whole year level, which means that I've had to go with the achievement standard course but keep pushing in unit standards because they haven't been able to cope, they don't get the credits, which means they switch off. (Experienced female teacher)

I'm not saying the deficit thing but what I'm saying is that our kids don't know how to read anymore. We have lost or along the way the art, the actual art of reading. I think has been lost, so that they can't read and see and hear. They just it's just words on a page to them ... Even as year 13s, we need to read so they can hear the tone, they can hear the nuances, they can hear all of that. I think that that's where our biggest deficit is at the moment, is in our kids' ability to read for pleasure and to read for stimulation, and to read for imagination but I think that's the missing link, is that they're missing the visualisation that goes along with the words.

(Experienced male teacher)

While these participants talk about genuine anxieties and difficulties associated with English skill development, any negative effects created by the culture and structures of school institutions are silenced. In this regard, struggling Māori students are positioned as "outsiders" from those who can flow with whiteness and only see the positive, helpful, and permissive role of the institution. The liberatory role of the institution to counter racial injustice was expressed by one participant working in a Māori-medium setting,

It's just like you know in the real world you won't be treated how you are here. Like they forget, they just don't realise that they're protected here because once they go out into the real world, you are going to be seen as a Māori, you are going to have these stereotypes that come with you, you're probably going to be picked on, so try and tell them that as much as possible. Yeah and tell them the only way you're probably not going to be seen like that is if you smash NCEA. 
Despite viewing the institution as the site to build the perceived skills and cultural attributes required for schooling success, a few participants spoke about the disparity between Māori and Pākehā student academic achievement and the struggle to pin-point where the problem lay.

Our Māori achieve amazingly. Still not quite the same [as Pākehā students] but on a par. (Experienced female teacher)

I haven't been at a kura yet where we go over and beyond what everybody else does. And what I'm struggling with is we still don't get the results that mainstream teachers do so there's something missing that you know. Because our kids have the ability. I'm just not sure what's missing. (Mid-career female teacher)

This section shows that participants perceive that Māori students struggle at school and the English subject because of cultural or educational deficits. The following group of findings reveal that Māori English teachers respond to this perceived deficit through curriculum and pedagogical approaches that attribute academic success to meritocracy and individual effort. Colourblindness is therefore central to the way that those in settler-colonial education systems are directed away from the racially biased culture and structures of schooling, towards state-endorsed solutions that blame indigenous peoples for their own subjugation.

\section{Teaching to whiteness}

The following findings relate to Māori English teachers' perceptions of their classroom practice in relation to the study of New Zealand literature. Pedagogical approaches underpinned by meritocracy and colourblindness focus on developing the cultural and personal deficits of Māori learners, through: building positive and caring relationships, integrating a cultural perspective, building cross-cultural understandings and developing literacy skills.

\section{Building positive and caring relationships}

Most participants in phase one spoke about nurturing a supportive learning environment through pedagogical strategies designed to boost the self-esteem of learners or create positive interpersonal relations between the teacher and students. At the centre of Māori English 
teachers' perceptions of building positive relationships is "caring about the person in front of you" (participant comment).

Strategies for building positive interpersonal relationships between participants and Māori students varied. Having a relaxed or open and honest demeanour, an "upfront" approach and "talking and laughing with the kids and getting them to buy in" were perceived to support learning and built respect. Humour was also important, and participants described being "jokey and relaxed in a way that Māori students seem to appreciate", being "quite cheeky" and using humour "as a huge part to teach from ... that comes from being Māori".

Group work was viewed as a pedagogical strategy that could deepen students' understanding about the studied text, but also provide another layer of support if groups were strategically put together according to students' academic or social needs,

As much as possible getting the peer work happening because there was a range of English abilities. For instance, one of my boys was not very good English, talked constantly. I put him with my bright girl who is a bit of... real growly growly. She'd say, "Piripi, shut up eow"27. He'd listen because she was quite fair as well and so I think she kind of freaked him out a bit. [I] check what the relationships are in my classroom, which I know doesn't always happen in a Pākehā class room, you just get paired up with anybody, but in the Māori context you can't just pair up anybody or groups. (Mid-career female teacher)

A few participants felt it was important to be calm and maintain a low-key demeanour, particularly when handling poor classroom behaviour,

Māori students seem to be a lot more, generally speaking a lot more sort of... more lively in class and school can quite often force people to be really quiet and so sort of allowing the Māori students who are in that, quite exuberant to sort of let them get away a little bit . . . I mean you can't really yell at a kid anyway, but if you yell or raise your voice to a Māori student, they seem to either take the longest to the restore that relationship. Which is good for like practice overall, so

27 "Eow" is a term that predominantly Māori youth use to emphasise a point when speaking with friends. 
you sort of know that when you're talking, or I would normally bring a student outside and talk to them quietly and just sort of explain the situation, which is quite good just for general practice with all kids. (Mid-career male teacher)

The use of relational pedagogies often assumed that Māori students need to be supported to overcome a schooling difficulty, rather than vice versa. For example, a few participants through it was important to keep Māori students in class or at school until year 13, while one teacher working in a rural community with substantial poverty was determined to show Māori students that they were meaningful by regularly bringing food and remaining at school outside school hours,

They see me at the marae and so they have that image in their head that I exist out of school, that I am a person, not just a teacher. But I do think it is things that I do, so it is that sense of really showing that care. Today, I stayed at school till five with them, so those who needed extra help could stay behind and get extra help and I made sure that there was afternoon tea that my husband had made. . I think it is that knowing that your cultural background allows them to relate to you better. (Mid-career female teacher)

This same participant also spoke about how the cultural environment of the school was unwelcoming for the Māori students at her school,

But I also I think just a relational aspect in the classroom, it's that understanding, just from having grown up on the marae myself, I think there is a really, the issues that our Māori kids are having is that they come to school and it's such a foreign environment to them, because they have grown up on the marae and at the marae, they have the sense that I had as a child, which is that every adult there cares about them and every adult there has a vested interest in their well-being and every adult there will tell them off if they have to and that sense of being meaningful to the adults around them. Whereas they come into a school, it's a very Eurocentric structure and they don't feel that every teacher that they deal with really cares about them, you know. They just don't have that sense, that sense of place and belonging that they have on a marae. (Mid-career female teacher) 
In critiquing the culture of the school, the participants suggest that the indifferent and uncaring attitudes of teachers present the main challenge to Māori students. The belief in caring and positive relationships as a significant means for improving Māori students' schooling experience was also demonstrated was through the idea that pedagogical approaches perceived to support Māori students would benefit all students. This view was shared among several participants from demographically different teaching contexts,

It's about who are the . . kids we're trying to help here or who needs to hear this more? Who are the most disadvantaged kids in our system? Who's our achievement supposed to be focussed on at the moment, Māori. So, what works for Māori works for everyone and that's the same with the literature. (Experienced female teacher)

I think overall the teaching approaches that work for Pākehā students, will work for Māori if you are using sort ako concepts for your approach in the first place and you are really relational with the students. I think probably a better way of putting that is, if your general mindset is in tune with the things that work for Māori students, then they also work for European students in which case you don't notice the distinction. (Mid-career female teacher)

These comments suggest that New Zealand schools would be more equitable if certain pedagogical actions aimed at overcoming psychological barriers were standard practice. This section of findings focusses on pedagogies that can build positive interpersonal relations and self-esteem. The following section similarly shows how a focus on the cultural background of students is informed by a colourblind view of schooling.

\section{Integrating a cultural perspective}

In line with Māori English teachers' perceptions that a culturally-connected Māori student is better positioned to attain academic success, many participants looked favourably on the way that mātauranga Māori and tikanga could be brought into lessons using New Zealand literature. For many participants, the inclusion of Māori content could support Māori 
students to build a connection with the text, which would consequently boost their engagement in English,

A lot of the time it's them finding their own kind of experiences about their own positives, especially around the marae or whānau gatherings and things like that. (Mid-career female teacher)

I think that I do have the strength of being able to pull Māori students into being interested in the topics, just because of being able to make cultural connections with different concepts. For example, if we were describing a character sometimes you might explain them in the context of mana rather than power. Obviously, mana is different, and it is a concept that they are very familiar and comfortable with. That gives them a greater insight into a character than what [usual] terminology might have done. (Mid-career female teacher)

I think we've had a real push towards using Māori authors because our kids are, well, we've got the huge percentage we have, and we think it's really important that they can see themselves in the literature. (Experienced female teacher)

A few participants spoke about a new school initiative focussing on a place-based, localised approach to learning that would include more mātauranga Māori in the curriculum. One participant said that re-writing their curriculum to reflect the tikanga and history of the awa would allow students to "see different things from different perspectives right in our own backyard",

We're re-writing some of the history curriculum so that it is really contextualised to [name of area]. So, they have to do a battle from two perspectives and they're doing one of the battles on the river. The Science department have looked at the use of the river, yeah, it's really exciting. We're building in a whole lot of themes that fit around our awa. (Experienced female teacher)

Another participant said her school was working with an outside education provider to create place-based education resources that incorporated iwi place names, stories or events centred on local geography, tikanga and oral traditions. It was hoped that students would relate this 
knowledge to their own worlds, by asking "what does that mean for me as a modern teenager and from [name of community]?"

The ability to build a connection between the student's culture (their personal experiences and prior knowledge) and the learning or text was perceived by many participants to be an important pedagogical approach. For example,

I made sure that I walked in their world. That's really powerful I think. See things through their eyes if you can. I don't understand where you are coming from but I respect where you are coming from. (Experienced female teacher)

I think it's more important to be driven by what interests and what they're passionate about and what we're passionate about. You have to, not be brave but be willing actually to know that if you go off you'll get back to where you need to be for the kids, in assessment. That might drive younger teachers more than it drives me, you end up seeing what's important and what are the skills and dispositions you want these girls to go out into the world with, really. (Experienced female teacher)

Once you get them to talk about their worlds they're fine, they're all ok. It's just we have to accept that they're gonna write things that aren't going to be our world and we just have to let that go. The other thing too is that students have to have that relatability to their world no matter what text it is. (Mid-career female teacher)

A few participants thought that this pedagogical approach was particularly important for Māori students,

What I have noticed though is Māori students tend to be able to produce better work when they can relate it to their own environment or their own lifestyle. So, if it's something quite distant from them, they don't necessarily have that level of engagement or... But if they can pull aspects out like when we do post colonialism, and that sense of injustice, or that sense of not fitting, or that sense of being the minority, they relate to that quite well. Or when we discuss identity or 
family. If they can pull on their experiences, I think they seem to do a lot better in their assessments. (Mid-career female teacher)

Supporting Māori students' English engagement by drawing on curriculum and pedagogical approaches that consider a cultural perspective resonates with research about a group of nonindigenous teachers who believed that racism is countered through incorporating forms of indigenous cultural knowledge into the curriculum (Gebhard, 2017). This additive approach reinforces an uncritical view of the culture of the institution and wider society. The findings in the following section consider classroom interactions that manage interpersonal relations and tensions between Māori and Pākehā students.

\section{Building cross-cultural understandings}

One significant finding that emerged from phase one was that most of the nineteen Māori English teachers conceptualised the idea of "critical literacy" as the ability to see the world differently by acknowledging different perspectives, points of view, or lenses. Many participants perceived that practicing critical literacy involved using constructionist pedagogies and intertexual analysis to "challenge my kids to think differently about ideas they may not have experienced", develop different "perspectives on life", or "getting [students] to respect and understand each other and their differences". This approach to critical literacy is congruent with claims that culturally responsive pedagogy is enacted in trivial ways because power relations are ignored (Castagno \& Brayboy, 2008; MacDonald \& Reynolds, 2017; Sleeter, 2012).

In line with taking a critical approach to teaching English, some participants sought to educate Māori about how to get along better with Pākehā. For example, one participant took his Māori students off school grounds, so they could develop an appreciation for Pākehā values,

I took a group of my year $13 \mathrm{~s}$ to perform at Sheila $\mathrm{Winn}^{28}$ this year. They did a scene from Othello and so they really got into it. It was interesting because when they were watching the girls from [another secondary school] and they were absolutely manic running around the place preparing. Our kids were all pretty

\footnotetext{
28 The Sheila Winn Shakespeare festival is held annually and is a competition in which groups of students from New Zealand secondary schools perform a scene from a Shakespearian play.
} 
chilled, I mean they just wore their basketball singlets and we set it within a basketball setting. But for them they saw and they were going "This is their Polyfest". Polyfest up here is like "the thing"; a kapa haka competition for all the secondary schools in the region. So they just noticed that whole comparative in terms of the culture of the Sheila Winn festival for these elite schools, in which they really excel, in comparison to us and our participation in Polyfest, where we really excel. (Experienced male teacher)

The view that Māori students would benefit from being exposed to a Pākehā world was also articulated by a mid-career participant from a mainstream school. She observed that Māori students “don't interact with non-Māori very well”, so reminded students that they do have positive relationships with some Pākehā and they have some "Pākehā [ethnic] background back there". The participant understood that Māori face poverty, deficit thinking and literacy issues but felt that the students could do more than sit back and blame Pākehā,

I'm about getting off the blame waka now, take control of your own shit and join in and do things. If you are failing, it's okay. Yeah, this Treaty of Waitangi and colonisation has got some kind of play in there but now it's your turn. Pick up the waka, pick up the paddle and get into it. (Mid-career female teacher)

Alternatively, building cross-cultural understandings for Pākehā students to develop empathy and understanding of a Māori worldview was also a priority for participants. Māori English teachers working with predominantly Pākehā students understood that they had to approach racial discussions sensitively to break through prejudice and resistance to learning about things Māori. Participants said you can't force your perspective on students, so the challenge was "trying to make Māori texts non-threatening and relevant", "figuring ways to open their mind more", or showing students that just because "something is different it isn't wrong in a way they could understand". A few participants said they appreciated hearing racist or negative comments from Pākehā students because it provided the opportunity for a more authentic learning experience,

I just loved it when they were like that because then you could explore it and allow them actually see where their gut feeling was coming from. Was it theirs? And if it was they better own it. I'm a bit of a radical teacher. I'd say, "yeah that 
cool to have those feelings but let's explore those, and let's have a look at where they really come from. Where have you heard that kōrerorero? Is that your kōrerorero? Is that you, or is that something that you've heard?" So, I'm sounding more like a Social Studies teacher. (Mid-career female teacher)

Another participant adopted a strategic approach when teaching Māori content or tikanga to Pākehā youth,

Like I say to them, my job is to challenge them and to educate them in terms of how does Māori fit in to Aotearoa and what's our responsibility as New Zealanders, to maintain a language and a culture? So, if you lose a language then the culture's going to die not long after. So, do we just become people who do the haka and then do it really poorly? Those are the things that I challenge some of our more disbelieving students with. But you know in all honesty that challenge probably doesn't happen until Term 3. Because I butter them up with the nicer side of Māori culture in terms of whanangatanga, manaakitanga, aroha. You know, kanohi ki te kanohi, communicating, having the opportunity to express yourself in an environment that's safe and, you know, without repercussions. (Mid-career female teacher)

The feeling that Māori teachers need to take a measured and cautious tone when discussing racial issues with Pākehā students was articulated by many participants who taught in majority-Pākehā contexts. These participants spoke about regulating the tone of their voice so that it was "temperate", didn't appear "biased" or the ideas were presented "neutrally for non-Māori’. For example, two participants said,

I think one of the disadvantages is that sometimes it might appear as a bias when I'm teaching ideas about Māori texts. Like I try not to be, I try to be neutral for my students who I'm teaching, so that they know that this is what I think, these are some of the ideas in the text. I think some of my students might see me... especially non-Māori might see me as if we're learning a Māori text, [and think] well of course you're gonna say that about the Māori text or about Māori. (Earlycareer male teacher) 
I find teaching English much easier as a Māori than I found teaching Social Studies, because I found as a Māori teaching non-Māori kids about the Treaty of Waitangi that I just didn't manage that at all because I was super defensive or tried not to sit on the fence too much. I find English so much easier because you're just talking about text and you can put yourself in the author's shoes ... [In Social Studies] you spend your whole time not taking a side because you know it's happened, and you're a bit scared but you don't want to be seen as that blimmin’ Māori teacher who doesn't see it from anybody else's point of view, and then you don't want to be seen as that Māori teacher who just sides with the other side. I found that very difficult. (Experienced female teacher)

Some Māori English teachers spoke about making strategic text choices based on the racial temperament of the class. White student backlash had taught one participant to modify the amount of work she could do based on New Zealand text,

Using Māori texts is something that I'm really passionate about when planning my course. I'm going to use Māori and Pacific poems, so I'll use some different Karlo Mila poems and some other Māori writers. But then I had decided well if I do that and then I choose "Boy" (Waititi, 2010) as my film, that means that my novel really can’t be a Māori novel. I feel like I can’t have Māori poems, Māori films, Māori novel. Even though all of the texts have to be thematically linked, I feel like that's too much, just a funny feeling ... I haven't met the kids yet, so I'll get a feel for them and see how they are after the first unit and then I guess depending on how much backlash there is, make a decision on what they can handle or how much they need to be moved. (Early-career female teacher)

The emotional and cognitive difficulties that Pākehā students experienced when studying literature with a Māori cultural perspective was perceived to impact negatively on assessment outcomes. One participant offered his students non-Māori literature for the exam, after it became apparent that they were struggling with the cultural perspective in a New Zealand text and were not producing the level of work required to get good grades,

I think where the problem comes is when they have to produce something tangible at the end of it that's supposed to relate back to some developed ideas or 
understanding of the text. When you've got numbers of Māori students in the class who don't understand the text and it becomes difficult for them to write about it, then you end up offering other texts and all sorts of other ways too. Quite a complex kind of idea for me. (Early-career male teacher)

Some participants indicated that they purposefully chose not to teach some New Zealand text because they were fearful of perpetuating stereotypes or creating emotional discomfort in themselves or students. Māori English teachers sought to build cross-cultural understandings by empowering Māori students to overcome social barriers or appreciate a Pākehā worldview. Alternatively, Pākehā students were resistant to learning about a Māori worldview, so participants were strategic about implementing teaching approaches to penetrate ignorant or racist attitudes. The following section is concerned with pedagogical approaches to address the educational and cultural deficits that are perceived to affect Māori students' literacy development.

\section{Developing literacy skills}

Most participants felt that the development of literacy skills, and the ability to read and write English as well as it is spoken, is key to academic success. Participants spoke enthusiastically about using a range of vocabulary, questioning, and reading comprehension strategies with their classes. Te reo Māori was utilised to better explain concepts, kaupapa, relationships or metaphor to students who were fluent reo speakers. Differentiated learning strategies were generously shared by participants who thought it important that classes of diverse literacy abilities access literature at their level and produce written work accordingly.

The findings in this section are focussed on the pedagogical approaches that participants implemented to counter Māori students' confidence in the subject of English, the written word and in their own abilities. One teacher in a rural school said she built confidence by selecting shorter text types and working from easy to harder aspects of text. Conversely, participants from high and low decile schools thought that teaching Shakespeare gave students the confidence to walk in the Pākehā world,

There is the view that students don't always want to be locked in to what they already know and I believe this to be true. I would like (and did some years ago) to teach Shakespeare and classic novels such as "Lord of the Flies" (Golding, 
1958) and "To Kill a Mocking Bird" (Lee, 1995). My thinking being that if students are not exposed to great writing when at school, when will they ever? Does it matter? Is it right to limit students' horizons because they are Māori/low decile/low literacy? And bow to the pressure of engagement and prior knowledge and teaching that which experience has shown the students will achieve in NCEA because they can easily write beyond the text. (Experienced female teacher)

Studying English was also perceived to be a source of anxiety for Māori students in predominantly-Pākehā settings. Some participants introduced pedagogies to counter this,

I think getting them into the habit of writing regularly, without fear of it being... and just having writing for them, they could write a song and rap a poem, piece of prize, whatever you wanted, as long as you wrote something, I think that was sort of a safety net for some of my Māori boys in particular who were quite reluctant writers. To be able to just write without it being assessed was quite good for them I think. (Early-career female teacher)

Other pedagogical approaches to support Māori students to share ideas about literature and overcome feeling whakamā in Pākehā-dominated environments included voicing opinions in students' own colloquial style of speaking, responding on paper instead of in front of the class or carefully choosing when Māori students read English text aloud. One participant noted,

Often [Māori students] couldn't speak as openly in a Pākehā context with a Pākehā teacher as they could in my class. Because yeah some of it is shocking but you can be more real with your Māori kids about letting them express themselves as they do; not feeling whakama that they are going to get into trouble because they used the wrong words or they haven't pronounced a Pākehā word correctly. Especially kura kaupapa kids that come with an accent, and they might get laughed at by their Pākehā peers in a Pākehā class. Say for instance some kids some Māori kids that come from kura kaupapa can't say L properly. It's a crack up when you listen to it [and] it's alright saying it in a Māori context because your mates come at it differently but when a Pākehā kid is laughing at you it's not 
so funny. That would affect them and then they clamp down. (Mid-career female teacher)

Some participants thought that academically struggling Māori students could be supported through pedagogical approaches that were associated with a perceived learning style,

I think the biggest tool is visualisation is that when you are trying to get them to understand the position of a character, you explain it to them in terms of their own world. So, imagine that you are at the marae and this has happened and this happened and this has happened. How do you feel? I think that kind of visualisation exercise is really effective and I probably tend to use that quite a lot. .. [my students] are so often visual learners that you do want to back up, like even if you are studying a book, you do want to back it up with a film adaptation at some point. (Mid-career female teacher)

I like mind maps. Try and get them to use a mind map to create a bigger picture and 'Oh look, there you've got a sentence, and oh look, there you've got five points around that sentence, oh, now you've got a paragraph", "Oh, true Whaea", "Oh there, titiro, look there's your picture. Got yourself an essay boy". Get the visual because they are visual kiddies. (Mid-career female teacher)

A lot of our kids engage with kapa haka and I think that has to do with the emotional connection that they make with the oral text in terms of kapa haka, and their visualisation or the stimulation of their senses through kapa haka as a medium, but through those oral texts as a medium. I think what is lacking for them is that similar visualisation and stimulation of their senses through the written word, and so for me that's why we most probably have to deliver the written word orally a lot more to them, and deliver it well so we have to read with passion so that they're able to, or read with the emotion so that they're able to pick that up and sense it. (Experienced male teacher)

I don't think they quite get... I think they see... like, it's always about the blatant, it's the things that they feel, the things that create quite a memorable reaction in them that they get, rather than the subtleties of something, yeah. Because Patricia 
Grace is quite passive in her writing. Her writing is more about provoking thought rather than being in your face about issues, is sort of how I see it. (Midcareer female teacher)

Utilising te reo Māori in the teaching and learning process was perceived to "break down that barrier of English being the dominant language" for students whose first language is Māori,

If they can engage critically within their first language, which is te reo, after their third year here because they're surrounded by te reo Pākehā, they're able to do that quite easily in English when it comes to Level 1 NCEA . . . That's what I mean about breaking down that barrier of English being the dominant language, to be able to engage, understand and respond within the language that is most comfortable for them. . . in year 9 and year 10 if we've really drilled that and I suppose acclimatise them to that type of thinking, then they're no longer feeling fearful of English as a subject or English text. (Experienced male teacher)

Participants therefore appreciated that there is a cultural, historical and political dimension to working with Māori students to develop literacy, and this knowledge elicited creative teaching approaches. Some participants who worked with a high proportion of Māori students appreciated that that literacy development with students who struggle in English takes time,

I guess the strength for me is I have a $100 \%$ belief that the English language can be achieved by all of us you know, in spite of whether we come in with some technical insecurities about spelling ... so I guess my strength would be allowing Māori students to decode their way through what they often see as English being a very difficult subject. (Experienced female teacher)

I found when I was really super planned that I took away flexibility and I took away their input because I had it planned ... While those kids got really good results they didn't love it as much as my kids previously had. That actually really hurt me because it took me a while to figure out what the problem was. . . And I think I was just too rigid. . I learnt I got good stuff when I had that dialogue all the time and I could have that giggle and we could just you know they didn't have 
to be writing the whole time or reading the whole time, actually talking about what they're doing is just as important as anything else. (Experienced female teacher)

[The students] didn't see why they had to do it in a such that was so prescriptive. I said it will be okay. We'll have fun with it, lets do it our way and then we've got to do it the other way, or lets do it the other way first and then we perhaps have some fun with it in our own way later. The challenge at the beginning that I was almost failing what I was doing. I wasn't teaching what they wanted me to teach. For example, if you are doing letter writing, the next thing you are doing is your short story. I just wasn't getting through the material. (Experienced female teacher)

The findings in this section reflect a range of concerns and strategies regarding the literacy development of Māori students. Māori English teachers spoke about building confidence in students' abilities through communicating in Te Reo, studying the English canon and sensitively catering to classroom dynamics and students' perceived learning styles. While these approaches do offer the students support, they attribute academic underperformance to either a cultural or cognitive deficit.

In summary, the section of findings that identify individual and interpersonal racism present participants' experiences of hitting walls of silencing. These walls draw attention to ineffective, school practices associated with colourmute policies designed to include and cater to the learning requirements of Māori students. Although the findings highlight some everyday effects of racial exclusion, the participants themselves had limited understandings of racial injustice due to their own structural blindness. The inability to see how silencing moderates' everyday interactions pulls Māori English teachers towards colourblind and colourmute readings of institutional existence. Consequently, Māori English teachers sink into the whiteness by perceiving that schools are helpful and provide opportunities for positive English outcomes. When flowing with whiteness, the responsibility for student success is attributed to good teaching. Participants therefore enact curriculum and pedagogical practices that are in line with the perception that Māori students may be taught how to overcome barriers (cultural or educational deficits) to attain success in English. The implication of investing in meritocracy and perceiving that institutions are racially neutral is 
that Māori English teachers become immersed in a silencing discourse, as they enact the policy, curriculum, and pedagogy structures of state schooling. The following chapter explore the nature of this immersion through the everyday classroom interactions of four Māori English teachers. 


\title{
Chapter Seven
}

\section{The hidden curriculum of settler silencing}

\begin{abstract}
I start moaning to a fellow colleague about the difficulties of implementing what I've learned from study in our workplace. I tell her I'm frustrated at how the school handles things Māori and suggest we push the school management team to hold the staff accountable to enacting culturally responsive pedagogical practices. I thought she was pretty open-minded, but she tells me I have a "bee in my bonnet". This makes me sad because she's pretty influential at work and if she decides not to listen then I don't know who will. I probably just need to tread a bit more cautiously or tone it down a bit but am wondering how far I can question some staff to think about the way we construct what it means to be Mãori at school.
\end{abstract}

(Research journal, 2016)

In Chapter Seven, I present data from phase two of the research design to address the second research question, "What is the shape of a hidden curriculum of settler silencing? What does the hidden curriculum reveal about the operations of a silencing discourse?" The shape of the hidden curriculum is presented through the following three dimensions: teaching pedagogies that soften and mute historical harm, assessment approaches that privilege neo-colonial imperatives, and lovely knowledge about Māori society. Each section of findings identifies practices conducted by Anahera, Nikau, Aroha and Maia as they perform the pedagogy, policy and curriculum structures that are associated with the operations of a silencing discourse.

\section{Teaching pedagogies that soften and mute historical harm}

This section of findings presents interview and observation data from Aroha, Maia, Anahera and Nikau concerning the pedagogical approaches they implemented during phase two of the research. Anahera, Maia and Nikau taught predominantly Māori students and enacted pedagogies that soften historical harm, including relating positively with students, building confidence, privileging cultural background, and teaching about context. Maia taught predominantly Pākehā students and performed pedagogies that mute historical harm, including validating student response and neutralising difficult ground. 


\section{Relating positively with students}

Each phase two participant related positively with their students with the view of establishing a constructive learning environment. Of the four participants, Aroha cultivated the friendliest relationships with her students. She spoke about how this pedagogical approach was a significant point of difference to that of her Pākehā colleagues,

I'm not going to say that I'm the best English teacher in the world because I'm not. To be honest, I don't know the ins and outs like a lot of my mainstream English colleagues ... I have a different teaching platform and I'm aware of that. So, I don't think that I'm as expert as some of them are and I'm okay with that too because that's why you have colleagues . . . I feel that I still have room to learn because I know that if they were to come in here I don't know if they would necessarily get the same results as I do because for me I know a lot of that is about relationships.

Although Aroha did not explicitly state what the "different teaching platform" was, it was clear from the context of the interview that she was referring a different cultural framework. Within this framework, Aroha perceived that relationships were important when working with Māori students and that operating from this distinct cultural position could be beneficial across a range of subject areas,

I could probably teach up to year 10 Maths as well and do aspects of Hangarau, cooking, food technology because I have a lot of those skills and that's because I'm an English teacher, I don't necessarily know if I could teacher to year 13. I could probably do Te Reo Māori to year 13, Te Reo Rangatira similarly, probably cooking similarly because in terms of my whānau that's my background. I'm one of the cooks on my marae, like Māori contexts, I always look at things in a Māori context, I have that skill base. So, while you're interviewing me to be an English kaiako within a Māori setting or as Māori kaiako who teaches English I don’t really like to be defined as that because I have all these other skills. I know I could teach History and Social Studies because I did at my previous school which I don't need to do that here 
Some of the strategies that Aroha demonstrated to accommodate a relational approach included upbeat classroom interactions, enthusiasm for the studied text and being genuinely pleased to see her students. Sometimes students broke out in spontaneous waiata because they seemed happy to be around her and in her class. An example of the close studentteacher relationship was observed at the end of one lesson,

Aroha: Okay, I look forward to seeing your work on Monday. Okay, so I'm going to leave the netbooks available to you - and you better be on task - and what working on is your connection report.

Student 1: Wait. Where're you going?

Student 2: Yeah.

Aroha: I have PD [professional development] tomorrow and Friday

Student 2: PD?

Student 1: Periodic Detention! (students laugh)

Aroha: And, thank God I'm working with other Māori educators and not Māori students who drive me barmy. Okay?

Student 1: Do you have a play date with other Māori men? You're not allowed a boyfriend. I don't allow you to have a boyfriend.

Aroha: You're not allowed one either then

Student 1: You're ours, not theirs!

Aroha: Oh, here we go (student banter)

Both Aroha and Anahera knew a lot about their students' backgrounds and lives outside of the classroom and appeared to use this information to support their students' learning. For example, Aroha spoke about one relationship with a student and explained why she ignored the sometimes vocal and disruptive behaviour,

[The student is] really opinionated and I'm going to say which is quite indicative of kids who come from kura kaupapa. I know that in some settings she's known as quite whakahīhī but I just think that her zest for life is gorgeous . . there's things that she does that I'll never be able to do. She's an amazing musician, amazing. She can write songs and you see that in her writing, even though grammatically it's not correct, her ideas and her depth of understanding is 
insightful and beautiful ... It's not my role to bring her down or put her in her place.

Jokes were used to take the edge off discipline and banter was frequently used by Anahera, Aroha and Nikau. However, there were times when the relaxed nature of the learning environment appeared to lead to off-task conversations. The boisterous and lively behaviour of students in Aroha and Anahera's classes could negatively affect learning. Aroha seemed aware of the issue when she said, 'I'm quite open and I'm going to be honest, I think sometimes it works in my favour, sometimes it doesn't because the kids like to discuss." Indeed, all four participants sought to develop textual understanding through a process of coconstructing meaning with students. However, the excitement and energy that this process generated in the students was most palpable in Aroha's class. For example, the following exchange occurred during the study of "The Dark Horse" (Robertson, 2014) (see Appendix $\mathrm{H})$,

Aroha: So let's talk about Genesis and Mana, what's the relationship?

Several Students: Uncle and Nephew

Aroha: Uncle and Nephew, ka pai, a good place to start. What else?

Student 1: Mana tries to pour influence over him...

Aroha: Initially but is that really what the story's about. I think that he, um... he tries it on but we only really see one incident of that. So initially he tries it on in terms of his Uncle but what is there relationship become? What does Genesis become for...?

Several Students: Dad... Baby... Brother (lots of student response)

Aroha: A dad?

Student 2: A role model

Several Students: A role model (several students say this, background student chatter)

Student 3: Someone he can look up to

Aroha: Or he accepts him?

Student 4: Mana accepts Genesis

Aroha: So Mana accepts his Uncle? And his mental illness? What does Genesis to for Mana though?

Student 3: Helps him play chess 
Aroha: He stands up for him...

Student 4: He cares for him

Aroha: ...he becomes his what?

Student 2: His guardian

Several Students: His angel... his bodyguard... he teaches him something (several responses)

When students' attention wandered away from the set learning task, participants were calm, controlled and addressed off-task behaviour in a low key but firm way. Aroha and Anahera spoke directly to students about how they expected them to act or selectively ignored off-task behaviour. For example,

Anahera: This is going to make this so easy for you... (a group of students start filing into class five minutes late) Mōrena, what took you so long? Were you putting your make-up on?

Student 1: Nah, it's just... (inaudible)

Anahera: Now, are you working on typing up your essay?

Student 1: Yeah

Anahera: So there's a computer there, anei Timoti (student burps)

Anahera: $\mathrm{Oh}$

Student 2: Sorry me

Anahera: Got pens?

Student 2: How come I have to sit by myself?

Anahera: 'Cos I like to have you right next to me

The performance of relational pedagogies was equally important to Anahera, whose students had experienced difficulties engaging in a mainstream school. Relating positively with Māori students softens historical harm by encouraging positive associations with schooling, thereby supporting students to see that the institution is a helpful and nourishing environment. In this vein, Anahera extended her range of relational pedagogies to include approaches that sought to build confidence in her students' English abilities. 


\section{Building confidence}

Anahera exhibited an acute understanding of the difficulties her students faced when writing and their low self-efficacy in English. She spoke about how her students struggled with the required English skill level, and cognitive and motivational barriers,

So, I said, "we did this at the start of the year!" and they're "Oh?" so you know, just have to keep going back. "What is it? Is there a letter missing? Who owns this?" I think for some of them there's so much brain damage through whatever they're never going to remember that actually and I think a lot of them have never finished a piece of work to the end. Um, so they haven't, they've never had to persist.

Anahera implemented several pedagogical strategies to help build the students' confidence and self belief. One way involved giving plenty of encouragement and openly acknowledging and celebrating individual success,

Student 1: Did you mark my thing Miss?

Anahera: Yes I did and I put the credits on

Student 1: Oh sweet thanks Miss

Anahera: So everybody give Morris a clap because he got Formal Writing (students clap)

Student 2: Does that mean he's got his literacy?

Anahera: Yes

Student 2: Oh brother, you're on to it

Small successes were also acknowledged and cause for celebration. During post-observation interviews, Anahera twice reflected on the students' behaviour and learning in class,

I found [today] rewarding because it showed that they've actually learned a lot in this whole unit. They interpret things heaps better.

I was impressed at how they stayed focussed today. Normally they get to a point and it's like "we've had enough", so they were focussed right through, so that was good. 
These observations indicate that Anahera was well-versed at looking for small instances of individual grown and little ways to boost students' confidence. When students were observed complaining about the difficulty of the work, Anahera was heard saying, "it's not supposed to be easy, but you'll get it". When students became really engaged in class discussions about the film, Anahera also boosted students' self-belief through comments such as, "Oh that's right, you guys know this movie".

One goal that Anahera had for her students was to participate in an external English exam at the end of the year. Sitting in the school hall alongside the mainstream student population would be a big achievement for some, because the students' prior “experience is they're naughty, so they tended to get kicked out",

But it's also really interesting because this is also the first external some of these kids will have done. Because I've said, "You're going to do the school exam in three weeks" and "Miss, I can't do exams. I can't write an essay" and I said "It's easy. This is the easiest section of the exam to do and we've got plenty of time to practice". So it's little steps, it's about getting them confident and they know so much, like they were able to pick up the lighting and how the lighting is supposed to make them look good or bad and stuff like that. So it's small steps.

To ensure that the students were confident and prepared for the end-of-year-exam, they were allowed to take a "cheat sheet" with some notes from the studied in the English school examination (a practice run for NCEA exams later in the year). During an interview, Anahera appraised the students' performance in the school exams,

Anahera: [Student 1] didn't [pass the exam] but he came really close, so he was quite... he said "Miss, I just fall asleep in exams. How are you going to get me to stay awake?"

Interviewer: But did he stay in the exam?

Anahera: He stayed in the exam. I let them go after an hour and a half because they were only doing one standard. So, I said okay... but some stayed. Like [student 2] stayed for two and a half hours or something to write his essay and he 
pa... oh, his was a borderline so I got Julia to moderate his and it passed ... Yeah, so it was really cool.

In Chapter Six, the findings suggest that the underlying premise of pedagogical approaches designed to foster positive relations and build confidence in students arises from the need to counter individual challenges or deficits arising from a legacy of colonisation; however, in doing so contemporary manifestations of structural racism that moderate school institutions and a lived Māori existence are overlooked. Another approach that Anahera, Aroha and Nikau used to build confidence and overcome a legacy of educational deficit was to privilege the cultural backgrounds of the students.

\section{Privileging cultural background}

Anahera, Nikau and Aroha each articulated a different rationale for enacting teaching pedagogies that integrate the cultural backgrounds of their Māori students into the teaching and learning process. Anahera spoke about students who came from whānau with gang connections, mental illness, dysfunction, and those who were "removed from their cultural background ... [or] immersed in their community". She spoke about using the students' prior knowledge about gang connections when analysing the "The Dark Horse" to encourage engagement with the film,

They knew so much more about gangs than I did, and they were able to read his body language, how he held the room in the opening scene when we see him, how the number of labels on his patch means that he was higher up. And we talked about the others sitting around them, "Oh yeah, well he's a nobody, their job, they're prospects, they're trying to be...". And it was just fascinating, and I thought this is real evidence of them bringing their cultural, or their prior knowledge, to the whole way they're watching it. It's interesting because some of them are going "Oh, I'm getting a bit hōhā with this film Miss" and they know every single word. . . They are so much more empathetic towards Ariki and what he's trying to do by putting his son in a gang then what we would be.

The students usually did not offer detailed responses to the text during class discussions, so Anahera was persistent at asking questions and playing "Devil's Advocate" to deepen text 
comprehension; feigning ignorance to position herself as a learner and the students as her teacher,

Anahera: So, are we feeling? How does the director making us feel about [the gang President]?

(Several students start speaking)

Anahera: Can we feel horrible? Is he scary?

Several students: Nah

Anahera: Nah. Is he... would you want to take him home and introduce him to your Nan[a]?

Several students: Nah (laughter)

Anahera: (laughing) How are we supposed to feel about this guy?

Several students: That he's... He's giving him the opportunity... He's an OG

(Original Gangster)... (laughter)

Anahera: Why... If he was going to be... I suppose if you put out there in normal society, who's he supposed to be? What is he? What did you say? If he's the President how could they make him look scary? 'Cos you imagine that Presidents of gangs should be tough and...

Several students: No!... Nah!... (lots of students chime in)

Anahera: But that's the general perception? (lots of student background noise)

Student 1: Yeah, Miss. Presidents have gotta be brainy

Student 2: They gotta be brainy

Anahera: Oh, they've got to be brainy?

Student 3: Yeah

Student 1: You don't want a dumb President

While Anahera drew on her students' prior knowledge to engage them in the study of film, Aroha spoke passionately about using English as a vehicle to advance te reo Māori and Māori interests in general. She incorporated aspects of Māori culture throughout her lessons to support the development of the cultural backgrounds of her students because she recognised that mainstream society significantly marginalises Māori interests,

I would like my students to be proficient in both languages and preferably Māori first. I'll be honest, because I think it actually doesn't matter how passionate a 
Māori speaker you are. English, on a day to day basis unless you work in certain settings, dominates your world. I work in kura kaupapa, I've worked in kura kaupapa and I can say that at least 14 hours of the day English still dominated my world. . . For me, it's always about the legitimacy of te reo Māori and how that fits into the world. So while I'm an English teacher, I'm a 250\% activist for te reo Māori and English should be informing te reo Māori and vice versa.

Aroha also observed that many Māori students had little understanding of te ao Māori. She spoke about a strategy she used to help build cultural understanding,

The other thing is I'm always surprised it how little [Māori students] know about things Māori. In terms of being a Māori kura, how little our kids actually know about things Māori historically. . . One of the things that I [do] with the kids is continually making connections 'cos that's what English is about, is about teasing out ideas, aye. So how do those ideas apply to them in terms of them being rangatahi Māori. . . So, what I would say to the kids is if you apply what your knowledge is what you learn at home to what you learn here, what you've learned at Primary [school], then you should have a basic understanding anyway at some level of whatever topic of discussion we're talking about.

To advance Māori interests and build students' cultural understanding of te ao Māori, Aroha co-constructed meaning by eliciting the cultural expertise of some students. In the following except, Aroha defers to the knowledge of a student who attended a kura kaupapa and was well-versed in te ao Māori,

Aroha: "He's as solid as a mountain" so what does a mountain suggest?

Group 1: He's strong

Aroha: Yup. He has a wisdom, he has a knowledge about him. Without being cold or distant. If we think about what Patricia Grace is very... um, what I know about her is she's very definite about her writing and a lot of it is informed by things Māori. So if we think about maunga and make that connection, what do we know about maunga? What do maunga stand as for Māori people? Ka tū hei aha? Te Koha, ka tū nga maunga hei aha? Hei... [English translation: Why are the mountains standing? What do they stand for? For...] 
Te Koha: Whakaruruhau

Aroha: Whakaruruhau. He aha te tikanga tō te whakaruruhau? [English

translation: What does whakaruruhau mean?]

Te Koha: Like a... something to fall back on... kaitiaki

Aroha: Kaitiaki. Kaitiaki?

Te Koha: Protector, guardian

Aroha: Guardian, protector. But if you think about how she writes things, those are the things underpin her text. That's why Whaea choses them, "Neither being cold nor distant". So there's a certain amount of formality there, do you get what I'm saying?

Aroha's approach to privileging cultural background is in line with the findings from phase one interviews, where participants articulated an "ideal" Māori learner identity who can walk in "two worlds", speak te reo Māori and demonstrate traditional cultural characteristics. However, Aroha noted during an interview that making connections between the text and te ao Māori could be difficult because "some [students] don't get it, some of them do though".

Advancing a Māori cultural perspective when making meaning about New Zealand literature was also important to Nikau; however, he regularly used the students' personal responses to "Rain of the Children" to promote higher-order thinking about the social, racial, and historical contexts of New Zealand literature (Bloom, 1956). During an interview Nikau said that it is important to "go with where the kids are taking you ... Otherwise you're talking to brick walls". One example of drawing on the students' prior knowledge and cultural backgrounds to develop contextual understanding occurred after one student called another a $\mathrm{FOB}^{29}$ because she pronounced the word "asked" as "arksed" during class discussion. Nikau appeared to overlook the exchange until later in the lesson when one student said he was interested in the way Puhi spoke,

\footnotetext{
${ }^{29}$ FOB stands for "Fresh Off the Boat"; a derogatory term for a recent immigrant from a neighbouring Pacfic island.
} 
Nikau: Do you know what the term is for that type of language, or what that type of language would've been defined as, or we would define that as?

Student 1: No

Nikau: No? Pidgin. P-i-d-g-i-n. Pidgin. So Puhi would've been a FOB back in the day and she would've been an example of a FOB because of the way she spoke the lingua franca. The way she spoke English was pidgin, which is usually a mix between English language and their native or the indigenous language that they speak. Sort of like a combination of that. So "I very tired [becomes] I sleepy-head this morning". (Nikau writes "pidgin" on the whiteboard) Student 1: So like, she has her own language for herself as a kind of... Nikau: So instead of saying if you were to speak proper English, "I was very tired this morning" you would most probably use "sleepy-head", you know she said "I very tired this morning. I sleepy-head".

Student 2: 'Cos she's like, missing out words aye

Nikau: Yeah, so words get missed out or "arkse" (students laugh)

Following the lesson, Nikau said that while the students make fun of the way Puhi speaks it's important to understand that they're "engaging with the text and . . . a feature that stands out to them". During a focus group interview, students said that being asked to give an opinion about studied text was challenging and a "struggle because you haven't done it before". However, two students said they "liked talking about people's opinions" and "having your own personal say" as opposed to subjects, like Science, that required you remember things by heart.

This group of findings demonstrate that different motivations underpin English curriculum approaches and pedagogies that privilege the cultural backgrounds of Māori students. Anahera encouraged students to draw on prior knowledge to build confidence and increase learning engagement, Aroha elicited student knowledge about te ao Māori to combat Eurocentric perspectives and deepen Māori cultural understandings, while Nikau used his students' prior knowledge to deepen their understanding about the content of the text. Although these approaches appeared to successfully engage students, the onus during the observed lessons was on advancing the students' individual understanding of text, rather than critical engagement with the cultural milieu of the classroom, the local community or society. 
However, one pedagogical approach I observed from Nikau that offered students a critical lens to appraise their world was teaching about context.

\section{Teaching about context}

During post and pre-observation interviews, Nikau voiced concern about how assessment pressures affected teachers' text choices, including whether to teach New Zealand literature, New Zealand history and bicultural relations,

It does come down to text selection. Like I say, I'm sure "American Beauty" would be more appealing in terms of popularity with our audience here, but does it help in terms of a local curriculum? Does it help Māori and Pākehā students alike? Does it help us as a society or as a nation? . . . Certainly, "American Beauty" in terms of [students] achieving the standard, is most probably a lot easier for - whether Māori or Pākehā students - is a lot more easier in regards to "Rain of the Children" (Ward, 2008). There's certainly a lot more teaching and educating that needs to take place with a New Zealand text in comparison to an American text. 'Cos I've read some of the responses to "American Beauty" and, you know, great analysis, great understanding, great reading of it as a text. But how much has that actually educated a New Zealand student about who they are and where they come from, and English as a subject and English texts within Aotearoa, you know? It's certainly taught them a lot about middle-class America or educated them about that, but what about our own history and knowledge as a nation? Like I say, it may help them to achieve the standard easier but in terms of a curriculum has it really delivered what the New Zealand curriculum is meant to deliver?

Nikau was motivated by deep text exploration that would give students "that understanding of, this is our history as a country this is our history as a people and either as Māori or as Pākehā or as Pākehā and Māori together”. He felt that purposeful teaching of the social, historical, and racial contexts that shape New Zealand texts was one way to achieve this. Nikau believed that students need to learn that all texts are shaped by a "whole context and history that you need to know and understand" and that this was as relevant to the study of Shakespeare as New Zealand literature, 
So that's why I think it's important for us to use the types of text that we do and really explore them in depth so that our tauira do have that understanding of, this is our history as a country this is our history as a people and either as Māori or as Pākehā or as Pākehā and Māori together, you know, having that understanding, you know. The colonials did what they did because that was the way, it's sort of like understanding either in King Lear or in Shakespeare, God, King, nobility, commoners, peasants, serfs etc. like that was the natural order of the world. Similarly, back then that was the natural order of the world, God, King, Pākehā Colonials and Māori underneath, yeah, and you are there for us to use and abuse you as is our divine right, as laid down and we are your conquers we are your kings type thing, do what we say, conform, assimilate, fall into, you can't have your language and you can't have your identity and you can't have your spiritual ways. White is right and that's what you're going to learn and we're going to teach you.

Consequently, Nikau spent three lessons supporting students to engage with the contexts of "Rain of the Children" (see Appendix G). He thought that studying context helped to engage students with the text more effectively "beyond their initial emotional reaction to it." The first lesson about context involved a lengthy exchange between the students and Nikau to establish a basic understanding about what context is. Students struggled to articulate an answer, until one said, "more understanding". To impart understanding, Nikau spent most of his teaching time directing students towards textual meanings. For example, one sequence of film in "Rain of the Children" showed the government storming Maungapōhatu and driving Rua Kenana and the Tūhoe community away from their tribal lands. Nikau worked with the students to connect that historical event with the present by underlining the significance of the Treaty of Waitangi in contemporary New Zealand society,

Nikau: What's the law that we call now in regards to the Treaty? What's always on the news in regards to the Treaty?

Student 1: Land

Student 2: Politics

Nikau: Land. What happens in regards to the land?

Student 2: Certain people can own certain parts 
Nikau: What does everyone moan about in regards to the Treaty now? What do New Zealanders moan about?

Student 3: The flag

Nikau: No

Student 2: We're losing land

Nikau: Usually in regards to this we've lost land. What are they doing in regards to the lost land and the lost resources? No, you're not going to get it. Treaty settlements or Treaty claims, that's what we have now. We have Treaty settlements when it comes to the government paying back for those wrongs that they did in regards to the Treaty. So when they went into Maungapōhatu, when they took the land, when they took the resources. Why do we have Treaty claims? That's why the iwi and people make Treaty claims to the government and the government settles because of those past wrongs, ok mārama? So what do we need to understand from that then, what do we understand in regards to the raid on Maungapōhatu? What do we understand in regards to the context?

Student 1: That it was okay for them to do that Nikau: Yes ... that it was okay for the government troops to go in and attack Maungapōhatu and to arrest and to drive them off and to do anything else that they did in regards to that history. Mārama?

During an interview, Nikau said that the class time required to support students to develop an understanding of context was surprising. He thought that it would "take 10 minutes with a 15-minute discussion in regards to the history and context stuff and then it was like, oh, it took the whole period". This realisation made him a little despondent. He asked "so how much do we need to pre-teach? Or how much do we need to ensure that they have that historical contextual understanding?" Another aspect of context taught by Nikau was the way in which the characters' lives were influenced by religion. He said, "I don't think [students] have an understanding of that type of psyche, so I think it's important to be able to explain that sort of contextual stuff to them or have them understand that".

The students agreed with this appraisal. During focus group interviews, some said they had a new appreciation for "Rain of the Children" after Nikau explained it more fully in class. One student thought with this type of film you needed to "read between the lines", while another said, 
It took me a while to understand what it was about though. Like when we first watched it it was confusing, like what's the moral of the story? I didn't get it, I was like "okay". I didn't get it until Nikau started analysing scene by scene and actually explained it more. I think it's hard to pick up and it's pretty straight forward. It's pretty much just him discovering all about her life but it was just a bit hard to understand. It's not an ordinary film, like you wouldn't see films like that.

It was apparent during the observed lessons that teaching about context challenged the students. Students were asked whether studying context was difficult during a focus group interview. After a lengthy period of silence, one student concluded "Sometimes, it depends. It's very difficult to find a wrong answer in English but it's also difficult to find the right answer". Despite the struggle, some students appreciated that there were benefits to thinking "outside the box ... to think of what the answer should be when you're analysing text".

At the end of three lessons, Nikau thought the students understood the importance of context but needed to develop more knowledge about New Zealand history. He said there are things that "you take for granted that [students] know or understand, they obviously don't have that understanding”. Discussions with students revealed that more teaching time was needed to embed contextual understanding. Some students could recall very little of what had been discussed during the lessons, while two students could not see that learning more about the history of Aotearoa had affected their view of contemporary New Zealand society,

\footnotetext{
Not really because I feel like I don't know enough to... I don't feel like I know enough to look differently at society. Like, I get angry when I hear stuff about land and the Treaty of Waitangi, like how it was misleading, like we're not even in control of our own country and our land. That's about it.
}

This student comment captures the tension implicit in teaching about context. That is, how to apply insights about historical and racial injustice to lived experience, and what of it? While teaching about context engages students with the topic of colonisation, historical harm is softened by silencing the structural nature of contemporary racial injustice. An examination of the historical context of New Zealand literature exposes students to the process of 
colonisation and how Māori are politically positioned in relation to the state. However, the lived consequences of historical harm are softened by pedagogical approaches that attend to the cultural deficits of individuals, silencing the way that whiteness and structural racial bias pervades state education. The remainder of the findings in this section now turns to teaching pedagogies enacted in classrooms of majority-Pākehā students.

\section{Validating student response}

This section of findings presents data that shows how one majority-Pākehā classroom environment drew on teaching pedagogies that mute historical harm to cater to the emotional sensibilities of Pākehā students. While pedagogical approaches in majority-Māori classrooms, underpinned by a philosophy of cultural and ethnic inclusion, responded to the notion of Māori student deficit by relating positively to students, building confidence, privileging cultural background and teaching about context, pedagogies that validate Pākehā student responses in relation to constructing meaning about New Zealand bicultural race relations seek to lessen white anxiety or fragility.

Arising from the ideology of "one people, one nation" (Brash, 2004), and the belief that New Zealand society has moved beyond race, is the centering of white anxiety. Pākehā students were observed performing white anxiety during a focus group interview, as they asserted themselves as victims in the process of learning about difficult histories and systemic racial injustice. At first, the students were anxious and hesitant when I asked them to tell me more about a moment in class when a fellow student said, "white guilt". The students went silent, then responded in various ways by saying "hmm" or "yeah, he did", while a third said, "yeah I know, shhh, shhhh". Other students laughed, then they attempted to articulate their uneasiness,

Student 1: I kind of feel like you have to be a bit careful, sort of, like it's kind of... like there's quite a lot of tradition and I feel like sometimes it's quite easy to say the wrong thing and so I feel like I have to be more careful even though maybe you don't and so it's not really like, a negative thing, it's just...

Researcher: Where does that come from?

Student 1: You just don't want to offend anyone. That's what I'm worried about Several students: Yeah.

Student 2: Yeah, I don't want to offend anyone 
Student 3: Yeah.

Student 4: When I say um, Māori words I'm so worried that I'm going to say it wrong and someone's going to go "Oh My God" you are so ... That's why when I sometimes see this [Māori word] I go "Whooh, okay" like earlier I didn't want to say any of the words 'cos I was so worried I was going to say...

Student 3: Oh wait, can someone else say it first...

Student 1: You don't want to stuff up

Maia seemed somewhat aware of the students' anxiety around race. During an interview she described the messages in “Our Tīpuna Remain” by Jacqueline Carter (2010) (see Appendix J) as "quite difficult" and "tricky" for students to discern. Maia spoke about wanting students to "feel something" in response to racism, however, the pressure to keep students engaged and adequately prepared for their assessments was also a significant issue. I asked Maia if she wanted to protect students from feeling guilt or disengaging,

Disengaging I do, but I know it's really, really hard. Um, from guilt... not so much. I think you have to feel guilty to want to make change. Or you have to feel something . . . and I think for Māori you have to feel hurt, like the poet does, to want to change things. But I don't necessarily think that they should feel personal guilt but you have to... like colonisation you have to feel something otherwise you just think it's okay. So, I don't... it's a fine line I guess...

Maia wanted her students to engage with the study of literature, so they could perform well in the English exam. When she was asked why she chose the poem for the students to study, Maia replied,

I chose it because I like it. I chose it because it has a lot of features in it. I chose it because it is very different from the one that we did, but I also chose it because I love history and I think this relates very well to... like, every text we've done this year has been New Zealand. Like I haven't done anything out of New Zealand. . . But I think this is the type of poem they'll get in unfamiliar text as well. They'll get something like this so that's why it's good practice. 
However, the study of New Zealand literature had the potential to undermine this goal by exposing students to difficult knowledge about colonial history and race relations. The pedagogical approach of validating student response diffused this tension because it was unlikely that students would offer up challenging or uncomfortable meanings that would evoke racial discomfort and white anxiety. The excerpt below is typical of the approach used during the study of "Māori Battalion Veteran" by Alistair Te Ariki Campbell (2001) (see Appendix I). Students were encouraged to look for language techniques, then discuss the effect (see underscored text). Sometimes Maia paraphrased the students' responses (see italicised text). After the students quietly read the poem, Maia turns to a class discussion,

Maia: When you find one just pop your hand up and we'll go through it. Yip [Student 1].

Student 1: Using a metaphor.

Maia: Cool, where is your metaphor?

Student 1: Um, "my dead mates come alive"

Maia: So that's in our, that's toward the end, isn't it? So it's in our second to last tercet. The stanza stays "sang the sacred hymn 'Aue ihu' my dead mates came alive and for the first time in years I wept". Okay, do you want to comment on the effect of that metaphor?

Student 1: Well, people can't really come alive Maia: Right, that's your description. Why do you think he's used that?

Student 1: Um, to give the effect that he's thinking about them and like (inaudible).

Maia: So maybe he's remembering them. Ah [Student 2]?

Student 2: Also, that kind of gives you an idea why he said, "the first time in years". It gives you an idea of how long it's been for him

Validating student response was a particularly important during the study of the poem, "Our Tīpuna Remain". The poem has strong messages relating to the consequences of colonialisation and colonial harm. However, Maia was always upbeat during the study of the poem and would often reassure students by saying "Poetry's cool [because] everyone will interpret things differently, so there isn't one specific right answer and there isn't a wrong answer either." The ability to validate the understandings that Pākehā students brought to the poem, allowed Maia to create some distance between herself and the ideas of racial 
oppression. Consequently, Pākehā students could talk about racism and New Zealand race relations without feeling like the teaching process or Maia (as Māori) was attributing blame to them personally,

Maia: So, what I'm going to get you guys to do is write down the message or a list of messages that this poem is portraying. (Maia refers to the students' summaries that she has written on the whiteboard). So, what is it saying? Sarah's given us some, Will's given us some and Jody's given us some, so there's some on the board for you already. Explain how the poet gets this message across. So, Jody gave us repetition of this word [Pākehā] which gets across this "I'm a bit angry. I'm a bit resentful", yeah? Write down who this poem may be directed at or directed to, and try to be as specific as possible get those details in.

Historical harm is therefore muted through a pedagogical approach that gives students control over what ideas and key messages about the text are privileged in class discussions and group work. Pākehā students are less likely to voice racially contentious issues about the text and gravitate towards sanitised understandings of colonisation. The following section closely examines how validating student response is implicated in a process that actively seeks to shut down the notion of colonial harm.

\section{Neutralising difficult ground}

There were times during class when Maia was complicit in creating distance and supporting students to view the nicer side of colonisation. In the poem "Our Tippuna Remain", "some Pākehā" are reprimanded for land confiscation. The meaning attributed to the poet's use of "some Pākehā" proved to be a significant discussion point during one lesson. One way that the potential for student backlash towards the term "Pākehā" was neutralised was through supporting student responses that muted the implications of colonisation,

Maia: (points to the word, "Pākehā" written on the whiteboard) Okay, anyone know what this one means? And some people have said that this is a derogatory term, aye, or it was a derogatory term but in our society. Do you think that it has a derogatory meaning, or do you think that it's just a...? Yep, go Simon.

Simon (student): It's not really a negative connotation

Maia: No it doesn't really, aye in today's society, so that's interesting. 
Another way that Maia neutralised difficult ground in response to the meanings that students brought to "Our Tippuna Remain", was to adopt a neutral tone to counter the potential for student anxiety regarding colonial violence and oppression. For example, focussing on the technical aspects of a personal response supported Pākehā students to share their views about race,

Student: The tone. The poet gets the message of resentment towards Pākehā and colonisation by repeating the words "some Pākehā" which is used in a derogatory manner. This demonstrates the poet's feelings of resentment towards the Pākehā and the way in which the Pākehā people colonised New Zealand.

Maia: Well done, that's well written.

Sometimes Maia was upbeat and non-judgemental which seemed to reassure students that they were engaging positively with the ideas in the poem. In this way, Maia was observed to direct students to racially "safe" spaces when engaging about contentious issues. The following passage occurred as Maia was moving around groups of students to discuss the poem,

Maia: Tina just brought up this point, and I have never thought about it, when she says "some Pākehā, some Pākehā". Tina said maybe she was talking about the government.

Student 1: That's really interesting.

Maia: That is, aye.

Student 1: But I still think that it may be directed at both... one man in charge who said... (inaudible)

Maia: But it's quite interesting aye, that the government... (inaudible)

Student 2: When she's talking about "some Pākehā" she's not just talking about all the Pākehā, some Pākeha... (inaudible)

Maia: So maybe that's the reason why she's repeating it because she wants us to make sure that we don't think she's talking to everyone.

Student 3: She says “some Pākehā” she's not saying (inaudible). She's saying some... (inaudible) 
Student 4: I think, oh here are some Pākehā people, I think it's just like here are some White people decided to...

Maia: So a generalisation?

Student 4: Yeah, a generalisation, it was a White guy who ruined my land... (inaudible)

Maia: Isn't it cool how everyone can get different meanings out of one little poem?

The perception that the poet was more "sad more than angry" and trying to send a "firm" message to Pākehā people about they way they treat others was echoed by students who stayed after class to participate in a focus group interview. Students continued to neutralise and distance themselves from colonial acts of racism and did not feel that the poem was attempting to blame contemporary Pākehā society for Māori loss,

Student 1: I don't think it's trying to shame the white people. I think it's just trying to say to them "hey, can you just be a bit more considerate to our values, um not just as an individual but as a collective group of people" so I think that's what, I don't think there's any white guilt in there. I think it's just more about spreading awareness to us and making it better for our future which is now, I suppose.

Students 2: Yeah, I don't think it's white guilt ...

Researcher: What is "white guilt"?

Student 2: Feeling guilty for the past

Student 1: Like shaming, like, personally I think it's shaming white people for doing something bad

Student 2: Even if they didn't do it though

Student 1: Yeah, exactly (voice goes quiet, Student 3 says "yeah 'cos")

Student 2: Like even though we ourselves didn't do all of that back then it's like...

Student 3: It feels like we're to blame...

Student 2: It feels like we're to blame because sometimes...

Student 1: Yeah, we're responsible for it...

Student 2: 'Cos they're our ancestors, they're our family from way back and they did all that 
Student 1: But like I don't think she's trying to say “we're blaming you now" I think, yeah. It's just saying (in a nice voice) "hey, this is what happened, would you mind changing it please?" . . . Yeah, also like, we're [Pākehā] are quite selfish. I feel as though that we were quite a selfish group of people when we came and then we didn't realise what we were doing um, and that actually it really made us click into saying "hey, right, okay, we need to change this" as well.

In this lengthy exchange, student one works hard at keeping bicultural relations upbeat. The group of students can be seen distancing themselves from the actions of their ancestors.

Students appear to share the view that Pākehā have moved away from being selfish towards a New Zealand that is now "One Nation"; therefore, claims of racial injustice are outdated. Towards the end of the interview, student one strengthens her argument about harmonious bicultural race relations by attributing discord to Māori. She adds that the poet is,

Dwelling a bit on the past ... [because] our society's completely different than what it was back then, maybe she should just forgive and forget and if it happens again then maybe she can consider that something needs to happen.

Other students remind her that it is important to learn from the past because racial oppression is still happening today. In making this point, they remind each other about all the "shit" that "blacks in America" go through, rather than consider the racism experienced by Māori. Further evidence of the way that students neutralised difficult ground and distanced themselves from the underlying message of land loss or confiscation was to focus on the theme of "cultural awareness". This theme featured strongly in students' individual written responses and focus group interviews, evoking comments such as "[the poem] just makes us as Pākehās remember or recognise how important culture is and even simple things to Māori people". During an interview, Maia said that cultural awareness had not been presented as a main theme but probably featured in class discussions about colonisation or cultural conflict.

During an interview, Maia hoped that the class would feel something in relation to past historical injustices. However, the students' positive reception to the poem, plus Maia's observation that the one student who was known to make outwardly racist remarks "actually 
agreed [and] went along with it", suggests that the students walked away from the study of "Our Tīpuna Remain” with sanitised understandings of historical harm firmly intact.

In conclusion, Aroha, Nikau, Anahera performed teaching pedagogies that soften historical harm because they focus on the psychological impact of a colonial legacy, whereas the teaching pedagogies enacted by Maia mute historical harm because they protect Pākehā from engaging with white privilege. In line with the findings in Chapter Six, the frameworks provided by culture and ethnicity directed the phase two participants towards the performance of pedagogical interactions that support ignorance and denial of the ongoing structuring force of colonisation. The next dimension of the hidden curriculum of settler silencing similarly highlights how colourblindness and silencing supports settler-colonial imperatives through the enactment of pedagogies that are perceived to adequately respond to NCEA assessment requirements.

\section{Assessment approaches that privilege settler-colonial imperatives}

This section of findings presents pedagogical approaches enacted by Maia, Nikau, Anahera and Aroha as they supported the development of English skills and literature conventions (including making meaning about the text) with the view of performing well in NCEA assessment. The following data is presented in four sections: starting the lesson, homework, scaffolding skill development and engaging with assessment tasks. The data highlights stark differences between the assessment approaches that Maia undertook when developing literacy in comparison to the other three participants. In this way, a silencing discourse is constructed through the obscured implications of white or colonial time in relation to the implementation of pedagogies that soften historical harm. This aspect of the hidden curriculum ensures that Māori students are distanced from advanced levels of English academic achievement, thus maintaining the racial heirachy between settlers and indigenous peoples.

\section{Starting the lesson}

The busy nature of Maia's class was instantly apparent at the start of each lesson, in which students were greeted, seated, told the learning intention (which was visually relayed through a powerpoint) and given the task instructions for the first learning activity. First Maia settled the class relatively quickly, 
Maia: I need your poem out from last week and... yeah, last in (laughs)... poem out... I don't know if there's any more spares... (lots of student chatter) Maia: (three minutes after the lesson begins) Alright. Thank you, year 11 looking this way. Shhh, this way now. You boys at the back. Okay, um, so we are continuing on with what we were doing last week. As I said, we'll probably spend about a week and a bit looking at poetry, preparing ourselves for the unfamiliar text standard.

Then Maia recapped on what has been taught in previous lessons,

So, last week we kind of, we did a few things actually. We got through quite a bit. So we began to analyse a poem and we kind of haven't done much poetry this year so it wasn't surprising that the unfamiliar text came back and that was our weakest point. So we read the poem, we had a little of a talk about what we thought it may be about. This bit we kind of missed out but we'll do it today. We did a lot around structure, sound and devices and looking at how they could tell us what the poem is all about.

Then she spoke to the class about the purpose and the pace of the lesson,

Today what we are going to focus on is finding the meaning, which is a bit part of that unfamiliar text and also looking at what the poet wants us as the audience to take away. Now, I know that a few of you were away, so we'll scoot through again, last week, so I think what we might do is start with another reading of the poem. When I look at poems I kind of find myself having to read and read and read a lot of the time, which is fine. This is poem is relatively short, so it should be okay. After we've read it we're going to go through some definitions. I saw some of you last week asking each other what some of these words meant, which was really good to see you guys helping each other out.

Culminating in a straightforward statement about what she hoped to achieve that lesson, 
Today we'll just do that as a class, so today when we look at the meaning you'll be able to understand all the words yourself, alright? So I'll just read it aloud to you, please follow through on your sheet as you go (proceeds to read poem)

By the end of the first 10 minutes, a class discussion about language techniques was well underway. Conversely, the start of Nikau, Aroha and Anahera's lessons occurred at a more relaxed pace because participants incorporated relational or cultural pedagogical strategies before talking about assessment, linking to previous learning or the lesson's activities. Aroha and Anahera in particular, worked hard to connect with students and their lives outside of the classroom at the beginning of the lessons. For example,

Anahera: Did he get excluded in the end? They didn't come to the meeting, aye?

Student 1: Ah, I don't know

Anahera: You don't know much

Student 1: No, 'cos I don't go see my Nan and them. Oh, sometimes I do but not all the time and he's at my Nan's.

Anahera: Is he?

Student 1: Yeah. Oh yeah, I got a drink!

Anahera: Is [the name of another teacher of the students'] here today?

Student 1: Everybody's saying he's sick

Anahera: Is he really sick? Ew, you don't need that sugar

Student 1: I just had some.

Anahera: Morning (to another student). Give it here. Work out how much sugar is in that one little bottle

Student 1: How much sugar?

Anahera: Yup. Do the maths.

Student 1: How you do that?

Anahera: It says - now my eyes are going crazy...

Student 1: A ha ha ha, Miss' eyes. Chur my brother (to another student)

Anahera: I need my glasses on. Mōrena koutou. . . Oh it's got, oh nah it's gross

Student 1: What?

Anahera: It's full of all sorts of things. 
Aroha and Anahera were also observed repeating task instructions to students who were absent, late to class or not listening. During an interview, Aroha said she was frustrated by students who were not in class because of extracurricular activities, while inconsistent student attendance and transient classroom issues affected lesson continuity in Anahera's class. The time taken by participants to settle students in Nikau, Anahera and Aroha's classes was considerably longer than Maia's. Another reason why the lessons in their classes took longer to get underway was because of the time it took to check homework.

\section{Homework}

Anahera, Aroha and Nikau were observed checking homework at least once. This process took up a significant amount of teaching time because only a handful of students had completed it. Maia managed to avoid was the issue of incomplete homework because she did not set any. It took at least 15 minutes in Nikau's class to determine that homework had only been completed by the most studious and academically able student (Student 6 in the following excerpt),

Nikau: Have we all chosen our scene for analysis? You're not looking very confident there Miss Wirihana (Student 1 laughs). Your body language is telling me that you

\section{Student 1: Haven't}

Nikau: Haven't. Which one didn't you do the reading log or the scene analysis Student 1: The analysis

Nikau: The analysis. You're not looking very confident Te Koha (Student 2 mumbles). Is the analysis done too? Have I seen a scene analysis? (student mumbles). Ok, I haven't seen it (student mumbles). Sorry, the scene analysis is one, so you've got the introduction one that we've done, the opening scene one that we've done one other scene that you've chosen yourself, have you got that? Student 2: No

Nikau: Log? (directed at Student 3, student response inaudible) ...scene analysis? (student response inaudible) So I should have a look, or... ? You will have a look. What's your scene, what scene did you chose? Student 4? (inaudible student response) ... you haven't chosen yet, have you. Log? Not yet. Student 5 ? Student 5: Police raid 
Nikau: Police raid and the reading log? (inaudible student response) Aye?

Almost finished. I'm going to talk to you about the rest of your reading log (Student 6). Are the majority of you working on log or finishing off $\log$ ? So by the time I'm finished with you I should be able to come in and see you.

Aroha set the homework task as a lesson activity after discovering, at the beginning of the lesson that none of the students had attempted it,

Aroha: On Monday we started with this quotes table, like we did with the last one. We were meant to do this for homework.

(Students go silent)

Student 1: You didn't tell us that

Aroha: Ah, kia ora Student 1, yes I did. You were meant to do that for homework. So where are we at with that? Some of you weren't here so come and grab one of these for you... Ah, no. If you already got one you ain't getting another one (Aroha starts to kōrero Māori with students) Alright, let's get back to this. (Students all talk over each other). Okay, let's get back, we digress. No, English. So, how many of you have done this? The first three? . . So how many of you have done your homework? So remember the whole idea of this that you would do five and we would share it and we would have a discussion around it and that would help you fill out your third reading log.

Student 2: I kind of forgot about it

Aroha: So what we are going to do, because this has all turned to custard. And, you know, the time I spend putting this together gets wasted 'cos you guys don't do what you're meant to do, year 13. I'd probably get a better response from year 9 - now I'm being facetious and sarcastic. So you've now only got half an hour, and I'm not giving out any more sheets I only print out enough.

As Aroha moved around the class, some students admitted they couldn't do the homework because they hadn't read the novel. The participant asked, "What will you be doing for homework tonight?" The student responded, "Not reading" and Aroha remarked, "That would be right". Revisiting the homework as a class activity took most of the lesson. Anahera similarly broached the issue of homework with her class at the beginning of one lesson, 
Anahera: Okay... whakarongo mai. Alright, remind me, yesterday, you were finishing off something for me for homework, confession time... who didn't do it?

Student 1: Oh yeah... I did mine... I did mine yesterday...

Anahera: Did you? Let's get them out then. Why didn't you?

Student 2: I've been busy, Miss...

Student 1: Forgot Miss... Nah, I didn't do it

Anahera: What about you?

Student 3: I couldn't even remember what we were meant to do!

Anahera: (kōrero Māori to student 4)

Student 4: (responds in reo Māori)

Anahera: Oh, really? Ok, in here?

Student 5: I don't know what we're meant to do, Miss

Focus group interviews with Nikau's class revealed that there were varied reasons why students didn't do their homework, such as the teachers forgot to check it, no access to the internet, homework was not vital to important learning, students didn't hear the homework or forgot to do it. Once the lessons got underway, all four participants enacted pedagogical approaches to deepen students understanding of the studied text.

\section{Scaffolding skill development}

Maia regularly gave consistent and clear feedback about how the learning focus linked to English skills and techniques. For example, when discussing "Māori Battalion Veteran" students would volunteer ideas about the studied text and these would be discussed in relation to ideas in previous lesson, or Maia used students' ideas to signal the next learning steps to the rest of the class,

Yup, (to a student) so do you think the whole poem is a stream of consciousness and a journey he's going through? That's really good. (To the class) When we come to look at the structure I'd like you guys to keep that in mind. [Student's name] idea of it being a journey, it being a stream of consciousness 'cos I'm going to give you guys a question and we'll see your thoughts on it. 
A "thinking aloud" strategy was regularly modelled by Maia and, to a lesser extent Anahera, to support students to see the effect created by the text:

Maia: Why do you think there is a lack of form or a lack of structure? Why do you think it's free flowing like that?

Student 1: Is that what his mind's like?

Maia: Yip. I reckon too aye. Did anyone else think of that? Like, we talked or [Student 2] talked about his journey that he's going through. [Student 3] brought up the idea that he is going through some type of trauma. So maybe what [Student 1]'s saying, I mean the form to me just scrambled - this is what I'm thinking all the time. So maybe that's why the poet has those ten times tercets with no spacing... um, few line breaks... to show the speaker's mind... and thought process. This comes back to what [Student 2] was saying about it being a stream of consciousness. It's kind of like go go go, this is what I'm thinking.

Later in the lesson, Maia asked the students to apply the text comprehension strategies to the assessment conventions. Maia modelled a metacognitive process that broke the development of English skills into smaller chunks. This scaffolding approach appeared to provide a clear pathway towards attaining high levels of NCEA achievement. For example, Maia talked to the students about the purpose of a strategy for approaching the assessment task,

Remember that when you are aiming for higher grades in unfamiliar text you need to be able to talk about the meaning and the purpose behind the poem - what the poet's trying to say. So to me there are three level of meanings in poems.

Then she spoke about how she would approach the assessment task,

Now you'll probably get teachers who tell you different processes, but this is how I analyse it, okay. So I see a literal meaning, which is the exact meaning. So if I was to write the poem it would be a literal translation of what was happening. The second one is the connotative meaning, so to me that is what I feel when I read a certain piece of poetry. And the third one is the symbolic meaning or the representative meaning, so that's what the poet wants you to think about when you are reading. 
Next, Maia directs students to an activity that required they practice the skills at the level of meaning-making they felt most comfortable with,

Now, what I'd like you guys to do it, we're going to choose a meaning, so a type of meaning, and you're going to write what you think this poem means. Now when I look at these three meanings I think that they come in levels. So for me, a literal meaning is probably the simplest form of meaning, connotative, that's a step up because you need to be able to think what type of imagery is being portrayed or the tone of that poem or whatever and then symbolic is the hardest meaning, I reckon, to get. And sometimes that's why we struggle with poetry is because the poets have these huge symbolic ideas and for many people they can be really hard to try and connect with. So at this level I'm just going to get you guys to choose. So you can choose either the literal, the exact, the connotative, how you feel, or the symbolic, what it's representative of and I'd like you to write a two to three sentence explanation of this poem, okay. Are there any questions about the meanings or the task?

Aroha and Anahera also spoke to students about how the classroom activities linked to assessment conventions, however, they did not apply the same degree of chunking and scaffolding as Maia. Consequently, feedback about assessment and skill progression occurred less frequently and was less detailed,

Aroha: We did "Property of Shiloh" (Logan, 2010), "The Dark Horse" (Robertson, 2014) and "Dustbins" (Ihimaera, 2009). And so techniques used to represent the relationships: emotive language, repetition, so obviously part of doing Level 3 is that you need to talk about how the author puts together the text. So those are language techniques, things that are similar, you need to include. On this piece of paper I've actually filled out some of the things you could potentially discuss, stuff that we've already identified. So we've talked about emotive language that could come under tone and atmosphere. How language was used to create a reaction from the reader or the audience. 
Anahera: This is what for Level $1 \ldots$ this is the kind of stuff you need to know. Then we've got to add into it the techniques the director uses to help us make these changes, okay? So we're just going to quickly scroll through and I'm going to stop it whenever we see. I'm going to stop it here... I'm going to stop it here... and I'm going to stop it here... and we're going to look at the actual techniques. So what are the techniques that we've seen most of so far?

Student 1: Over the shoulder shots.

Anahera: Over the shoulder shots, what else?

Participants also gave students variable degrees of choice about what and how they could learn. In the previous excerpt from Maia's class, students were give options about how they could elicit meaning and purpose from text by focussing on literal, connotative or symbolic meanings. Differentiation supported students to analyse the poem at a level they felt most comfortable with. In comparison, the other three participants offered choice around text or topic selection for an assessment task. For example,

Aroha: So you now have five minutes left. I want you to choose your second text and I want you to find how you're going to connect it to "The Dark Horse" or the two texts you're going to do and what those connections are going to look like and we're going to feedback really quickly.

Student 1: Are we going to do "The Dark Horse".

Aroha: No, you can choose what you like to do. It's up to you I'm leaving it up to you, ka pai? Kia kaha.

The difference between how Maia approached the English skill development process, in comparison to Nikau, Aroha and Anahera, highlights how everyday classroom performance is constrained by colonial time. Pedagogical actions involved in starting the lesson, setting homework, building relationships, incorporating students' culture and teaching about context fill a lesson timeframe at the expense of applying strategies that support students to develop a deep understanding of the studied text and the literacy skills required to elicit such meaning. The consequences of the effects of colonial time and how this shaped the way that the four participants approached assessment tasks are explored in the following section. 


\section{Engaging with assessment tasks}

Anahera's class were rarely exposed to skill development that transcended Achievement. ${ }^{30}$ The students' complex backgrounds and the vocational pathway programme requirement that students obtain Level 1 and 2 English literacy ${ }^{31}$ to progress to the apprenticeship stage, were likely reasons why Anahera seemed to primarily focus on preparing her students to do well in the NCEA exam. During one interview, Anahera was pleased to observe that students were demonstrating their understanding of visual and verbal techniques,

I was really surprised when they were talking about watching TV last night and seeing the impact of that on it and that was a real moment for me ... that's a cool thing and I'd been pushing the whole "you're manipulated" and it felt like that's what [the student] was talking about, so that was cool.

The students' performance in the school exams had highlighted areas of skill development that needed more work. Anahera said the students' results had shown they were "really good at pointing out the techniques but they're not good at actually describing what they can see and that came across in the [practice] exams, so for me the next steps with them are about describing scenes". Consequently, Anahera's students were rarely required to develop textual meanings beyond what was required to pass assessments, which involved describing a film technique and explaining its effect,

Anahera: What's Ariki's face. What's that scene showing us? ... So we would say, we see a medium close up on Mana aye, but Ariki's face is still half in it. Is that a medium close up or is that a close up?

Student1: Close up

Anahera: It's a close up also, so there's also Ariki's face is half-way, well it's a close up on half of Ariki's face too. The look on their faces...

Student 1: Is it a medium shot?

\footnotetext{
${ }^{30}$ To get an Achieved grade for passing secondary school English NCEA assessments, students must demonstrate description and explanation (Level 1), analysis (Level 2) and critical evaluation (Level 3) of text conventions (for example, character, ideas, and language techniques). Students who progress to a Merit or Excellence grade demonstrate a deep and sustained understanding of the text and an appreciation of the contexts in which the literature sits.

${ }^{31}$ NCEA Level 1 and Level 2 English have a literacy benchmark of eight credits in identified assessment standards that denote the minimal requirement for English proficiency.
} 
Anahera: It's a medium close up on him but it's a close up on... it's not an extreme close up it's not right up there. What do we want Ariki to do here?

Student 4: Stand up for him

Student 1: Change his mind

Anahera: Yeah, or at least give him to somebody else, aye

Student 1: Yeah

Anahera: But he doesn't so this is the change where we start to change how we feel about what Ariki is doing. What else don't we know here?

Student 4: That he's dying

Anahera: Yeah, we don't know that Ariki's dying at this point

Student 2: The President gave him to Mutt for a reason

Anahera: Yeah, why would the President do that? (Students start talking) He's supposed to be the brainy one who has the...

Student 3: That is brains

Student 5: Give him to the hardest person

Anahera: But he could see that Ariki didn't really want to give him to him. He could see that Mana didn't really want to do it.

Several students: You want to say yes... Oh well... Give him to the hardest $\operatorname{man} . .$.

Anahera: Okay, are we all done there? (Students slowly become silent)

While Anahera and her students had their sights primarily set on Level 1 or 2 English literacy, Nikau, Maia and Aroha aspired to high levels of academic achievement (Merit or Excellence) with the view that their students could achieve high grades. The school examination process similarly showed Maia that her class of predominantly Pākehā students had struggled with the poetry section of the unfamiliar text assessment. Maia approached a practice assessment task designed to support students to answer questions based on an unfamiliar text during the third lesson observation, after students had learned the skills in previous classes,

So what I want to do today is get you guys through one more practice for your unfamiliar text. We're going to follow the structure that we looked out, jeez, 
before the school exams, so PILATES ${ }^{32}$. If kind of tells you what you need to do in a response to get Excellence. First of all though, we'll go over just a class revision kind of thing on the three key aspects of the poem. You did this in groups last lesson but what I want to do is break it down as a class this time. So I think what we might do is just have our poem in front of us and do a huge brainstorm revision type of thing on what we think this poem is about, okay? We'll start with meaning, we'll move I think, from literal straight into connotative. So what do we think? Hands up, just keywords or key ideas, what do you think the meaning is behind this poem, or what do you think it's saying?

Maia brainstormed ideas with the class for 15-20 minutes before the students are asked to start working on the practice test. The class moves into the task straight away. The beginning of the assessment task did not run so smoothly in Nikau and Aroha's classes. Aroha's class were required to write a report for a Level 3 English assessment that required developed levels of thinking associated with analysing and critiquing significant connections across a range of texts. In previous lessons, Aroha did a lot of work with her students around developing different themes from studied text. In this lesson, she was observed reading the assessment task instructions to the students,

Aroha: Remember our theme is "relationships". Planning your report, plan significant connections across text using supporting evidence. So this, um, it's bigger than explain, remember in this you should be analysing and critiquing, yup? Your report needs to show that you are analysing and critiquing...

Student 1: What's analysing?

Student 2: What are we looking at?

Aroha: This piece of paper, up top. Analysing and critiquing, can we put that in there?

Student 2: Where are you reading from?

Aroha: The top of it. Your report needs to show... in the box. So your report needs to show that you are analysing and critiquing significant connections across text and you need to support your points with evidence from the text.

\footnotetext{
${ }^{32}$ PILATES is an acronym that presents students with a formula to aid textual analysis ( $\mathrm{P}$ stands for purpose and audience, I ideas, L language, A analysis, T techniques, E effect and S synthesis)
} 
Connections may include links, commonalities and or relationships between knowledge, experience and ideas, purposes and audience, language features and structures. You need to organise your text into two sets of two texts that you feel work well together. You will analyse two connections in your report, the other connections will emerge throughout your report. You are advised to analyse... $\mathrm{mmm}$, a significant stylistic connection as your second link between text.

Next, Aroha links the task instructions to the work that students had done in class up to that point,
So my understanding, this is from Level 1 connections, so I've actually borrowed this template to help you guys put together your report. You need to identify the connections between the four texts yourselves. In your logs you have already supported information on the character who reveals the theme, how the character or characters reveal the theme, the author's/director's purpose, what stylistic features help support the purpose of the text. Um, you have planning tables, diagrams that have helped you bring the four texts together, you will consider these ideas as you look to establish what the texts have in common and how these connections between your texts are significant. So remember our focus is relationships but what are those relationships based on?

During an interview, Aroha acknowledged that she had given the students a Level 1 planning template to prepare them for the report writing assessment, but she recognised she needed to "tweak [the Level 1 template] a bit more" to suit Level 3 purposes. There was little exploration or scaffolding during the observed lessons of the ideas and skills associated with critique and analysis, other than making comparisons between studied texts in relation to the theme of relationships or "making connections to the wider world". After some discussion about the assessment task, one of the most academically able students in year 13 (identified as such by Aroha in an interview) asked for more guidance about the task,

Student 1: Do you have any good examples? I guess they're online then.

Aroha: Um, I think that you should just write it because I just think you'd reword things and...

Student 1: I've just got no idea like even how to start it, like... 
Aroha: Read this table

Student 2: Chur $^{33}$

Aroha: Start by giving your first connection a label; name of connection link to the idea of your theme and the two texts that share this connection. It's all there if you actually read it (directed at Student 1)

Student 2: It's all there

Aroha: It's all there

Student 3: It's all there

Aroha: Um, explain how this idea is presented in each text...

Student 1: Ohhh, I get it

Aroha: And what character's situation show you this idea. I have included it all there for you

Student 1: Thank you Whaea

The students were very fond of Aroha and it was rare to see them question the learning process. Student 1's initial concerns about how to start the written task quickly disappeared after other students backed up Aroha's assertion that the instructions contained all the required information.

The process that Nikau undertook for a scene analysis and reading log writing tasks for internal assessment showed a similar level of disorientation from students. Nikau asked students to complete a personal response about a favourite scene in "Rain of the Children" for homework that could later be developed for assessment. As Nikau moved around to speak to students about what they were going to write for their scene analysis it became clear that most of them had not watched the film. The students were told to use a reading log that they had completed earlier in the year as an exemplar, although it appeared that many had yet to complete this task either. One student asked how long it had to be and Nikau responded,

Nikau: As long as a piece of string is. You know what I mean by that? So, go back to our analysis of the opening scenes and ensuring that your one is as detailed in the analysis as what that one is.

Student: Okay

\footnotetext{
33 "Chur" is a term of acknowledgement or thanks
} 
Nikau: So basically, everything is within that scene and you capture it and the key thing, so just like our first one, is why. Why is the film that way or why is it this way? And for that one there, always go back to what's the purpose.

During interviews, Nikau and Aroha spoke about the difficulties their students experienced engaging with the reading and writing process and achieving high grades in English. One concern that Nikau expressed during his phase one interview was that his Māori students appeared to have lost the "art" of reading. He identified a "missing link" in the reading process and associated it with a lack of visualisation and stimulation that could be found in activities like kapa haka. During post observation phase two interviews, Nikau again spoke about how students could develop a better understanding of the text if they find a personal or emotional connection,

I do think Māori kids for them to have that personal connection to the text. Or otherwise it just sort of sits out there it doesn't have any effect on them or doesn't affect them in any way, yeah.

Aroha similarly spoke about the literacy strengths and weaknesses of her Māori students. She said that her students are good at remembering and articulating a nuanced understanding of the studied text, and some have an "amazing work ethic",

The kids like to discuss, verbally their very good at discussing, verbally the kids get a lot of the ideas. Where they really struggle is with that, is actually reading. Reading for meaning, reading for please just to actually expand their knowledge. But, um, secondly is actually written work, is actually putting their ideas down onto writing we talk about that all the time in terms of there seems to be a huge gap in the process from what they know and to putting that on paper

The bilingual unit offered extra classes to counter academic struggles. However, some students said during focus group interviews that they felt pressured by the number of assessments that were due at the same time and thought that you just needed to work hard to be successful in English. This belief in meritocracy, coupled with a misguided perception that Māori student schooling success is assured through pedagogical and curriculum 
initiatives, gives credence to the view that "education for indigenous children has often been a zero-sum game" (Kidman et al. 2018, p. 235).

In summary, participants' classroom performances pertaining to scaffolding skill development and engaging with assessment tasks are affected by colonial time. The teaching approaches in this section show how the NCEA assessment pathway privileges a "timelessness and racelessness" (Mills, 2014b, p. 32) account of institutional existence that mutes historical harm and prioritises the sensibilities of Pākehā students. Alternatively, Māori student achievement in English is curbed by the impossible task of including pedagogies required to attain English academic success alongside those that attend to the notion of cultural and ethnic inclusion. In this way, settler-colonial imperatives suppress opportunities for Māori youth to attain academic success by privileging colonial time and a schooling experience that is in line with the lived experiences of Pākehā students. The following section shows how ongoing indigenous oppression is legitimised through the construction of a state narrative of biculturalism.

\section{Lovely knowledge about Māori society}

This section of findings shows that Anahera, Maia, Nikau and Aroha worked with students to perpetuate "lovely knowledge" about Māori society. In Chapter Three, I introduced the temporal subcontract and described how white time and state ideologies of that biculturalism freeze indigeneous temporalities. Regarding the latter, the frameworks of settler-colonialism direct those operating within institutions towards a view of Māori existence that is frozen because whiteness is positioned as central to everyday operations. As Rifkin (2017) explains, the "extant legal and administrative frames" of settler-colonial institutions advance "nonnative discourses [that] themselves employ temporal narratives that produce limited visions of Native collective selfhood" (p. 6). This aspect of the Settler Contract was particularly evident through the way that temporal structures orientated the four phase two participants towards classroom interactions that produced idealised Māori identities, advanced traditional Māori culture, presented Māori as a political collective and ensured that racism was associated with individual prejudice and discrimination. Consistent within each group of findings is a view of Māoridom that is culturally and ethnically homogenous and distanced 
from the effects of contemporary structural racism to produce a feel-good view of Māori society that is in line with Pākehā sensibilities.

\section{Idealised Māori identities}

A traditional and stereotyped view of Māori personhood and culture that is connected to idealised Māori identities were evident in three of four participants' lessons. This aspect of lovely Māori identities featured most frequently in Anahera's class in relation to a short film study based on "Mr Frosty and the BMX Kid" 34 directed by Tim McLachlan (2010). The film was an entry for a competition sponsored by Tourism New Zealand and cultivated popular stereotypes about New Zealand or Kiwi culture ${ }^{35}$. In the film, a well-known New Zealand teenage actor called James Rolleston epitomises a carefree, rural Māori boy. Rolleston (as the BMX kid) is cheeky and speaks English with what mainstream New Zealand may describe as a Māori vernacular. During the film, the BMX kid takes off his shirt and teaches Mr Frosty (aka God) how to jump off a cliff and make a mighty splash (otherwise known as a "bomb") into the pristine waters of the South Island fiorjdlands. Throughout several viewings of the film, Anahera spoke about being directed towards the notion of a New Zealand paradise, however, students kept returning to the idea that the film was representing a particular type of Māori identity,

Anaera: Okay, so if you were going to do techniques for that one what would you do?

Student: Setting

Anahera: Setting, what else?

Student: Sound

Anahera: Sound, or what? What would you use too? What do they do that makes that film?

Student: Dialogue

Anahera: The dialogue aye. What else?

Student: (quietly) Just describes us Māoris

\footnotetext{
34 "Mr Frosty and the BMX Kid" may be retrieved from https://www.youtube.com/watch?v=ibC8LJ0_dVA

${ }^{35}$ In mainstream society, a Kiwi identity is associated with the perception that New Zealand is a multi-cultural society (for example, see: https:/www.nzherald.co.nz/nz/news/article.cfm?c id=1\&objectid=11188987). An alternative viewpoint is that a Kiwi identity is linked to the silencing of colonial oppression, through an "origin story of a good keen man wanting to give everyone a fair go" (Jackson, 2018).
} 
Anahera: Write down, be specific about the techniques. C'mon

Student 1: So what are the techniques? Just shots...

Anahera: Setting, dialogue, music, lighting

Student 2: What's dialogue?

Anahera: Dialogue? Conversation

Student 3: We know who's talking

Anahera: Yeah, and that makes... what was the point of that?

Student 1: To show us...

Student 3: To show us beautiful New Zealand

Student 1: To show our, like, how good Māoris are maybe

Anahera: (laughs) yeah, kind of...

(Film starts. Dialogue: "We call it Aotearoa around here, bro". Boys laugh.)

Student: I wouldn't say that to God

Student 1: It's like every sentence he's saying Bro

Student 2: Bro or $\mathrm{Cuz}^{36}$

Anahera: What's the point of that?

Student 2: To show how New Zealand characters are...

Anahera: Yeah, New Zealanders talk

Student 1: Oh, look he's saying "C'mon cuz"

Student 2: And that... "Chur!"

Anahera: Yes, absolutely. Okay, so by the end of the film he's got God saying cuz, but the whole point of that... what was this film made for, do we know?

Student 3: Representing Māori... oh Eden?

Anahera: It was an advertising advert about how great New Zealand was for people to come and visit.

Twice during the lesson Anahera points to the dialogue as being "very, very stereotypical Māori . . . because we don't all talk like that", but at other times she also describes the dialogue "cuz", "bro" and "choc top" as "typically Kiwi" (as demonstrated in the third classroom exchange above). During another moment in the lesson, a student asks,

\footnotetext{
36 "Bro" and "Cuz" are words that originated from a Māori-English vernacular but are now associated with a
} Kiwi vernacular. They are terms of familiarity or endearment. 
Student 1: Is it a New Zealander Kiwi or a Māori kid?

Student 2: Yeah, he's hori ${ }^{37}$ as

Anahera: It's not hori, excuse me. How does he use it?

Student 2: Um strong

Student 3: As a New Zealander

Anahera: Yeah, kind of just as we know. Now when people come over here and they hear it they are...

Student 2: Yeah but that's like hori, isn't it?

Anahera: You wouldn't call it hori because hori's a bit of a derogatory term

Anahera continued to stress that the film was representative of New Zealand culture, in what appeared to be an attempt to negate the negative "hori" label that the students were attributing to the BMX kid. However, the relationship between the film's portrayal of an idealised Māori identity and the use of Māori vernacular within a text promoting Kiwi culture was not a topic of discussion

Conversely, a spontaneous teaching moment in Maia's predominantly Pākehā class shifted the discourse from the transmission of anglocentric values associated with the teaching of English conventions, literary analysis and assessment writing processes to a discussion about the historical context of "Māori Battalion Veteran" by Alastair Te Ariki Campbell (2001) (see Appendix I). Maia spoke to students about the history, comradeship and familial relationships that connected the men in the $28^{\text {th }}$ Māori Battalion who fought in during World War Two. Consequently, students were directed to look beyond idealised Māori identities, towards a burgeoning understanding of the historical sacrifices that iwi made in support of the idea of a bicultural partnership. During a focus group interview, one student said that the historical context of "Māori Battalion Veteran" helped them appreciate that the poem has a Māori perspective, while others said,

Student 1: I feel as though it changes the tone the poem when you know that's the Māori battalion because it just kind of seems more heartfelt when you know it's kind of like a veteran.

37 "Hori" is a term that historically has negative connotations used to describe Māori. 
Student 2: Do you think that might be because of the closeness that was experienced by those men because that was the only battalion there was... And so that a lot of them would've known each other and I suppose that makes it a lot more... rather than just a whole bunch of people heaped in and taken from all over the country...

The moment when Maia relayed some historical context associated with the study of "Māori Battalion Veteran" was fleeting but there was evidence that it helped to deepen students understanding of the complexity of historical relations between Māori and Pākehā. However, the findings from Anahera's lessons show how romanticised and idealised notions of Māori identities may be reproduced through New Zealand text that are underpinned by nationalist narratives that celebrate Kiwi culture and a sanitised view of race relations. A traditional Māori cultural approach also has the potential to support an idealised perception of Māori society, as discussed below.

\section{Traditional Māori culture}

All four phase two Māori English teachers frequently referred to traditional aspects of Māori culture in relation to teaching about Māori society when studying New Zealand literature. As previously discussed, the ability to communicate the breadth and depth of Māori worldviews in institutions is constrained because the temporal subcontract freezes Māori society into a timeless past. Consequently, the participants in this study sometimes defaulted to a perspective of contemporary Māori society that is in line with traditional Māori cultural characteristics. Drawing on Māori tradition and history when teaching about New Zealand literature is vital to imparting mātauranga Māori to youth and strengthening Māori society, however, the findings in this section also reveal how the structures of settler-colonial schooling subtly direct the transmission of Māori epistemologies to forefront lovely knowledge and support the notion of settler belonging.

As discussed in previous findings sections, the cultural marginalisation of Māori in mainstream New Zealand society motivated Aroha to implement teaching strategies that advanced a Māori worldview. She was personally driven to further the status of Māori in society and indicated that good teaching could help achieve this, 
I would like... I would love to have kids that come out of here and become researchers, authors, teachers, you know? Doctors, lawyers, that's sort of what my goal is; that we can compete at every level of society with a Māori view and it has legitimacy. Because that didn't happen when I was a kid you know, in my family it did but if you stepped outside of my world, it was very Pākehā. I don't want that. I want that choice to be for our kids that they can have a Māori doctor. That they can go to a Māori dentist, you know what I mean? That's what I... that's how I see New Zealand and hence why I became a kaiako.

During interviews, Aroha spoke about the importance of teaching Māori kaupapa, passing on her passion for te reo Māori and helping students to make "those connections with te ao Māori and te ao Pākehā and find the legitimacy of both languages in both worlds". These beliefs informed why she drew on tradition to make visible and normalise Māori perspectives when discussing relationships, characters and ideas during the study of New Zealand texts. For example, during the study of "Tū" by Patricia Grace (2004) Aroha discusses family dynamics associated with different Māori brothers who decide to join World War Two, and their father, whose involvement in World War One led him to suffer from post-traumatic syndrome,

Aroha: If we think about his father, because they know the consequences of the war because look at what happened to their dad ... So I what I want you to do is think about those relationships and belonging to a whānau and how older siblings take on tuakana role, and as teina, because there's that whole thing of tuakana/teina, teina/tuakana and those roles. Explain how this quote develops the idea of a relationship in a text. So everything revolves around what happens to their dad and the choice of going to war.

The seamless integration of traditional Māori cultural concepts in the study of New Zealand literature also occurred in a lesson focussed on relationships in "The Dark Horse" by James Napier Robertson (2014). Aroha worked with her students to develop insights about the relationships that the main character, Genesis (who is a homeless schizophrenic), establishes with others in the film, including his older, gang-affiliated brother Ariki, and Ariki's son Mana. Genesis has a gift for the game of chess. As the film unravels, his love of the game 
becomes his salvation in the real world. At the beginning of one class discussion, some students picked up on many of the negative themes in the film. Then Aroha changes tack,

Aroha: So let's look at the positives because I don't think the relationships always have to be negative. I think that even though there are some darker themes in some of these texts, we could look at some of the positive aspects. So if we were to look at a positive aspect of "The Dark Horse" what would those be?

Student 1: The chess club ...

Aroha: So in terms of his relationship with the chess club, tell me about that. What does that look like? What are some of the ideas that are played out in that? Student 2: He kind of gives them something to look forward to?

Aroha: Yup, so he creates a sense of...?

Student 1 and 2: Hope... belief

Aroha: Yup, so he creates a sense of hope and belief. What else does he do within the chess club?

Student 2: Creates a family

Aroha: Creates a family, awesome. And how does he do that? What's something really symbolic that he does to show that?

Student 3: He gives out the chess pieces and it symbolises their self

Aroha: Yeah, so he creates a whānau. So the use of the chess pieces and him handing those out is symbolic of that ...

Student 2: He takes them to a marae

Aroha: So he gives them? ... So he creates a connection, maybe? ... So he creates a connection with their Māoritanga.

In this exchange, Aroha directs students towards the view that the hardships Genesis faced could be redeemed through establishing a chess club that helped disaffected Māori youth connect to their Māoritanga. In doing this, she references a sense of cultural connectedness aimed at fostering intellectual, social and epistemic capital within her Māori students. However, the ability to naturalise a frozen and traditional state of Māori personhood as representative of all lived Māori experience is advanced by the limited epistemological space that educators are given by the state to explore Māori interests (through, for example, positioning policies of cultural and ethnic inclusion outside the white core of the institution). 
This ensures that a significant but partial account of Māori society is reproduced in classroom settings.

Advancing the traditional and historical aspects of Māori culture with a view to empower Māori youth and challenge the dominant Pākehā cultural perspective was similarly demonstrated by Nikau during the study of "Rain of the Children" by Vincent Ward (2008). In one class discussion, Nikau connected traditional Māori cultural concepts to a view of the New Zealand landscape,

Nikau: What makes this distinctly New Zealand or distinctly Aotearoa?

Student 1: It has that New Zealand touch?

Nikau: What is that New Zealand touch? Define that New Zealand touch for us, those characteristics.

Student 1: It's more of a spiritual thing, you know like, how we, the land?

Student 2: The land

Student 3: The greenery, birds flying

Nikau: I think that's important. So significantly what you've said is that there is a sense of wairua or spirit there. I think you - have you got this written down? So, it's distinctly New Zealand because there's this sense of wairua or spirit and that's captured through a landscape and the setting.

Another way that traditional aspects of Māori culture were drawn into the classroom, occured when Nikau worked with another teacher from the bilingual unit to show students how Māori culture is evolving and less willing to hold on to tradition,

Nikau: The other thing that Whaea and I talked about was, you know, because our people had such whakapono, such belief, our people are so spiritual that was something that they carried with them all of the time. Prior to Pākehā arriving here and our traditional beliefs, oh sorry the first arrival and the first recording talked about how our tippuna used to karakia all the time ... But we notice the difference with you lot that yous most probably don't have that same view that we have, just because it's not been amongst you.

Visiting teacher: ...grew up going to church. That was part of our tikanga every Sunday but now... 
Nikau: Made to feel guilty all of the time (laughter)

Visiting teacher: Families, church is part of the family home, that family is not something that you see or valued. When you get older you recognise the value of going to church, the true value of wairuatanga, the values that underpins it. . . You see the change is it's become very much an 'I' world, not about the 'we' world. I don't know if you think that but unless you've brought up in that and the other people that you work with everything's kind of focussed around themselves. You can't be where you are without everyone else around you. It's actually knowing that value of the "we", the whānau, your extended whānau, kura.

In this section, Nikau and his colleague highlight the changing nature of Māori culture ("it's become very much an 'I' world, not about the 'we' world") to show the students how Māori traditions work in opposition to whiteness. That is, by referencing the spiritual and collective strengths of traditional Māori society, Nikau draws on Māori epistemologies to challenge the way that dominant racial discourses associated with whiteness aim to fragment and divide Māori communities. However, this form of indigenous resistance draws on phrases such as "our people" and "our traditional beliefs", directing students back to the view of Māori as a homogenous ethnic collective who are frozen in history. Ironically, this language has the adverse effect of constructing divisions in contemporary Māori society by obscuring cultural diversity and silencing ways in which structural racial bias negatively impact many Māori. The following section shows how even politicised approaches to race relations are usurped by the Settler Contract in ways that circulate lovely knowledge about Māori society.

\section{Māori as a political collective}

A third curriculum approach that generated lovely knowledge about Māori society emerged when ideas about the studied text were linked to political concerns and issues of race in mainstream New Zealand society. During the study of "Rain of the Children", Nikau supported students to see themselves as part of a Māori collective who have developed political awareness about unequal power relations with Pākehā. Despite incorporating a strong historical and political perspective during the lessons, Māori were generally presented as a homogenous ethnic group and the present-day structuring effects of colonisation were overlooked. 
To fully appreciate the context shaping the narrative in "Rain of the Children", Nikau taught his students about early settler-indigenous relations and what motivated Māori and Pākehā to form a relationship. Nikau introduced the term "lingua franca" and unpacked the significance of the English language as the "language of money" needed to acquire European commodities. This historical background supported the students to see how English was central to the assimilation process. Later in the lesson, one student demonstrated her understanding of lingua franca by asking if that's why "the three main subjects [are] Math, English and Science?" Nikau brought the conversation back to the way historical events may impact Māori society and schooling today,

But we, as a people, after 150 years, since the Treaty of Waitangi and colonial government, we as a people have become quite assimilated into our Pākehā ways and into reo Pākehā as being important. And it still is important. So, in terms of the three subjects: English, Math and Science, yeah, they still dominate, aye. Don't they? That's where the power is, mārama? Understand? ... we're still dominated by a Pākehā society and a Pākehā culture, you know, and when you said, "What's the important subjects, English, Math, Science". So reo Māori and tikanga Māori, don't have that same status as those other subjects, do they?

Unequal power relations between Māori and Pākehā were further emphasised through comparisons between Māori society in the 1970s to today, to show students that race relations are an evolving process. In the opening scenes of the film, Nikau spoke about the ease in which Vincent, a young Pākehā film director, was accepted into Puhi's life. Puhi was an elderly Māori woman who lived on the fringes of the Tūhoe community and Nikau suggested that her invitation to let Vincent into her life symbolised how naïve Māori peoples were in the 1970s. Nikau attributed Puhi's welcoming nature to manakitanga and sharing kai. He also explained that in the 1970s, it wasn't unusual for Māori to respond this way and defer to the dominant culture,

Nikau: People would've been like "Oh, that's nice they want to film her, oh ka pai” you know? "Oh, she's lucky, that Pākehā fulla is interested in her life” Not, "Oh what is he doing here? Who does he think he is?" You know, what we might say now, we'd probably challenge him now but back then I think we would've been a lot more tolerant in our treatment of him. 
Student 1: So, are you saying she wasn't judging him?

Nikau: She wasn't judgemental, and we were a lot - as Māori - we were a lot more accepting of things than say, what we are now ... I think we are now more inclined to question "Why do you want to come and take a photo of my Nan now? What do you going to do with it? Are you going to make money off it? Or if you're going to make money off it we want some of it, you know, is Nanny going to get her cut?" Type thing, so as we have become more knowledgeable with the lingua franca as well and more politically aware. We would ask, we would challenge. Whereas before we would've been more accepting, "Oh haere mai, bro. Sweet as. Yeah, we'll feed you, we'll look after you’. Mārama?

Nikau used the moment when Puhi welcomed Vincent into her home to show that Māori society has progressed and become smarter since the 1970s. He told students that Māori used to be more accepting, wanted to be like Pākehā and have "the nice house, the flash car, the good job. . . You know you wanted to have Pākehā friends”. During the post-observation interview, Nikau said he wasn't surprised that students didn't identify that Māori were assimilated, tolerant and submissive in the 1970s,

I suppose growing up in that time as well, that you always reflect on those with nostalgia and being the golden years of Aotearoa New Zealand when we were "one people", you know. It's not strange that he went in to record Puhi's life story in regards to that and it's not strange that she was accepting of him either, you know, and took him in. Just trying to get them to understand, although you know I sort of feel that we got their understanding, or the importance of context clear with them, you know. Which then I think helps them to lead into the text a lot more effectively just beyond their initial emotional reaction to it.

In these observation and interview exchanges, a narrative of progression is generated which suggests to students that the social context surrounding Māori society has improved, and that Māori as a political collective are savvier and better equipped to challenge marginalisation in mainstream society. Aroha similarly advanced a narrative of progression through a comment about being able to impart te reo Māori and tikanga to her students because she lacked this experience at school. Maia also believed that the strong tone in "Our Tìpuna Remain" by Jaqueline Carter (2010) was evidence of a more progressive society. 
Positioning Māori as a political collective emphasises that, over time, Māori continue to develop strategies and forms of resistance to the dominance of Pākehātanga and the selfserving motivations of some Pākehā people who wish to exploit Māori interests. However, failing to juxtapose measures of resistance against the material realities of indigenous peoples, advances lovely knowledge about Māori society through the belief that social conditions are improving. Persistent ethnic disparities between Māori and Pākehā in health, education, incarceration and youth suicide rates (as referenced on page 2 of the thesis) suggests that Māori are not collectively enjoying the material benefits of positive change in mainstream New Zealand society. By silencing race, the epistemological structures of state schooling push away the educator's ability to supplement historical movements of indigenous resistance with ongoing ways that contemporary manifestations of whiteness infuse mainstream society to oppress and suppress Māori peoples. Consequently, classroom interactions that continually return to the circulation of lovely knowledge in the absence of meaningful structural racial critique play a critical role in reproducing the terms of the Settler Contract. Another reason why critique about inequitable social and ethnic disparities did not occur in participants' classes was because discussions about racism did not move beyond the notion of individual prejudice and discrimination, as discussed in the following section.

\section{Racism as individual prejudice and discrimination}

The circulation of lovely knowledge about Māori society was furthermore aided by classroom interactions that framed racism as individual prejudice and discrimination. In Anahera's class, some students were forthright about refusing refugees from war-torn countries. In line with teaching approaches that sought to build cross-cultural understandings in Chapter Six, Anahera wanted students to acknowledge the other side of the argument,

Anahera: If our country suddenly had civil war or we suddenly had a group of people who were completely determined to wipe all Māori out let's say, and the only chance we had was to leave the country... 'Cos that's what's happening in Syria, they're not being... it's because they hold certain cultural beliefs or religious beliefs that they are being killed...

Student: Let their girls and their kids come over. Let their men...

Anahera: What makes them different to any of us?

Student: They might come over here and start taking over 
Anahera: They're not the ones who are taking over

Student: We might start getting dictated by other people

Student: They might start taking all our jobs

Several students: Yeah

Student: Send them to Auckland

Student: Nah, the jobs are already taken

Several students: ... Indians (laugh)... house shortage (lots of student comments)

In this part of the exchange, Anahera perceives that her students are discriminating against refugees because of their cultural backgrounds, however, the students' prejudices appear to arise out of work and housing insecurities. Anahera articulated during interviews that most of her students (who are Māori) come from difficult and struggling backgrounds, therefore, the students' reluctance to accept immigrants may be more in line with a struggle to acquire the necessities of life in the face of structural racism, than individual prejudice and discrimination. However, the complexity of the students' perspectives is overlooked by Anahera, who builds on her point by referring to Australia's treatment of immigrants.

Anahera: Interesting, 'cos have you been, how many of you have been to Auzzie for a little bit? (to another student) Did you go to Auzzie for some time?

Student: Nah Miss

Anahera: Who's been to Auzzie? Whose parents were thinking they'd move to Australia? Why should we be allowed to go to Australia?

Student: Because we're all good Miss (other comments)

Anahera: You're just going to take Australian jobs

Student: Yeah... Australia's big enough

Anahera: So why should Australia let us in?

Student: Their choice, Miss

Anahera: Exactly, so they do that for us... (Students start to protest). You've got different rules to you... (Students continue to talk). Lots of Kiwis are being sent home. Even the ones who were born in it or have grown up in Australia. Now if they commit a crime Australia are putting them in kinda like a refugee camp and sending them back to New Zealand. 
In this exchange, Anahera responds to the taboo of communicating individual and interpersonal racism (perhaps in conjunction with her social locatedness as a middle-class professional), while the structural racism implicit in the students' perspectives has been silenced.

Discussions about institutional racism in Aroha, Nikau and Maia's classes also framed racial injustice as interpersonal acts. This perspective was directly articulated by Aroha during an interview when she described institutional racism as "about a person who works for a different agency and then uses that position as a platform to practice their own beliefs". Students in each class seemed surprised to learn that people working within institutions can be racist. Aroha spoke to some students about the moment in "The Hills" (Grace, 1988) when the narrator was told by Police to "Shut your big black mouth". Aroha told the students that this was an example of the misuse of power and desire to dominate another culture.

Aroha: So have you heard of institutional racism? Where a person uses his position of power, in this case a policeman, to dominate another culture.

Student: Oh like in America

Aroha: Oh, not just in America, I think it still happens in New Zealand as well.

Students in Maia's class similarly associated racism with the United States, and not New Zealand.

Student 1: And I just think that because we're at a... our society's completely different than what it was back then, maybe she should just forgive and forget . . . I don't think she should dwell on the past too much. That's just my personal thought.

Student 2: We can learn from the past thought because this isn't the only time that white people have suppressed a culture, like look at the blacks in America

Student 3: It still happens

Student 2: And all the shit they're going through

Student 3: Mmm, yeah, so it is kinda relevant to today

Student 2: Yeah it is relevant

Student 3: Look at the black shootings in America, sort of relates to this. 
Likewise, Nikau and his students conceptualised institutional racism as an act committed by individuals working on behalf of the state,

Nikau: This raid [the police on Maungapōhatu] happened 100 years ago though. What happened just a few years ago in Tūhoe. Like, just five years ago?

Student 1: Was that the thing with Tama Iti?

Nikau: With Tama Iti. So, what did they do?

Student 1: They raided

Nikau: They raided another Tūhoe settlements. So, 100 years ago it was all right for the government to go in and raid and shoot and kill and maim and confiscate and take land and five years ago it is still alright for the government to go in with guns and raid and confiscate and arrest people. Luckily, they didn't shoot anyone. So, for us as Māori, or for Tūhoe, has anything really changed in 100 years?

\section{Student 2: No}

Nikau: So, in terms of your thinking Mr Castle, you're excited by that. When you watch that ... you're thinking to yourself that happened 100 years ago and yet five years ago the same thing was happening, the only thing is they didn't shoot or kill anyone but it's the same mentality.

These classroom exchanges show that notions of institutional racism were largely attributed to bad attitudes and actions, rather than a critique of systems and structures that mediate the behaviours and attitudes of individuals and those working in institutions. Consequently, the participants focussed on the possibilities of overcoming individual and interpersonal racism. For example, Aroha said she used "The Hills" to encourage students to think about how they would respond to police brutality, "what would your reaction be if that happened to you? Would you choose to be passive and not deal with it? Or would you choose to speak to your parents about it and try to resolve what I think was quite blatant racism between the police and the young man."

Although imparting knowledge about traditional Māori culture and conceptualising Māori as a political collective were observed during the study of New Zealand literature as a means to challenge the status quo and empower taiohi Māori, I witnessed the temporal subcontract working in conjunction with state education policies that advance limited notions of inclusion 
to produce a homogeneous Māori collective that is consistent with a "two worlds" framework (Kidman, 2018a). In doing so, the participants in this study unintentionally reproduced lovely knowledge about society by erasing difficult questions about culture and ethnicity through the performance of a narrative of Māori society that excludes structural racial bias, thus advancing the notion of improving or harmonious race relations. Conversely, idealised Māori identities and conceptualising racism as individual prejudice and discrimination arise out of the naturalisation of dominant mainstream racialised discourses and ideologies about national identities and the nature of racism. The perception that racial injustice is primarily located in the past, paves the way for legitimising state institution policies that excluded the realities of a racialised existence.

In conclusion, Chapter Seven presented the shape of a hidden curriculum of settler silencing as it emerged from the classroom interactions and interviews of four Māori English secondary school teachers. The micro-level curriculum and pedagogical practices and policy approaches described in this chapter are attributed to three aspects of the hidden curriculum, namely, teaching pedagogies that soften or mute historical harm, assessment approaches that privilege settler-colonial imperatives and lovely knowledge about Māori society. The findings demonstrate the operations of a silencing discourse through meso-level epistemological structures (policy, curriculum and pedagogy) of a settler-colonial education system that excludes issues of race through focussing on culture and ethnicity. In Chapter Eight, I examine how the push-pull process of a silencing discourse reinforces state ideologies of biculturalism at the macro-level of the hidden curriculum of settler silencing, to fulfil the aims of the Settler Contract. 


\section{Chapter Eight}

\section{Oppression and resistance}

I didn't mean to start crying but the problems with my form teacher had gotten worse. A disagreement about ear piercings had quickly turned into mutual hatred. I had been warned that she picked on Mäori girls but I hadn't believed it. This morning the old bitch stripped me of the class captain badge. Couldn't even wait until I made it to class; met me out on the asphalt and said it was time another student had a turn. She seemed rather pleased with herself. So here I was, in front of the Dean and sobbing over a fairly inconsequential late pass. She looks at me, a knowing look because Ms Simpson has a reputation, and asks if there's anything I need to tell her. "It's nothing" I mumble. I look at my shoes and force down quiet scream. "It's probably just me. It's probably my fault".

(Class memory, age 14)

In this chapter, I answer the third research question, which is, "How does the hidden curriculum of settler silencing fulfil the aims of the Settler Contract (and consequently the claim that New Zealand schools are institutionally racist)?" To recap, the aims of the Settler Contract are to maintain ignorance and denial of the structuring force of colonisation, with the view of sustaining white supremacy and advancing the aims of settler-colonialism in New Zealand society. The first section in this discussion chapter reveals how a racial heirarchy of settler supremacy and indigenous oppression is sustained through a silencing discourse that pushes away the lived realities of race. This is followed by findings that demonstrate how a state narrative of harmonious bicultural relations reconstitutes social existence to appeal to a sense of settler belonging, through erasing indigenous peoples' lived reality. In the final section of this chapter, I draw on literature about the nature of hauntings and crypt to consider an alternative approach to the colonial-indigenous "partnership" that defines New Zealand's settler-colonial education system.

\section{Pushing away race: sustaining racial hierarchies}

The findings in phase one and two of the research design (see Chapters Six and Seven) demonstrate the complexities and fluidity of race, ethnicity and culture. However, the 
contested and negotiated nature of these constructs sit within a macro-level framework that fosters structural blindness, cultural racism and erroneous notions of "deficit thinking" to covertly push away issues of race, keep Pākehātanga at the centre of everyday school operations and sustain racial hierarchies in New Zealand society. Although the following sections present each concept separately, they work in interrelated ways to push away evidence of a racialised existence (much like the subcontracts of the Settler Contract).

\section{Structural blindness}

In line with studies concerning the education of indigenous students and the implications of a hidden curriculum (Kidman et al., 2011; Luykx, 1993; Milne, 2017; Regalsky \& Laurie, 2007), the Eurocentric or Pākehācentric nature of state schooling was a theme that strongly emerged in phase one and two findings. In Chapter Six, Pākehācentrism was articulated by Māori English teachers directly, who challenged Pākehā about narrow interpretations of cultural and ethnic inclusion. What emerged from viewing the data through the lens of the hidden curriculum of settler silencing in Chapter Seven was more insidious means of perpetuating Pākehācentrism in state schooling because of the naturalisation of structural blindness.

In Chapter Six, many phase one participants indicated that they were somewhat aware of the hegemonic implications of policies of cultural and ethnic inclusion by identifying hidden ways in which a Pākehā worldview dominated and constrained aspects of their schooling lives. As was noted, moments when participants hit institutional walls of silencing - cultural habits that represent the sedimentation of structural oppression - were attributed to individual and interpersonal acts of racism. For example, a few participants directly challenged the rhetoric of "Māori achieving success as Māori" (Ministry of Education, 2013) by identifying that the policy statement was inconsistent with everyday school operations,

If we were gonna say [what] a successful person [is], then those are the things that the curriculum demands, yet it all boils down to a grade in a class and a year at school. (Early-career, male teacher)

You know there was some talk about teachers having to know some Māori and I'm not seeing that. (Mid-career, female teacher) 
Although many participants in phase one exposed ways in which ideologies of biculturalism reflect a limited commitment to Māori interests, they were heavily implicated in reproducing the silencing discourse and directing school operations towards Pākehācentric ontology. That the naturalisation of a "two worlds" perspective was evident throughout each phase one interview, demonstrates the pulling power of ideologies of biculturalism that freeze Māori temporalities, as set out by the temporal subcontract. The subcontracts of the Settler Contract operate in interlocking ways to sustain a silencing discourse.

Structural blindness is cultivated through a silencing discourse. Scholarly literature has established that the normalisation of dominant racial discourses may occur through museums (Bell, 2006; Kidman, 2018a), or the media (Barnes, Taiapa, Borell, \& McCreanor, 2013). The findings in Chapters Six and Seven show that the state secondary school education system also reproduces a silencing discourse through the hidden implications of an epistemological subcontract that maintains cultural and historical amnesia regarding educational policy, curriculum and pedagogy (Kidman et al., 2018). Through this process, the institution naturalises structural blindness so that, despite some discomfort, Māori English teachers primarily perceive that Māori students' educational interests are adequately included through policies of cultural and ethnic inclusion, and subsequent pedagogy and curriculum approaches.

In this way, policies of inclusion implemented by the Ministry of Education are a form of hegemony that facilitate the colonial aims of a settler-colonial education regime that retains white interests at the heart of its structural design. As has been noted by Kidman et al. (2018) and Veracini (2011), the British colonial administration sought to involve Māori in the Native schooling system as a strategic approach to assimilate and control the indigenous population. Structural blindness facilitates Māori English teachers' belief that the state has provided the frameworks that enable Māori students to attain academic success. Some evidence of some of the ways a settler-colonial school system continues to sustain colonial-indigenous racial hierarchies starts to emerge through the findings in Chapter Seven.

A comparison between Maia's everyday classroom interactions with those of Nikau and Aroha reveals that the NCEA assessment process is aligned with a teaching and learning pathway that is both timeless and raceless (Mills, 2014b). Unlike Anahera, whose goal was to ensure her students gain literacy, Nikau, Aroha and Maia wanted their students to strive for 
Excellence grades. Maia was observed teaching three lessons about unfamiliar text, culminating in a written formative assessment during the final lesson observation. The lessons and activities were carefully organised so that the written assessment task was a demonstration of skills and techniques that the students had already practiced. The ease in which Maia was able to provide the necessary preconditions for students to successful engage with NCEA assessment, show that assessment approaches support a Pākehācentric view of schooling that privilege the values, emotional disposition and schooling success of Pākehā students.

This analysis was made apparent through the struggles faced by Nikau and Aroha to apply assessment approaches that sought to respond to NCEA assessment requirements and include the strategies ordained by the Ministry of Education to support the schooling needs of Māori youth. For example, the preparation time that Nikau and Aroha gave students prior to a written assessment task was less vigorous because a large part of their teaching time was given to implementing pedagogical approaches in line with culturally responsive teaching. Pedagogies implemented to foster positive relationships with Māori students, build confidence in students' ability to engage with the English subject, ensure that learning resonates with students' cultural backgrounds and linking texts to historical, social and political contexts, alongside settling students at the start of lesson and setting and checking homework, required class time that was not utilised by Maia - the only phase two teacher who did not implement a culturally responsive teaching approach. The conscious decision not to do so was apparent during an interview when Maia said, "I don't think we should label our kids", as she felt that it was important to approach each student in a similar manner.

Instead, Maia focussed on developing her students' English skills for the NCEA exam at the end of the year, which involved the transmission of anglocentric values underpinning the English curriculum and NCEA assessment; for example, English conventions, modes of literary analysis and assessment writing processes. That Maia could enact literacy processes and assessment approaches (including scaffolding, metacognition, modelling, differentiation and a range of comprehension strategies) and guide her students towards a position where it appeared that students felt confident and capable to successfully engage with the assessment task indicates that white time is aligned "the metropolitan power's dominant cultural values" (Docker, 1978, p. 30). 
In contrast, Nikau and Aroha imparted assessment approaches that included a culturally responsive pedagogical approach that attends to a historical legacy of colonial harm (Pratt, 2014), and the marginalisation of Māori interests in mainstream New Zealand society. By focussing on the perceived psychological impact of historical harm and cultural marginalisation, educators are directed away from considering how the racialisation of contemporary school structures are a significant contributing factor in limiting Māori students' academic success. The implementation of pedagogies that soften historical harm compromised Aroha and Nikau's ability to implement the full range of literacy strategies that would support their Māori students to attain Excellence grades (the implications of which are also discussed in the following two sections). That Maia was able to implement a varied range of literacy strategies alongside pedagogies that mute historical harm, is consistent with the way that white time "excludes the non-white times that would make the remedying of non-ideal injustices the normative priority" (Mills, 2014, p. 33).

Milne (2017) and Kidman et al. (2011) argue that limited notions of academic success and achievement impedes positive school outcomes for Māori and Pacific students. However, the findings in this thesis highlight the extent to which Pākehācentric notions of school success are validated through colonial time that operates in conjunction with the epistemological structures of a silencing discourse. Deep structural change is required to ensure equitable academic outcomes from Māori youth, not just a change in how "Māori achieving success as Māori” (Ministry of Education, 2013) is conceptualised by individuals to support students' educational needs. The following section explores how a climate of structural blindness and a discourse of meritocracy supports cultural racism to thrive in state secondary school institutions.

\section{Cultural racism}

This section of the discussion explores how cultural racism is reproduced and perpetuated in settler-colonial education systems as another means of pushing away issues of race to sustain racial hierarchies. In Chapter Two, I stated that cutural racism assigns groups of people with specific cultural attributes which makes individuals more predisposed to deficit discourses and stereotypes (Mukhopadhyay \& Chua, 2008). In this study, Māori English teachers who are structurally blind and immersed in a silencing discourse, generally believed that Māori students could succeed at school if they were culturally supported and developed confidence in their abilities (and the teachers themselves worked hard to ensure this was possible) 
(Doane \& Bonilla-Silva, 2003). What emerged through the study was the ways a silencing discourse that fosters meritocracy acts as a deficit discourse. A sole focus on the performance of the individual Māori students, as opposed to structural racial bias, provides the necessary preconditions for cultural racism. The wider study in turn shows the notion of cultural racism is differentiated according to the whether it is understood in individual or structural terms.

As the literature review in Chapter Two reveals minoritised educators attribute cultural racism to overt comments and attitudes of white educators (Dovemark, 2013; Graham \& Robinson, 2004; Hällgren, 2005; Kohli, 2009; Santoro \& Reid, 2006; Young et al., 2010), and identify white racial bias occurring at the curriculum, assessment and administration levels of schooling (Kidman \& Chu, 2017; Kohli, 2009; Stanley, 2006). In this study, Māori English teachers also perceive instances of interpersonal and individual racism and in similar ways to others internationally. What the lens of the colourmute policy framework adopted by the state adds to this discussion in the field is how school structures are implicated in producing cultural racism. The analysis of the data through the colourmute lens shifts ways of accounting for individual and interpersonal racism. Participants in this study were feeling their way towards a better explanation of the way that Pākehā work colleagues could legitimately exhibit forms of cultural racism. The explanation from the perspective of colourmute education policies would be that such policies actually sanction a wide and so nebulous approach to regarding how the inclusion of minoritised students' interests may be facilitated in classrooms. As one experienced, male Māori English teacher said,
Are we, as teachers and as departments, are we getting off lightly in terms of being able to just tick the boxes and say "yes, I know my students and yes, I've developed relationships" and like I say, that's really, really important, but is there a difference between knowing and understanding as well? Do you understand your students? Do you understand their history? Do you understand their background? Do you understand their stories?

A study by Gebhard (2017) similarly demonstrates the drawbacks to a cultural approach to policy that aims to include indigenous students. She finds that non-indigenous teachers felt as they were meeting the needs of indigenous students through policies that promote the cultural inclusion of indigenous students' backgrounds. A stronger point here is that the 
marginalisation or omission of diverse Māori perspectives due to colourmute policies may actually encourage cultural racism to thrive. For example, Māori English teachers identified that the partial inclusion of Māori perspectives in New Zealand literature could produce cultural stereotypes and legitimise Eurocentricism in other areas of the English curriculum.

This structural process happens internationally. A study of minoritised female academics by Samuel and Wane (2005) demonstrated the way a Eurocentric curriculum excluded scientists from developing countries. In this study when participants' articulations of "the wall" are filtered through a colourmute policy framework that appears to include Māori interests through such components as de-racialised language, the role that the institution plays in shaping the way that interpersonal and individual racism are executed by Pākehā comes to the fore. Rather than attribute micro-level manifestations of racism by Pākehā teachers solely to "deficit beliefs", the hidden curriculum of settler silencing exposes a relationship between the notion of implicit bias to the institutional frameworks provided by the state (Blank et al., 2016; Houkamau, 2016). Indeed, colourmute policies cultivate cultural racism because Pākehā are permitted to conceptualise and practice the notion of cultural and ethnic inclusion according to their own comfort levels and interests.

A second way that the notion of cultural racism in this study is differentiated from established scholarly literature examining silencing and racism in the fields of education and indigenous studies is through an association with a discourse of meritocracy. Unlike literature that examines how whites reify whiteness for their own self-interests (Ahmed, 2012; Andersen, 2003; Doane, 2006; Leonardo \& Zembylas, 2013), this study illustrates how Māori English teachers unwittingly reproduce Pākehātanga through institutional frameworks that attribute school or academic failure to a personal, individual and/or cultural deficit. Doane and Bonilla-Silva (2003) and Giroux (1983) note that meritocracy is legitimised through structural blindness that relieves the institution of any wrong-doing. State ideologies that biculturalism should feel good are provide the institution with the semblance that it is helping and supporting underachieving students, all the while directing educators away from implicit structural racial bias.

In New Zealand, structural blindness consolidates Pākehā as the "silent centre of biculturalism" (Bell, 2006, p. 264), and Māori as "Other" (Spivak, 1988) in state school institutions. Such positioning ensures that the diversity and richness of a lived indigenous 
perspective is erased and (re)conceptualised in fixed and traditional cultural terms that align with the aims of settler-colonialism (a point I will discuss in more detail in the following section). Although participants in this study provided cultural supports that are helpful to many Māori students, this approach has the effect of locating failure or success with individuals and their circumstances. This puts a huge amount of pressure on indigenous youth, while obscuring the significant role that racialised school structures play towards determining educational success. While many individual Māori students may feel supported by teaching approaches that respond to cultural-locatedness and positive home environments, many are disadvantaged by the idea that without such supports Māori students are perceived to be "outsiders" or failures.

The result of positioning in terms of cultural supports in this study was that Māori English teachers tended to generate meritocratic solutions to Māori student underachievement, lack of English subject engagement, interpersonal or individual racism and cultural marginalisation. They showed this tendancy by utilising pedagogical approaches that supported or bolstered Māori students to feel comfortable or "to feel strong about yourself" (participant comment). A critique of a Pākehācentric school culture was echoed by one mid-career Māori English teacher in this study who said,

At the marae, they have the sense that I had as a child, which is that every adult there cares about them and every adult there has a vested interest in their wellbeing and every adult there will tell them off if they have to and that sense of being meaningful to the adults around them. Whereas they come into a school, it's a very Eurocentric structure and they don't feel that every teacher that they deal with really cares about them, you know. They just don't have that sense, that sense of place and belonging that they have on a marae.

This comment suggests a line of thinking that if students are supported to feel more comfortable or develop a "sense of place and belonging" it will counter the effects of a dominant school culture that does not align with indigenous students' backgrounds. Once the problem is articulated in this way it becomes clearer why it is not an adequate solution. The problem is not unique to New Zealand. The study by Gebhard (2017) similarly noted that the one indigenous teacher participant identified that cultural approaches to learning (for example, making dream catchers and little tuna drums) were superficial, and thought that the 
school environment constrained underachieving indigenous students, who “don't feel comfortable or that there's a place for them" (p. 768). This finding similarly shows that the participant did not understand the implications of how structural racial bias may direct students to arrive at this emotional state.

Participants in the study however were caught in the trap of thinking that strengthening the cultural identity of their students within the school could remediate its more instrinsically hostile nature. In phase one of the research design sought to build positive and caring relationships, integrate a cultural perspective and build cross-cultural understandings. The teaching pedagogies that soften historical harm (see Chapter Seven) similarly sought to relate positively to students, build confidence, privilege students' cultural backgrounds and teach about context. The wide-ranging view among participants of the importance of capitalising on the culture of Māori students to enhance schooling success was captured by the following comment by Aroha,

I have a different teaching platform and I'm aware of that. So, I don't think that I'm as expert as some of [the mainstream English teachers] are and I'm okay with that too because that's why you have colleagues ... I feel that I still have room to learn because I know that if they were to come in here I don't know if they would necessarily get the same results as I do because for me I know a lot of that is about relationships.

While positive relationships are certainly an important strategy to attract students to the learning process, policies of cultural and ethnic inclusion position Māori interests outside a "normal" Pākehācentric framework. Validating the use of culturally responsive pedagogies as "the solution" has the result of advancing narrow views about the learning requirements of Māori youth. As a result, some of those learning needs are not addressed, and the responsibility to meet them is neutralised. Pedagogical approaches that advance the development of individual attributes and do not incorporate the complexities of a lived racialised existence are a precursor to cultural racism. The cultural attributes that are acknowledged by a silencing discourse that advances meritocracy generates deficit thinking, in which schooling success and failure is located with the perceived cultural "needs" of minoritised students and not the racial bias of school structures. In this way, a silencing discourse supports hegemonic conditions that further consolidate structural blindness and the 
inability to see how a hidden curriculum of settler silencing distances Māori students from high levels of academic attainment. The implications of a silencing discourse that sustains meritocracy as a form of deficit thinking are discussed in the following section.

\section{Reconceptualising "deficit thinking"}

In a landmark New Zealand professional development programme called "Te Kotahitanga”, Bishop et al. (2014) conducted in-depth interviews with Māori students, their whānau and teachers (who were predominantly Pākehā) to better understand how to support Māori students in mainstream schools. One significant finding was that teachers wanted to support Māori learners but “identified what they saw as Māori students' deficiencies as the main reason for their low achievement ... [including] poor parental support, low educational aspirations and limited skills and knowledge" (p. 6). Findings such as these contributed to the development of an Effective Teaching Profile to support teachers to see themselves as "agents of change" to challenge deficit thinking. Some of the dimensions of the Effective Teaching Profile include that teachers care for the students as culturally located individuals, have high expectations for students' learning, and know a range of strategies that can facilitate learning interactions (Bishop et al., 2014).

The participants in this study arguably demonstrated many, if not all the dimensions of the Effective Teaching Profile advanced by Te Kotahitanga. According to frameworks established by this professional development initiative, Maia, Nikau, Aroha and Anahera and likely many of the participants in phase one - are the antithesis of deficit thinking. This section of discussion argues that the hidden curriculum of settler silencing (see Chapter Seven) demands a reconceptualisation of the notion of "deficit thinking" to include the way that institutional racism generates repressive conditions for Māori youth operating in state secondary schools. The status quo is protected by an ignorance that fails to recognise that the New Zealand settler-colonial education system and its seminal structures (policy, curriculum and pedagogy) are racially biased; that the social and cognitive frameworks normalised through a silencing discourse direct educators towards the view that schooling success and failure reside with the individual performances of teachers and students and not the institution. 
A silencing discourse ensured that many Māori English teachers in this study felt they could approach the English curriculum in various ways; from the curriculum strengths of the teacher to the perceived needs of the student. As one experienced female teacher said,

You see yourself as an English teacher but then you also see yourself as what you're bringing from your kind of experiences into a classroom. English gives you the scope to be able to do what you want to do, if that's where you want to go. That's what I love about English, you can reinvent stuff and do what you want.

However, the first section of this discussion chapter points to the way that Māori interests are side-lined in a settler-colonial education system that places whiteness at the centre. The racism embedded in a "cultural differences" policy approach implemented through a colonial regime to assure colonial domination over indigenous populations (Kidman et al., 2018), is reconstituted through a framework of cultural and ethnic inclusion provided by the Ministry of Education (Ministry of Education, 2007, 2011, 2013). Furthermore, this framework is not considered within an NCEA assessment pathway framed by a white temporal imaginary (Mills, 2014b). Aroha and Nikau's classroom interactions were juxtaposed against Maia's to signal the impossible task of juggling pedagogies purported to equitably "include" Māori interests, while incorporating the depth of text comprehension and scaffolding needed for students to attain high levels of academic achievement.

The challenge of accommodating policies and practices pertaining to cultural and ethnic inclusion, alongside NCEA curriculum and assessment requirements, was a hidden source of frustration for Aroha and Nikau. They operated within a well-respected and reputable bilingual unit that holds Māori interests at the heart of everything they do, yet an inability to see how teaching practices are constrained by a silencing discourse leads Aroha to believe that Māori students really struggle to write. She notices that her students are good at remembering, articulating a nuanced understanding of the studied text and have an "amazing work ethic". However, she found that "when it comes to them to put it on paper they're just not connecting". Aroha thought that students would do better in assessments if they could verbally relay their understanding of text and said there was "a huge gap in the process from what they know to putting that on paper". Deficit thinking that attributes minoritised students' inability to perform at the same levels as the dominant race to a cultural deficit, is 
identified in literature critiquing colourmute teaching practices and education policies privilege white imperatives (Castagno, 2008; Gillborn, 2005; Pollock, 2004).

Moreover, the ease in which the Māori English teachers in phase one and two of this study attributed student underachievement to a cultural or personal deficit, in comparison to the way that the stakeholders in the study by Pollock (2004) were involved in blame shifting activities, highlights how policy approaches to include indigenous students provides a forum to legitimise deficit thinking. The teachers in Pollock's study did engage in discussions that attributed achievement disparities to the cultural deficits of certain ethnic groups, but they also exhibited a wider range of finger-pointing (the district, economics and parents). Like the teachers in the study by Siteine (2016), Māori English teachers were guided by the policy framework provided by the Ministry of Education. The participants in this study played by the state rulebook and within the confines of an establishment that facilitates structural blindness and cultural racism. When the frameworks that Māori English teachers are given do not produce the expected outcome, the participants have no other option but to blame the students. As Aroha states,

I haven't been at a kura yet where you know we go over and beyond what everybody else does, and what I'm struggling with is we still don't get the results that mainstream teachers do so there's something missing you know. Because our kids have the ability. I'm just not sure what's missing. . . [The achievement is] pretty phenomenal but it's not across all subjects, so our kids do really well in two or three subjects not in six. While they achieve NCEA overall, if you were to break it down in to subject areas they're still struggling.

Consequently, Māori students (and teachers) who cannot sink into whiteness, or will not, are branded as "outsiders". I again return to the notion of structures of resentment to describe how the institution establishes inclusionary and exclusionary mechanisms for Māori. The Ministry of Education generates policies and pedagogical practices that are designed to push away a racialised existence in line with the affective concerns of Pākehā (Zembylas, 2010). One way that resentment is manifest is through the hidden implications of colonial time, in which a white temporal norm guides the teaching and learning process and "the suppression of the alternative histories, the non-white times, of other humans" (Mills, 2014b, p. 32). Consequently, racial hierarchies that advance Pākehā supremacy and suppress indigenous 
peoples are sustained through structural blindness, cultural racism and flawed notions of deficit thinking. In this way, "the colonised still labours for the coloniser even after the colonial relation has been formally discontinued" (Veracini, 2011, p. 7). White supremacy in New Zealand society is furthermore assured by state secondary school performances of a state narrative of biculturalism that advances the notion of harmonious settler-colonial race relations by marginalising or denying violent colonial histories and their consequences in the present.

\section{Pulling towards the state narrative of biculturalism and indigenous erasure}

In order for the settlers to make a place their home, they must destroy and disappear the Indigenous peoples that live there. . . For the settlers, Indigenous peoples are in the way and, in the destruction of Indigenous peoples, Indigenous communities, and over time and through law and policy, Indigenous peoples' claims to land under settler regimes, land is recast as property and as a resource. Indigenous peoples must be erased, must be made into ghosts (Tuck \& Yang, 2012, p. 6)

In Chapter Four, I proposed that an epistemology of ignorance is sustained by a circular arrangement between a silencing discourse (via a state narrative of biculturalism) and state ideologies of biculturalism. This section describes how the Settler Contract advances the aims of settler-colonialism in state secondary schools by generating a narrative of equitable race relations that aims to eradicate, subsume or displace indigenous peoples and establish settler permanence (Tuck \& Yang, 2012; Veracini, 2010, 2011, 2015; Wolfe, 1999, 2006). The findings in phase two of the research design are the basis of the following discussion in the sections, lovely knowledge and two worlds, to show how the hidden curriculum of settler silencing facilitates a process of cultural forgetting and remembering to counter deep-rooted settler insecurities pertaining to the nature of belonging and occupancy of indigenous lands (Kidman, 2018a; Schwab, 2010) .

\section{Lovely knowledge}

In this study, "lovely knowledge" about Māori society was central to the performance of a silencing discourse designed to produce affect positions that disseminate whiteness or Pākehātanga (Hook, 2005; Leonardo \& Zembylas, 2013). The everyday performance of a 
state narrative of biculturalism that directs those in school institutions towards a certain way of thinking and feeling to support the aims of settler-colonialism, is a significant departure from established scholarship investigating how the curriculum is implicated in the suppression of indigeneity.

For example, the role of historical textbooks in generating false knowledge about historical colonial harm is examined in studies by Brown and Brown (2011) and Van de Kleut (2011) in movement two of the literature review (see Chapter Two). However, this analysis produces a limited account of the way that dominant racial discourses are reproduced through the culture of the classroom. A study by St. Denis (2011) in movement three is more wideranging, as she identifies that multicultural policy can support non-indigenous teachers avoid engaging with indigenous interests in education; a process that is implicated in the dismissal of indigenous land-title to strengthen settler claims. However, empirical data that establishes a link between everyday interactions, institutional structures, and how this is implicated in the aims of settler-colonialism, is also very limited.

By adopting a holistic approach to examining the micro-, meso-, and macro-levels of a settler-colonial schooling, this thesis displays how state education is implicated in a system of racial domination. In many respects, the study is aligned with research by Zembylas et al. (2014) and Zembylas (2010). However, rather than associating emotions, pedagogical interaction and memories of national history with divisive feelings against the non-dominant Other (Zembylas et al., 2014), or asserting racialized dichotomies that pit dominant cultural "victims" against non-dominant "perpetrators" (Zembylas, 2010), settler-colonial education seeks to alleviate colonial guilt and historical violence by co-opting indigenous peoples into a common national identity that disavows contemporary structural racial bias (Kidman et al., 2011; Luykx, 1993; Milne, 2017; Regalsky \& Laurie, 2007).

A desire to create strong "redemptive narratives about harmonious 'race' relations" is observed by Kidman (2018) in relation to the "Signs of a Nation" exhibition at Te Papa. She writes "even when there is an inclination to represent and remember historical conflict between indigenous groups and the state, national museums frequently depict 'race' relations as being both reconciled and transcended in the interests of nationhood" (p. 99). Veracini (2010) similarly refers to settler-colonial narratives as a palindrome where there is a sense of "progressing" towards a better national imaginary. The findings in Chapter Seven show that 
this type of narrative is performed in state secondary school institutions as a "softer" form of violence that holds greater scope for securing and holding indigenous territories (Wolfe, 2006; Kidman et al., 2018).

Indeed, the carefully constructed silencing discourse worked hard to smooth away any emerging crinkles in the notion a bicultural partnership, so students could imagine that New Zealand is progressing towards a fair and equitable society,

I feel as though that we were quite a selfish group of people when we came and then we didn't realise what we were doing um, and that actually it really made us click into saying "hey, right, okay, we need to change this" (student comment)

As Kidman (2018a) observes, lovely knowledge supports "Pākehā citizens to imagine themselves as partners with Māori in the nation-making quest” (p. 105). In doing so, mainstream New Zealand can reason that the moral fibre of society is moving forward because the racist behaviours and attitudes exhibited by previous generations of Pākehā are disappearing. This belief proved to be an entrenched aspect of a state narrative of biculturalism because it was also exhibited in Anahera, Aroha and Nikau's classroom settings. For example, Nikau advanced the notion of progressive bicultural relations by teaching students that Māori are less willing to accept the motivations underpinning Pākehā involvement in Māori society. But the scope to develop these ideas further was limited by spatial and temporal subcontracts that pulled the narrative towards cultural homogeneity, emphasising social advancement through notions of inclusion, while withholding the concept of race as a reason for the ongoing causes of ethnic and racial disparities in state institutions. It was an issue Nikau seemed somewhat aware of as he stated, during an interview, that he felt more pre-teaching or time was needed to support students to truly understand context. One student also articulated this frustration in her own way towards the end of the study of "Rain of the Children",

I don't feel like I know enough to look differently at society. Like, I get angry when I hear stuff about land and the Treaty of Waitangi, like how it was misleading, like we're not even in control of our own country and our land. That's about it. 
Another way that affect positions transmit lovely knowledge is through teaching pedagogies that soften historical harm. As stated in Chapter Four, the notion of historical harm caused by a colonial "legacy" supports the view that Māori students are "timelessly noble, or longsuffering victims" of historical harm (Lehrer \& Milton, 2011). In this way, culturally responsive pedagogies may primarily focus on student-centred approaches to learning, thereby supporting educators to feel like they are meeting minoritised students' schooling requirements without engaging with the structuring force of colonisation. Teaching pedagogies that build confidence in students, privilege cultural backgrounds, teach about context are meritocratic solutions that were articulated by phase one participants and observed through Anahera, Nikau and Aroha's practice to counter a perceived cultural, personal or historical deficit in Māori students. The hidden implications of decisions to prioritise cultural or social knowledge over academic or anglocentric forms of knowledge distance Māori youth from advanced levels of academic achievement (Kidman et al., 2011; Siteine, 2016). In this way, "lovely knowledge" advanced through culturally responsive pedagogies, is a double-edged sword that focusses on personal empowerment but disguises the way that structural racial bias prevents Māori youth from achieving at the same levels as Pākehā.

Culturally responsive pedagogies that operate within a settler-colonial framework guided by the affective influence of white fragility and the drive to advance a sense of settler belonging, are a significant tool of hegemony. In taking this position this study challenges and attempts to move beyond literature that discusses the token or simplified implementation of culturally responsive pedagogy (Castagno \& Brayboy, 2008; Gutschlag, 2007; Ladson-Billings, 1995; MacDonald \& Reynolds, 2017; Sleeter, 2012), or ways in which neoliberalism impacts how teachers approach culturally responsiveness (Morrison et al., 2008; Sleeter, 2012), to demonstrate that the approach is a fait accompli that aligns with the precepts of settlercolonialism. Historical amnesia and silencing permeates New Zealand society and is purposefully built into the very fabric of the education system, thus erasing the critical consciousness needed to challenge historical and contemporary structural racial bias (LadsonBillings, 1995). The hidden implications of colonial time and the racism underpinning settler-colonial administrations ensures that culturally responsive pedagogy is advanced as the "solution". 
The reality of the underlying hegemony can be seen in the example in this study of Maia. The threat of potential attack from a dominant society perspective will always, in the end, trump and undermine the culturally responsive solution. Maia faced a distinctly different set of racial challenges because she dealt directly with the threat of white fragility and anxiety in response to learning about colonial violence and the effects of colonisation. Classroom interactions, particularly in relation to the study of "Our Tīpuna Remain", revolved around protecting Pākehā students from meaningfully connecting with the racially oppressive state of settler-colonial relations because this might impede student engagement and compromise academic success. Consequently, Maia and her students engaged in a pedagogical and curriculum "dance" that involved validating historically sanitised textual meanings and neutralising difficult ground by focussing on the technical construction of the poem (BonillaSilva, 2014). Although Maia said she wanted her students to "feel something" in relation to historical grievance, affect positions were generated that supported Pākehā students to avoid feeling implicated in historical violence and contemporary white privilege.

The issue of "safety" and the need to avoid or diffuse racialised classroom exchanges to accommodate white insecurities was the subject of studies in Chapter Two (Castagno, 2008; Fine, 1987; Pollock, 2004; Vass, 2013). However, these findings show that while Maia's pedagogical practices were also determined by the emotional concerns of whites, a silencing discourse is strengthened by the interplay of the subcontracts of the Settler Contract. Assessment policy and curriculum decisions were implicated in the way that Maia considered the affective requirements for avoiding white fragility and maintaining a state of settler belonging.

\section{Two worlds}

Another aspect of lovely knowledge that emerged through phase one and two participants' interviews and classroom practices was a "two worlds" perspective (Kidman, 2018). The ingrained nature of two worlds and Māori cultural homogeneity was demonstrated through phase one findings that showed limits to conceptualising racism.

For me a Māori text is something is something that Māori kids can relate to, I suppose. So, it doesn't even have to be... it doesn't have to be directed by Māori... I guess it's where the character... where they see themselves in the characters if they are Māori, I guess ... I guess anything New Zealand is still 
Māori but then you wouldn't say Katherine Mansfield is Māori. . . So, I think then, what is the Māori text then? I suppose it is because it's from a Māori perspective. (Anahera)

Participants in phase one and two also acknowledged that Māori peoples' cultural experiences are diverse, yet they articulated teaching approaches that were in line with a frozen and fixed Māori temporal existence. The studies in movement two of the literature review (see Chapter Two) describe the impact of ethnic labelling policy and practices to include indigenous students in schooling. For example, a black/white racial binary in United States schools invisibilised indigenous students (Castagno, 2005; Milner, 2015), and Pollock (2004) argues that the curriculum is affected by the validation of "official" ethnic groups . However, this study indicates that a settler-colonial education system does not altogether exclude indigenous identities but rather seeks to include them in a form that is palatable to the dominant setter population and that in some ways may be more insidious. As described in Chapter Four, a frozen Māori temporality attends to the emotional disposition of the settler community, protecting Pākehā from white fragility and examining structural racial bias (Kowal, 2015; McIntosh, 2005; Rifkin, 2017). This has huge implications if the effect is that such silencing suppresses the need to implement government policies to successfully rectify whānau and individual disadvantage (O'Sullivan, 2007).

So how to explain the persistence of a state narrative of biculturalism in majority-Māori school environments? Although Aroha, Anahera and Nikau did not have to contend directly with pressures associated with the emotional concerns of Pākehā bodies in the way experienced by Maia, the findings in Chapter Seven shows that the temporal subcontract is upheld in majority-Māori settings too. This in turn indicates that affective investments in the official bicultural narrative are implemented because they are a deeply ingrained institutional habit, in which the socially constructed nature of race takes on a biological and given status (Lee, 2014). Nikau, Aroha and Anahera's classroom interactions show that the inherited habit of marginalising Māori interests, set by colonial administrations and maintained through contemporary education policy and discourse, has created a frame of reference for conceptualising Māori subpersonhood. Even without the emotional pulling power of white bodies, the momentum of the institution to reproduce "two worlds" and "lovely knowledge" pulls brown spaces towards the notion of harmonious bicultural race relations. 
The circular relationship that is established between the state narrative of biculturalism and the silencing discourse renders teachers blind to the way that indigeneity is shaped to "better fit extant legal and administrative frames" of settler-colonialism (Rifkin, 2017, p. 6). Consequently, the capacity for epistemological structures to maintain silencing practices is strengthened, and the belief that race is of no consequence hardens further into a habit and settler denial over the consequences of colonial violence towards indigenous peoples (Ahmed, 2007, 2012; Kidman et al., 2018). Indeed, theories of racism that do not account for the structures that support silencing further entrench the macro-level racial inequalities described here. Although the participants in this study do work to combat individual and interpersonal racism and elevate their students' awareness of the issue, everyday racism conceptualised as implicit or unconscious bias maintains contemporary forms of imperialism (Blank et al., 2016; Clair \& Denis, 2015; Essed, 1991). Can this circular relationship be broken? This is the question I address in the following section.

\section{The resolute Settler Contract?}

Dysfunctions in expressiveness may then be read as symptoms and symptomatic silences or traces pointing to a secret that is both kept and revealed in language. It is not so much the content of the secret or the story that is revealed but rather the imprint it has left, perhaps over generations, on affect and its expression in speech or writing. (Schwab, 2010, p. 53)

In this final section of the chapter, I ask whether the Settler Contract is a resolute and immutable part of settler-colonial education. In the excerpt above, Schwab (2010) speaks about the character of narrative in relation to transgenerational trauma in perpetrators of historical violence. I consider a state narrative of biculturalism to be a "dysfunction in expressiveness" and wonder about the indelible imprint that it leaves on past and future generations of New Zealand citizens. The notion of racial harmony is far from truth. Under the narrative, Māori (not Pākehā) inherit lower educational achievement, poorer health outcomes, higher youth suicide rates and incarceration rates (to name but a few). True notions of partnership would not tolerate such abuse, but silencing legitimises ignorance and the excuse not to "see". 
However, "to read against the grain" of established social narratives is to trace dysfunction and the hidden ways that these are imprinted in everyday life (Schwab, 2010). In the first section of this chapter, I argued that the academic difficulties faced by Māori youth in secondary school English are attributed to the hidden ways that settler-colonial education administrations reproduce colourblindness, cultural racism and new forms of deficit thinking. Drawing on the work of Gordon (2008), the continuing face of colonisation may be described as a "haunting", which is "a process that links an institution and an individual, a social structure and a subject, and history and a biography" (p. 19). In line with these insights, the achievement disparities between Māori and Pākehā, and the way these were rationalised by the participants in the study, constitutes a "ghost" of unresolved, inherited and oppressive colonial bias. As Gordon (2008) explains,

If haunting describes how that which appears to be not there is often a seething presence, acting on and often meddling with taken-forgranted realities, the ghost is just the sign, or the empirical evidence if you like, that tells you a haunting is taking place. The ghost is not simply a dead or a missing person, but a social figure, and investigating it can lead to that dense site where history and subjectivity make social life. The ghost or the apparition is one form by which something lost, or barely visible, or seemingly not there to our supposedly well-trained eyes, makes itself known or apparent to us, in its own way, of course. The way of the ghost is haunting, and haunting is a very particular way of knowing what has happened or is happening. Being haunted draws us affectively, sometimes against our will and always a bit magically, into the structure of feeling of a reality we come to experience, not as cold knowledge, but as a transformative recognition. (p. 8)

Māori English teachers in this study may have been drawn into the whiteness of school institutions, the illusion of meritocracy and racism as an individual act, but there was a felt understanding articulated by every participant that the story they were telling was not really their own. Taking off the silencing blindfold puts into words how affectively-moderated structures direct educators operating in state schools towards the performance of an oppressive bicultural narrative. As O'Sullivan (2007) writes, "Partnership is problematic because 'as long as dominant groups keep a monopoly of defining the others, the 
decolonization of the mind and need for real economic, political, cultural, and linguistic decolonization is difficult to achieve"” (p. 25). The state indoctrinates educators to personify the structures that continue to reproduce racial hierarchies and the aims of settler-colonialism, so that what may be accessed through an orientation of "culture" and "ethnicity" appears to be adequate, even generous (Merleau-Ponty, 1962). In this way, the historical and social contexts of lived experience direct institutional existence, affecting how beings interact with the physical environment and their relationships with others. As noted by Ahmed (2007) it is from "here" - the different existential dimensions of embodied lived experience - "that the world unfolds" (p. 151). As was discussed in the first section of this chapter, the Settler Contract is legitimised when Māori teachers are invited to play by the state rulebook; by investing in state ideologies of biculturalism and the notion of progressive race relations.

The answer to breaking the Settler Contract must somehow lie in the ability for Māori to act in solidarity for the interests of all Māori; that is cohesively, to demand social and institutional conditions that elevate Māori to the status of full personhood, not subpersons of colonial design (Mills, 1997). This means pushing back against whiteness and its various ideological and discursive forms by not playing the game of harmonious race relations. This approach aligns with the work of anticolonialism, which seeks to end a relationship that sustains the subordinate position of the colonised (Veracini, 2010, 2015), in a related manner "the struggle against settler-colonialism must aim to keep the settler-indigenous relationship ongoing" (Veracini, 2011, p. 7). These seemingly paradoxical forms of state resistance are complementary when it is understood that the colonial-indigenous relationship that must end is the false one established by the current bicultural narrative of equitable partnership.

A new narrative of biculturalism that preserves settler-indigenous relations must be infused with "difficult knowledge". Kidman (2018a) argues, difficult knowledge is "the recognition that understandings of our collective selves of national identities are partial and incomplete and often rely on factual misrepresentation as well as a degree of structural forgetting about the colonial past" (p. 98). An analogy of crypt by Abraham and Torok (1986) is a helpful way of thinking about how state education fulfils the aims of the Settler Contract, and how indigenous oppression may be broken by redefining bicultural relations. They argue that when dealing with trauma, a psychic crypt may be erected to house the silences and secrets found in traumatic loss. In the case of national trauma, a collective crypt may be established to silence violent histories and their consequences in the present, foreclosing the ability to 
mourn. A settler-colonial education system could embrace difficult knowledge and transcend silencing by opening the crypt. In doing so, the process of "mourning" historical colonial harm shifts from incorporation (a refusal to mourn by disavowing the loss and keeping it alive inside) to introjection (the loss is integrated into the psychic fabric of national identity) (Abraham \& Torok, 1986).

Schwab (2010) links post-war Germany's inability to mourn the trauma of Nazism to a defensive reaction against feelings of shame, fear and guilt. This uncomfortable but fitting parallel to the genocide of indigenous Māori by the British Empire, highlights how processes of mourning can challenge New Zealand's affective avoidance of white fragility. Currently, catering to the threat of white fragility to accommodate the notion of settler belonging supports Pākehā to remain frozen in guilt, thus preventing processes of challenging and working through colonisation. As the students in Maia's class demonstrated,

Researcher: What is "white guilt"?

Student 2: Feeling guilty for the past

Student 1: Like shaming, like, personally I think it's shaming white people for doing something bad

Student 2: Even if they didn't do it though

Student 1: Yeah, exactly (voice goes quiet, Student 3 says "yeah 'cos")

Student 2: Like even though we ourselves didn't do all of that back then it's like...

Student 3: It feels like we're to blame...

Student 2: It feels like we're to blame because sometimes...

Student 1: Yeah, we're responsible for it...

Student 2: 'Cos they're our ancestors, they're our family from way back and they did all that

Facing white fragility head-on through a process of mourning "is not a melancholic attachment to injury but, on the contrary, prepares the ground for a future-oriented integration of the past" (Schwab, 2010, p. 13). Opening the crypt and speaking of a difficult, violent, and silenced colonial past creates conceptual space to acknowledge the temporal multiplicity of indigenous peoples and the capacity for self-actualisation so that all Māori are given a genuine opportunities to live out their hopes and dreams through schooling (hooks, 1994; 
Rifkin, 2017). Kidman et al. (2018) argue that the defeat of Māori at a significant battle at Ōrākau in 1864 may serve as a form of resistance. During the battle, Māori were slaughtered by the British to make way for settler occupation. Yet despite the bloodshed, the event symbolises resistance and hope for future generations of Māori. Stories of historical violence, unending suppression and entanglement need to take centre-stage in a new narrative of biculturalism if New Zealand society aims to transcend the Settler Contract. To do this, the epistemological structures of schooling must be remade accordingly, from the covert privileging of anglocentric values towards a philosophy of settler-colonial education that prioritises local and national histories of state oppression, the emotional toll of mourning and challenges to manifestations of contemporary structural racism. This is the basis from which the Settler Contract is supplanted with a "middle ground" in which there is no sense of one group holding more power than the other (White, 2011).

Regarding the ontological turn, Zembylas (2017) argues that the notion of different worlds or states of ontological existence are not incommensurable; that such claims should not obstruct "educators in taking seriously the political ideas and claims of people as ontologies that are radically different from their own" (p. 1410). Consequently, the socially-constructed notion of race can be placed at the centre of an education system through "counter colonial" thinking. Mika (2016) posits that counter colonialism is "a cultural metaphysics of the writer's group whilst reacting to another's voice" (p. 2). This "brush with the other" should involve critical reflection of the way that processes of cultural memory and forgetting are subject to different ontological conditions, to challenge the peculiarities of silencing within any given school context (Kidman, 2018a; Schwab, 2010). Silencing may be challenged by collapsing space and time, so that an imbricated relationship between the spatial and temporal subcontracts is visible. This would allow educators to appraise everyday teaching practices (for example, culturally responsive practices that focus on the performance of individuals) in relation to the cultural biases of settler-colonialism, annihilating the logics of meritocracy. To do this, Māori need Pākehā to take a leap of faith. A middle ground may only be established when the dominant culture is thinking and acting as liberators (White, 2011).

The circulation of state ideologies of biculturalism via a relationship with a silencing discourse is not set in stone. Practising a different race relations narrative will generate counter ideologies that lift mainstream New Zealand society from "false consciousness" (van Dijk, 1998). As it stands, racial silencing has nothing to offer Māori except marginalisation 
and dehumanisation, regardless of the hegemonic concessions offered by the state. bell hooks (1990) points out that the dominant culture suppresses those at the margins by naming their conditions of existence; that authorised stories of oppression are in line with how whites choose to understand the world. But she argues that marginality does not have to be a place of oppression. The margins can be a place of resistance for the colonised and white allies to come together: by vocalising repressed narratives of marginality, then by working collaboratively to demand that the oppressors meet the oppressed the margins of society,

Enter that space. I am writing to you. I am speaking from a place in the margins where I am different - where I see things differently. Speaking from the margins. Speaking in resistance. I open a book. There are the words on the back cover "NEVER IN THE SHADOWS AGAIN," a book which suggests the possibility of speaking as liberators. (hooks, 1990, p. 343) 


\section{Chapter Nine}

\section{Conclusion}

This thesis has examined how a silencing discourse is negotiated in state secondary school institutions through the lived experiences of nineteen Māori teachers of English language as they teach New Zealand literature.

Silencing and historical amnesia is prevalent across New Zealand society; a phenomenon that supports the dominant culture to remain blind to historical and ongoing manifestations of colonial violence. In this thesis, Mills $(1997,2007)$ work about the Racial Contract and white ignorance is key to examining how silencing is established and maintained in secondary school institutions. Following Mills, Kidman et al. (2018) contend that a Settler Contract maintains dominant/subordinate settler-indigenous power relations through a process of "rewriting and reorganising of colonial violence" (p. 234) embedded in the policy, curriculum and pedagogy structures of schooling. This process is integral to a silencing discourse, which pushes away any sense of historical structural racial bias to advance a state narrative of biculturalism. The narrative sustains historical amnesia, a belief in harmonious race relations and settler denial of the structuring force of colonisation.

The findings highlight the comprehensive reach of a silencing discourse, as indigenous Māori who work in state secondary education embody the epistemological structures of schooling, to transmit affect positions in line with sustaining ignorance. Māori English teachers' perceptions of race and racism and their role in the hidden curriculum of settler silencing reveal that they perform a narrative of benign and progressive bicultural relations with their students, while also focussing on individual approaches to remediate perceived personal, cultural or inherited deficits in Māori students. Meritocratic solutions to academic underachievement, alongside policies and pedagogies that attend to cultural and ethnic inclusion, are at the forefront of the teaching and learning process. Participants are unaware of the way that racially biased structures moderate what can or cannot be reached by virtue of the affective requirements of the dominant settler-Pākehā population. 
The consequences of "a certain schedule of structured blindnesses and opacities" (Mills, 1997, p. 19) were explored in the discussion. This was done firstly by drawing on data to indicate how settler-colonial administrations maintain the coloniser/colonised relationship through structures that reproduce the racist underpinnings of colonialism. It was approached secondly, through examining how the aims of settler-colonialism are fulfilled through the everyday classroom performance of a state narrative of biculturalism. In this way, the aims of the Settler Contract are fulfilled, as Pākehā are able to maintain cultural and racial domination over Māori in New Zealand society, by reaching for a state of settler permanence. I offered an alternative approach to settler-colonial education in the final section of Chapter Eight by arguing that Māori may transcend subpersonhood if difficult knowledge is seminal to the epistemological structural design of state schooling. In effect, if the state is willing to open the crypt.

This thesis makes an original contribution to research by showing how white supremacy is grounded in the institutional structures, processes and practices of a settler-colonial education system. I have shown that the settler-colonial context differs from research that examines other forms of the oppressor/oppressed dichotomy through a hidden curriculum framework. The hidden curriculum reveals a purposeful relationship between micro-level classroom interactions, state institutions, and the ongoing oppression of indigenous peoples through ideologies that exert a national identity. An examination of institutional racism through a hidden curriculum framework is a strength of this study because it highlights the structural and systemic nature of racial injustice. As the thesis shows, conceptualising racism as an individual and interpersonal act has many drawbacks, particularly when investigating racism in institutions.

Another strength is that I have examined silencing and institutional racism through the perceptions and practices of indigenous educators. The transmission of dominant racial ideologies and discourses in institutions by those who they are designed to oppress, stresses how powerful invisible structures and the taken-for-granted norms of everyday life are on our personhood and life trajectories. A challenge that I personally had to overcome was the fear of positioning Māori practitioners as perpetrators of racism, particularly teachers who are tūturu in cultural traditions and Māoritanga. However, it should be clear that this thesis is not an attack on teacher professionalism or racial nous but whiteness. I would again like to thank the participants in this study for providing the means to challenge state oppression. 
One limitation to conceptualising the shape of the hidden curriculum of settler silencing in this thesis is the data in Chapter Seven comes from four participants who represent demographically and contextually specific school contexts. For example, over half of the participants interviewed for phase one were teaching in ethnically mixed or predominantlyPākehā environments (although most participants taught/had taught in majority-Māori settings too), however, Maia was the only phase two participant who taught predominantly Pākehā students. This meant that many of the trends emerging from phase one findings were not represented in phase two. For example, some phase one participants attempted to build cultural understandings with their Pākehā students and spoke about navigating a degree of discomfort and conflict. In contrast, Maia was representative of those teachers in phase one who adopted curriculum and pedagogical approaches to maintain a tranquil racial equilibrium.

Consequently, the limited number of lesson observations of each participant in phase two, means there are classroom interactions and dynamics that have yet to be investigated in the hidden curriculum of settler silencing. For example, many participants in phase one spoke about the complexities of developing literacy skills with Māori students in predominantlyPākehā classrooms. Māori English teachers interviewed in phase one seemed to understand some of the affective pressures faced by minoritised students in white dominant discursive spaces (Harries, 2014). Some spoke about strategically supporting Māori students to wear a "mask of performance" to protect them from Pākehā insult (Rollock, 2012). These kinds of pedagogical approaches and micro-level forms of resistance, which may make the shape of the hidden curriculum more nuanced, are not investigated in this thesis. These gaps are opportunities for future research.

Perhaps the most significant limitation to the study is the changing face of racial ideology and discourse. As societies adapt and evolve in response to political and social challenges, so does the Racial/Settler Contract (Doane, 2017). While I am critical of culturally responsive approaches to teaching in this thesis, it is important to acknowledge these teaching methods were not designed to entrench whiteness in schools (Banks, 2014; Bishop et al., 2014; Ladson-Billings, 1995). However, the fate of this approach (and its continued popularity in schools today) emphasises the nature of hegemony and power. The necessary concessions that Pākehā must make to authorise and participate in settler-colonial education that embraces 
a socially just racial existence are deep and systemic. That this song has been sung many times before means that Māori cannot wait on goodwill alone. We must give Pākehā a reason to be liberators by fighting for the right for our children to exist in an education system that is in breech of the Settler Contract (Leonardo, 2015). I close the thesis with an extended vignette suggesting ways in which educators may challenge the truth-claims of state ideologies of biculturalism through everyday actions that are opposed to a hidden curriculum of settler silencing. Although these approaches are not exhaustive or enough by themselves to counter the entrenched racism generated by settler-colonial education administration systems, it is a grass-roots beginning. For the Settler Contract can be undone, but only if we demand it so.

(post PhD, returning to the classroom)

I give my year 12 class the online article, Princesses - and the sanitising of British history (Kidman, 2018b) to read and we launch into a class discussion. Many of the Pākehā students start to get up-in-arms about the thought that New Zealand looked to British culture with such obedience today. I explain that the article was about social and cultural narratives, and that a society usually circulates one dominant narrative that reflects the attitudes, values and beliefs of those who are part of the mainstream culture. I ask them to share their opinions about the article.

"It's all about what Māoris think," says Chris.

Janet pipes up, "Māori are lucky that they got all this new technology from the British". I explain that a technology is not necessarily a material item, technologies can also comprise of skills, techniques, practices, knowledges and forms of language (Foucault, 1977). I ask, "What technologies did the British bring, and what did they take away? Do you know anything about the technologies of the indigenous Māori whose land we're standing on?" Then we talk about the local iwi, how tangata whenua continue to live here and how they never ceded their claim to the land. We talk about colonial conflict, introduced disease and cultural, language and land displacement. It had taken me some time to find out this information from local kaumātua and the library. The students listen quietly.

Later in the lesson, I overhear Andrew speaking loudly to other students about Mãori cannibalism. I am too drained to challenge him because the talk about local history was difficult. The students may have been quiet, but many were looking away or doing their 
best to seem uninterested. Then I ease up and remind myself that I don't alway have to keep hitting the wall. Tomorrow, we would have an open discussion about their emotional discomfort and connect this to today's discussion about social narrative. I remind myself that the work I do around white supremacy and settler-colonialism will significantly affect how my Pākehā and Māori students think and feel about themselves and each other. I hope that this approach will help them make choices that empower minoritised peoples throughout the rest of their lives.

At the end of class, I head to the staffroom. I sit down to drink my cup of tea and Chelsea, a Deputy Principal, sidles in next to me. She says, "I'm disappointed that you didn't stay for the entire staff meeting yesterday afternoon. The new professional development programme is going to help teachers do a better job at supporting Māori students towards academic success. The school is making a strong commitment to be more culturally responsive and it has great potential."

"But what about the idea I spoke to you about?" I shot back. I met with Chelsea last week asking for a firm committment from senior management to meet with iwi and commit to one school-wide professional development programme that would build teachers' understanding of local history. I explained that staff would also need time build new understandings of settler privilege (including epistemological bias) into their teaching programmes. I told senior management that this was in line with our professional obligations to the Treaty of Waitangi and pointed out the flaws in current approaches. Of course Chelsea says, "It's a shame you won't let that go. I think you're just trying to cause trouble and the staff could learn a lot from you about working with Māori students. Just think about that."

She walks away and I do think... that there's no way I'll support school initiatives that keep Māori boxed at the margins. I can see that the culturally responsive professional development initiative may appear to contribute to meaningful change, but know that it will not produce meaningful results for Māori students or challenge the Pākehācentric climate of this school. I will not help non-Māori staff feel better by agreeing with their misplaced notions of "inclusion" and hope they feel uncomfortable with my decision not to join in. I understand that this refusal to play the game will come at a personal cost. There will be no promotions and most of the staff will quietly shuffle away from me when I walk by. 
At the end of the school day, I make my way to a meeting with the Māori PPTA ${ }^{38}$. Māori secondary school teachers within our rohe have been gathering each month to talk about ways we can challenge institutional racism in secondary schools. At this time, we are focussing our collective energies towards appealing to the Ministry of Education and the NZQA (New Zealand Qualifications Authority) to make the teaching of local and national New Zealand colonial histories and Māori resistance movements compulsory in all levels of secondary school. We know this is ambitious but we have pulled together research and amassed stories from a range of Māori that demand our histories, lived experiences and stories be understood and recognised by all New Zealanders. We have a long list of changes that we aspire to get through. One is that the Ministry of Education mandates that Māori and Pākehā have equal representation on each school's Board of Trustees ${ }^{39}$. Another is that the Ministry of Education funds teachers training colleges according to the number of Māori teachers who graduate. This means that these institutions re-evaluate their candidate selection criteria and the values and vision of teacher education. Whatever we work on next, it is with the common view of pushing back against the structural silencing of Māori in state schooling.

We support each other in other ways too. Recently a year 10 student's father had laid a complaint against me at work. The parents were unhappy with the "Māori issues" I was covering in class and throught that my discussions about racism were confrontational and untrue. The complaint was about my approach to the poem, Sad Joke on a Marae (Taylor, 1983). In order for students to begin to understand the hardships faced by the speaker we'd talked about colonisation, assimilation, Pākehā privilege and the way that institutions and social structures are shaped for the benefit of some and the exclusion of others. I said I felt conflicted about being perceived as either Māori or Pākehā and the shame that this entailed. I tell my students I don't have the answer but I know that one answer is not to talk about it. For homework, the students were to talk to their parents or relatives and find out what their experiences of New Zealand society had been between 1860 and the 1900s so we could explore the implications of this family history in the following lesson.

The head of the English department had been tasked with dealing with the complaint. She explained the situation and said she couldn't believe how ignorant the community

\footnotetext{
${ }^{38}$ PPTA stands for Post Primary Teachers' Association. It is the nationwide secondary school teachers' and principals' union. The branch of the PPTA devoted to Māori interests called "Te Huarahi Māori Motuhake". 39 The Board of Trustees is responsible for the management of the school. For example, the Board makes school employment decisions and is responsible for setting the school's strategic directions.
} 
could be at times. In saying that, it wouldn't hurt to tone it down a bit? Perhaps wait until later in the year before delving into more sensitive issues? I listen stonefaced, noting another way that whiteness is trying to put me in my place. After the meeting I call my Mãori PPTA representative. They speak to the school management team and remind them that everything I'd done was in line with the New Zealand curriculum and exemplied Te Tiriti o Waitangi in action. They suggest that the school tell that to disgruntled parents directly, rather than trying to change teachers who are helping students learn what biculturalism is really about.

I'm back at home in Porirua. The dinner dishes have been washed. My daughter has been bathed. The TV is on but I turn to watch her play with her new bright purple slime. Not as bright as her hair, I think, and wonder again how a child so white could come from my body. I think about her going to school. I know that her experience will not be like mine but it will still be filled with racism. She will learn that there can be some comfort in drawing on silence so that no-one will ever think that she is Māori. Despite my attempts to tell her othewise, she may come to believe this too.

I cannot know for sure what school will be like for her. I only hope that my actions are making her world better. When and how I engage with the Settler Contract is somewhat of a choice but the battle is futile when fought in isolation. It is clear to me that the only way to progress the fight against silencing and institutional racism is with others who live the truth of its existence. Together. In solidarity. For their future. 


\section{References}

Abraham, N., \& Torok, M. (1986). The Wolf Man's magic word: A cryptonymy. Minneapolis: University of Minnesota Press.

Ahmed, S. (2004). The cultural politics of emotion. Edinburgh: Edinburgh University Press.

Ahmed, S. (2007). A phenomenology of whiteness. Feminist Theory, 8(2), 149-168.

Ahmed, S. (2012). On being included: Racism and diversity in institutional life. London: Duke University Press.

Alcoff, L. (1991). The problem of speaking for others. Cultural Critique, 20(20), 5-32. doi:10.2307/1354221

Alcoff, L. (2007). Epistemologies of ignorance: Three types. In S. Sullivan \& N. Tuana (Eds.), Race and epistemologies of ignorance (pp. 39-58). Albany: State University of New York Press.

Alcoff, L. (2014). The future of whiteness. In E. S. Lee (Ed.), Living alterities: Phenomenology, embodiment and race (pp. 255-282). Albany/New York: SUNY Press.

Aldiabat, K., \& Le Navenec, C. (2011). Clarification of the blurred boundaries between grounded theory and ethnography: Differences and similarities. Turkish Online Journal of Qualitative Inquiry, 2(3), 1-13. doi:10.17569/tojqi.04785

Allen, R. L. (2005). Whiteness and critical pedagogy. In Z. Leonardo (Ed.), Critical pedagogy and race (pp. 53-68). Oxford: Blackwell Publishing.

Althusser, L. (2008). On ideology. London: Verso.

Andersen, M. L. (2003). Whitewashing race: A critical perspective on whiteness. In A. Doane \& E. Bonilla-Silva (Eds.), White out: The continuing significance of racism (pp. 21-34). Florence: Taylor and Francis.

Apple, M. W. (2004). Ideology and curriculum. New York: RoutledgeFalmer.

Apple, M. W. (2014). On being race critical. In A. D. Reid, E. P. Hart, \& M. A. Peters (Eds.), A companion to research in education (pp. 263-265). Netherlands: Springer. 
Banks, J. A. (1993). Chapter 1: Multicultural Education: Historical Development, Dimensions, and Practice. Review of Research in Education, 19(1), 3-49. doi:10.3102/0091732X019001003

Banks, J. A. (2014). An introduction to multicultural education. Boston: Pearson.

Barnes, A. M., Taiapa, K., Borell, B., \& McCreanor, T. (2013). Māori experiences and responses to racism in Aotearoa New Zealand. MAI Journal, 2(2), 63-77. Retrieved from http://www.journal.mai.ac.nz/sites/default/files/MAI\%20Journal \%20Vol.2_2\%20pages\%2063-77\%20Moewaka\%20Barnes\%20et\%20al..pdf

Barrington, J. M. (2008). Separate but equal? Māori schools and the Crown, 1867-1969. Wellington N.Z.: Victoria University Press.

Belich, J. (2007). Making peoples: A history of the New Zealanders: From Polynesian settlement to the end of the nineteenth century. North Shore, N.Z.: Penguin.

Bell, A. (2006). Bifurcation or entanglement? Settler identity and biculturalism in Aotearoa New Zealand. Continuum, 20(2), 253-268. doi:10.1080/10304310600641786

Bell, A. (2009). Dilemmas of settler belonging: Roots, routes and redemption in New Zealand national identity claims. Sociological Review, 57(1), 145-162. doi:10.1111/j.1467-954X.2008.01808.x

Bell, D. (1992a). Faces at the bottom of the well: The permanence of racism. New York: Basic Books.

Bell, D. (1992b). Racial realism. Connecticut Law Review, 24(2), 363-379.

Benitez Jnr, M. (2010). Resituating culture centers within a social justice framework: Is there room for examining whiteness? In L. Patton (Ed.), Culture centers in higher education perspectives on identity, theory, and practice (pp. 119-134). Virginia: Stylus Publishing.

Bishop, R. (1999). Culture counts: Changing power relations in education. Palmerston North, N.Z.: Dunmore Press.

Bishop, R. (2005). Freeing ourselves from neo-colonial domination in research: A Kaupapa Māori approach to creating knowledge. In N. K. Denzin \& Y. S. Lincoln (Eds.), The SAGE handbook of qualitative research (pp. 109-135). Thousand Oaks, CA: Sage Publications. 
Bishop, R., Berryman, M., Cavanagh, T., \& Teddy, L. (2007). Te Kōtahitanga phase 3 whānaungatanga: Establishing a culturally responsive pedagogy of relations in mainstream secondary school classrooms. Wellington, N.Z: Ministry of Education, Research Division.

Bishop, R., Berryman, M., \& Wearmouth, J. (2014). Te Kotahitanga: Towards effective education reform for indigenous and minoritised students. Wellington, New Zealand: NZCER Press.

Blank, A., Houkamau, C. A., \& King, H. (2016). Unconscious bias and education: A comparative study of Māori and African American students. Retrieved from http://www.oranui.co.nz/images/oranui_reports/unconscious-bias-and-education.pdf

Bloom, B. S. (1956). Taxonomy of educational objectives, handbook I: The cognitive domain. New York: David McKay Co Inc.

Bonilla-Silva, E. (2014). Racism without racists. United Kingdom: Rowman \& Littlefield Publishers.

Bowles, S., \& Gintis, H. (1976). Schooling in capitalist America: Educational reform and the contradictions of economic life. London: Routledge.

Brash, D. (2004). Nationhood [Press release]. Retrieved from http://www.nzherald .co.nz/ treaty-of-waitangi/news/article.cfm?c_id=350\&objectid=3545950

Britannica, E. (2018). Cognitive dissonance. Retrieved from https://academic.eb.com/levels/ collegiate/article/cognitive-dissonance/24662

Brown, K. D., \& Brown, A. L. (2011). Silenced memories: An examination of the sociocultural knowledge on race and racial violence in official school curriculum. Equity \& Excellence in Education, 43(2), 139-154. doi:10.1080/10665681003719590

Browne, K. (2005). Snowball sampling: Using social networks to research non-heterosexual women. International Journal of Social Research Methodology, 8(1), 47-60. doi:10.1080/1364557032000081663

Campbell, A. (2001). Māori Battalion: A poetic sequence. Wellington, N.Z.: Wai-te-ata Press.

Candlin, C. (1997). General editor's preface. In B. L. Gunnarsson, P. Linell, \& B. Nordberg (Eds.), The construction of professional discourse. London: Tavistok. 
Carmichael, S., \& Hamilton, C. (1967). Black power: The politics of liberation in America. New York: Random House.

Carter, J. (2010). Our tīpuna remain. In A. Wendt, R. Whaitiri, \& R. Sullivan (Eds.), Mauri ola: Contemporary polynesian poems in English (pp. 45-46). Auckland, NZ: Auckland University Press.

Castagno, A. E. (2005). Extending the bounds of race and racism: Indigenous women and the persistence of the Black-White paradigm of race. The Urban Review, 37(5), 447-468.

Castagno, A. E. (2008). "I don't want to hear that!": Legitimating whiteness through silence in schools. Anthropology \& Education Quarterly, 39(3), 314-333.

Castagno, A. E., \& Brayboy, B. M. J. (2008). Culturally responsive schooling for indigenous youth: A review of the literature. Review of Educational Research, 78(4), 941-993.

Charmaz, K. (2006). Constructing grounded theory: A practical guide through qualitative analysis. London: Sage Publications.

Clair, M., \& Denis, J. S. (2015). Racism, Sociology of. In International encyclopedia of the social and behavioral sciences (pp. 857-863). Oxford: Elsevier.

Cornell, S. E., \& Hartmann, D. (1998). Ethnicity and race: making identities in a changing world. Thousand Oaks, Calif: Pine Forge Press.

Crenshaw, K. (1988). Race, reform, and retrenchment: Transformation and legitimation in antidiscrimination law. Harvard Law Review, 101(7), 1331-1387. doi: $10.2307 / 1341398$

Delpit, L. D. (1988). The silenced dialogue: Power and pedagogy in educating other people's children. Harvard Educational Review, 58(3), 280-298.

Denzin, N. K., \& Lincoln, Y. S. (2005). The SAGE handbook of qualitative research (3rd ed.). Thousand Oaks, CA: Sage Publications.

Denzin, N. K., Lincoln, Y. S., \& Smith, L. T. (2008). Handbook of critical and indigenous methodologies. Los Angeles: Sage Publications.

DiAngelo, R. (2011). White fragility. International Journal of Critical Pedagogy, 3(3), 5470.

DiAngelo, R. (2012). What Does it Mean to be White? Developing White Racial Literacy. New York: Peter Lang. 
Doane, A. (2006). What is racism? Racial discourse and racial politics. Critical Sociology, 32(2-3), 255-274. doi:doi:10.1163/156916306777835303

Doane, A. (2017). Beyond color-blindness: (Re) theorizing racial ideology. Sociological Perspectives, 60(5), 975-991. doi:10.1177/0731121417719697

Doane, A., \& Bonilla-Silva, E. (2003). White out: The continuing significance of racism. Abingdon, Oxon: Taylor and Francis.

Docker, J. (1978). The neocolonial assumption in university teaching of English. In C. Tiffin (Ed.), South pacific images (pp. 26-31). Brisbane, Australia: The South Pacific Association for Commonwealth Literature and Language Studies.

Donaldson, M. (1996). The end of time? Aboriginal temporality and the British invasion of Australia. Time \& Society, 5(2), 187-207. doi:10.1177/0961463X96005002004

Dovemark, M. (2013). How private 'everyday racism' and public 'racism denial' contribute to unequal and discriminatory educational experiences. Ethnography and Education, 8(1), 16-30. doi:10.1080/17457823.2012.717199

Du Bois, W. E. B. (1935). Black reconstruction: An essay toward a history of the part which black folk played in the attempt to reconstruct democracy in America, 1860-1880. New York: Harcourt Brace \& Company.

Duhn, I. (2008). Globalising childhood: Assembling the bicultural child in the New Zealand early childhood curriculum Te Whāriki. International Journal of Critical Childhood Policy Studies, 1(1), 82-105.

Edwards, R., \& Holland, J. (2013). What is qualitative interviewing? London, UK.: Bloomsbury Academic.

Eisenhardt, K. M. (1989). Building theories from case study research. Academy of Management Review, 14(4), 532. doi:10.5465/AMR.1989.4308385

Ellsworth, E. (1989). Why doesn't this feel empowering? Working through the repressive myths of critical pedagogy. Harvard Educational Review, 59(3), 297.

Essed, P. (1991). Understanding everyday racism: An interdisciplinary theory. United States: Sage Publications Inc.

Fanon, F. (1970). Black skin, white masks. London: Paladin.

Fanon, F. (2004). The wretched of the earth. New York: Grove Press. 
Fine, M. (1987). Silencing in public schools. Language Arts, 64(2), 157-174.

Fine, M. (1991). Framing dropouts: Notes on the politics of an urban public high school. Albany: State University of New York Press.

Fivush, R. (2010). Speaking silence: The social construction of silence in autobiographical and cultural narratives. Memory, 18(2), 88-98. doi:10.1080/09658210903029404

Fleras, A. (2016). Theorizing micro-aggressions as racism 3.0: Shifting the discourse. Canadian Ethnic Studies, 48(2), 1-19.

Foucault, M. (1977). Discipline and punish: The birth of the prison. New York: Pantheon Books.

Freire, P. (1970). Pedagogy of the oppressed. New York: Seabury.

Frideres, J. (2015). Being white and being right. In D. E. Lund \& P. R. Carr (Eds.), Revisiting the great white north? Reframing whiteness, privilege and identity in education (pp. 43-53). Rotterdam: SensePublishers.

Garcia, J. L. A. (2001). The racial contract hypothesis. Philosophia Africana, 4(1), 27-43.

Gay, G. (2002). Preparing for culturally responsive teaching. Journal of Teacher Education, 53(2), 106-116.

Gebhard, A. (2017). 'Let's make a little drum': Limitations and contradictory effects of cultural approaches in indigenous education. Race Ethnicity and Education, 1-16. doi:10.1080/13613324.2017.1377172

Gillborn, D. (2005). Education policy as an act of white supremacy: Whiteness, critical race theory and education reform. Journal of Education Policy, 20(4), 485-505. doi:10.1080/02680930500132346

Gillborn, D. (2006). Citizenship education as placebo: "Standards", institutional racism and education policy. Education, Citizenship and Social Justice, 1(1), 83-104. doi:10.1177/1746197906060715

Gillborn, D. (2008). Racism and education; coincidence or conspiracy? London: Routledge.

Gilroy, P. (2004). After empire: Melancholia or convivial culture? London: Routledge.

Giroux, H. A. (1983). Ideology and agency in the process of schooling. Journal of Education, 165(1), 12-34. doi:10.1177/002205748316500104 
Giroux, H. A. (2003). Spectacles of race and pedagogies of denial: Anti-black racist pedagogy under the reign of neoliberalism. Communication Education, 52(3-4), 191211. doi:10.1080/0363452032000156190

Golding, W. (1958). Lord of the flies. London: Faber and Faber.

Gordon, A. (2008). Ghostly matters: Haunting and the sociological imagination. In. Minneapolis: University of Minnesota Press.

Grace, P. (1988). The hills. New Zealand: Stout Research Centre. Literary Archive National Library.

Grace, P. (1990). Going for the bread; Butterflies; The Lamp; An interview with Patricia Grace. In. Wellington, N.Z.: New Zealand Learning Media.

Grace, P. (2004). Tu. New Zealand: Penguin Group.

Graham, M., \& Robinson, G. (2004). "The silent catastrophe": Institutional racism in the British educational system and the underachievement of black boys. Journal of Black Studies, 34(5), 653-671.

Gramsci, A. (1992). Prison notebooks. New York: Columbia University Press.

Gray, C., Jaber, N., \& Anglem, J. (2013). Pakeha identity and whiteness: What does it mean to be white? Sites, 10(2), 82-106. doi:10.11157/sites-vol10iss2id223

Gutschlag, A. (2007). Some implications of the Te Kotahitanga model of teacher positioning. New Zealand Journal of Teachers' Work, 4(1), 3-10.

Hall, S. (1986). The problem of ideology-Marxism without guarantees. Journal of Communication Inquiry, 10(2), 28-44. doi:10.1177/019685998601000203

Hällgren, C. (2005). 'Working harder to be the same': Everyday racism among young men and women in Sweden. Race Ethnicity and Education, 8(3), 319-342. doi:10.1080/13613320500174499

Harries, B. (2014). We need to talk about race. Sociology, 48(6), 1107-1122.

Heron, J., \& Reason, P. (1997). A participatory inquiry paradigm. Qualitative Inquiry, 3(3), 274-294. doi:10.1177/107780049700300302 
Hokowhitu, B. J. (2003). 'Physical beings': Stereotypes, sport and the 'physical education' of New Zealand Māori. Culture, Sport, Society, 6(2-3), 192-218. doi:10.1080/14610980312331271599

Hokowhitu, B. J. (2017). Identity appropriation and the unsettling desire to be indigenous. Paper presented at the Race, Whiteness and Indigeneity: An International Conference, Queensland, Australia.

Holt, N. L. (2003). Representation, legitimation, and autoethnography: An autoethnographic writing story. International Journal of Qualitative Methods, 2(1), 18-28. doi:10.1177/160940690300200102

Hook, D. (2005). Affecting whiteness: Racism as technology of affect (1464-0538). Retrieved from http://eprints.1se.ac.uk/956/

hooks, b. (1990). Marginality as a site of resistance. In M. Ferguson, T. Gever, T. T. Minhha, \& C. West (Eds.), Out there: Marginalization and contemporary cultures. Cambridge, MA: MIT Press.

hooks, b. (1994). Teaching to transgress: Education as the practice of freedom. New York: Routledge.

Houkamau, C. A. (2016). What you can't see can hurt you: How do stereotyping, implicit bias and stereotype threat affect Māori health? MAI Journal, 5(2), 124-136. doi:10.20507/MAIJournal.2016.5.2.3

Hunter, M. (2004). Light, bright, and almost white: The advantages and disadvantages of light skin. In C. Herring, V. M. Keith, \& H. D. Horton (Eds.), Skin deep: How race and complexion matter in the "color-blind" era (pp. 22-44). Chicago, IL.: University of Illinois Press.

Ihimaera, W. (2009). Dustbins. In W. Ihimaera (Ed.), Witi Ihimaera: His best stories. North Shore, N.Z.: Raupo.

Illich, I. (1973). Deschooling society. Harmondsworth, Middlesex: Penguin.

Iparraguirre, G. (2016). Time, temporality and cultural rhythmics: An anthropological case study. Time \& Society, 25(3), 613-633. doi:10.1177/0961463X15579802

Jackson, A. Y., \& Mazzei, L. A. (2008). Voice in qualitative inquiry challenging conventional, interpretive, and critical conceptions. New York: Routledge. 
Jackson, M. (2018). Understanding racism in this country. E-Tangata: A Māori and Pasifika Sunday magazine. Retrieved from https://e-tangata.co.nz/comment-and-analysis/ moana-jackson-understanding-racism-in-this-country/

Johansson, J. (2004). Orewa and the rhetoric of illusion. Political Science, 56(2), 111-129. doi:10.1177/003231870405600212

Johnson-Bailey, J., Valentine, T. S., Cervero, R. M., \& Bowles, T. A. (2008). Lean on me: The support experiences of Black graduate students. The Journal of Negro Education, 77(4), 365-381.

Jungkunz, V., \& White, J. (2013). Ignorance, innocence, and democratic responsibility: Seeing race, hearing racism. The Journal of Politics, 75(2), 436-450. doi:10.1017/s0022381613000121

Keith, V. M., \& Monroe, C. R. (2016). Histories of colorism and implications for education. Theory Into Practice, 55(1), 4-10. doi:10.1080/00405841.2016.1116847

Kidman, J. (2009). Shifting margins, shifting centres: Development paradigms in Māori education. International Journal of Development Education and Global Learning, 2(1), 5-18. doi:10.18546/ijdegl.02.1.02

Kidman, J. (2015). Indigenous youth, nationhood and the politics of belonging. In J. Wyn \& H. Cahill (Eds.), Handbook of children and youth studies (pp. 637-649). Singapore: Springer Science+Business Media.

Kidman, J. (2018a). Pedagogies of forgetting: Colonial encounters and nationhood at New Zealand's national museum. In T. Epstein \& C. Peck (Eds.), Teaching and learning difficult histories in international contexts: a critical sociocultural approach (pp. 95108). New York: Routledge.

Kidman, J. (2018b). Princesses - and the sanitising of British history. E-Tangata: A Māori and Pasifika Sunday magazine. Retrieved from https://e-tangata.co.nz/reflections /princesses-and-the-sanitising-of-british-history/

Kidman, J., Abrams, E., \& McRae, H. (2011). Imaginary subjects: School science, indigenous students, and knowledge-power relations. British Journal of Sociology of Education, 32(2), 203-220. doi:10.1080/01425692.2011.547306 
Kidman, J., \& Chu, C. (2017). Scholar outsiders in the neoliberal university: Transgressive academic labour in the whitestream. New Zealand Journal of Educational Studies, 52(1), 7-19. doi:10.1007/s40841-017-0079-y

Kidman, J., Chu, C., Fernandez, S., \& Abella, I. (2015). Māori scholars and the university. Retrieved from http://www.maramatanga.co.nz/sites/default/files/project-reports/ Kidman\%20Chu\%20Fernandez\%20Abella\%20Maori\%20Scholars\%20Final\%20repor t\%202015.pdf:

Kidman, J., Ormond, A., \& MacDonald, L. (2018). Everyday hope: Indigenous aims of education in settler-colonial societies. In J. E. Petrovic \& R. M. Mitchell (Eds.), Indigenous philosophies of education around the world (pp. 228-245). New York: Routledge.

Kim, E. J. A. (2015). Neo-colonialism in our schools: Representations of indigenous perspectives in Ontario Science curricula. McGill Journal of Education, 50(1). doi:10.7202/1036109ar

Kincheloe, J. L. (2004). Critical pedagogy. New York: Peter Lang.

Kincheloe, J. L., \& McLarin, P. (2008). Rethinking critical theory and qualitative research. In N. Denzin \& Y. Lincoln (Eds.), The Landscape of Qualitative Research (pp. 403456). Thousand Oaks: Sage.

King, J. (1991). Dysconscious racism: Ideology, identity, and the miseducation of teachers. The Journal of Negro Education, 60(2), 133-146. doi:doi:10.2307/2295605

King, M. (2012). The Penguin history of New Zealand. Auckland, N.Z.: Penguin.

Kohli, R. (2009). Critical race reflections: Valuing the experiences of teachers of color in teacher education. Race, Ethnicity and Education, 12(2), 235-251. doi:10.1080/13613320902995491

Kowal, E. (2015). Time, indigeneity and white anti-racism in Australia. Australian Journal of Anthropology, 26(1), 94-111. doi:10.1111/taja.12122

Kraehe, A. M. (2015). Sounds of silence: Race and emergent counter-narratives of art teacher identity. Studies in Art Education, 56(3), 199-213.

kumar, h. (2010). Speaking in silences. International Review of Qualitative Research, 2(4), 433-444. 
Ladson-Billings, G. (1995). Toward a theory of culturally relevant pedagogy. American Educational Research Journal, 32(3), 465-491.

Ladson-Billings, G. (1997). I know why this doesn't feel empowering. In F. P., J. W. Fraser, D. Macedo, T. McKinnon, \& W. T. Stokes (Eds.), Mentoring the mentor: A critical dialogue with Paulo Freire (pp. 127-141). New York: Peter Lang.

Ladson-Billings, G. (1998). Just what is critical race theory and what's it doing in a nice field like education? International Journal of Qualitative Studies in Education, 11(1), 7-24.

Ladson-Billings, G. (2014). What It means to be critical: Beyond rhetoric and toward action. In A. D. Reid, E. P. Hart, \& M. A. Peters (Eds.), A companion to research in education (pp. 259-261). Netherlands: Springer.

Ladson-Billings, G., \& Tate, W. F. I. V. (1995). Toward a critical race theory of education. Teachers College Record, 97(1), 47-68.

Lashley, M. E. (2000). Implementing treaty settlements via indigenous institutions: Social justice and detribalization in New Zealand. The Contemporary Pacific, 12(1), 1-55. doi:10.1353/cp.2000.0018

Lee, E. S. (2014). Introduction. In E. S. Lee (Ed.), Living alterities: Phenomenology, embodiment and race (pp. 1-18). Albany, New York: SUNY Press.

Lee, H. (1995). To kill a mockingbird New York: Harper Collins Publishers.

Lehrer, E. T., \& Milton, C. E. (2011). Curating difficult knowledge violent pasts in public places. In. New York: Palgrave Macmillan.

Leonardo, Z. (2002). The souls of white folk: Critical pedagogy, whiteness studies, and globalization discourse. Race Ethnicity and Education, 5(1), 29-50.

Leonardo, Z. (2005a). The color of supremacy: Beyond the discourse of 'white privilege'. In Z. Leonardo (Ed.), Critical pedagogy and race (pp. 1-36). UK: Blackwell Publishing.

Leonardo, Z. (2005b). Critical Pedagogy and Race. UK: Blackwell publishing.

Leonardo, Z. (2009). Race, whiteness, and education. New York: Routledge.

Leonardo, Z. (2013). The story of schooling: Critical race theory and the educational racial contract. Discourse: Studies in the Cultural Politics of Education, 34(4), 599-610. doi:10.1080/01596306.2013.822624 
Leonardo, Z. (2014). Dialectics of race criticality: Studies in racial stratification and education. In A. D. Reid, E. P. Hart, \& M. A. Peters (Eds.), A companion to research in education (pp. 247-257). Netherlands: Springer

Leonardo, Z. (2015). Contracting race: Writing, racism, and education. Critical Studies in Education, 56, 86-98.

Leonardo, Z., \& Porter, R. K. (2010). Pedagogy of fear: Toward a fanonian theory of "safety" in race dialogue. Race Ethnicity and Education, 13(2), 139-157.

doi:10.1080/13613324.2010.482898

Leonardo, Z., \& Zembylas, M. (2013). Whiteness as technology of affect: Implications for educational praxis. Equity \& Excellence in Education, 46(1), 150-165. doi:10.1080/10665684.2013.750539

Lingard, B., \& Thompson, G. (2017). Doing time in the sociology of education. British Journal of Sociology of Education, 38(1), 1-12. doi:10.1080/01425692.2016.1260854

Lipsitz, G. (1998). The possessive investment in whiteness how white people profit from identity politics. Philadelphia: Temple University Press.

Logan, I. (2010). Property of Shiloh. Spasifik, Mar/Apr(3), 23-26.

Lorde, A. (1984). Sister outsider: Essays and speeches. Trumansburg, NY: Crossing Press.

Luykx, A. (1993). The citizen factory: Language, labor and identity in Bolivian rural teacher education. (Unpublished $\mathrm{PhD}$ thesis), The University of Texas at Austin, USA.

Lynn, M. (2005). Critical race theory, afrocentricity, and their relationship to critical pedagogy. In Z. Leonardo (Ed.), Critical pedagogy and race (pp. 127-140). UK: Blackwell Publishing.

MacDonald, L., \& Reynolds, M. (2017). "It's all part of the job": Everyday silencing in the life of a secondary school teacher. MAI Journal, 6(1), 47-60.

Macfarlane, A. H. (2004). Kia hiwa ra! Listen to culture: Māori students' plea to educators. Wellington, N.Z. : New Zealand Council for Educational Research.

Macpherson, W. (1999). The Stephen Lawrence inquiry. Retrieved from https://assets.publishing.service.gov.uk/government/uploads/system/uploads/attachme nt_data/file/277111/4262.pdf 
Mamdani, M. (1999). Historicizing power and responses to power: Indirect rule and its reform. Social Research, 66(3), 859-886.

Matias, C. E., \& Zembylas, M. (2014). 'When saying you care is not really caring': Emotions of disgust, whiteness ideology, and teacher education. Critical Studies in Education, 55(3), 319-337. doi:10.1080/17508487.2014.922489

Matsuda, M. J. (1993). Words that wound: Critical race theory, assaultive speech, and the First Amendment. Boulder, CA: Westview Press.

McIntosh, P. (1989). White privilege: Unpacking the invisible knapsack. Philadelphia, PA.: Women's International League for Peace and Freedom.

McIntosh, T. (2005). Māori identities: Fixed, fluid, forced. In J. H. Liu, T. McCreanor, T. McIntosh, \& T. Teaiwa (Eds.), New Zealand identities; Departures and destinations (pp. 38-51). Wellington: Victoria University Press.

McLachlan, T. (2010). Mr Frosty and the BMX Kid. Retrieved from Your Big Break competition: https://www.youtube.com/watch?v=ibC8LJ0_dVA

McNeil, B. (2011). Charting a way forward: Intersections of race and space in establishing identity as an African-Canadian teacher educator. Studying Teacher Education, 7(2), 133.

Merleau-Ponty, M. (1962). Phenomenology of perception. London: Routledge \& Kegan Paul.

Meyer, L., Penetito, W., Hynds, A., Savage, C., Hindle, R., \& Sleeter, C. E. (2010). Evaluation of Te Kötahitanga, 2004-2008: Report to the Ministry of Education (0478342845). Retrieved from https://www.educationcounts.govt.nz/publications/ 91416/english-medium-education/evaluation-of-te-kotahitanga-2004-2008/chapter-6impact-on-schools

Mika, C. (2016). A counter-colonial speculation on Elizabeth Rata's -ism. Journal of World Philosophies, 1(1), 1-12. doi:10.2979/jourworlphil.1.1.01

Mika, C. (2017). The uncertain kaupapa of Kaupapa Māori. In T. Hoskins \& A. Jones (Eds.), Critical conversations in Kaupapa Māori (pp. 119-132). La Vergne: Huia (NZ) Ltd.

Mika, C., \& Stewart, G. (2016). Maori in the kingdom of the gaze: Subjects or critics? Educational Philosophy and Theory, 48(3), 300-312. doi:10.1080/00131857.2015.1013017 
Mills, C. W. (1997). The racial contract. Ithaca: Cornell University Press.

Mills, C. W. (2002). The racial contract as methodology (not hypothesis). Philosophia Africana, 5(2).

Mills, C. W. (2007). White ignorance. In S. Sullivan \& N. Tuana (Eds.), Race and epistemologies of ignorance (pp. 13-38). Albany: State University of New York Press.

Mills, C. W. (2014a). Materializing race. In E. S. Lee (Ed.), Living alterities:

Phenomenology, embodiment, and race (pp. 19-41). Albany, New York: SUNY Press.

Mills, C. W. (2014b). White time. Du Bois Review, 11(1), 27-42.

doi:10.1017/S1742058X14000022

Milne, A. (2017). Coloring in the white spaces: Reclaiming cultural identity in whitestream schools. New York: Peter Lang.

Milner, D. (2015). "Too White to be Black and too Black to be White": The consequences of a color-blind orientation on Black/White biracial students' college choice process and racial identity development. (Unpublished $\mathrm{PhD}$ thesis), The University of Arizona, Retrieved from https://search.proquest.com/docview/1749007855?accountid=14782

Ministry of Education. (2007). The New Zealand curriculum. Wellington, N.Z.: Ministry of Education Retrieved from http://nzcurriculum.tki.org.nz/The-New-ZealandCurriculum.

Ministry of Education. (2011). Tātaiako: Cultural competencies for teachers of Māori learners. Retrieved from Wellington, N.Z.: https://educationcouncil.org.nz/ required/Tataiako.pdf

Ministry of Education. (2013). Ka hikitia: Accelerating success, 2013-2017. Wellington, N.Z.: Ministry of Education Retrieved from https://www.education.govt.nz/assets/Documents/Ministry/Strategies-andpolicies/Ka-Hikitia/KaHikitiaAcceleratingSuccessEnglish.pdf.

Morrison, K., Rose, D., \& Robbins, H. (2008). Operationalizing culturally relevant pedagogy: A synthesis of classroom-based research. Equity \& Excellence in Education, 41(4), 433-452.

Mueller, J. C. (2017). Producing colorblindness: Everyday mechanisms of white ignorance. Social Problems, 64(2), 219-238. doi:10.1093/socpro/spw061 
Mukhopadhyay, C. C., \& Chua, P. (2008). Cultural racism. In J. H. Moore (Ed.), Encyclopedia of race and racism (Vol. 1, pp. 377-383). United States of America: Thomson Gale.

Nanni, G. (2011). Time, empire and resistance in settler-colonial Victoria. Time \& Society, 20(1), 5-33. doi:10.1177/0961463X10369765

Nanni, G. (2013). The colonisation of time: Ritual, routine and resistance in the British Empire. Manchester: Manchester University Press.

O'Sullivan, D. (2007). Beyond biculturalism: The politics of an indigenous minority. Wellington, N.Z: Huia.

O'Sullivan, D. (2008). Needs, rights and "one law for all": Contemporary debates in New Zealand Māori politics. Canadian Journal of Political Science, 41(4), 973-986. doi:10.1017/S0008423908081122

O’Malley, V., \& Kidman, J. (2017). Settler colonial history, commemoration and white backlash: Remembering the New Zealand wars. Settler Colonial Studies, 1-16. doi:10.1080/2201473x.2017.1279831

Omi, M., \& Winant, H. (1986). Racial formation in the United States: From the 1960s to the 1980s. New York: Routledge \& Kegan Paul.

Orange, C. (2014). What happened at Waitangi? Wellington, N.Z.: Bridget Williams Books.

Pateman, C. (2007). The settler contract. In C. Pateman \& C. Mills (Eds.), The contract and domination (pp. 35-78). Cambridge, U.K.: Polity Press.

Penetito, W. (2010). What's Māori about Māori education? The struggle for a meaningful context. Wellington, N.Z.: Victoria University Press.

Perkins, M. (1998). Timeless cultures. Time \& Society, 7(2-3), 335-351. doi:10.1177/0961463X98007002009

Peters, M. A., \& Mika, C. (2017). Aborigine, Indian, indigenous or first nations? Educational Philosophy and Theory, 49(13), 1229-1234. doi:10.1080/00131857.2017.1279879

Pihama, L. (2001). Tihei mauri ora: Honouring our voices: Mana wahine as a kaupapa Māori theoretical framework. (Unpublished PhD thesis), University of Auckland, Auckland, New Zealand. Retrieved from http://www.tutamawahine.org.nz/ tihea_mauri_ora 
Pilkington, A. (2011). Institutional racism in the academy: A case study. Stoke on Trent: Trentham Books.

Poata-Smith, E. (2008). The evolution of contemporary Māori protest. Retrieved from http://www.maorinews.com/writings/paper/other/protest.hmtl

Pollock, M. (2004). Colormute race talk dilemmas in an American school. Princeton, NJ: Princeton University Press.

Pratt, M. L. (2014). In the neocolony: Destiny, destination and the traffic in meaning. In M. Morana, E. Dussel, \& C. Jáuregui (Eds.), Coloniality at large: Latin America and the postcolonial debate (pp. 459-475). ProQuest Ebook Central: Duke University Press.

Regalsky, P., \& Laurie, N. (2007). 'The school, whose place is this'? The deep structures of the hidden curriculum in indigenous education in Bolivia. Comparative Education, 43(2), 231-251. doi:10.1080/03050060701362482

Reports of Inspectors. (1862). Native schools act. Auckland: Parliamentary papers Retrieved from https://paperspast.natlib.govt.nz/parliamentary/AJHR1862-I.2.1.6.4.

Rifkin, M. (2017). Beyond settler time: Temporal sovereignty and indigenous selfdetermination. Durham: Duke University Press.

Ritchie, J., Skerrett, M., \& Rau, C. (2014). Kei tua i te awe māpara: Countercolonial unveiling of neoliberal discourses in Aotearoa New Zealand. International Review of Qualitative Research, 7(1), 111-129.

Robertson, J. N. (Writer). (2014). The dark horse. In T. Hern (Producer). New Zealand: Transmission Films.

Rodriguez, D. (2011). Silent rage and the politics of resistance: Countering seductions of whiteness and the road to politicization and empowerment. Qualitative Inquiry, 17(7), 589-598.

Rollock, N. (2012). The invisibility of race: Intersectional reflections on the liminal space of alterity. Race, Ethnicity and Education, 15(1), 65-84. doi:10.1080/13613324.2012.638864

Rollock, N., Gillborn, D., Vincent, C., \& Ball, S. (2014). The colour of class: The educational strategies of the black middle classes. New York: Routledge.

Saldaña, J. (2013). The coding manual for qualitative researchers. Los Angeles: Sage. 
Samuel, E., \& Wane, N. (2005). "Unsettling relations": Racism and sexism experienced by faculty of color in a predominantly white Canadian university. The Journal of Negro Education, 74(1), 76-87.

Santoro, N., \& Reid, J. A. (2006). 'All things to all people': Indigenous teachers in the Australian teaching profession. European Journal of Teacher Education, 29(3), 287303. doi:10.1080/02619760600795072

Schwab, G. (2010). Haunting legacies: Violent histories and transgenerational trauma. New York: Columbia University Press.

Sharma, S. (2014). In the meantime: Temporality and cultural politics. Durham: Duke University Press.

Sheehan, M. (2011). "Little is taught or learned in schools": Debates over the place of history in the New Zealand school curriculum. In T. Taylor \& R. Guyver (Eds.), History wars and the classroom: global perspective (pp. 107-124). Charlotte, NC: Information Age Publishing.

Sibley, C. G., Stewart, K., Houkamau, C. A., Manuela, S., Perry, R., Wootton, L., . . Asbrock, F. (2011). Ethnic group stereotypes in New Zealand. New Zealand Journal of Psychology, 40(2), 25(12).

Sibley, C. G., \& Ward, C. (2013). Measuring the preconditions for a successful multicultural society: A barometer test of New Zealand. International Journal of Intercultural Relations, 37(6), 700-713. doi:10.1016/j.ijintrel.2013.09.008

Simon, J. A., Smith, L. T., \& Cram, F. (2001). A civilising mission? Perceptions and representations of the native schools system. Auckland, N.Z.: Auckland University Press.

Siteine, A. (2016). Recognising ethnic identity in the classroom: A New Zealand study. International Studies in Sociology of Education, 1-15. doi:10.1080/09620214.2016.1264869

Sleeter, C. E. (2012). Confronting the marginalization of culturally responsive pedagogy. Urban Education, 47(3), 562-584.

Smith, L. T. (2012). Decolonizing methodologies: research and indigenous peoples. New York: Palgrave Macmillan. 
Smits, K. (2014). The neoliberal state and the uses of indigenous culture. Nationalism and Ethnic Politics, 20(1), 43-62. doi:10.1080/13537113.2014.879764

Solórzano, D. G. (1998). Critical race theory, race and gender microaggressions, and the experience of Chicana and Chicano scholars. International Journal of Qualitative Studies in Education, 11(1), 121-136. doi:10.1080/095183998236926

Solórzano, D. G., \& Yosso, T. J. (2002). Critical race methodology: Counter-storytelling as an analytical framework for education research. Qualitative Inquiry, 8(1), 23-44. doi:10.1177/107780040200800103

Spivak, G. (1988). Can the subaltern speak? In C. Nelson \& L. Grossberg (Eds.), Marxism and the interpretation of culture (pp. 271-313). Basingstoke: Macmillan Education.

Spry, T. (2001). Performing autoethnography: An embodied methodological praxis. Qualitative Inquiry, 7(6), 706-732.

St. Denis, V. (2007). Aboriginal education and anti-racist education: Building alliances across cultural and racial identity. Canadian Journal of Education, 30(4), 1068-1092.

St. Denis, V. (2011). Silencing aboriginal curricular content and perspectives through multiculturalism: "There are other children here". Review of Education, Pedagogy, and Cultural Studies, 33(4), 306-317. doi:10.1080/10714413.2011.597638

Stake, R. (2005). Qualitative case studies. In N. K. Denzin \& Y. S. Lincoln (Eds.), The sage handbook of qualitative research (pp. 443-466). Thousand Oaks: SAGE publications.

Stanley, C. A. (2006). Coloring the academic landscape: Faculty of color breaking the silence in predominantly white colleges and universities. American Educational Research Journal, 43(4), 701-736.

Stewart, G. M. (2007). Kaupapa Māori science. (Doctor of Philosophy (PhD) Doctoral), The University of Waikato, Hamilton, New Zealand. Retrieved from https://hdl.handle.net/10289/2598

Taylor, A. (1983). Apirana Taylor reads a selection of his poems. In. Stout Research Centre. Literary, Archive: Radio New Zealand. Sound, Archives.

Thomas, E. (2015). "We always talk about race": Navigating race talk dilemmas in the teaching of literature. Research in the Teaching of English, 50(2), 154-175. 
Thompson, E. P. (1967). Time, work-discipline and industrial capitalism. Past \& Present, 38(1), 56-97.

Tuck, E., \& Gaztambide-Fernández, R. (2013). Curriculum, replacement, and settler futurity. JCT, 29(1), 72-89.

Tuck, E., \& Gorlewski, J. (2016). Racist ordering, settler colonialism, and edTPA: A participatory policy analysis. Educational Policy, 30(1), 197-217. doi:10.1177/0895904815616483

Tuck, E., \& Yang, K. W. (2012). Decolonization is not a metaphor. Decolonization: Indigeneity, Education \& Society, 1(1), 1-40.

Van de Kleut, G. (2011). The whiteness of literacy practice in Ontario. Race Ethnicity and Education, 14(5), 699-726. doi:10.1080/13613324.2011.585338

van Dijk, T. A. (1998). Ideology: A multidisciplinary approach. In. doi: http://ebookcentral.proquest.com/lib/vuw/detail.action?docID=1024022

Vass, G. (2013). Hear no race, see no race, Speak no race: Teacher silence, indigenous youth, and race talk in the classroom. Social Alternatives, 32(2), 19-24.

Vass, G. (2015). Putting critical race theory to work in Australian education research: 'We are with the garden hose here'. The Australian Educational Researcher, 42(3), 371394. doi:10.1007/s13384-014-0160-1

Veracini, L. (2010). Settler colonialism: A theoretical overview. New York: Palgrave Macmillan.

Veracini, L. (2011). Introducing: Settler colonial studies. Settler Colonial Studies, 1(1), 1-12. doi:10.1080/2201473X.2011.10648799

Veracini, L. (2015). The settler colonial present New York: Palgrave Macmillan.

Waititi, T. (Writer). (2010). Boy. In C. Curtis, A. Gardiner, \& E. Michael (Producer). New Zealand: Transmission Films.

Walker, R. (2004). Ka whawhai tonu mātou: struggle without end. Auckland, N.Z.: Penguin.

Wallerstein, I. (1997). Eurocentrism and its avatars: The dilemmas of Social Science. Sociological Bulletin, 46(1), 21-39. doi:10.1177/0038022919970102 
Ward, C., \& Masgoret, A.-M. (2008). Attitudes toward immigrants, immigration, and multiculturalism in New Zealand: A social psychological analysis. International Migration Review, 42(1), 227-248. doi:10.1111/j.1747-7379.2007.00119.x

Ward, V. (Writer). (2008). Rain of the children. In V. Ward, T. Stephens, \& M. Slater (Producer). New Zealand: Forward Films.

White, R. (2011). The middle ground: Indians, empires, and republics in the Great Lakes region, 1650-1815 (20th anniversary ed.. ed.). New York: Cambridge University Press.

Wolfe, P. (1999). Settler colonialism and the transformation of anthropology: The politics and poetics of an ethnographic event. New York: Cassell.

Wolfe, P. (2006). Settler colonialism and the elimination of the native. Journal of Genocide Research, 8(4), 387-409. doi:10.1080/14623520601056240

Young, M., Chester, J.-L., Flett, B. M., Joe, L., Marshall, L., Moore, D., . . Huber, J. (2010). Becoming 'real' Aboriginal teachers: Attending to intergenerational narrative reverberations and responsibilities. Teachers and Teaching, 16(3), 285-305. doi:10.1080/13540601003634370

Zembylas, M. (2010). Racialization/Ethnicization of school emotional spaces: The politics of resentment. Race Ethnicity and Education, 13(2), 253-270. doi:10.1080/13613321003751528

Zembylas, M. (2017). The contribution of the ontological turn in education: Some methodological and political implications. Educational Philosophy and Theory, 49(14), 1401-1414. doi:10.1080/00131857.2017.1309636

Zembylas, M., Charalambous, C., \& Charalambous, P. (2014). The schooling of emotion and memory: Analyzing emotional styles in the context of a teacher's pedagogical practices. Teaching and Teacher Education, 44, 69-80. doi:10.1016/j.tate.2014.08.001 


\title{
Appendices
}

\section{Appendix A: Phase one research participant information and consent form}

\author{
VICTORIA UNIVERSITY OF WELLINGTON \\ Te Whare Wananga o te Upoko o te Ika a Maui
}

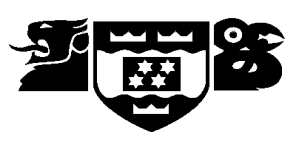

\section{Phase One Research Participant Information Sheet}

\section{PROJECT TITLE}

Teaching from the margins: An investigation of the lived experiences of Māori English secondary school teachers

\section{Introduction and Background}

My name is Liana MacDonald. I am a PhD student from Te Whānau o Ako Pai ki Te Upoko o te Ika a Māui, Faculty of Education, Victoria University of Wellington and am undertaking a research project leading to a Doctorate thesis. The University requires that ethics approval be obtained for research projects involving human participants. This information sheet will provide you with information about my research and your possible involvement. It is important that you make an informed decision about whether you want to participate.

\section{Aim of the research}

This research aims to investigate the lived realities of secondary school English teachers who identify as Māori in relation to the New Zealand English curriculum requirements; such as the teaching of critical thinking, responding to student identity and bi-cultural issues in secondary school classroom contexts. To my knowledge, no research has been undertaken to capture the voice of teachers of English who also identify, culturally and ethnically, as Mãori. This study argues that the implications of curriculum references to biculturalism must be explored from the perspectives of tangata whenua if they are to have real meaning and substance.

There are two phases to this research. The first is aimed at gathering a breadth of data by conducting semi-structured interviews with a number of Māori English teachers. This data will help to inform the second phase of the research design; a multiple case study of three teachers and a selection of their students. In this second phase I will collaborate with the teachers about the most effective ways to collect data in order to meet the research aims.

\section{Volunteers}

I am seeking volunteers to take part in phase one of this study. These participants will need to meet the following criteria, so the aims of the research study may be met. I will be approaching 20 - 30 teachers who:

- Identify as Māori 
- Currently teach or have taught secondary English to at least one class of Years 9 to 13 students

All participants will be asked if they would like to participate in phase two of this study, however, involvement in phase one does not commit you to participate in phase two. If you do wish to continue, further involvement requires that participants are in a position to teach a text by a Māori writer/ director in 2015 and in the term that fits with the two other participants. Only three teachers will be required for this phase of research and they will be strategically selected as representative of contrasting school contexts, whose student populations are drawn from diverse decile ratings and ethnic and gender compositions. These teachers must be prepared to engage in a collaborative research design process for a multiple case study.

\section{Will I be identified in this research?}

No findings that could identify any individual participant will be published. Any reference to individual participants, or to your school, will be by code name, with only me and my supervisor knowing the real names to which the codes refer. If you agree to take part, you can withdraw your consent at any time up until the end of 2015, when the collection of data has ceased.

\section{What happens to the research data?}

All written material (interview notes, transcripts etc.) will be kept in a locked file and access will be restricted to the researchers. All written materials will be destroyed at the conclusion of the research. Any audio recordings will be returned to participants and/or electronically wiped.

Information gained through this research will be used in the writing of my PhD thesis and for publication in academic journals and conferences.

Thank you for agreeing to take part in this study. Your thoughts are important to me because the study will add to the current knowledge base about lived experiences of teachers, but particularly Māori teachers working in an English curriculum context, of which little is known.

If you have any questions about this research, or would like to discuss aspects of it further, please don't hesitate to contact me via email: macdonlian@myvuw.ac.nz or phone: 021299 2101.

Yours sincerely

Liana MacDonald

Should you have any complaint concerning the manner in which this research is conducted, please do not hesitate to contact Dr. Gillian Hubbard,

Faculty of Education

Victoria University of Wellington

P.O. Box 17-310, WELLINGTON

Email: gillian.hubbard@vuw.ac.nz

This research has been assessed and approved by Victoria University of Wellington Ethics Committee 


\section{Phase One Research Participant Consent Form \\ PROJECT TITLE}

Teaching from the margins: An investigation of the lived experiences of Māori English secondary school teachers

I agree to take part in phase one of the above research project. I have had the project explained to me and I have read the information sheet, which I will keep for my records. I understand that agreeing to take part means that I:

- Am willing to be interviewed by the researcher.

- Allow the interviews to be audiotaped and I understand that I can also review the audiotape.

- Make myself available for further interviews and discussion should that be required.

- Understand that the interview will be transcribed by a third party who has signed a confidentiality agreement.

- Understand that any information I provide is confidential, and that no information that could lead to the identification of any individual will be disclosed in any reports on the project, or to any other party.

- Understand that my participation is voluntary, that I can choose not to participate in the project, and that if I do choose to participate I can withdraw up until the end of 2015 without being penalised or disadvantaged in any way.

- Understand that information gained through this research will be used in the writing of a PhD Thesis and for publication in academic journals and conferences. I also understand that I have the right to check interview notes and challenge the observations of the researcher.

By ticking this box I understand each of the points listed above and agree to participate in the research project.

Name:

Signature:

Date: 
Appendix B: Phase one interview questions

VICTORIA UNIVERSITY OF WELLINGTON
Te Whare Wananga o te Upoko o te Ika a Maui

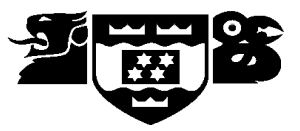

Teaching from the margins:

Navigating critical approaches to text, identity and biculturalism through the lived experiences of Māori English secondary school teachers

Demographic data:

Age range $\quad 20-30 \quad 30-40 \quad 40-50 \quad 50-65$

Male / Female

$\begin{array}{llllllll}\text { Years of teaching experience } & 1 & 2 & 3 & 4 & 5 & 5+\end{array}$ (specify)

Position Assistant teacher Assistant HOD/HOF HOD/HOF Other

School Single-sex Co-educational State Integrated Private

$\begin{array}{llllllllll}\text { Decile ranking of school } & 1 & 2 & 3 & 4 & 5 & 6 & 7 & 8 & 9\end{array}$

Description of ethnic / cultural background in own words:

\section{Primary research question:}

What are the lived experiences of English teachers who identify as Māori as they attempt to respond to critical approaches to text, identity and biculturalism through the literature they teach to students in secondary school classrooms? And how do their students respond to their efforts?

\section{Phase one interview questions:}

1. As a teacher who identifies as Māori, what strengths do you bring to English teaching and what challenges do you face?

2. What text by Māori writers or directors do you use?

3. How do your Māori and non-Māori students respond to text by Māori writers?

4. What affordances or constraints (advantages or disadvantages) arise for you as a Māori teacher teaching Māori texts?

5. What pedagogical approaches do you use in the English classroom? (e.g. open discussion, literature circles, journal response writing)

6. Do you consciously use any critical literacy approaches? (e.g. questions around how the text positions the reader, varying the text from alternative perspectives, considering the power relationships in the text)

7. Would you like to continue your involvement in this research study by participating in phase two of this study? The multiple case design means that you will participate in further intensive research for the duration of a unit of work related to a studied text by a Māori writer/ director. 


\title{
Appendix C: Phase two schools/ principals information sheet
}

\author{
VICTORIA UNIVERSITY OF WELLINGTON \\ Te Whare Wananga o te Upoko o te Ika a Maui
}

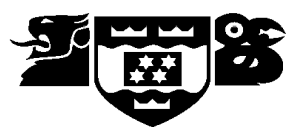

\section{Phase Two Schools/ Principals Information Sheet}

\section{PROJECT TITLE}

Teaching from the margins: Navigating critical approaches to text, identity and biculturalism through the lived experiences of Māori English secondary school teachers

Tēnā koe

\section{Introduction and Background}

My name is Liana MacDonald. I am a PhD student from Te Whānau o Ako Pai ki Te Upoko o te Ika a Māui, Faculty of Education, Victoria University of Wellington and am undertaking a research project leading to a Doctorate thesis. The University requires that ethics approval be obtained for research projects involving human participants. This information sheet will provide you with information about my research and your school's possible involvement.

\section{Aim of the research}

This research aims to investigate the lived realities of secondary school English teachers who identify as Māori in relation to the New Zealand English curriculum requirements; such as the teaching of critical thinking, responding to student identity and bi-cultural issues in secondary school classroom contexts. To my knowledge, no research has been undertaken to capture the voice of teachers of English who also identify, culturally and ethnically, as Māori. This study argues that the implications of curriculum references to biculturalism must be explored from the perspectives of tangata whenua if they are to have real meaning and substance.

There are two phases to this research. The first is aimed at gathering a breadth of data by conducting semi-structured interviews with a number of Māori English teachers. This data will inform the second phase of the research design; a multiple case study of three interviewed teachers and a selection of their students. In this second phase data will be gathered through semi-structured interviews, in-class observations, and document analysis (teacher plans and student work samples). It is this second phase of the research design that affects your school's involvement.

\section{Characteristics of participants}

I am seeking permission from secondary school principals who will allow me to conduct the phase two research design in their school with one English teacher who also identifies as Māori (identified as 'primary participants') and their students (identified as 'secondary participants').

\section{Teachers}

The teacher research participants have been sought based on the following criteria, so the aims of the research study may be met: 
- Currently teach secondary English to at least one class of Year 9 to 13 students

- Identify as Māori

- Are in a position to teach a text by a Māori writer/ director in 2015 and in the term that fits with the two other participants

- Are prepared to engage in a collaborative research design process for a multiple case study.

- Have been strategically selected to represent contrasting class and school contexts, whose student populations are drawn from diverse decile ratings and ethnic and gender compositions.

\section{Students}

This study will also include a student participant perspective from the class associated with the English teacher who identifies as Māori. I will inform all students about the scope of the study, then invite any student who is willing to participate. Parental consent is vital to their involvement.

Each of the research participants will be required to sign a consent form that will be attached to their information sheet. Their consent indicates that they have been fully informed of the research process and requirements.

\section{Will the school be identified in this research?}

No findings that could identify any individual participant, or school, will be published. Any reference to individual participants, or to the school, will be by code name, with only me and my supervisor knowing the real names to which the codes refer. If you agree to take part, you can withdraw your consent at any time up until the end of data collection.

\section{What happens to the research data?}

All written material (interview notes, transcripts etc) will be kept in a locked file and access will be restricted to the researchers. All written materials will be destroyed at the conclusion of the research. Any audio recordings will be returned to participants and/or electronically wiped.

Information gained through this research will be used in the writing of my $\mathrm{PhD}$ thesis and for publication in academic journals and conferences. I intend to hold a hui upon completion of the thesis in which the findings of the research will be made available to all research participants.

Thank you for agreeing to take part in this study. Your school's involvement is important to me because the study will add to the current knowledge base about lived experiences of teachers, but particularly Māori teachers working in an English curriculum context, of which little is known.

If you have any questions about this research, or would like to discuss aspects of it further, please don't hesitate to contact me via email: macdonlian@myvuw.ac.nz or phone: 021299 2101.

Yours sincerely

Liana MacDonald 
Should you have any complaint concerning the manner in which this research is conducted, please do not hesitate to contact Dr. Gillian Hubbard,

Faculty of Education

Victoria University of Wellington

P.O. Box 17-310, WELLINGTON

Email: gillian.hubbard@vuw.ac.nz

This research has been assessed and approved by Victoria University Faculty of Education Ethics Committee 


\title{
Appendix D: Phase two research participant information and consent form
}

\author{
VICTORIA UNIVERSITY OF WELLINGTON \\ Te Whare Wananga o te Upoko o te Ika a Maui
}

\section{Phase Two Teacher Research Participant Information Sheet}

\section{PROJECT TITLE}

Teaching from the margins: Navigating critical approaches to text, identity and biculturalism through the lived experiences of Māori English secondary school teachers

Tēnā koe

\section{Introduction and Background}

My name is Liana MacDonald. I am a PhD student from Te Whānau o Ako Pai ki Te Upoko o te Ika a Māui, Faculty of Education, Victoria University of Wellington and am undertaking a research project leading to a Doctorate thesis. The University requires that ethics approval be obtained for research projects involving human participants. This information sheet will provide you with information about my research and your possible involvement. It is important that you make an informed decision about whether you want to participate.

\section{Aim of the research}

This research aims to investigate the lived realities of secondary school English teachers who identify as Māori in relation to the New Zealand English curriculum requirements; such as the teaching of critical thinking, responding to student identity and bi-cultural issues in secondary school classroom contexts. To my knowledge, no research has been undertaken to capture the voice of teachers of English who also identify, culturally and ethnically, as Māori. This study argues that the implications of curriculum references to biculturalism must be explored from the perspectives of tangata whenua if they are to have real meaning and substance.

There are two phases to this research. The first is aimed at gathering a breadth of data by conducting semi-structured interviews with a number of Māori English teachers. This data will inform the second phase of the research design; a multiple case study of three interviewed teachers and a selection of their students. In this second phase data will be gathered through semi-structured interviews, in-class observations, and document analysis (teacher plans and student work samples).

\section{Volunteers}

I am seeking three English teachers who also identify as Māori to take part in phase two of this study. These participants will need to meet the following criteria, so the aims of the research study may be met:

- Currently teach secondary English to at least one class of Year 9 to 13 students

- Identify as Māori

- Are in a position to teach a text by a Māori writer/ director in 2015 and in the term that fits with the two other participants 
- Are prepared to engage in a collaborative research design process for a multiple case study.

- Will be strategically selected to represent contrasting class and school contexts, whose student populations are drawn from diverse decile ratings and ethnic and gender compositions.

\section{What would your involvement mean?}

These three English teachers will be known as the study's 'primary participants'. One primary participant and their approach to a unit of work delivered to a secondary English class (approx. six weeks) will be the research focus during one school term. The unit must be based on a text be a Māori writer/ director. The following methods of data collection will likely be applied:

- Teacher interviews

- Student interviews or focus groups

- In-class observations

- Document analysis (teacher plans and student work samples)

- Participant journals

Although each school term will have a particular focus on one teacher, I would like to observe and interview the other teacher and student participants over the course of one week in the other terms.

Collaborative processes between the researcher and the three primary participants are a significant part of the research design. For example, the methods of data collection are open to discussion and in our initial meeting we may change them, or if participants agree to journaling we may discuss how and with what frequency you would like to journal your thoughts in response to your teaching (Online blog? Written diary entries?). Also, the primary participants' understanding of critical approaches to text, identity and biculturalism from the chosen text will set limits to how data is collected and analysed. For example, I will ask primary participants to suggest the best lessons when I might observe learning based around their understanding of critical approaches to text or biculturalism.

Each primary participant will be asked to member-check interview transcripts and offer their perspectives on my analysis of data, so they can comment on whether my analysis is an accurate portrayal of what transpired.

\section{Will I be identified in this research?}

No findings that could identify any individual participant will be published. Any reference to individual participants, or to your school, will be by code name, with only me and my supervisor knowing the real names to which the codes refer. If you agree to take part, you can withdraw your consent at any time up until the end of data collection.

\section{What happens to the research data?}

All written material (interview notes, transcripts etc) will be kept in a locked file and access will be restricted to the researchers. All written materials will be destroyed at the conclusion of the research. Any audio recordings will be returned to participants and/or electronically wiped. 
Information gained through this research will be used in the writing of my $\mathrm{PhD}$ thesis and for publication in academic journals and conferences. I intend to hold a hui upon completion of the thesis in which the findings of the research will be made available to all research participants.

Thank you for agreeing to take part in this study. Your thoughts are important to me because the study will add to the current knowledge base about lived experiences of teachers, but particularly Māori teachers working in an English curriculum context, of which little is known.

If you have any questions about this research, or would like to discuss aspects of it further, please don't hesitate to contact me via email: macdonlian@ myvuw.ac.nz or phone: 021299 2101.

Yours sincerely

\section{Liana MacDonald}

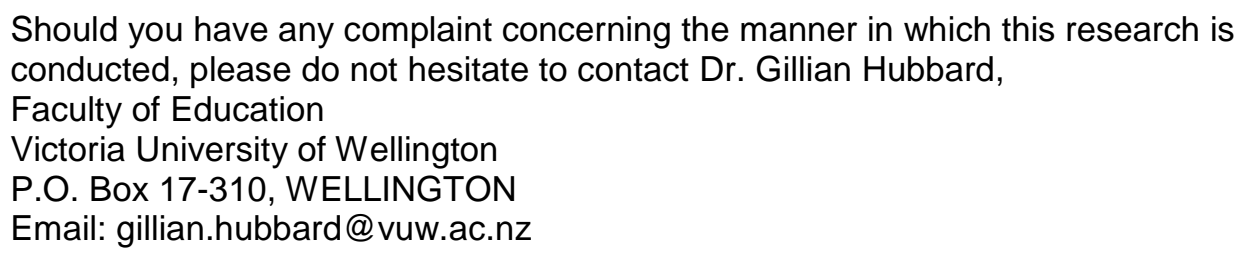

This research has been assessed and approved by Victoria University Faculty of Education Ethics Committee 


\section{Phase Two Teacher Research Participant Consent Form}

\section{PROJECT TITLE}

Teaching from the margins: Navigating critical approaches to text, identity and biculturalism through the lived experiences of Māori English secondary school teachers

I agree to take part in phase two of the above research project. I have had the project explained to me and I have read the information sheet, which I will keep for my records. I understand that agreeing to take part means that I am willing to:

- Be interviewed by the researcher

- Allow the interviews to be audiotaped and I understand that I can also review the audiotape.

- Make myself available for further interviews and discussion should that be required.

- Be observed by the researcher and understand that anything I say or do during class time may be recorded for research purposes.

- Participate in collaborative research processes that will inform how and what data is collected and analysed by the researcher. I understand that once the limits of the study have been established, the collected data will be used for research purposes.

- I understand that any information I provide is confidential, and that no information that could lead to the identification of any individual will be disclosed in any reports on the project, or to any other party.

- I also understand that my participation is voluntary, that I can choose not to participate in the project, and that if I do choose to participate I can withdraw up until the end of 2015 without being penalised or disadvantaged in any way.

- I understand that information gained through this research will be used in the writing of a PhD Thesis and for publication in academic journals and conferences. I also understand that I have the right to check interview notes and challenge the observations of the researcher.

By ticking this box I understand each of the points listed above and agree to participate in the research project.

Name:

Signature:

Date: 


\title{
Appendix E: Phase two student research participant information and consent form
}

\author{
VICTORIA UNIVERSITY OF WELLINGTON \\ Te Whare Wananga o te Upoko o te Ika a Maui
}

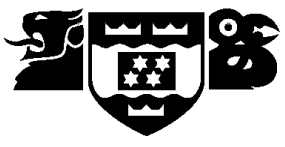

\section{Phase Two Student Research Participant Information Sheet}

\author{
PROJECT TITLE \\ Teaching from the margins: Navigating critical approaches to text, identity and \\ biculturalism through the lived experiences of Māori English secondary school teachers
}

Tēnā koe

\section{Introduction and Background}

My name is Liana MacDonald. I am a PhD student from Te Whānau o Ako Pai ki Te Upoko o te lka a Māui, Faculty of Education, Victoria University of Wellington and am undertaking a research project leading to a Doctorate thesis. The University requires that ethics approval be obtained for research projects involving human participants. This information sheet will provide you with information about my research and your possible involvement. It is important that you make an informed decision about whether you want to participate.

\section{Aim of the research}

This research aims to investigate the lived realities of secondary school English teachers who identify as Māori in relation to the New Zealand English curriculum requirements; such as the teaching of critical thinking, responding to student identity and bi-cultural issues in secondary school classroom contexts. To my knowledge, no research has been undertaken to capture the voice of teachers of English who also identify, culturally and ethnically, as Māori. This study argues that the implications of curriculum references to biculturalism must be explored from the perspectives of tangata whenua (indigenous Māori) if they are to have real meaning and substance.

There are two phases to this research. The first is aimed at gathering a breadth of data by conducting semi-structured interviews with a number of Māori English teachers. This data will inform the second phase of the research design; a multiple case study of three interviewed teachers and a selection of their students. In this second phase data will be gathered through semi-structured interviews, in-class observations, and document analysis (teacher plans and student work samples).

\section{Volunteers}

I am seeking student participants from the class associated with one of the three English teachers who also identify as Māori to take part in phase two of this study. Any student from the class can be involved provided the parents have given their consent. I will inform all students further about the scope of the study during a lesson at school.

\section{What would your involvement mean?}


The students who give consent to be involved in the study will be known as 'secondary participants' and will be involved in the following methods of data collection in one school term:

- Student interviews or focus groups

- In-class observations

Each teacher will present a unit of work based on a text by a Māori writer/ director during one term in 2015. I will be observing lessons, recording conversations and making notes about what I see during this time.

Focus group interviews will be conducted midway through this unit of work and a second after the unit has concluded. In a focus group, students will be grouped into sets of four and each table group will have an interview schedule and a digital recorder. The interview questions will allow students to communicate their thoughts about the text by the Māori writer/ director and they will also be asked to comment on how their teacher views the text. Their teacher will not be able to view the student responses until the publication of the thesis to ensure anonymity of student participants. This means that the students' relationship with their teacher is not affected by this research.

Although each school term will have a particular focus on one teacher, I would like to observe and interview the other teacher and student participants over the course of one week in the other terms.

\section{Will I be identified in this research?}

No findings that could identify any individual participant will be published. Any reference to individual participants, or to your school, will be by code name, with only me and my supervisor knowing the real names to which the codes refer. If you agree to take part, you can withdraw your consent at any time up until the end of data collection.

\section{What happens to the research data?}

All written material (interview notes, transcripts etc.) will be kept in a locked file and access will be restricted to the researchers. All written materials will be destroyed at the conclusion of the research. Any audio recordings will be returned to participants and/or electronically wiped.

Information gained through this research will be used in the writing of my $\mathrm{PhD}$ thesis and for publication in academic journals and conferences. I intend to hold a hui (meeting) upon completion of the thesis in which the findings of the research will be made available to all research participants.

Thank you for agreeing to take part in this study. Your thoughts are important to me because the study will add to the current knowledge base about lived experiences of teachers, but particularly Māori teachers working in an English curriculum context, of which little is known.

If you have any questions about this research, or would like to discuss aspects of it further, please don't hesitate to contact me via email: macdonlian@ myvuw.ac.nz or phone: 021299 2101.

Yours sincerely 


\section{Liana MacDonald}

Should you have any complaint concerning the manner in which this research is conducted, please do not hesitate to contact Dr. Gillian Hubbard,

Faculty of Education

Victoria University of Wellington

P.O. Box 17-310, WELLINGTON

Email: gillian.hubbard@vuw.ac.nz

This research has been assessed and approved by Victoria University Faculty of Education Ethics Committee 


\section{Phase Two Student Research Participant Consent Form}

\section{PROJECT TITLE}

Teaching from the margins: Navigating critical approaches to text, identity and biculturalism through the lived experiences of Māori English secondary school teachers

I agree to take part in phase two of the above research project. I have had the project explained to me and I have read the information sheet, which I will keep for my records. I understand that agreeing to take part means that I am willing to:

- Be interviewed by the researcher and/ or participate in focus group interviews.

- Allow the interviews to be audiotaped and I understand that I can also review the audiotape.

- Make myself available for further interviews and discussion should that be required.

- Be observed by the researcher and understand that anything I say or do during class time may be recorded for research purposes.

- I understand that any information I provide is confidential, and that no information that could lead to the identification of any individual will be disclosed in any reports on the project, or to any other party.

- I also understand that my participation is voluntary, that I can choose not to participate in the project, and that if I do choose to participate I can withdraw up until the end of 2015 without being penalised or disadvantaged in any way.

- I understand that information gained through this research will be used in the writing of a PhD Thesis and for publication in academic journals and conferences. I also understand that I have the right to check interview notes and challenge the observations of the researcher.

By ticking this box I understand each of the points listed above and agree to participate in the research project.

Name:

Signature:

Date: 
Appendix F: Sample of the third iteration of phase one data analysis - process coding (Text category page 10/21)

\begin{tabular}{|c|c|c|c|}
\hline Summary of data & Sub codes & Codes & Sub categories \\
\hline $\begin{array}{l}\text { Participant believes resourcing Māori texts is a challenge because her } \\
\text { school doesn't have them and they're not online }\end{array}$ & $\begin{array}{l}\text { Resourcing Māori texts a } \\
\text { challenge }\end{array}$ & & \\
\hline $\begin{array}{l}\text { "I think addressing the teenage aspect of being Māori in the modern } \\
\text { world I don't think is done very well... or urban modern world" }\end{array}$ & $\begin{array}{l}\text { Identifying a lack of urban } \\
\text { Māori texts }\end{array}$ & \multirow{5}{*}{$\begin{array}{l}\text { Needing Māori text that are } \\
\text { inclusive of diverse Māori } \\
\text { student identities }\end{array}$} & \\
\hline Participant can't find a relevant text that speaks to rangatahi Māori & Seeing no suitable text & & \\
\hline Texts don't "embody who they [her students] are" & Seeing no suitable text & & \\
\hline There is a gap in the market for texts that speak to urban Māori - a void & Seeing no suitable text & & \\
\hline It's a challenge "coming up with texts that are reflective of our kids" & Seeing no suitable text & & \\
\hline $\begin{array}{l}\text { Participant doesn't believe that all NZ texts need to be taught in every } \\
\text { NZ school }\end{array}$ & Branching out & Choosing non-NZ texts & \\
\hline $\begin{array}{l}\text { Participant feels that a lot of new NZ films are more for entertainment } \\
\text { than good for }\end{array}$ & $\begin{array}{l}\text { Believing that newer texts have } \\
\text { less substance }\end{array}$ & \multirow[t]{7}{*}{$\begin{array}{l}\text { Criticising the quality of } \\
\text { Māori text }\end{array}$} & \multirow[t]{10}{*}{$\begin{array}{l}\text { Questioning the suitability } \\
\text { of available Māori text }\end{array}$} \\
\hline Huia themes aren't as well developed as books by English authors & $\begin{array}{l}\text { Believing that some Māori text } \\
\text { have less developed themes }\end{array}$ & & \\
\hline $\begin{array}{l}\text { Participant feels that Patricia Grace and Witi Ihimaera are "two of the } \\
\text { stronger Māori authors out there" but some Māori texts don't have as } \\
\text { well-developed themes as English }\end{array}$ & $\begin{array}{l}\text { Believing that some Māori text } \\
\text { have less developed themes }\end{array}$ & & \\
\hline $\begin{array}{l}\text { Participant thinks there are better novels to study than those written by } \\
\text { Māori authors, that gets him excited and overall everyone will connect } \\
\text { with }\end{array}$ & Critiquing Māori text & & \\
\hline $\begin{array}{l}\text { JGeek and 'I'm a Māori Boy' reinforces a tokenistic and mocking } \\
\text { portrayal of Māori culture }\end{array}$ & $\begin{array}{l}\text { Critiquing superficiality of Māori } \\
\text { text }\end{array}$ & & \\
\hline $\begin{array}{l}\text { Witi lhimaera can get a bit tiring because you "do those over and over } \\
\text { and you hash it out as much as you can" }\end{array}$ & $\begin{array}{l}\text { Believing that some Māori texts } \\
\text { are overused }\end{array}$ & & \\
\hline $\begin{array}{l}\text { Witi Ihimaera has a "hierarchical thing" in his books that the participant } \\
\text { doesn't like }\end{array}$ & $\begin{array}{l}\text { Criticising Māori author } \\
\text { approach }\end{array}$ & & \\
\hline Hard to find Māori texts that aren't OWW - & Seeing limitations in Māori text & \multirow{3}{*}{$\begin{array}{l}\text { Criticising the range of Māori } \\
\text { text }\end{array}$} & \\
\hline The Whale Rider is "more of an isolated view of Māori" & Seeing limitations in Māori text & & \\
\hline $\begin{array}{l}\text { Participant felt that the Māori texts she used for a unit on identity and } \\
\text { cultural misunderstandings are "old things ... Apirana Taylor [texts]" }\end{array}$ & Seeing out-dated text & & \\
\hline
\end{tabular}




\section{Appendix G: Synopsis of "Rain of the Children"40}

A woman walks between the worlds of the living and the dead in search of her lost children.

Vincent Ward weaves drama with documentary to unravel the extraordinary story of Puhi, the Tuhoe woman who welcomed the young filmmaker into her home in 1978. Ward made the observational film In Spring One Plants Alone about Puhi's day-to-day life in the remote Urewera Ranges. By then almost 80, she was obsessively caring for her schizophrenic adult son Niki, whose violent fits terrified her. In this new cinema feature Ward sets out to unravel the mystery that has haunted him for 30 years: Who was Puhi?

And why was she so obsessed with this last remaining son?

Using his relationship with Puhi as the framework to explore her life, he finds a woman of extraordinary fortitude who, at the age of 12, was chosen by the great Tuhoe prophet Rua Kenana to marry his son, Whatu. Rua gave her the name, Puhi ("special one"). At 14, she had her first baby while hiding in the bush, having escaped from the 1916 police raid on Rua's community at Maungapohatu, where she witnessed the arrest of Rua and Whatu and the killing of Toko, Rua's other son, said to be her lover.

She would go on to have 13 more children. But by the time Ward made his initial film, there were few signs of what had become of them. He finds out how the loss of her children affected the course of her life. The tragedies she lived through were so powerful that some, including her, believed she was cursed.

After a tumultuous second marriage and the manslaughter of her third husband, Puhi was left with her dependant son, Niki. She dedicated herself to this man-child, trying to protect him at all costs, even from beyond the grave.

This is Ward's search for the truth of a woman who has remained a touchstone for him throughout his life.

\footnotetext{
${ }^{40}$ Retrieved from https://www.nzfilm.co.nz/films/rain-children
} 
Starring an extraordinary New Zealand cast, The Dark Horse is an inspiring true story based on the life of a charismatic, brillant but little-known New Zealand hero and chess champion - Genesis Potini.

Written and directed by James Napier Robertson, The Dark Horse is an inspiring true story based on the life of a charismatic, little-known New Zealand hero, Genesis Potini, played by Cliff Curtis (Once Were Warriors, Whale Rider, Boy). The film also stars James Rolleston (Boy), Kirk Torrance (Stickmen, Sione's 2 - Unfinished Business), Xavier Horan (Dean Spanley), Miriama McDowell (Dean Spanley) and newcomer Wayne Hapi.

Once a heralded chess champion, Genesis has spent the last few years in and out of mental institutions, battling with severe bipolar disorder. After being released from the psychiatric ward for one more chance at life, he moves in with Ariki, his gang-patched and distant brother (Hapi), and Ariki's soon-to-be-patched teenage son, Mana (Rolleston).

Needing a purpose and a reason to get out of the gang house, Genesis joins a rough-as-guts local chess club, with the wild idea of coaching the motley crew of kids to the national chess championship. On the way, Gen must face the responsibility that comes with being a leader, navigate conflict within the gang world and try to survive the potentially devastating strife that breaks out between him and his brother over his nephew's future.

The Dark Horse opened the 2014 New Zealand International Film Festival in Auckland and Wellington and will have its international premiere at the prestigious Toronto International Film Festival in September 2014.

\footnotetext{
${ }^{41}$ Retrieved from https://www.nzfilm.co.nz/films/dark-horse
} 
I have fought throughout the war

from Greece to Crete, from Crete

to North Africa, and from there

to Italy. I am battle scarred.

I have been wounded in a dozen

places. My mind doesn't work

properly anymore. I have nightmares

Night and day I see pictures

of my closest mates falling

beside me in so many battles

I have forgotten when and where

it was they died. I have shed

so many tears, I have no tears

left to shed. Where my mind used to be there is nothing

but darkness, the sound of roaring, and emptiness. I have become an empty street in a town

that has been blown to pieces.

No one lives there any more, no one who loves sunlight-

and yet at the special church service at Maadi at the end of the war when the battalion 
sang the sacred hymn 'Aue Ihu'

my dead mates came alive, and for the first time in years I wept,

and so did the strong men singing

beside me. That night at base camp

I dreamt of rain in the desert 
Nothing like a lone-standing nīkau

in the middle of some paddock

owned by some Pākehā

to make you feel mamae

Surrounded by maunga

who serve to remind you

that once that whole paddock

had that same sense of tapu

It's a bit like that urupā

in the middle of that reserve

that used to be a papakainga

till some Pākehā had it burned

So consider yourselves warned:

It'll take more

than

a change of name

a chopping down of trees

a burning down of whare

to make us forget

our tīpuna remain. 